\title{
FAMILY TIME AND OWN TIME \\ ON HOLIDAY: \\ GENERATION, GENDER, AND GROUP \\ DYNAMIC PERSPECTIVES FROM \\ NEW ZEALAND
}

By

Heike Annette Schänzel

\begin{abstract}
A thesis
submitted to the Victoria University of Wellington in fulfilment of the requirements for the degree of

Doctor of Philosophy

in Tourism Management
\end{abstract}

Victoria University of Wellington

2010 


\begin{abstract}
This thesis is about the family holiday experiences of the whole family group and its individual members by studying the anticipations before the holiday and the short- and longer-term holiday experiences/recollections after their holiday. This primarily qualitative study links a survey with data triangulation of whole-family interviews. The combination of different methods reflects the holistic and critical research approach within the interpretive research paradigm. It takes a symbolic interactionist perspective which allows a focus on inter-personal relations and forms the basis for a grounded theory methodology (GTM).
\end{abstract}

There is an absence of family tourism research on the experiences of the father, the child, and on group dynamics which has excluded the individual and collective perspectives on the different phases of the holiday. The conceptual framework addresses the gaps identified (as reflected in the research question) by exploring the social experiences and meanings of family holidays over time using gender, generation, and group perspectives. This study is based on a parental survey through schools which was followed by three rounds of whole-family interviews (once before and twice after the holiday) conducted over about one year (2006-2007). The survey with 110 parents provided context and selection of participants for the intensive study of 10 families and their members (20 parents and 20 children).

This study resulted in a definition of family holidays based on parental perspectives from the survey and familial perspectives from the interviews which encapsulated notions of togetherness, plurality of families, purpose, change of routine, fun, balance, individual pursuits, compromise, conflict, and length. The iterative research combined with the GTM resulted in a theoretical framework of the main themes on family holidays as governed by family time and own time. Family time encapsulates the time spent together with the immediate and extended family while own time encapsulates freedoms from family commitments to pursue own interests alone or with peers. The relationship between these notions of time leads to the internal family group dynamics of cooperation, 
compromise, and conflict which are influenced by contextual factors. While family time dominates the Western discourse on family life, it is the inclusion of more individualistic elements in own time that acknowledges a more realistic and sustainable presentation of family holidays. Other results highlight that parents and children bring different purposes on holiday in that parents are more deliberate about social identity formation whereas children seek fun and sociality. The findings also emphasise the undervaluation of the fathers' role as main entertainer of the children. Thus, more debate is needed about the different generational, gendered, and group roles and understandings on holiday. Family holidays, then, have multiple meanings and purposes reflecting the multivocality of its members. A more holistic and critical approach in thinking and research is needed to allow for a homeostasis between social identities based on collective pursuits and on more individual interests. 
For Demian, Anaïs, and Maya, you are the future of New Zealand

To the families in this study, it has been a wonderful experience 


\section{Acknowledgements}

During the past three years and three months innumerable people have assisted me in my goal of writing a $\mathrm{PhD}$ thesis. They have offered their time, knowledge, experience, wisdom, and support. It is impossible to mention everyone by name but here are a few of the individuals who deserve acknowledgement, with sincere apologies to those who have not been mentioned by name.

Firstly, to my supervisors Dr Karen Smith, Dr Adam Weaver, and Professor Doug Pearce, I would like to say a big thank you. You helped me make sense of a project which at times seemed overwhelming, provided sound advice and encouragement, and kept me focused on the end goal. I have learned a lot from you and feel privileged to have had such a committed supervisory team.

I would also like to thank all the staff members at VMS, and other colleagues at VUW who provided support or offered friendly words of encouragement. A special thanks to Linda Walker, Helen Jiang, and Sophia Lum for great administrative support and Deborah Jones for being such an efficient $\mathrm{PhD}$ director.

I am also indebted to VUW for giving me the financial support through the $\mathrm{PhD}$ scholarships and the research funding from VMS. Without this I would have been unable to commence and complete this project.

I cannot forget my $\mathrm{PhD}$ colleagues who have gone through the process with me and have provided a wonderful social environment filled with laughter and encouragement. Thank you and best wishes to Garoon Pongsart, Zanele Ndaba, Lois Parkes, June Longit, Rebecca Bednarek, Jorge Velez, Guillaume Rosquin, Cesar Guala, Janine Williams, Huong Nguyen, and Wayne Pihema.

To the families in this study, thank you so much for sharing your time and your stories, and welcoming me into your homes. I feel privileged to tell your stories.

Finally, I want to thank my children, husband, and friends for supporting me in this intellectual pursuit. 


\section{Table of Contents}

1. Introducing the study 1

1.1 Introduction 1

1.2 Background to the study 1

1.3 Philosophical perspective 5

1.4 The family on holiday 6

1.5 Research context - New Zealand 9

1.6 Research questions 14

1.7 Methodology 15

$\begin{array}{lll}1.8 & \text { Chapter outline } & 19\end{array}$

2. Family, leisure and tourism: A literature review 20

2.1 Introduction 20

2.2 Families in New Zealand: Background and context 21

2.2.1 Families, time, and work/home-life relationships 23

in New Zealand

2.2.2 Family leisure in New Zealand 26

2.2.3 Kiwi family holidays and the domestic tourism context 27

$2.3 \quad$ Researching families at home: International perspectives 32

2.3.1 The idealisation of family time in Western society 33

2.3.2 Gender and generational perspectives on family time 36

$2.4 \quad$ Researching families within leisure: International 40 perspectives

2.4.1 The Western idealisation of family leisure 40

2.4.2 Gender and generation in family leisure 42

$2.5 \quad$ Researching family holidays: International marketing $\quad 45$ perspectives

2.5.1 Motivations for family holidays 47

2.5.2 Family holiday decision making 50

$\begin{array}{lll}\text { 2.5.3 Family holiday satisfaction } & 54\end{array}$

$2.6 \quad$ The experiential and temporal dimensions of family 56

holidays - a conceptual framework

2.6.1 The individual tourist perspective 58

- a Western male perspective

2.6.2 The dyadic partnership perspective 60

- a gendered perspective

2.6.3 The triangular family group perspective 65

$\begin{array}{ll}\text { - gender, generation, and group dynamic perspectives } & \\ 2.7 & \text { Conclusion }\end{array}$

$3 \quad$ Research paradigm and methodology 73

$\begin{array}{lll}3.1 & \text { Introduction } & 73\end{array}$

$\begin{array}{lll}3.2 & \text { Research paradigm } & 74\end{array}$

$\begin{array}{lll}\text { 3.2.1 Progressive qualitative tourism research } & 77\end{array}$ 
$\begin{array}{lll}3.3 & \text { Qualitative research strategies } & 79\end{array}$

3.3.1 Grounded theory methodology (GTM) 81

$\begin{array}{lll}3.3 .2 & \text { Case study inquiry } & 82\end{array}$

3.3.3 Whole family research 84

3.4 Methodological framework 86

3.4.1 Linking of survey with whole-family interviews 86

3.4.2 Data triangulation and whole-family research 89

$\begin{array}{lll}3.5 & \text { Phases of the methodology } & 94\end{array}$

3.5.1 Phase 1: Survey through schools 95

3.5.2 Phases 2-4: Whole-family interviewing 100

3.5.2.1 Family interviews pre-holiday 106

3.5.2.2 Family interviews post-holiday (short-term) 109

3.5.2.3 Family interviews post-holiday (longer-term) 113

$\begin{array}{lll}3.6 & \text { Analytical framework } & 116\end{array}$

3.6.1 Analysis of phases through the GTM 117

$\begin{array}{ll}\text { 3.6.2 Evaluation and reflexivity } & 127\end{array}$

$\begin{array}{lll}3.7 & \text { Conclusion } & 130\end{array}$

$4 \quad$ Defining the family holiday: Background and themes 132

4.1 Introduction 132

4.2 Background to family holiday behaviour 132

$\begin{array}{lll}\text { 4.2.1 Family travel patterns } & 133\end{array}$

$\begin{array}{ll}\text { 4.2.2 Parental perspectives on motivations } & 140\end{array}$

$\begin{array}{ll}4.3 \quad \text { Definition of family holidays } & 141\end{array}$

$\begin{array}{ll}\text { 4.3.1 Parental definition } & 142\end{array}$

4.3.2 Familial definition 146

$\begin{array}{lll}4.4 & \text { Contextual factors } & 148\end{array}$

$\begin{array}{ll}\text { 4.4.1 Destination choice } & 149\end{array}$

$\begin{array}{lll}4.4 .2 & \text { Finances } & 150\end{array}$

$\begin{array}{lll}\text { 4.4.3 Weather } & 151\end{array}$

4.4.4 Accommodation space 153

4.4.5 Length 154

4.4.6 Other factors 156

4.5 Overview of the theoretical framework of the main themes 158

4.5.1 Family time: Time spent together 158

4.5.2 Own time: Freedom from family commitments 159

$\begin{array}{lll}4.6 & \text { Conclusion } & 160\end{array}$

$5 \quad$ Family time on holiday $\quad 162$

$\begin{array}{lll}5.1 & \text { Introduction } & 162\end{array}$

5.2 Ideal of family time 162

5.3 Change of routine/quality time 164

5.3.1 Different from normal 165

5.3.2 Fun/entertainment 175

$\begin{array}{lll}5.4 & \text { Social connectedness/VFR } & 180\end{array}$

$\begin{array}{lll}\text { 5.4.1 Time for (re)connecting } & 181\end{array}$ 


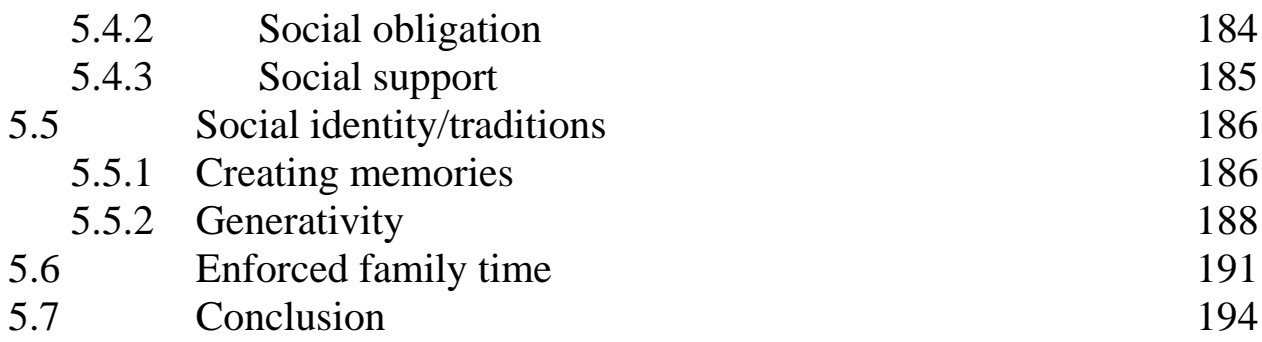

$6 \quad$ Own time on holiday 196

6.1 Introduction 196

6.2 Balance of time 196

6.3 Own interests 198

$\begin{array}{lll}\text { 6.3.1 Activities } & 199\end{array}$

6.3.2 Relaxation 203

$\begin{array}{lll}6.4 & \text { Peer time } & 207\end{array}$

6.4.1 Couple/adult time 208

6.4.2 Sibling/friends time 209

6.5 Comparisons 211

6.5.1 Age differential 211

6.5.2 Non-family holidays 212

$\begin{array}{lll}6.6 & \text { Internal dynamics } & 214\end{array}$

$\begin{array}{lll}\text { 6.6.1 Cooperation } & 215\end{array}$

6.6.2 Compromise 216

6.6.3 Conflict 217

$\begin{array}{lll}6.7 & \text { Temporal dimension } & 219\end{array}$

6.7.1 Pre-holiday: Anticipations and recollections of ideals 220

6.7.2 On-holiday: Everyday experiences 221

6.7.3 Post-holiday: Recollection and anticipation of ideals 222

$\begin{array}{lll}6.8 & \text { Conclusion } & 224\end{array}$

$7 \quad$ Theoretical interpretation of family holiday experiences $\quad 226$

$\begin{array}{lll}7.1 & \text { Introduction } & 226\end{array}$

7.2 Thematic dimension: Negotiation of time on family 227 holidays

7.2.1 Family time 228

$\begin{array}{lll}7.2 .2 & \text { Own time } & 234\end{array}$

7.2.3 Internal dynamics 235

7.3 Familial dimension: Perspectives within the family 236

$\begin{array}{ll}\text { 7.3.1 Generational perspective } & 237\end{array}$

7.3.2 Gender perspective 240

7.3.3 Group dynamic perspective 245

7.4 Temporal and spatial dimension: Continuity and 246

7.5 New Zealand context: Domestic holidays 248

$\begin{array}{lll}7.6 & \text { Conclusion } & 251\end{array}$ 
8 Conclusions 253

8.1 Introduction 253

8.2 Research questions revisited 254

8.3 Methodological contributions 258

$\begin{array}{lll}8.4 & \text { Theoretical contributions } & 261\end{array}$

8.5 Implications for tourism industry and policy 263

8.6 Future directions 266

8.7 Conclusion 268

$\begin{array}{ll}\text { Reference list } & 270\end{array}$

Appendices

Appendix A: $\quad$ Parental survey

Appendix B: Information letter and consent forms

Appendix C: $\quad$ Interview schedule (pre-holiday)

Appendix D: $\quad$ Interview schedule (post-holiday)

Appendix E: $\quad$ Interview schedule (final) 


\section{List of Figures}

Figure 1.1 Phases of methodology and research questions

Figure 2.1 Proportion of women with dependent children by number of 22 children and family type in 2001

Figure 2.2 The different aspects of work-life balance 24

$\begin{array}{lll}\text { Figure 2.3 The holiday as a process of journey experiences and ideals } 56 & 56\end{array}$

$\begin{array}{lll}\text { Figure 2.4 Conceptual framework: The experiential and temporal } & 57\end{array}$ dimensions of family holidays

$\begin{array}{lll}\text { Figure 3.1 Methodological framework } & 87\end{array}$

$\begin{array}{lll}\text { Figure 3.2 Analytical framework for family holiday behaviours } & 118\end{array}$

$\begin{array}{lll}\text { Figure 3.3 Analytical framework for whole family experiential } & 119\end{array}$

Figure 3.4 Illustration of development of initial theme VFR through 125

Figure 4.1 Map of regional destinations in New Zealand 135

$\begin{array}{lll}\text { Figure 4.2 } & \text { Month of travel for main past holiday } & 137\end{array}$

$\begin{array}{lll}\text { Figure 4.3 Top seven domestic regional destinations for upcoming } & 138\end{array}$

$\begin{array}{lll}\text { Figure 4.4 Main parental motivations for past and upcoming holidays } & 140\end{array}$

$\begin{array}{lll}\text { Figure 4.5 Main characteristics of a definition of family holidays } & 143\end{array}$

$\begin{array}{lll}\text { Figure 4.6 Minimum length of a family holiday } & 144\end{array}$

Figure 4.7 Theoretical framework of the main themes on family holidays 157

Figure 6.1 Circularity of temporal dimension of family holidays 219

Figure 7.1 Dynamic state of balance or homeostasis of family holiday 229

Figure 7.2 Conceptual family holiday life cycle: 233

'Repertoire of experiencescapes' as based on holidays with school-aged children

Figure 7.3a Family holiday experiences for the children 238

$\begin{array}{lll}\text { Figure 7.3b } & \text { Family holiday experiences for the parents } 238\end{array}$

Figure 7.4a Family holiday experiences for the mothers 242

Figure 7.4b Family holiday experiences for the fathers 242

$\begin{array}{lll}\text { Figure 7.5a } & \text { Family holiday experiences for the girls } & 244\end{array}$

$\begin{array}{lll}\text { Figure 7.5b Family holiday experiences for the boys } & 244\end{array}$

Figure 7.6 Continuity and discontinuity on holiday compared with family 247 realities at home

Figure 7.7 Continuum of experiences compared with destinations 250 


\section{List of Tables}

Table 2.1 Summary of the key themes affecting the work-life balance of 25 families in New Zealand

Table 2.2 Differences in definitions between routines and rituals 35

Table 2.3 Family life cycle stages $\quad 54$

Table 3.1 Paradigm, qualitative strategies, and methods used for this 80

Table 3.2 Temporal dimension for methodology and analysis 92

Table 3.3 Profile of schools and survey response rate 96

Table 3.4 Characteristics of survey respondents 97

$\begin{array}{lll}\text { Table 3.5 Recruitment process of interview families } & 101\end{array}$

Table 3.6 Demographic profile of the family case studies 103

Table 3.7 Travel characteristics of family case studies 104

Table 3.8 Research reflections on family interviews pre-holiday 108 (Dec 2006-Jan 2007)

Table 3.9 Research reflections on family interviews post-holiday 112 (short-term) (March-April 2007)

Table 3.10 Research reflections on family interviews post-holiday 115 (longer term) (August-November 2007)

$\begin{array}{lll}\text { Table 3.11 Development of interview questions regarding themes } & 120\end{array}$ through the research phases using the GTM

Table 4.1 Selected travel patterns for past and upcoming family holidays 134

\section{List of Abbreviations}

$\begin{array}{ll}\text { AA } & \text { Automobile Association } \\ \text { APE } & \text { Auto-photo-elicitation } \\ \text { DoC } & \text { Department of Conservation } \\ \text { DT } & \text { Data triangulation } \\ \text { DTS } & \text { Domestic Travel Survey } \\ \text { GTM } & \text { Grounded theory methodology } \\ \text { NZTP } & \text { New Zealand Tourist and Publicity Department } \\ \text { TIANZ } & \text { Tourism Industry Association New Zealand } \\ \text { VFR } & \text { Visiting friends and relatives }\end{array}$




\section{CHAPTER 1： INTRODUCING THE STUDY}

\subsection{INTRODUCTION}

This thesis is about the holiday experiences of the whole family and its individual members. Through studying the anticipations before the holiday and the shortand longer-term holiday experiences and memories after their family holiday, the research examines how the family unit and its individual members interact and are interconnected regarding gender, generation, and group dynamics. A survey provides background and context to a primarily qualitative study into the holiday experiences of all family members. Personal experience intersects this research to provide some context and rationale for the study. This introductory chapter presents background to the study, outlines the direction of the research, including the importance of domestic tourism compared with international travel, and the research questions of the study. The chapter concludes with an outline of the organisation of the thesis.

\subsection{BACKGROUND TO THE STUDY}

My interest in this topic was triggered by my own experiences of holidaying with three children and my husband, and raising them in Eastbourne, a seaside community 25 minutes` drive from Wellington, New Zealand's capital. For children, going off on holiday forms an important and eagerly anticipated part of their school breaks. The issue of where to go to on holiday, and when, is a lively topic of conversation for adults and children alike, and something to look forward to and remember on return. Family holidays can produce experiences that are treasured and talked about for a long time afterwards, the cost of taking the children away seems often daunting or there is simply not enough time to allow for a break from the routines of running a family and earning a living in today's society. From my own experience I have noticed yearly increases in accommodation costs in New Zealand that outweigh any average wage/salary increases. Cropp (2006b) confirms this by stating that the costs of domestic travel in New Zealand have increased by $40 \%$ since about 1999 . Additionally, it is my 
perception that more accommodation providers upscale their facilities and turn them into 'luxury' and 'upmarket' lodges like the Awaroa Lodge in Abel Tasman National Park. These are places which used to cater for the middle income family and are now enticing wealthier clients mainly from overseas or affluent domestic couples. This is echoed by an article in North \& South, a prominent current affairs magazine, stating that 'luxury' and 'lodge' are two of the most over-used words in the New Zealand tourism industry (Cropp, 2006a, p. 67).

With their overseas marketing campaign Tourism New Zealand (2009) actively pursues the wealthier Interactive Traveller ${ }^{\circledR}$ who typically falls into two demographic groups: either single or partnered individuals who do not have children yet (25-34) or empty nesters whose children have left home (50-64). This, however, means that less importance is placed on the family market on a national scale, even for inbound family visitors like from Australia (Allen, 2005). There is room for more balance between lower-budget and family travellers and the higher spending Interactive Travellers ${ }^{\circledR}$. The emphasis placed on export earnings has resulted in less research that focuses on domestic tourism, and there is no national domestic tourism policy or strategy. In the domestic travel studies available, consumers are not segmented by travel group composition (like groups with children) which makes them indistinguishable from other travellers, while most studies on domestic family tourism are fairly narrow and focus on camping holidays. There is an inherent contradiction in that families bring a lot of business to the New Zealand tourism industry but the extent is not recognised as such.

Instead, New Zealanders are increasingly travelling overseas with the relative cost increasing only by about 5-10 percent since 1999 (Cropp, 2006b). With the growth in outbound travel, especially to Australia, there is now considerable debate from political parties and some initiatives from non-governmental organisations about a domestic tourism campaign that centres on family tourism. It appears that families as a valid market segment need more attention from New Zealand's tourism industry and government institutions. While the economic importance of inbound tourism is now an undisputed reality for New Zealand, the study of domestic family tourism requires more attention for both economic and non-economic reasons. Apart from the monetary value of domestic tourism it is 
also important to examine the social meanings families gain from their holiday experiences. Thus, the focus should not just be on tourists as consumers but also on their holiday experiences because the core product, of tourism are the experiences (Prentice et al., 1998). Only an understanding of the subjective and social experiences gained while holidaying can realize the true value of tourism.

Enjoyment of New Zealand's outdoors, and particularly its extensive coastal areas, is perceived as an essential part of the Kiwi (or New Zealander) lifestyle, with access to it considered a birthright (Barnett \& Wolfe, 1993). Yet, the unrestricted sale of coastal properties to developers increasingly restricts access to beaches and campgrounds, especially in the upper North Island where the vast majority of New Zealanders go for their summer camping holiday (Department of Conservation (DoC), 2006), thereby endangering the traditional family camping holiday (Larson, 2005) and an iconic part of Kiwi culture (Taylor \& Beston, 2005). Also, the dream of holiday homes, called 'baches' or 'cribs', began to fade with increasing property values (Phillips, 2007). All of these developments can affect the affordability, choices, duration, and, eventually, the quality of the Kiwi family holiday. Some of these points were acknowledged by the New Zealand Tourism Strategy 2015 (Ministry of Tourism, 2007c) around making domestic travel more affordable (e.g., family-friendly holiday packages), especially as the average New Zealand income is lower than that of most international visitors. However, strategy implementation is in the early stages.

It is my particular interest to contribute to the study of domestic family tourism by providing insights into the experiences and meanings New Zealanders derive from their family holidays. I am a European, white, middle-class female with three children, married to a European. I have adopted New Zealand as my home. Having grown up in Germany, I am aware of the European tradition of visitorrelated social tourism (see Minnaert et al., 2006). The liberal democracies of Europe see family holidays as a social right (as social inclusion or having equal opportunity to go on holiday) (Hazel, 2005). In New Zealand there is a notable absence of this concept of social tourism for families in need, which may reflect not only politics but is also an expression of widely held values. 
It is against this context that the data collection took place over about one year from November 2006 to November 2007 and that the participating families discussed their holidays within an economic climate of relative prosperity. The current global recession has given a boost to domestic tourism (Ministry of Tourism, 2009) which strengthens the relevance of this study. While this brings more attention to the role of domestic tourism there is still no coordinated industry body charged with its marketing or management nor any government funding for it (Blackwell, 2009). Domestic family holidays are not only considered a lower priority within New Zealand but holidays with children have largely been marginalised in tourism and leisure research as well.

Tourism is currently promoted more for its economic benefits than for any health and social benefits (Hazel, 2005), which is also reflected by the predominance of economics in tourism research (Tribe, 2006). Most family tourism research is market- and consumer-driven and focused on decision-making (e.g., Nanda et al., 2006) with a lack of research into broader experiential dimensions. The concept of travelling for a 'domestic family holiday' has been neglected. What is known about family holidays is normally from the perspective of the mother (e.g., Richmond \& Tolich, 2000) or focused around specific attractions (e.g., Johns \& Gyimothy, 2003). So far, no study has explored the whole family that takes into account the perspectives of all family members and different phases of the holiday. Adding to this is a statement by American humorist Benchley (2001) that 'there are two classes of travel - first class, and with children', referring to the burdens associated with travelling with children. While research that addresses travel has focused on the 'first class' holiday, very little is known about holidays with children, which are deemed to be a more 'mundane' and trivial type of tourism (Bærenholdt et al., 2004). This research project addresses this gap by not only giving a voice to families but in turn giving a voice to children as well. It provides, therefore, an understanding of the meanings of holiday experiences for the family and all its members by encompassing the sociality of spending time together and the individual elements of family travelling. 


\subsection{PHILOSOPHICAL PERSPECTIVE}

It has been argued by Phillimore \& Goodson (2004) that all research processes need to deal with the philosophical assumptions of the nature of reality (ontological question) and the way of knowing (epistemological question). Tourism research that only relies on a positivistic epistemology, and quantification, is considered limited in its scope (Botterill, 2001) and has been questioned in the past (Tribe, 2006; Walle, 1997) although it has its merits, such as data which can be easily summarised, compared, and illustrated. That is why a quantitative survey was developed to provide background, demographic profile, and leads for questions in this primarily qualitative study. The qualitative research movement is built on a profound concern with understanding what other human beings are doing or saying (Schwandt, 2000). The linking of a survey with data triangulation of interviews reflects the holistic research approach used here within the interpretive research paradigm (see Figure 3.1). This study adopts the philosophy of interpretivism with the goal of understanding the complex world of lived experience from the point of view of those who live it. It is concerned with the emic or insider point of view, with understanding meaning, and with grasping the researched person's definition of a situation (Schwandt, 1994).

This study is part of a wave of new tourism research as advocated by Tribe (2005) and Ateljevic et al. (2005). It moves beyond a narrow fascination with applied business research and embraces more critical, reflexive, and interpretive paths of academic research. The term critical is used to encompass the array of innovative frameworks, methods, and philosophies employed for this study (Wilson et al., 2008). Reflexivity is used here as a means of looking and reflecting inwards upon myself as researcher, and outwards upon those who are 'researched'. My embodied experiences and worldviews, thus, entangle me with the research process (Ateljevic et al., 2005). I take a symbolic interactionist perspective which allows a focus on inter-personal relations within the family group and recognizes the gendered and generational nature of tourism experiences. Symbolic interactionism also forms the basis for a grounded theory approach. In this sense tourism is not an escape from the everyday world but an escape to a social space which allows for interaction and growing (Wearing \& Wearing, 1996). 
Tourist experiences cannot be understood without taking into account 'social space’ (Yarnal \& Kerstetter, 2005). In line with individual subjective experiences and meanings, and with the feminized emphasis on interpersonal relationships, the idea of the holiday space as 'chora' is suggested, forming a bridge between the mind and body (Grosz, 1995). This includes accepting children as producers of their own experiences and recognising that they may have different values about space and interactions than adults (Matthews et al., 1998). It shifts the basic conceptualisation of the tourist as a gazer or observer (Urry, 1990) to that of an interacting person within a more interactive holiday space (Wearing \& Wearing, 1996). The concept of chora, embodiment, and the feminized dimension of tourism will be further explained and developed in chapter 2 .

\subsection{THE FAMILY ON HOLIDAY}

This is a pertinent time for a comprehensive consideration of the family holiday. The concept of the 'family' is itself in question. There is recognition of plurality of family forms, to the effect that many would refer to families rather than to the family in that different family members are likely to perceive the composition of their families in different ways (Dumon, 1997; Shaw, 1997). Nevertheless, despite the diversity of family forms, a common denominator is that 'they all serve as person-supporting networks' (Dumon, 1997, p. 181). Finding a definition of family is a complex undertaking not only for researchers but also one that confronts society with new challenges. Yet, the concept of relationships and interaction between family members is essential to any notion of family and underlies most literature on family leisure and tourism. Researching the family holiday must be considered within this context of changing family structures and societal values, and wider political and economic policies and trends. In the UK, a family holiday is most commonly defined in literature and policy as a recreational break of four or more nights away from home (Hazel, 2005). This is fairly narrow in that it is based on length and does not take into account experiences. Instead, this research project establishes a definition of family holidays within the New Zealand context that is inclusive of the children's and the parents' experiences. 
While there are several studies outside of New Zealand regarding family holiday decision-making and other market-driven consumer behaviour, there is little published on the effect of the holiday experience on families. This seems unusual considering the high degree of importance placed on families and on holidays by societies around the world (Chesworth, 2003). Instead, there is a commonsense assumption that holidays are beneficial but little research to support those claims when all members of the family are considered (Hazel, 2005). There have been some studies on the collective perspective of family holiday experiences (e.g., Gram, 2005) and on mainly individual family members' perspectives (Hilbrecht et al., 2008; Shaw et al., 2008). The recent work by Hilbrecht et al. and Shaw et al. fits the whole-family approach but was neither conceptualised in this way nor inclusive of all family members over time. A strength of this thesis is that it is a complete whole-family study inclusive of all family members' individual and collective perspectives. This study explores the different holiday experiences of all family members engaging in activities together (such as going for meals and playing games), as well as more individual holiday experiences (such as reading and surf kayaking), thus capturing a diversity of subjective and sensory experiences. The individual and collective meanings and identities attached to these experiences include a complex mix of benefits and drawbacks such as maintaining social relationships through (re)connecting with family and friends (e.g., Larsen et al., 2007), a change from routine (Smith \& Hughes, 1999), creating positive memories (Bærenholdt et al., 2004), as well as family tension and conflict. Thus, this study explored in-depth the interrelationship between family time and time apart on holiday or as Gram (2005, p. 20) identified:

"A dilemma in family holidays is that parents seek togetherness but seem to find this strenuous in practice, and also enjoy having space for themselves on holiday". Moreover, this study is about the whole family and not only the parental perspective.

The lack of research into whole families might explain why there is no framework or analogue in the literature for this project. The issues of treating the family holiday experiences holistically and giving a voice to all family members raises several unique points in tourism studies: first, virtually nothing is known about the father's experience on a family holiday (independent of the combined parent 
voice); second, very little is known about the experiences of children; and third, very few studies focus on the experiences of different family members during the same holiday, or how group dynamics can inflame or heighten the individual holiday experience (Pritchard \& Havitz, 2006). Instead, most tourism studies that deal with tourism experiences discuss representations of the self (tourist) and the other (host) usually in an international (exotic) holiday environment (e.g., GalaniMoutafi, 2000; Suvantola, 2002), or other external factors (e.g., Pritchard \& Havitz, 2006). Yet, the host-guest structure that is applied to international tourism is not well suited to domestic tourism (Aramberri, 2001). It also neglects issues of sociality, especially with 'significant' others (Larsen et al., 2007) and grafting theories about individual tourist behaviour onto group contexts may not work (Yarnal, 2004). One way to 'de-exoticize' tourism theory is by placing family and friendship relations at the centre of tourism research through the social turn (Larsen, 2008). What is needed then is a familial perspective, as argued by Smith \& Hughes (1999), which puts the social into travel and forms part of a new inclusive framework as discussed in chapter 2 .

As a strategy, the mainly qualitative inquiry employed here generates theory by placing emphasis on understanding the world from the multiple perspectives of all family members with their gender and generational differences and similarities as well as their family group dynamics, and views the holiday life as being the product of interactions and interpretations. This study considers separateness and connectedness as the underlying condition of family life and explores how individuals shape a holiday in an intimate group (Hess \& Handel, 1959). It makes a distinction between thinking and acting as an individual family member, the ' $\mathrm{I}$ perspective', versus as a family group member, the 'we-perspective'. It adopts the central theory by Tuomela (2007) that the we-mode is seen as primary compared to the I-mode, making family holidays mainly about collective intentionality essential to social identity formation rather than individual pursuits. This differs from social identity construction dependent on place (see McCabe \& Marson, 2006) rather than travel party. Also, this research project is about the holiday experiences that are different from daily life, termed 'peak experiences' (Quan \& Wang, 2004), along with the supporting experiences and interactions that are intrinsic to everyday life (McCabe, 2002). A more flexible post-disciplinary 
approach is taken that erodes arbitrary boundaries between tourism and leisure, and tourism and home.

Tourism, then, is just one form of leisure-oriented, voluntary temporary mobility (Coles et al., 2005). Instead of downplaying the banal in tourism this research project addresses a gap, as portrayed by Franklin \& Crang (2001), and found that family holidays are not banal or ordinary at all but an experience filled with many meanings especially when considering the gendered, generational, and group dynamic dimensions of family life that also travel. As a result, this research project has implications for tourism theory, policy, and practice.

\subsection{RESEARCH CONTEXT - NEW ZEALAND}

Families have been selected as the focus of this study for a number of reasons. Since 2004 families in New Zealand have received more attention through the establishment of the Families Commission (2008). Within the context of tourism, the family, including children, represents one of the largest markets for holiday service providers (Carr, 2006). For example, in 2001 there were 446,000 twoparent families and 198,000 one-parent families comprising $45 \%$ of households in New Zealand (Statistics New Zealand, 2004). Over 1 million New Zealanders or about $26 \%$ of the population are under 18 years old, and most of them are nurtured within the context of the family (Statistics New Zealand, 2006b). Children, thus, represent a significant proportion of the population and an important current and future market for the tourism industry.

In the year ended June 2007, domestic travel expenditure by New Zealand residents totalled $\$ 7.9$ billion (including daytrips), of which $\$ 5.1$ billion was spent on overnight trips, an increase of $10.5 \%$ from the previous year (Ministry of Tourism, 2007a). The domestic travel market, however, is competing with a strong outbound market. The total number of overseas trips undertaken for the year ended October 2007 was 1.959 million, up 5.4\% on the previous year, with about 50\% going to Australia (Ministry of Tourism, 2007b). There has been an increase in New Zealanders travelling both domestically and internationally with 
the Ministry of Tourism (2007a) concluding that it is encouraging to see New Zealanders enjoying their own back yard as well as offshore destinations. However, the strong demand for overseas holidays not only makes a holiday in Australia part of the New Zealand travel culture (Cropp, 2006b), it also raises questions about the continuing importance of domestic family travel compared to international travel.

D. Pearce (1993) argued that domestic tourism in New Zealand has generally been the neglected cousin of international tourism, in terms of official policy and research. The rapid growth in overseas arrivals in the 1990s and a marked diversification in demand tended to focus attention increasingly on international tourism (Pearce, 2001). Total international visitor expenditure for the year ended 2007 period reached NZ\$ 6.3 billion (Ministry of Tourism, 2007b). The expansion of international arrivals has, however, obscured the social and economic significance of domestic tourism and the growth in travel by New Zealanders abroad (Pearce \& Simmons, 1997). An independent study commissioned by holiday parks in New Zealand concluded that domestic campers can be as valuable as international visitors (Coventry, 2007a). It needs to be noted that expenditure on domestic travel still accounts for over half of all tourist spending. Also, the domestic travel market is predicted to grow by $1.0 \%$ a year over the next 5 years, which is underpinned by the one-week increase to four weeks in the statutory minimum annual leave entitlement from 2007 (DoC, 2006), but very little is known about the social importance of family travel.

Part of the issue is the transformation of the world's longest established tourism department with a wide range of functions into a more narrowly defined tourism board with an international marketing mission (Pearce, 1999) with Tourism New Zealand's \$69 million budget dedicated solely to promoting New Zealand overseas (Cropp, 2006b). Responsibility for domestic tourism has been left to regional tourism organizations (RTOs) (Pearce, 1993) but there is no single national organisation focusing on the domestic market for driving research and developing a strategy (Tourism Industry Association New Zealand (TIANZ), 2005). Domestic data are collected through the domestic travel survey (DTS) and some regional data through the regional visitor monitor (RVM), but the focus of 
government lies on understanding the major inbound visitor markets rather than developing the domestic market (Ministry of Tourism, 2006). There have been voices promoting domestic tourism from various corners, such as the Labour Party (2005), the Green Party (2005), the Automobile Association (AA) (2006), and the TIANZ (2006). The Green Party's (2005) reasoning is that there are significant cultural benefits to be gained from holidaying within New Zealand and this would also help the balance of payment. In 2006 the AA launched an initiative with the aim of encouraging domestic travel. There is, therefore, an increasing call for domestic tourism research which explains the Ministry of Tourism's (2006) report into New Zealanders' domestic and outbound travel patterns.

Over the years there have been several studies into domestic travel in New Zealand. Early regional surveys indicated (e.g., Johnston et al., 1976 in Pearce \& Simmons, 1997) that about two-thirds of the population took an annual holiday. This is confirmed by the New Zealand Tourist and Publicity Department (NZTP) (1989) and also that households with children usually take their holiday all at once over summer. Manning (1980) stated that there was a renewed interest in family camping holidays. Steel \& Riddell (1981) found that a summer holiday is mostly seen as a beach, swimming, and relaxation type holiday, and that parents feel a need to provide their children with a holiday at this time of the year. However, these studies usually did not focus on the family and most are outdated now. A more recent exception is Lawson et al. (1997), segmenting the Kiwi family holiday as making up $14.4 \%$ of all domestic travel. The family's characteristics are staying mainly in baches/cribs (25\%) and camping grounds (25\%), and participating in lots of outdoor and group activities. A recent study into camping holidays in New Zealand found that camping is 'part of the Kiwi way of life' and that its back-to-basics approach enables people to experience and appreciate the environment and their families in a way that they cannot do in their normal busy day-to-day lives (DoC, 2006). However, none of these studies provided an insight into the different experiences and social interactions of a family group and its individual members on holiday in New Zealand, especially in light of more recent changes to families. 
In Western societies, the structure of families has changed considerably in recent years, with marked increases in both solo and multi-generational living arrangements (Jackson \& Pool, 1994). These changes lead to more diverse and complex relationships between parent(s) and child(ren) over the life course (Allen et al., 2000). These shifts in demographics and lifestyles, and the broadened definition of families, have important consequences for travel behaviour. Travel by non-traditional family groups has already been documented, such as grandparent/grandchild travel, multigenerational travel, extended family member travel (such as aunts and uncles taking trips with their nieces and nephews), gay/lesbian family travel, and solo parent travel (Gardyn, 2001). Significantly, 'grandtravel' now accounts for at least one-fifth of all trips taken with children in the United States which can be attributed to more active older people having the time and income to travel (Yeoman, 2008). New Zealand demographics reflect recent social trends in the developed world, such as cohabitation and delayed childbearing, fewer total births, longer life expectancy, and women's increased involvement in the paid workforce (Thompson et al., 2002). A recent study noted an increased concern that working fathers and mothers do not spend enough time with their children (Lawson et al., 2006), which is coupled with an increased importance placed on children (Todd et al., 2001). Consequently, parents value a holiday that offers them the opportunity to spend quality time with their children (Coventry, 2006). According to the Department of Labour (2006), 40\% of New Zealand workers have some or a lot of difficulty getting the work-life balance they want. Women still undertake the bulk of unpaid work, particularly domestic work and caring for others (Statistics New Zealand, 1999). In both the public and private realms gender differences still shape socio-economic relationships and opportunities within New Zealand society (Magee, 2001).

Within the above context, holidays need to be considered as offering some relief from time and place, two of the key constraints of everyday life. In terms of quality of life, thus, holidays can be argued to play a crucial role. Holidays can provide health and social benefits such as physical and mental rest, and thereby reduce family stress. It is not surprising that holidays have come to be seen as a social right forming an essential part of contemporary life in Western societies (Richards, 1999; Smith \& Hughes, 1999). Yet, the ability to take family holidays 
is still constrained by a variety of factors. Lack of time or holiday entitlement, income or available finances, work commitments, vehicular mobility, school holidays, personal health, and care-giving responsibilities may all limit people’s ability to take advantage of the opportunities offered by the tourism industry (see Gladwell \& Bedini, 2004; Schänzel et al., 2005). Researching the family holiday must be considered within this context of changing family structures and societal values, and wider governmental policies and trends. This study takes into account the fact that families are not static structures but are in a continual process of change according to family type and ethnic background (Sterry \& Beaumont, 2006), resulting in families being defined as multigenerational social groups that include at least one child and one adult.

In order to respond to recent studies in related fields (e.g., family and leisure research) addressing fatherhood, which is absent from tourism research, a lack of research into the children's perspective of family holidays, and a dominance of family tourism research from the mothers' perspective, this study demanded the introduction of a new conceptual framework. This framework moves from an individual perspective (one dimensional) to a more inclusive family group perspective (the triangular dimensions of mothers, fathers, and children) with its implicit gender, generation, and group dynamic perspectives (see Figure 2.4). An initial parental survey, distributed through schools, provided context, demographic profile, and selection of participant families for the larger qualitative research project. However, to explore the social experiences and meanings of fathers, mothers, and children together on holiday this research project focused on two-parent families with at least one primary school child for the qualitative interviewing over three time periods (pre-holiday and twice post-holiday). The 10 participating nuclear families for the qualitative study were selected from the 110 questionnaire respondents which were supported by the vast majority of families being headed by two parents (93.6\% of survey respondents). Using a holistic research approach the survey is, thus, linked within the interpretive research paradigm with the qualitative interviewing of whole families. 


\subsection{RESEARCH QUESTIONS}

The research questions build on the familial perspective used as the conceptual framework which arose from the gaps identified in the literature. Most tourism studies on family holidays are market- and consumer-driven and not focused on the broader experiential dimension (before, on, and after the holiday). Instead, there is much tourism work on the individual, mainly male, experiences to the detriment of the female and child perspective. However, within the family group there is an absence of research on the father, the child, and group dynamics, which has excluded the experiences of all individual family members and the whole family. Asking the research questions allows me to address issues related to gender relations or family roles, generational differences, and group dynamics over time. Families, however, cannot be considered as a separate or unitary whole but must be understood in relation to the broader social context. In other words, it must be recognised that each family member expects and experiences a unique holiday reflecting the influences, amongst others, of their gender or roles and age or generation within the family group and contemporary New Zealand society.

Overall question: What are the social experiences and meanings of family holidays over time for the family and its members using gender, generation, and group dynamic perspectives?

Other research questions are contained within the overall question and reflect the iterative research design:

- What are the individual and collective anticipations for their family holiday experiences?

- How do individual family members, and the entire family, experience and remember their time on holiday?

- How are anticipations connected to the actual meanings derived from the holiday experience for the family and its members?

The secondary research questions provide a New Zealand context to the primary research questions:

- How do families in New Zealand describe or define a family holiday? 
- How important is the New Zealand holiday setting or space for the family and its members?

The main purpose of this study is to explore the social experiences and meanings of family holidays for the family and its members pre-trip with those derived from the actual holiday post-trip (over time) using gender, generation, and group dynamic perspectives. This research involved four phases of data collection and analysis with each phase informing the next phase. It was informed by two preholiday phases (parental survey and family interviews) and two post-holiday phases (family interviews). Phase 1 of data collection and analysis involves a parental survey to provide background and selection of participants, as well as a parental perspective on family holiday motivations and definitions. Phases 2-4 of data collection and analysis involve the whole family as well as individual family interviews to explore in more depth the family holiday anticipations of experiences and meanings before the holiday (phase 2) and the short- and longerterm recollections of actual holiday experiences and meanings after the holiday (phases 3-4). The four phases of data collection and analysis are spread out and linked over one year to explore the full range of anticipation, visual holiday experiences (through the use of auto-photoelicitation), and short- and longer-term recollection of family holiday experiences. While the interviews are mainly centred on the domestic summer holiday taken by the 10 families in 2006/07, interview questions address other holidays taken by the families as well. The explicit links between the research questions and the different phases of the methodology are now addressed in more depth.

\subsection{METHODOLOGY}

The methodological framework is underpinned by the research paradigm and philosophical perspective of symbolic interactionism. As the name suggests, 'symbolic interactionism' focuses on the connection between symbols (e.g., shared meanings) and interactions (e.g., verbal and nonverbal actions and communications) on which the grounded theory methodology (GTM) is based. The inductive research process of the GTM is used here because this exploratory 
family research is novel to tourism research and leads to the construction of theory grounded empirically and conceptually. Symbolic interactionism has a strong research tradition in family research (LaRossa \& Reitzes, 1993), as well as leisure research and, in particular, the gendered nature of interaction processes (Kelly, 1994). The interpretive paradigm is particularly suitable for this study where the focus is on the experiences and meanings of a family group, thereby acknowledging the multiple perspectives or realities present on holiday.

A case study enquiry is used here with the multiple case studies being the families and the social phenomenon being the holiday environment. Case studies of families are mainly based on interviews and a small number of cases (Handel, 1991). The inherently private nature of families and mobility on holiday does not allow for field observation and restricts access during the holiday. Instead, case studies of 10 whole families informed by in-depth interviewing before and after their summer holiday experience make up this study. Families represent more than a set of individuals and a family is more than a sum of its individual members. That is why a whole-family approach was used for this study. Multiple family members as informants were interviewed together in a group (concurrently) and one at a time (sequentially) (Astedt-Kurki et al., 2001). These family interviews were conducted with 10 families, usually first with the whole family followed by individual interviews with all family members over 6 years of age.

This study uses a holistic research approach within the interpretive research paradigm that sequentially links a survey with data triangulation of family interviews. It is primarily qualitative but quantitative data are used for background and context. This makes for a primary/secondary combination of linking methods within a study where the qualitative method takes precedence over the quantitative method (Henderson, 2006) and is explained in more detail in chapter 3. The parental survey provides demographic profile and travel behaviour data in which to contextualise this small-scale intensive study, as well as identify and select potential participant families. The quantitative information also provides leads for exploring issues in greater depth through qualitative interviewing (Henderson \& Bedini, 1995). 
Data triangulation which may include time, space, or person triangulation (Fielding \& Fielding, 1986) is then used, which is the first form of triangulation (the others are investigator, theoretical, and method) (Decrop, 1999). The triangulation of whole-family interview data is made up of time triangulation (exploring temporal influences by longitudinal design through three phases of interviewing) and person triangulation (at gender, generational, and group dynamic level through the familial perspective). Data triangulation is considered the best application of the term triangulation because all data collection is of the same kind and based on the same ontology and epistemology, which adds breath and depth to the analysis (Oppermann, 2000). Much too seldom are studies replicated with the same methodology at different times and from the same people's different perspectives in order to find similarities and differences. This study further uses photographs taken by the interviewees on their holiday as stimuli for projective interviewing in the post-holiday phases. This form of photoelicitation is termed 'auto' indicating that the "interview is 'driven' by informants who are seeing their own behaviour" (Heisley \& Levy, 1991, p. 260), and is a valuable tool for opening up the children's worlds to researchers and giving children opportunities to actively interpret their own experiences (Clark, 1999). It also underlines the importance of family holiday photography in creating longerterm memories (Haldrup \& Larsen, 2003) and includes actual visual experiences in the study.

There are four main phases of research data collection that are interconnected and iterative. Figure 1.1 addresses how the purpose of research is related to the research questions for each of the four phases. However, some research questions are tailored to a particular phase of the methodology as indicated by the italics and explained more in chapter 3. 
Figure 1.1 Phases of methodology and research questions

\begin{tabular}{|c|c|}
\hline Phases and purpose & Methodology and questions \\
\hline $\begin{array}{l}\text { Phase } 1 \\
2006\end{array}$ & Parental survey \\
\hline $\begin{array}{l}\text { Purpose of research: } \\
\text { - Providing context } \\
\text { - } \quad \text { Demographic profile } \\
\text { - Selection of participant fa milies } \\
\text { - Individual parent perspective on family holiday } \\
\text { motivations, beha viours, and definitions } \\
\text { - Preliminary a nalysis and the de velopment of } \\
\text { interview questions for phase } 2\end{array}$ & $\begin{array}{l}\text { Research questions: } \\
\text { - How do parents in New Zealand describe or } \\
\text { de fine a family holiday? } \\
\text { - What are the parental anticipations for their } \\
\text { family holiday experiences? }\end{array}$ \\
\hline $\begin{array}{l}\text { Phase } 2 \\
2006\end{array}$ & Pre-holiday family interviews \\
\hline $\begin{array}{l}\text { Purpose of research: } \\
\text { • Individual and group perspectives on family } \\
\text { holiday motivations, anticipations, and definitions. } \\
\text { - Gender, generati onal, and group dynamic } \\
\text { perspectives as anticipated before the holiday } \\
\text { • Preliminary a nalysis and the development of } \\
\text { interview questions for phase } 3\end{array}$ & $\begin{array}{l}\text { Research questions: } \\
\text { - What are the individual and collective } \\
\text { anticipations for their family hol iday experiences? } \\
\text { - How do families in New Zealand describe or } \\
\text { define a family holiday? }\end{array}$ \\
\hline $\begin{array}{l}\text { Phase } 3 \\
2007\end{array}$ & Post-holiday family interviews \\
\hline $\begin{array}{l}\text { Purpose of research: } \\
\text { - Individual and group perspectives on family } \\
\text { experiences and memories as recollected after the } \\
\text { holiday. } \\
\text { - Gender, generational, and group dynamic } \\
\text { perspectives as recollected (short-term) post holiday } \\
\text { - Preliminary a nalysis and the development of } \\
\text { interview questions for phase } 4\end{array}$ & $\begin{array}{l}\text { Research questions: } \\
\text { - How do individual family members, and the } \\
\text { entire family, experience and remember their time } \\
\text { on holiday in the short term? } \\
\text { - How are anticipations connected to the actual } \\
\text { meanings derived from the holiday experience for } \\
\text { the family and its members? } \\
\text { - How important is the New Zealand holiday } \\
\text { setting or space for the family and its members? }\end{array}$ \\
\hline $\begin{array}{l}\text { Phase } 4 \\
2007 \\
\end{array}$ & Post-holiday family interviews \\
\hline $\begin{array}{l}\text { Purpose of research: } \\
\text { - Individual and group perspectives on family } \\
\text { experiences and memories as recollected after the } \\
\text { holiday. } \\
\text { - Gender, generational, and group dynamic } \\
\text { perspectives as recollected (longer-term) post } \\
\text { holiday } \\
\text { - Individual and group perspectives on family } \\
\text { holiday motivations and anticipations }\end{array}$ & $\begin{array}{l}\text { Research questions: } \\
\text { - How do individual family members, and the } \\
\text { entire family, experience and remember their time } \\
\text { on holiday in the longer term? } \\
\text { - What are the individual and collective } \\
\text { anticipations for their family holiday experiences? } \\
\text { - How are anticipations connected to the actual } \\
\text { meanings derived from the holiday experience for } \\
\text { the family and its members? } \\
\text { - How important is the New Zealand holiday } \\
\text { setting or space for the family and its members? }\end{array}$ \\
\hline
\end{tabular}




\subsection{CHAPTER OUTLINE}

This thesis is presented in eight chapters. Chapter 1 has provided a background to the study and outlined the research questions to be investigated. Chapter 2 reviews the literature on family, leisure, and tourism. This chapter begins with families and their traditions in New Zealand including family holidays before moving to the family studies and family leisure literature in general. It then reviews the wider tourism literature by first considering the marketing or consumer perspective before evaluating the wider experiential and temporal dimensions of family holidays. This chapter not only addresses the literature but also the conceptual framework used for this study which informed the methodology. Chapter 3 outlines the methodological, analytical, and theoretical frameworks within which I have designed and undertaken this study and interpreted the results. It describes the methodological approach to the research and the different phases of research. The method of data analysis and reflections on the research process are discussed at the end of this chapter. Chapters 4 to 7 present the findings of the research. Chapter 4 provides a context for this study by discussing the findings of the parental survey leading to a definition of family holidays based on the familial perspective. This chapter includes a discussion of the contextual factors and summarizes the main themes of family time and own time. Chapters 5 and 6 present the findings on family time and own time from the different perspectives of gender, generation, and group dynamics. Chapter 6 finishes with discussing the temporal dimension based on the stages of holiday. Chapter 7 provides a theoretical understanding of the meanings of holiday experiences for the family and all its members. It interprets the data with regards to the themes, perspectives, and temporal and spatial dimensions, thereby conceptualizing and developing theory grounded in the data. It further discusses the domestic holiday context of this research. Chapter 8 is a summative conclusion and discussion that distils the findings from the preceding chapters. The research questions are revisited and the key findings are summarized; contributions to theory, policy, and practice are suggested as are recommendations for further research. 


\section{CHAPTER 2: FAMILY, LEISURE AND TOURISM:}

\section{A LITERATURE REVIEW}

\subsection{INTRODUCTION}

This chapter reviews the study of families within the context of New Zealand and the wider family, leisure, and tourism literatures which in turn focus on family experiences at home, around the home, and away from home. The discussion in chapter 2 is based on the premise that experiences and meanings within the family are shaped by societal ideals and changes within contemporary families' lives which have an influence on gender and generational roles. This review moves away from a narrow business focus and dominance of individual tourism perspectives in the literature (one dimensional) and instead highlights a need for a new conceptual framework that is inclusive of the experiential and temporal dimensions present on family holidays from gender, generation, and group dynamic perspectives (three dimensional). The focus is on the social interactions and relationships that shape family group experiences and how they are influenced by different notions of time, different locations (at home, at leisure, and on holiday), and from different perspectives (gender and generation).

Family holidays are primarily about the collective experiences of the group with all family members contributing to the construction of its meaning, in this case mothers, fathers, and child(ren). This includes different phases of the holiday experience which are represented by the anticipation of experiences before and memories of experiences after the holiday. The research questions followed from the conceptual framework that entails the triangular family group experiences over time (see Figure 2.4) and the need to better understand the significance and definition of holidays for New Zealand families. In order to provide background and context for this study, this chapter begins with a discussion of the composition of New Zealand families, their work-life balance, and family leisure and holiday behaviour. However, it is the international literature on families within the home, at leisure, and on holiday that provides the central exploration of theories and 
concepts to this study of New Zealand family tourism. In this way, the literature review presented here is sensitive to the local context but more importantly speaks to a global audience and addresses gaps in the study of family holidays on an international scale.

\subsection{FAMILIES IN NEW ZEALAND: BACKGROUND AND CONTEXT}

The concept of family is deeply embedded in our lives at individual, communal, and social levels. Yet the definition and nature of families are vigorously contested, perhaps more so in the twenty-first century than ever before. According to Pryor (2006) this contesting encompasses an unprecedented focus on the meaning, importance, imputed demise and renegotiation of families. Family life in contemporary Western society is characterised by anxiety and uncertainty about what it means to 'be family', and indeed what the functions of families are. The stability provided by external sources such as church, state and community is being steadily eroded as families become increasingly secular and diverse. Within this context the family is understood in the plural form as endorsed by the Families Commission in New Zealand and scholars in general (see Dumon, 1997). Most literature on the conceptualisation of families is based in Europe or North America. Yet, within New Zealand a rich diversity of families is also both more evident and increasingly approved by large sectors of society today, existing side by side with the 'nuclear' family but closing in on it in terms of numbers (Pryor, 2007). It is the radical social and economic changes of the past 50 years that have given rise to a more dynamic and complex understanding of families.

A couple today is more likely to have fewer children at significantly later ages and to be in paid work (Ministry of Social Development, 2004). The current total fertility level is about 2.0 births per woman, which is below the replacement level but relatively high compared with other OECD countries. Also, fewer parents are marrying, with different family forms and household types becoming more common. The proportion of single-parent families has risen from $10.4 \%$ of families with dependent children in 1976 to 29.2\% in 2001 (Ministry of Women's Affairs, 2008). As Figure 2.1 shows, women in two-parent families were more 
likely than their sole-parent counterparts to have more than one dependent child, with over $40 \%$ having two dependent children (Statistics New Zealand, 2005). Adding to the diversity of families is that at the 2006 census almost a quarter of people living in New Zealand were born overseas compared with $17.5 \%$ in 1996, emphasizing the increasing immigration from countries such as China and South Africa (Statistics New Zealand, 2007).

Most social research on families in New Zealand is focused on women, highlighting a lack of understanding on the role of fathers in society. This has only recently been addressed by the Families Commission (e.g., Gage, forthcoming). Qualitative data show that New Zealand women often hold as an ideal having a family of two or three children, and most consider a one-child family as undesirable and frowned upon by society (Sceats, 2002). The loss of larger families and its accompanying values was regretted by these women, while others saw New Zealand as a great place to raise children in the presence of family networks, despite a lack of family-friendly policies (Pool et al., 2007).

Figure 2.1 Proportion of women with dependent children by number of children and family type in 2001

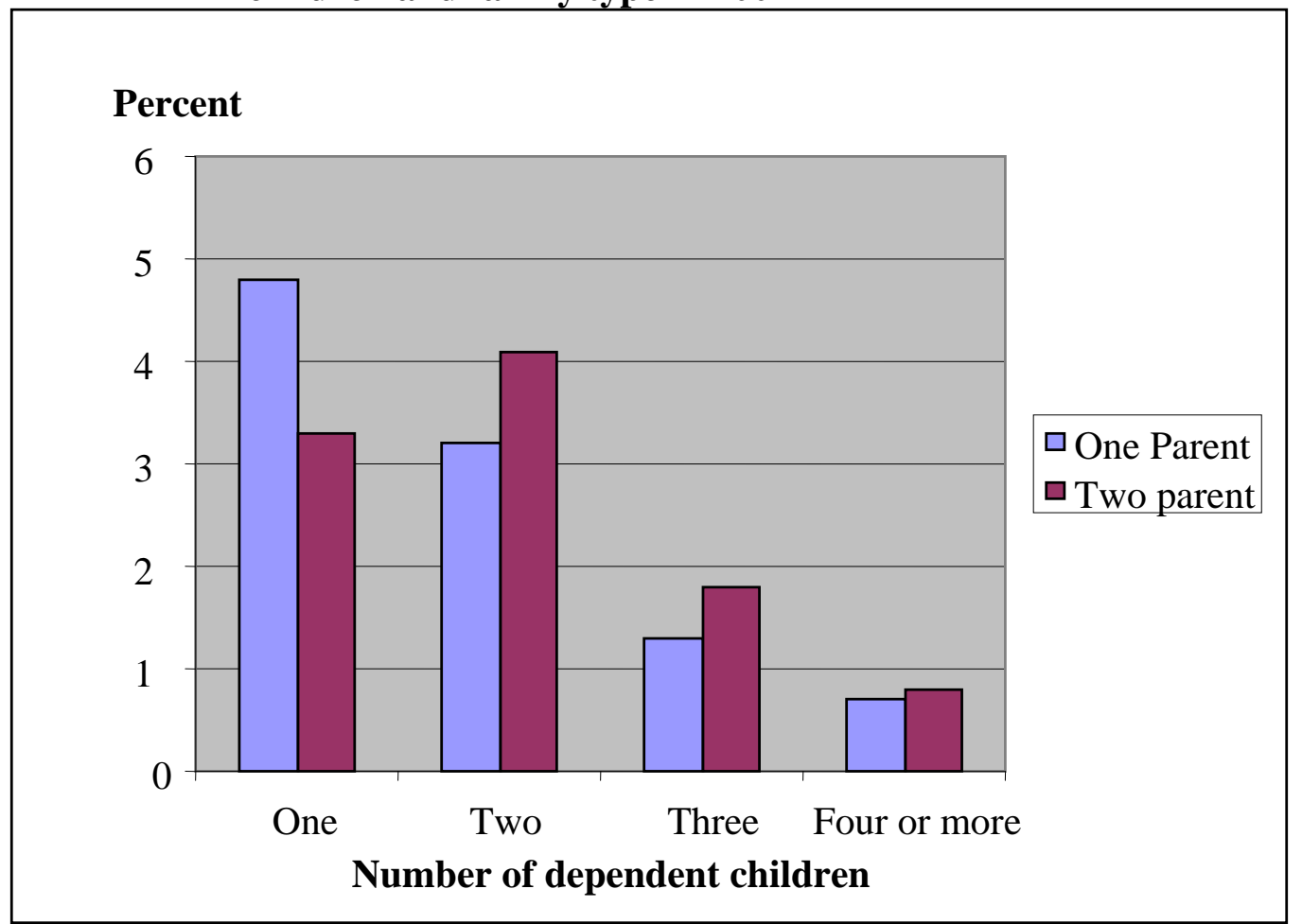

Source: Statistics New Zealand (2005, p. 37). 
Over the years the norms of parenthood in New Zealand have changed to accommodate combining motherhood and paid work alongside increasing involvement by the fathers. While there are cultural norms and preferences for having one parent at home full-time for pre-school children, in reality this is often overridden by financial needs (McPherson, 2006). Rising grocery, living, and electricity costs are continuing to squeeze household budgets, with low- and middle-income families feeling the pinch (Statistics New Zealand, 2008). As a result, increasingly both parents are in paid employment often through need rather than choice, which has an influence on the quantity and quality of time spent within families and the nature of relationships amongst family members.

\subsubsection{FAMILIES, TIME AND WORK/HOME-LIFE RELATIONSHIPS IN NEW ZEALAND}

Family members allocate their time to different tasks and activities, such as work, family life, and leisure, which makes the notion of time fundamental to any discussion of families. A qualitative study (Department of Labour, 2003) found that three key components are needed for a person to achieve a healthy lifestyle: paid work, unpaid work, and personal time. Personal time included 'me-time' and family time (Figure 2.2) which all needed to be present in a person's life to achieve a proper balance. However, in any review of the factors affecting the family in New Zealand, the interrelationship between work and home becomes the most critical factor.

According to a national survey on work-life balance in New Zealand, 46\% of workers experienced some degree of work-life conflict (Department of Labour, 2006). Balancing work and family time is a major challenge for many families; in particular, finding time for the children is a major concern (Lawson et al., 2006; Robertson, 2006). While it is common for families to feel time-pressured, being able to balance time alone with time spent with family is critical for achieving family wellbeing (Families Commission, 2006) and providing strengths for New Zealand families (Cook, 2007). It also fosters social connectedness, which refers to the relationships people have with others (mostly family and friends), and is integral to wellbeing (Ministry of Social Development, 2007). This is in contrast to recent immigrant families who can struggle to adjust to a new country (Cook, 
2007), and who usually do not have the support of their extended families here to balance the work/home-life relationship.

Figure 2.2 The different aspects of work-life balance

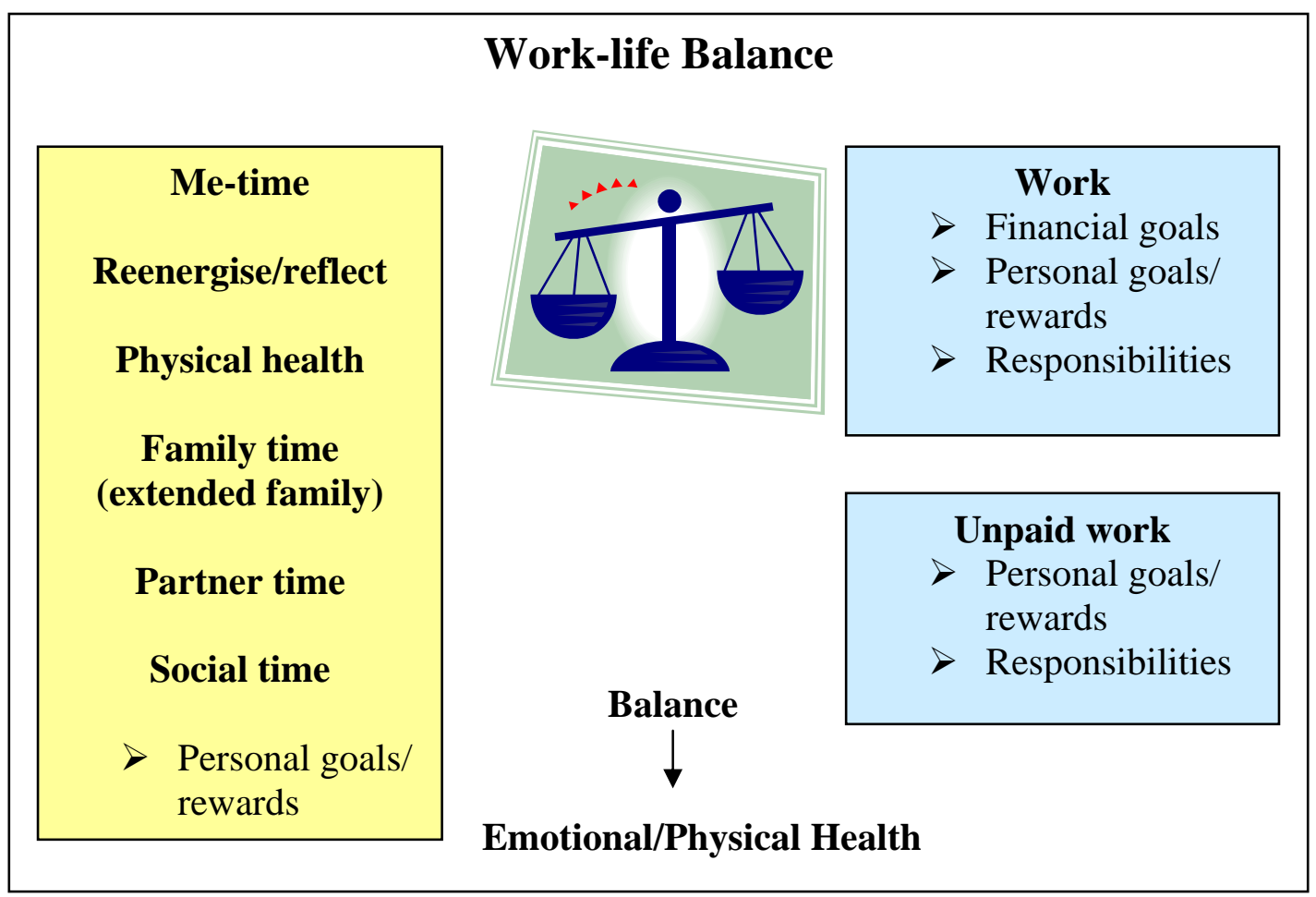

Source: Department of Labour (2003, p. 14).

There are some key variables that affect the work-life balance in New Zealand, such as recent government policy, increased participation by women in the workforce, continuing gender differences, and the increased importance placed on children (Table 2.1). As a result, tensions arise within the family, not only between the traditional and contemporary roles of parenting, but also between the pressures of society and the perceptions of parents. Incorporating family holidays into this work-life balance is a challenge with so many competing demands on family time. Family holidays are often practised as demarcations of 'special time' from ordinary time and are ways for families to escape the demands of regular time. Many New Zealanders put particular significance and even symbolism on domestic summer holidays (Pryor, 2006). All of this gives rise to the different notions of time within a family, with particular emphasis put on spending quality family time with child(ren). Time at work (paid or unpaid) is considered as more 


\section{Table 2.1 Summary of the key themes affecting the work-life balance of families in New Zealand}

\begin{tabular}{|c|c|c|}
\hline Key themes & Issues & Effect on family life \\
\hline Government policy & $\begin{array}{l}\text { Economic restructuring of the welfare state in } \\
\text { the early 1990s (Pool et al., 2007). }\end{array}$ & $\begin{array}{l}\text { - Led to labour market flexibility which is found } \\
\text { to be extremely disruptive to normal family life } \\
\text { (Sceats, 2002). }\end{array}$ \\
\hline $\begin{array}{l}\text { Increased } \\
\text { participation by } \\
\text { women in the } \\
\text { workforce }\end{array}$ & $\begin{array}{l}\text { - In 2004, } 59.6 \% \text { of women were participating } \\
\text { in the paid workforce, compared with } 73.8 \% \\
\text { of men. A high rate compared with other } \\
\text { OECD countries (Ministry of Women's } \\
\text { Affairs, 2008). }\end{array}$ & $\begin{array}{l}\text { - Influenced the changing gender roles regarding } \\
\text { work/home responsibilities. } \\
\text { - Virtually all New Zealanders (96\%) believe that } \\
\text { both parents are equally important to children } \\
\text { (Gendall, 2003). } \\
\text { - There are sentiments that working women do } \\
\text { not spend enough time with their children } \\
\text { (Lawson et al., 2006; Todd, et al., 2001). }\end{array}$ \\
\hline $\begin{array}{l}\text { Continuing gender } \\
\text { differences }\end{array}$ & $\begin{array}{l}\text { - Women undertake the bulk of unpaid work, } \\
\text { particularly domestic work and caring for } \\
\text { others, regardless of employment status } \\
\text { (Statistics New Zealand, 2001). } \\
\text { - } 80 \% \text { of New Zealanders believe men should } \\
\text { be more involved in their children's lives } \\
\text { (Gendall, 2003). }\end{array}$ & $\begin{array}{l}\text { - Mothers and fathers experience work-family } \\
\text { life conflict as they strive to meet changing } \\
\text { social expectations (McPherson, 2006). }\end{array}$ \\
\hline $\begin{array}{l}\text { Increased importance } \\
\text { placed on children }\end{array}$ & $\begin{array}{l}\text { - Parents are having fewer children who } \\
\text { become the focus of intense attention and a } \\
\text { major source of emotional gratification. This } \\
\text { has led to an elevation of children's powers } \\
\text { (Pryor, 2006). }\end{array}$ & $\begin{array}{l}\text { - There are far more tensions between individual } \\
\text { and collective identities than in the past (Pryor, } \\
\text { 2006). }\end{array}$ \\
\hline
\end{tabular}


regulated than time away from work routines, which is considered more personal or leisure time. The following section discusses family leisure within New Zealand before reviewing the domestic family tourism literature. Tourism is one dimension of leisure in the sense that tourism is a form of leisure that takes place away from home. This is particularly relevant for family travel and will be elaborated on at an international level later in this chapter.

\subsubsection{FAMILY LEISURE IN NEW ZEALAND}

As the gender roles have changed in relation to work/home responsibilities, so too have they changed in other spheres of life. In everyday leisure Phillips (1999) documents a convergence of the leisure patterns of men and women from the 1970s, prior to which they were very different. Today, women have more time, money, and leisure to participate in activities outside of the home than before. In the home, both men and women participate in family leisure activities, but for fathers it often involves spending time with the children rather than the entire family unit. Thus, exclusive gendered cultures are declining and men and women in New Zealand are facing a greater diversity of options together which, in part, is a reflection of a more diverse society (Phillips, 1999). The traditional role of sport and its importance in New Zealand culture in the last century reinforced hegemonic masculinity and provided New Zealand men with a national identity (Phillips, 1996; Thomson, 2000). Today, a strong collective male identity is no longer so prominent (Thomson, 2000), but in spite of this gender differences in physical activity are still apparent with significantly more boys (74\%) than girls (64\%) achieving more than 2.5 hours activity per week (Sue et al., 1999).

A study by Thompson et al. (2002) provides a snapshot of how midlife New Zealanders (40-54 year olds and a dominant group with dependent children) experience their leisure time. It found few gender differences related to the availability of leisure time, and involvement with family members as an integral part of their leisure experiences. One interpretation of the result is that by midlife one has settled into leisure lifestyles through years of negotiation and adaptation (Grant \& Thompson, 2000). Gardening, walking, and swimming are the main leisure activities for 35-49 year olds (Sport \& Recreation New Zealand, 2006). However, this does not capture the informal nature of much family activity and 
instead focuses on leisure outside the home which is easier to differentiate (Joux, 1985). Compared with international leisure research, which will be discussed later, New Zealand research does not address an overlap between 'domestic work' and 'leisure' in many family activities and neglects the meanings assigned to leisure which are inclusive of gender considerations.

In New Zealand there are few studies dealing with critical leisure research (e.g., Aitchison, 2005). Leisure research is simply not taken seriously by the majority of social scientists in New Zealand, nor is it seen important enough to attract significant government or private sector funding (Perkins \& Gidlow, 1991). Instead, research is of an applied nature directly relating to departmental policies that fails to 'deepen' the understanding of leisure in New Zealand (Cushman, 1995). A recent example is Sport \& Recreation New Zealand (SPARC) (2007), which was established in 2003 with the aim of getting New Zealanders more active but not focusing on leisure dimensions within the home. There is an absence in New Zealand of published literature into broader family leisure that includes gendered interpretations and home-based activities which corresponds with a lack of research into domestic tourism behaviour and family holiday experiences. For this reason, some comparisons with Australian and other international domestic travel studies are made in the following section.

\subsubsection{KIWI FAMILY HOLIDAYS AND THE DOMESTIC TOURISM CONTEXT}

New Zealand is an island nation with a small population (4.26 million in April 2008), low population density, and varied natural resources. It is relatively distant from other countries, which explains the traditional importance of domestic tourism not only for the tourism industry (about 56\% of all tourism spending; Ministry of Tourism, 2007b) but also for New Zealanders themselves. The beach is for many Kiwis the essence of their holiday, and days spent there are considered a highpoint of childhood (Phillips, 2007). For over a century this coastline has attracted stays in holiday homes, and about half of New Zealand's campgrounds are located there. The experience of camping is also passed down through the generations along with a sense of place (Hay, 1998). The annual summer family camping holiday is perceived to be part of the Kiwi way of life 
(Richmond \& Tolich, 2000): an activity that epitomises what it means to be a New Zealander (DoC, 2006). The literature here is dominated by camping holidays. Less is known about other forms of holidays and the significance of holidays for the families and its members.

The domestic family holiday can be a stressful time, particularly for women because it traditionally occurs directly after the celebration of Christmas which women usually plan, organise, and orchestrate (Fitzgerald, 1993). Two qualitative studies in New Zealand highlight that for mothers the caring and domestic work continues on holiday (Fitzgerald, 1993; Richmond \& Tolich, 2000). Family holidays are enjoyed by women for providing opportunities to nurture relationships and for a reduction in the pace and standards of work. This notion of women performing the bulk of tasks while on holiday, and especially work that reveals a caring ethic, is common throughout feminist leisure and tourism literature as elaborated on later. However, no studies have been carried out on fathers and children on family holidays in New Zealand.

A recent review into camping opportunities in New Zealand found that most New Zealanders (80\%) have been camping at some point in their life (DoC, 2006). This is confirmed by focusing on January, the main month for domestic summer family holidays, when 35\% of all commercial guest nights were spent in holiday parks in 2007 (Coventry, 2007b). The continued popularity of the traditional Kiwi camping holiday is further reflected by camping being voted the ninth most popular activity in the AA (2006) campaign. There is increasing demand for selfcontained units (Coventry, 2008), with holiday parks heading toward low-level resorts (Gautier, 2003). Holiday parks, therefore, are changing the nature of camping by offering more comfortable options to sleeping in tents while still preserving the traditional Kiwi holiday feel.

The same trend of travellers preferring fixed-site accommodation at holiday parks is happening in Australia (Tourism Australia, 2005). Australia is particularly relevant due to its close cultural, geographic, and economic ties with New Zealand and is the main tourist inbound and outbound market for New Zealand. In both countries the major users of holiday and caravan parks continue to be family 
groups (Tourism Australia, 2005). Several studies in Australia have highlighted the social nature of these holiday park experiences, in particular raising the importance of interpersonal relationships and a sense of community (e.g., Marles, 2002; Winter, 2005). This corresponds with findings by DoC (2006) which found that benefits associated with camping in New Zealand are increased social relationships and the ability to spend quality family time. The notion of social capital in that such tourist behaviour is concerned with (re)producing social networks is raised by Foley (2007) in the Australian context. This social dimension of tourism will be expanded on later in this chapter. However, none of these studies focuses specifically on families or on all of its members.

What else is known about the New Zealand family holiday market and other forms of travel? The Domestic Travel Survey does not segment by travel group (such as groups with children) and only provides general information, e.g., 85\% of domestic tourists travelled by car/van and $27.6 \%$ travelled exclusively to visit friends and relatives (VFR) (Ministry of Tourism, 2008a). This leads to an underestimation of the VFR market (Brocx, 2003). International studies acknowledge that VFR is a substantial portion of the domestic market that has remained under-researched (e.g., Morrison et al., 2000; Pennington-Gray, 2003; Seaton \& Palmer, 1997). In Australia, Jackson (1990) and Backer (2007) found that the size and value of VFR travel is underestimated, and that it can be either a prime trip motive or one of a set of activities or regional attractions (Moscardo et al., 2000). Lockyer \& Ryan (2007) in New Zealand reported a difference between 'visiting friends' and 'visiting relatives' in that the later is oriented towards family relationships and outings with children.

A study by Lawson et al. (1997) identified the Kiwi family holiday market as making up $14.4 \%$ of the total domestic tourism market with a further $20.7 \%$ travelling for special family occasions. This, however, means that a distinction is made between travelling with the immediate family (Kiwi family holiday) and travelling to visit extended family (special family occasions) when there might be overlaps such as Christmas celebrations being part of the family holiday. A compilation of domestic data found that about half of family holidays are spent in the homes of relatives and friends (Manning, 1980). Other domestic travel studies 
such as those by Steel \& Riddell (1981) and NZTP (1989) did not segment into the family travel market. This compares with about $11 \%$ of international visitors to New Zealand travelling with family for which there are nation-wide data available (Ministry of Tourism, 2008b). In fact, very little is known about the real importance of the domestic family market, not only for the tourism industry but also for the family members experiencing it.

Some studies have pointed out that travelling in New Zealand is about 'doing' rather than just 'seeing', and the reason for this is a long-standing pattern of active and adventure-based domestic tourism (Perkins \& Thorns, 2001). The range of outdoor recreational opportunities available to New Zealanders is as diverse as the landscape, and active participation is considered in more cultural terms as being healthy and morally virtuous (Devlin \& Booth, 1998). The cultural tradition of the Kiwi holiday, then, is based on easy access to relatively uncrowded landscapes that offer myriad opportunities for outdoor activities (Perkins \& Thorns, 2001). For example, Kaikoura is perceived as a family destination in which to pursue marine activities among attractive coastal scenery (Fairweather \& Swaffield, 2001). Yet, Devlin \& Booth (1998) pointed out that there is a lack of New Zealand studies into the motivations and experiences of those outdoor behaviours. However, tourism experiences based on Maori culture hold little appeal for nonMaori (Pakeha) New Zealanders (Ryan \& Pike, 2003). One explanation is that Pakeha tourists in their own land are culturally apart, but not economically, socially, or politically and, thus, avoid the Maori attractions (Ryan, 2002b).

A study into domestic perspectives of New Zealand holiday destinations ranked Bay of Islands and Nelson as the most family oriented with sea/sand/beach as their main attractions (Kearsley et al., 1998) (see Figure 4.1 for a map). Also, New Zealanders ranked New Zealand highest as a holiday destination compared with other countries on four attributes; natural landscape, clean/unpolluted, for the whole family, and friendly people (Driscoll, 1990), rather than for culture or entertainment. Again these studies are not focused on the family market and instead are more about domestic tourism in general. What can be taken from these studies is that holidays in New Zealand are mainly about outdoor activities, centred around the beach for families, and with a particular emphasis placed on 
campground holidays which are seen as enhancing social relationships. These themes are also relevant for holiday or second home tourism but because of a lack of research within New Zealand, international studies focusing on domestic tourism are included next.

Jafari (1986) indicates that domestic tourism can produce several socio-cultural benefits such as fostering a greater sense of national awareness but little is known about the social processes in which people experience national identity through tourism (Palmer, 2005). There are numerous studies into second home ownership globally as an important element of domestic tourism; most comprehensive is that of Hall \& Müller (2004). Largely missing from this literature is discussion of the second home in the context of family life and associated interpersonal relations as well as better linking of spaces and experiences with the primary home (Perkins \& Thorns, 2006). Historically, second homes have been an integral component of New Zealand lifestyles and for many Kiwis represent a simpler way of life (Keen \& Hall, 2004). According to the Tourism Research Council (2000), holiday homes/baches account for $13.9 \%$ of accommodation used on holiday in New Zealand. Despite their recognised significance within the Kiwi culture there is little research on them apart from Keen \& Hall’s (2004) study into planning issues, which is why international studies provide more detail on this subject.

It has been recognised that removal or inversion from everyday urban life appears to be a main attraction of second homes. For example, in the Canadian context Jaakson (1986) describes a desire to get back to nature on holiday. This is confirmed by Williams \& Kaltenborn (1999) in the case of Norwegian and American holiday cottages where the refuge in nature is considered the most direct form of escape from modernity. Also, the second home provides for family togetherness of a different kind from that in the city (Jaakson, 1986), which Haldrup (2004) calls a laid back mobility. A recent Norwegian study found that the ideal of the primitive cabin has given way to the ideal that the second home is a place for social gathering and outdoor activities but also with growing demands for comfort and convenience (Vittersø, 2007). These studies confirm previous themes of domestic holidays being primarily about nature experiences, providing social occasions, and becoming more comfortable while preserving cultural 
traditions. However, these studies are only focused on second-home tourism and do not provide a broader perspective on domestic family holidays in general.

In summary, there is a gap in our understanding of families travelling in New Zealand that includes all family members in a range of holiday experiences from camping to VFR to staying at holiday homes or motels. Instead, studies of New Zealand family holidays have been either fairly narrow or were nondistinguishable from the general population. Also, until this study no research has been carried out on the significance or definition of Kiwi family holidays for the family members themselves, given its importance in New Zealand's psyche. In order to develop the research questions more background is needed on families in general. The discussion now moves to the international family literature that provides a better understanding of the basic underlying issues of family functioning including the importance of family time and gender and generational considerations.

\subsection{RESEARCHING FAMILIES AT HOME: INTERNATIONAL PERSPECTIVES}

Families are shaped by the society in which they live, which makes the New Zealand context essential to this study. It is also important to look at Western societies in general and further identify basic characteristics that are common to all functioning families. Families must be seen as a distinctive focus of study. Several characteristics and conditions reflect the unique nature of families as social groups: privacy; a collective consciousness not readily available to others; permanent relationships; shared traditions; intense involvement; and a collage of individual interests and qualities (Daly, 1992). The most general condition is that members are connected to one another, and they are also separate from one another. Every family gives shape to these conditions in its own way and may show greater emphasis on the one or the other, yet both are constitutive of family life. Thus, every family must work out a pattern of separateness and connectedness by dealing with this dual condition of inevitable individuality and inescapable connection (Handel, 1996; Hess \& Handel, 1959). However, the focus 
is generally on time together rather than time away from family (e.g., Stevens et al., 2007) which is discussed under the ideological notion of family time later.

Another condition is that families must deal with the basic biosocial issues of sex/gender and age/generation and negotiate differences that arise from interfamilial differences in these meanings (Handel, 1996). The gender roles of mothers and fathers within families and the parent/child or generational relationships will be discussed later in this section with regards to meanings of family time. Durkheim (1933 cited in Lareau, 2000) made an important point often overlooked in family studies. He argued that groups have a reality in and of themselves or that the whole is more than the sum of its parts. Also, families are groups with members interacting in a fluid and dynamic fashion. In fact, Hill (1949 cited in Handel, 1965) referred to families as thinking at the threedimensional level in contradistinction to thinking at the level of the individual and the pair, one- and two-dimensional, respectively. The notion of threedimensionality in families will be elaborated on in the conceptual framework later in this chapter. First, this discussion will centre on the ideology of family time and the nature of family rituals in contemporary Western society.

\subsubsection{THE IDEALISATION OF FAMILY TIME IN WESTERN SOCIETY}

Family time is now a central part of the Western discourse when referring to the day-to-day experiences of families. In response to the fast pace of technology and the dramatic increase of women in the paid labour force, family time has been idealised as the private still point in an otherwise frenzied pattern (Daly, 1996a). One of the repercussions of this is the emergence of a discourse in the popular and academic press that emphasizes a 'growing time famine in families' (Daly, 2004, p. 9). In spite of this perception that parents are spending less time with their children, national time studies indicate that parents are spending more time with their children (e.g., Bittman, 1999; Gauthier et al., 2004; Sandberg \& Hofferth, 2001; Zuzanek, 2001). In fact, parents report spending greater amounts of time with their children today than in the 1960s, particularly fathers (Sayer et al., 2004). One explanation is that the time that families spend together has become more goal oriented, structured, and saturated with activity (Daly, 2004), and there is increased emphasis on the 'consumption' of experiences (Robinson \& Godbey, 
1997). Paradoxically, it is the very abundance of family time that is contributing to the sense that there is not enough time for family. The proliferation and the high standard expected of every occasion have added to the effort and sense of busyness that characterises family life today (Gillis, 2001). It is also important to discuss how contemporary families perceive their time together and the cultural changes accompanying this. The time families live by as captured by quantitative studies might not be the same as the quality of time they live with (White, 1996) which is grounded in experience (Daly, 2003).

The ideals of spending quality family time and child-centeredness are important guiding principles for modern Western families. Although family time is subject to serious competition from changing work and societal structures, ideas on family time seem resistant to change (Mestdag \& Vandeweyer, 2005). There is discordance between the traditional ideal of family togetherness and the reality of the everyday experiences. Parents today may feel increased cultural pressure to provide large amounts of time to children in order to be considered 'good parents' (Sayer et al., 2004; Snyder, 2007). According to Giddens (1984) time has both lived, inter-subjective aspects and structured, normative dimensions. With regards to family life it is the normative dimension that directs families to act in certain ways (Daly, 2001). Everyone has two different families that live in a state of tension, 'one that they live with, and another that they live by' (Gillis, 1996, p. $\mathrm{xv})$. The strong cultural standards that families 'live by' play an important role not only in preserving continuity with traditional values but also in leading to dissatisfaction about family time, which is usually expressed in guilt (Daly, 2001). Instead of changing ideals about family time and being more realistic about it, the achievement of family time is seen as a personal trouble that requires a private solution rather than a systemic or public dilemma applying to all families (Daly, 2002). Today's families live by what they call 'quality time', which is different to the time they actually share together (Gillis, 2000) such as rituals and routines.

Within the home the routines of family meals are still the most important family activity (Mestdag \& Vandeweyer, 2005). Family life is also conducted outside the home, but this public aspect, such as outings to the zoo, is seldom studied (DeVault, 2000). Today, there is a range of rituals in family life, which includes 
everything from special family meals to family holidays, that are not like other times, but rather a time-out-of-time, a social and cultural construction (Gillis, 2001). These ritualised times are different in that they require anticipation and preparation, are the subject of extensive remembering, and provide a sense of identity (Fiese et al., 2002). Rituals such as family holidays stand out as more symbolic, steeped in memories, and spanning across generations compared with everyday routines (see Table 2.2), and can come to resemble religion (White, 1996). However, the scientific study of routines and rituals remains relatively immature (Fiese et al., 2002) and tends to reproduce privatised notions of family life (DeVault, 2000). In fact, while family holidays are mentioned in some family literature (e.g., Gillis, 2000; Pryor, 2006; Snyder, 2007), no family study has yet focused on the symbolic and enduring meanings of family time on holiday.

Table 2.2 Differences in definitions between routines and rituals

\begin{tabular}{|l|l|l|}
\hline Characteristic & $\begin{array}{l}\text { Routines of daily living } \\
\text { e.g., family meals }\end{array}$ & $\begin{array}{l}\text { Rituals in family life } \\
\text { e.g., family holidays }\end{array}$ \\
\hline Communication & $\begin{array}{l}\text { Instrumental } \\
\text { "This is what needs to be } \\
\text { done." }\end{array}$ & $\begin{array}{l}\text { Symbolic } \\
\text { "This is who we are." }\end{array}$ \\
\hline Commitment & $\begin{array}{l}\text { Perfunctory and momentary. } \\
\text { Little conscious thought } \\
\text { given after the act. }\end{array}$ & $\begin{array}{l}\text { Enduring and affective. } \\
\text { The experience may be } \\
\text { repeated in memory. }\end{array}$ \\
\hline Continuity & $\begin{array}{l}\text { Directly observable and } \\
\text { detectable by outsiders. } \\
\text { Behaviour is repeated over } \\
\text { time. }\end{array}$ & $\begin{array}{l}\text { Meaning extends across } \\
\text { generations and is } \\
\text { interpreted by insiders. }\end{array}$ \\
\hline
\end{tabular}

Source: Fiese et al. (2002, p. 382).

It must be remembered that a balance is needed between family time together and time apart. According to Olsen's circumplex model of marital and family systems (Olsen \& Gorall, 2003), cohesion (togetherness) is defined as the degree of emotional bonding between family members. A balanced or midrange level of cohesion indicates a healthy sense of both connectedness and separateness in family relationships. Extreme high or low levels lead to either enmeshment (too 
much closeness) or disengagement (too little closeness) (Perosa \& Perosa, 2001). This leads back to Hess \& Handel's (1959) notion that families have to establish a pattern of separateness and connectedness. Recent work by neurobiologists and clinical psychologists lays claim to biological differences in that males are more separated (and disengaged) and females are more connected (and enmeshed) (Baron-Cohen, 2004; Brizendine, 2006; Pinker, 2008). In terms of connectedness, women show a higher desire for relationships than males, which is relevant for the following discussion on gender. Discussions of family time also do not typically include any negative aspects or the different meanings associated by each family member (Daly, 2001). It must be remembered that all members of the family contribute to the meaning of family time, including mothers, fathers, and children. To address this, a whole-family perspective is taken that is inclusive of gender, generation, and group dynamics.

\subsubsection{GENDER AND GENERATIONAL PERSPECTIVES ON FAMILY TIME}

Families are organised around two structural axes, gender and generation, which means that a preoccupation with dualisms (men vs. women) is shifted to a more multilayered concept (Osmond \& Thorne, 1993). Families cannot be considered as a unitary whole separate from society but can only be understood in relation to the broader social context (Ferree, 1990). It has to be remembered that the meaning of family time differs by gender and generation because of the relative weight that mothers, fathers, and children place on their family identities. The term gender has been adopted by feminist scholars as acknowledging the influence of social structures on family roles (Walker, 1999). In general, there are quantitative differences in that mothers spend more time with their children than fathers, regardless of their work status (Sayer et al., 2004). There are also qualitative gender differences in that a substantial amount of the time mothers spend with their children involves child care and maintenance, whereas fathers spend more time with their children playing (Craig, 2006; Roxburgh, 2006) and taking responsibility for their home environment (Allen \& Daly, 2005). This leads to gendered and generational differences in the way family time is defined. The discussion now addresses the notion of family time with regards to motherhood, fatherhood, parenthood, and childhood within contemporary Western society. 
According to McMahon (1995) contemporary motherhood is contested terrain. It is often defined as a state of being, but women usually describe their mothering as activity-based rather than identity-based (Maher, 2005). Douglas \& Michaels’ (2004) analysis of the context for mothering outlines unattainable ideals for 'moms' that promulgate standards of perfection beyond their reach. Maume (2006) suggests that these cultural messages have intensified with time in the popular literature, as women are now responsible for all aspects of preparing their children for adulthood. While mothers continue to exert more control over the organisation of time in families, thus portraying a more traditional role, time negotiations have become a more complex and demanding activity (Daly, 2002), such as the struggle to meet the schedule demands of their children (Hochschild \& Machung, 1989). Also, mothers preserve time for interacting with their children by accepting greater task density, in other words, working harder than fathers (Craig, 2006). As a result, mothers want slower, high quality time with their children (Roxburgh, 2006). Cowdery \& Knudson-Martin (2005) suggest that many couples hold contradictory ideologies related to parenting. These couples want fathers to be involved, but the ideology of mothering as a gendered talent perpetuates separate sphere parenting and gender inequality. The meaning of family time for mothers is, thus, linked to the ideology of motherhood which is intricately related to how fatherhood is constructed.

The family literature on fatherhood has mushroomed since the 1990s (Marsiglio et al., 2000). Most has been grounded in feminist concerns regarding the division of labour, gender, power, and fairness with mainly quantifiable studies (e.g., Blair \& Johnson, 1992; Craig, 2006). Less has focused on the qualitative dimensions of fatherhood such as the important social role of fathers in teasing, talking to, and teaching children (Lareau, 2000). Scholars have realised that fathering must be understood in its own context and not simply as an adjunct to maternal care giving (Brotherson et al., 2005), yet research is still dominated by the challenges faced by working mothers (Daly \& Palkovitz, 2004). Social expectations of the father's role have changed considerably from being mainly an economic provider to now being the 'new father' who is expected to provide as much care to children as the mother (Yeung et al., 2001). This led to a disjunction between the ideals and the 
realities of being a provider and an engaged father, and a discrepancy between fathers' desire to spend more time with their children and work constraints (Daly, 1996b; McDonald \& Almeida, 2004), and might explain why fathers are more likely than mothers to feel time deficits with their children (Milkie et al., 2004). This all points to conflicts experienced by fathers as they seek to navigate their work and family lives while embracing greater responsibilities at home.

Fathers, in general, are spending significantly more time in child-care activities today than in the past (Sayer et al., 2004). Yet, fathers are relatively rarely alone with their children and instead join their wives as helpers in the task (Craig, 2006) which has potential effects on father-child relations. Dollahite et al. (1997) developed the concept of generative fathering to describe fathering that responds readily and consistently to a child's developmental needs over time. Fathers primarily connect with their children through shared leisure activities (Brotherson et al., 2005) which makes them more satisfied with their lives (Eggebeen \& Knoester, 2001). Spending time with the kids is also a notion that is deeply embedded in the social discourse about being a good father (Daly, 1996b) rather than being inherited from their own fathers. The ideology of fatherhood has an effect not only on the meaning of family time for fathers and their desire for more time with their children but also on their identity formation (Allen \& Daly, 2005). Also, active father involvement promotes marital satisfaction (Matta \& KnudsonMartin, 2006). The benefits of increased father involvement are, thus, for all the relationships in which they are embedded including parenthood.

It has to be remembered in any discussion of gender that a review of literature concluded that men and women are far more alike than they are different (Kimmel, 2004). Hence parenthood is all about collaboration and sharing of similar goals in rearing children. However, current cultural ideals of parenthood are shaped by both inherited gender traditions and the desire for new and more balanced practices which convey a sense of what parents should do (Daly, 2004). For example, middle-class parents in the US engage in 'concerted cultivation' by actively fostering children's talents and skills through organised leisure activities, but in the process the parents' leisure preferences become subordinate to those of their children (Lareau, 2003). This is coupled with smaller families where each 
child becomes in a sense 'more precious' (Sayer et al., 2004), resulting in shifting power relationships between parents and children, especially parents' increasing psychological investment in their children (Mintz, 2004). The age of the youngest child is another factor that shapes parental feelings about time with children. Parents of young children tend to spend more focused time with them and feel more time strain, compared to those with older children (Milkie et al., 2004). So it is with a tone of self-sacrifice that parents emphasize the greater importance of family time for their children (Daly, 2001). The culture of parenting, therefore, is one that not only requires adaptability to societal change but also involves fundamental change in the nature of the generational relationship which also has an effect on the nature of childhood and the meaning of family time for children.

The conception of childhood in today's society is built around the emotionally priceless child (Zelizer, 1985). Many years of study have shown that parents are the key in predicting child developmental outcomes, but parents are also influenced by their children and the child has a key influence in family dynamics (Crouter \& Booth, 2003). The parent-child relationship, then, becomes an interactive process, one of mutual influence (Handel et al., 2007) or bidirectionality (Lollis \& Kuczynski, 1997) which involves a concept of contestation and negotiation (Thorpe \& Daly, 1999). However, there is little research that compares parents' and children's perspectives on family time (Daly, 2001). Two studies found that children like the family time to be less rushed (Galinsky, 1999) and that it is not the quantity but how parents spend their time with their children (Christensen, 2002). Also, children are happier with the amount of family time than their parents (Christensen, 2002; Galinsky, 1999), which highlights the methodological necessity of including the perspective of children in any research involving families. It underlines gendered and generational differences in the social meaning of family time in that mothers seek more quality and fathers more quantity family time, while children want less stressed time together.

The discussion now turns to the importance of 'family leisure' for families which refers primarily to time that parents and children spend together in recreational activities in and around the home. The adoption of this term reflects recognition 
that leisure is inextricably connected to social context and daily life experiences (Shaw, 1997). Also, the most common social context for leisure time activities for parents and children is the family (Shaw, 1997) but the same can also be said for family holiday time. Thus, the gender and generational perspectives of family groups at home have a strong bearing on the discussion of family leisure literature that follows here and the family tourism literature later in this chapter.

\subsection{RESEARCHING FAMILIES WITHIN LEISURE: INTERNATIONAL PERSPECTIVES}

Tourism and leisure have historically been studied in isolation but recent research is more inclusive of the relationship between them (e.g., Carr, 2002b; Coles et al., 2005). Adequate conceptualisations of tourism require research that goes beyond the narrowly economic and appreciates the relationship of leisure and tourism with other social practices and behaviour (Hall et al., 2004). A study by Carr (2002a) supports the notion that tourists' behaviour is influenced by a combination of socio-cultural norms and personal values that are present in both the home and holiday environments. This is particularly relevant for the study of family groups as the gendered and generational roles and social values present at home are taken along on holiday. Also in contrast to tourism, family leisure and gender differences in leisure behaviour have been relatively well researched. While tourism has some unique qualities that may not be found in everyday leisure, such as the 'notion of departure' from what is routine (Urry, 1990), it is also about the supporting experiences and interactions that are intrinsic to everyday life (McCabe, 2002). Tourism is also increasingly interpreted as one form of leisure-oriented, voluntary temporary mobility (Coles et al., 2005). A discussion of international family leisure around the home provides not only a wider context and connection with the everyday for this study into family holiday behaviours but also insight into gender and generational research that is not present to the same extent within tourism research.

\subsubsection{THE WESTERN IDEALISATION OF FAMILY LEISURE}

Leisure researchers have devoted considerable attention to family leisure (e.g., Kelly, 1997). Most of this work is driven by the popular sentiment that 'a family 
that plays together stays together' (Freysinger, 1994; Mactavish \& Schleien, 2004) based on the recognition that leisure experiences provide the context in which most family members establish, maintain, and develop relationships with each other (Cromie et al., 1997; Siegenthaler \& O'Dell, 2000), as well as their friends and extended family (Kyle \& Chick, 2004). The positive contributions of family leisure to family cohesion, family interaction, and overall satisfaction with family life dominate the research literature (Orthner \& Mancini, 1990; Reilly, 2002/2003). Zabriskie \& McCormick (2001) found that having both core (i.e., everyday, home-based) and balance (i.e., less common, away from home) family leisure activities were positively related to higher levels of family functioning. Family leisure is also advanced as a key context in which most children develop life-long skills and values (Mannell \& Kleiber, 1997; Shaw \& Dawson, 2001). Family leisure, thus, has been portrayed in a relatively beneficial manner by researchers operating from a social psychological paradigm that did not consider gender inequality (Rehman, 2001; Shaw, 1997) or conflict amongst its members. This approach to research has not recognized the potential for different viewpoints within a family.

There is a realisation amongst researchers that 'family leisure' has an underlying ideological notion that reflects a hegemonic and romanticised version of family life that reifies family leisure not only in leisure studies but also the popular media (Harrington, 2001; Hilbrecht et al., 2008). This idealisation of family leisure can have negative consequences for parents through increased feelings of guilt and stress, especially among mothers, when the ideal of family togetherness is difficult for them to achieve (Shaw, 2001). Several studies have found that mothers reported a less positive leisure experience than fathers (e.g., Freysinger, 1994; Wearing, 1993). There is increasing research evidence that family leisure activities may not always be a positive experience for all family members (Larson et al., 1997; Shaw \& Dawson, 2001). For example, watching television is reported as the most common of the limited shared leisure time at home (Beck \& Arnold, 2009), even so it becomes a source of conflict among family members (Harrington, 2001). Acknowledgment of both the benefits and difficulties of family leisure can lead to a more realistic view of this valued aspect of family life (Shaw \& Dawson, 2003/2004). 
Most research on family leisure has focused on the heterosexual married couple rather than the family as a whole (Mactavish \& Schleien, 2004), or on the mother to represent the views of the family (Harrington \& Bell, 1999). Also, most studies of family leisure have not acknowledged the increasing diversity of family forms like single-parent families (Shaw, 2001) or gay and lesbian families (see Bialeschki \& Kimberly, 1997). This can be addressed with research that is sensitive to gender issues, examines both positive and negative aspects of family leisure, and explores the contradictory aspects of family leisure for all family members within a variety of families (Shaw, 1997) or a whole-family study that includes generational and gendered aspects of family leisure experiences.

\subsubsection{GENDER AND GENERATION IN FAMILY LEISURE}

According to Shaw (1997) studies in family leisure have to explore the gendered and generational perspectives of family members to understand all its aspects and meanings. There are a few studies in leisure that have included the perspectives of mothers, fathers, and children into their research process, but no whole-family study. These are Larson et al. (1997) and Zabriskie \& McCormick (2003) with only one child per family participating; Shaw \& Dawson (2001) in Canada which was replicated by Harrington (2001) in Australia with parents and their children taking part. However, neither Shaw nor Harrington have reported their findings on the children. While there is acknowledgement by leisure researchers that children's perspectives on family leisure need to be recognised, there is still a lack of them in the published literature. Thus, the generational dimension of parentchild within family leisure is as yet largely unexplored. There is also a lack of research into couple leisure within the family (Dyck \& Daly, 2006) or the role of individual parent leisure away from children (Harrington, 2001; Kay, 2003) which forms part of the generational dimension. A discussion now follows about the findings of family leisure studies that have a gender or generational perspective which continues in the international family tourism literature.

Shaw \& Dawson (2001) found family leisure to be purposive in that the time together was used to develop a sense of family and to teach children about values. For Zabriskie \& McCormick (2003), family leisure was more strongly related to parental satisfaction than it was for their children who had a more immediate 
focus. This introduces a generational perspective in that as children move through adolescence, the amount of leisure time spent with family decreases along with parental influence (Harrington \& Bell, 1999; Siegenthaler \& O'Dell, 2000). Instead, young adolescents gain more pleasurable social leisure experiences with their friends (Larson et al., 1997) who provide an escape from the established world (Øksnes, 2008) and are also connected to the fun factor (Francis \& Kentel, 2008). This means that family leisure activities become more difficult to organise because of the different aged-based interests of children (Shaw, 2001) which makes family leisure activities dependent on the age(s) of the child(ren).

Harrington (2001) confirms that the rationale for family leisure is facilitating family interaction which is less reliant on choice of activity or location. However, contradictions and conflicts appeared in the meaning of family leisure in that children's sport was valued while acknowledging its invasive and time-consuming nature. Parents also felt pressured to always put their children first at the expense of their individual leisure. This is linked to a general ideology of family life which applies to family leisure as well as family time, as demonstrated earlier. Harrington's (2001) study found gender-based differences in the way mothers and fathers spend leisure time with their children and carve out individual time which confirmed Larson et al. (1997). In sum, a gender gap in family leisure emerges (Bittman \& Wajcman, 2004) which leads to wider discussion of gender. While there is extensive research on women and mothers' leisure, as discussed first, the research on fathers' leisure is more recent and limited, and follows.

There is a growing literature addressing women's leisure (e.g., Cyba, 1992; Kay, 2001; Shaw, 1985) with two key issues appearing: (a) women's experiences of time tend to be much more fragmented than those of many men, and (b) women tend to be the facilitators of others' leisure, and only secondarily the recipients of leisure themselves (Kinnaird \& Hall, 1996), which means that family leisure becomes a source of both satisfaction and frustration for women (Clough, 2001). It also means that women participate significantly less in physically active leisure than men (Miller \& Brown, 2005). These issues are associated with the 'ethic of care' in relation to women's leisure (e.g., Bialeschki, 1994; Henderson \& Allen, 1991) and are based on Gilligan (1982). Gilligan’s research has highlighted that 
women's greater concerns for social responsibility and relationships place a constraint upon their lives as 'others' are often placed before self. Women often receive double messages about the value of individuality, achievement, and also the need to be in connection with others (Chodorow, 1978) and, thus, lack autonomy compared with men (Wearing \& Wearing, 1988).

The largely feminist literature on women's leisure has debated whether leisure can be both empowering and constraining and if it differs between women (Hall et al., 2003). This means a recognition that the ethic of care may operate as a constraint to some women (Rehman, 2001) but can also be a source of identity and power (Henderson et al., 2002). Women's leisure can also be a means of resisting socialised gender roles because personal leisure provides them with independence and freedom from responsibilities (Freysinger \& Flannery, 1992), and more mothers today believe that they have a right to time and space for themselves (Wearing \& Fullagar, 1996). It should be remembered that men, as well as women, face gender-related constraints, and that most leisure research has focused on mothers which leaves fathers’ leisure deserving of greater attention.

Understanding fatherhood is a relatively new pursuit for family leisure scholarship (Such, 2006). As established earlier, leisure-based activities are potentially more prominent in fathering than they are in mothering (Kay, 2006a). For example, in Australia, "sport is perceived as a major site for fathering to occur" (Thompson, 1999, p. 53) and for fathers to show emotional connection to their children (Harrington, 2001, 2006), which is comparable to New Zealand. A recent special publication on fatherhood in leisure (Kay, 2006c) showed that mothers perceived family leisure as more work-like or 'being there' for the children. In contrast, fathers described leisure to mean 'being with' their children, resulting in a kind of 'leisure-based' parenting (Such, 2006). There was also a sense of fostering the next generation through children's leisure activities which is central to the generative notion of fathering (Harrington, 2006).

In summary, fathers still see the traditional provider role as the defining function of fathering, which can be contextualised by an 'ethic of work' with an emotional dimension (Kay, 2006b), while feeling under increasing pressure to fulfil modern 
expectations of their role (Lewis, 2000). This disjunction between the ideals and realities is not unique to fathers and also applies to working mothers as discussed earlier. Strong ideological notions of how parents ought to behave underpin much of family leisure. There are cultural standards of putting children first whereby the character and achievements of children are linked to the moral worth of parents (Coakley, 2006). Fathers are expected to be more intimate and have greater involvement with their children (Kay, 2003), while the ideology of being a 'good mother' is still pervasive (Miller \& Brown, 2005) which leads to feelings of guilt for taking time out for individual leisure (Harrington, 2001). Family leisure is, thus, seen as an obligatory aspect of parental responsibility (Shaw, 2008), yet the achievement of family leisure, just as family time, is perceived as a personal problem rather than a societal dilemma.

While family leisure research conducted from a gender perspective has highlighted the female and adult experience, it has underplayed the dual gender and generational dimensions. A whole-family analysis is, therefore, still missing in the leisure literature. The multi-dimensionality of family will be further explored later within the tourism experiences literature where a distinct lack of gender, generational, and group research made the introduction of a new conceptual framework necessary. The discussion first turns to the tourism marketing literature, as a critical review of the family holiday literature by Schänzel et al. (2005) established that most tourism work is market-driven and not focused on the experiential and temporal dimension. Thus, it highlights the need for a more inclusive and holistic approach to researching family holidays.

\subsection{RESEARCHING FAMILY HOLIDAYS - INTERNATIONAL MARKETING PERSPECTIVES}

Marketing began to focus on the family as an important social unit within consumer behaviour in the late 1950s and 1960s (e.g., Sharp \& Mott, 1956; Wolgast, 1958). The family, here, is mainly considered as a consuming and decision-making unit, and the dominant themes in the literature are travel motivations, decision-making roles, and satisfaction, as well as market research. Most of these have tended to focus on pre-holiday expectations coupled with post- 
holiday satisfaction and on purchase decisions for families rather than actual experiences, and neglect the immediate and longer-term meanings of holidays. As a result, the focus has been on a narrow set of issues in marketing and the family holiday has seldom been examined as part of a wider social system (Commuri \& Gentry, 2000). Thus, the social and gender dimensions of family holiday experiences such as social interactions, gender roles, group dynamics, and interpersonal relationships have been neglected. Whilst there is acknowledgement that children have a role to play in decision-making, most studies that have included the influence of children have been from parental responses (e.g., Thornton et al., 1997), rather than through consulting children directly (Carr, 2006; Wang et al., 2004). It appears that children are being marginalised both theoretically and methodologically by some of the more consumer-oriented research, and that a focus on how meanings differ by gender and generation is needed in marketing (Shaw et al., 2000).

Market and consumer research is also carried out by certain sectors of the tourism industry, namely transport and travel providers and accommodation and attraction operators, which has focused on family groups. The transport-related research that includes a family component, such as that of Van Middelkoop et al. (2003) and Morin (1984), is mostly concerned with management-related matters and planning issues, thereby failing to provide an understanding of the experiences gained from different transport modes. Other consumer research focuses on child-friendly holiday deals (McWhirter \& Brookes, 2001), children’s programmes (Gaines et al., 2004), family travel service failures (Park et al., 2008), or family resorts (Brey \& Lehto, 2008). Additional proprietary research is conducted by, for example, resorts and cruise lines (see Nickerson \& Jurowski, 2001). Thompson et al. (1996) looked at the social consequences of marketing casino products to families. There is also a wide selection of practical books available about travelling with children, ranging from travel guides (e.g., Wheeler \& Lanigan, 2002) to more personal market research (e.g., Siese, 2007) to travel tips by parents (e.g., Kaufman, 2006). Also, several magazines are dedicated to family holidays, such as the Australian 'Holidays with Kids'. These are all catering to families as a significant component of the travel market, but they do not take a broader experiential and temporal approach and do not explore the underlying family dynamics present on holiday. 
Visitor studies carried out at particular attractions have included families as part of the sample (e.g., Andereck \& Caldwell, 1994; Digance \& Marles, 2004; Serrell, 1980); however, in most instances, families and children did not form the focus of the research but only a sub-group of visitors. This is despite the importance of children in generating a family visit to an attraction (Ryan, 1992; Turley, 2001) such as museums and animal and theme parks. Attractions have a vested interest in capturing the family market, and thus maximising their economic potential, and the activities and marketing strategies there are often designed with families in mind (e.g., Braun \& Soskin, 1999), despite very little being known about family groups (Sterry \& Beaumont, 2006). Increasingly, however, visitor studies are shifting towards an in-depth understanding of experiences as most suitable for research into families (Christensen et al., 2007), such as family learning in museums (Sterry \& Beaumont, 2006) and theme parks (Johns \& Gyimothy, 2002, 2003). Because the role children play in shaping family experiences has been under-researched and under-valued (Carr, 2006), an approach to the study of families at attractions that makes the whole family group the unit of analysis (Sterry \& Beaumont, 2006) is, therefore, needed. Yet, specific attractions, transport modes, and market analysis only make up a small component of the family holiday. There is a need to consider the family holiday more broadly and systematically, and to examine how motivations are connected to the experiences and memories that all family members derive from their holiday taking gender, generation, and group dynamic perspectives. The discussion now turns to the general motivation literature before focusing on the social group motivation literature.

\subsubsection{MOTIVATIONS FOR FAMILY HOLIDAYS}

In order to market tourism services and destinations well, marketers must understand the motivating factors that lead to travel decisions and consumer behaviour. While motivation is only one of many variables it is nevertheless regarded as the driving force behind all tourist behaviour (Fodness, 1994) which is considered multi-motivational (P. Pearce, 1993; Prentice, 2004). The essence of a holiday as being a break from routine has been established by Crompton (1979) as the main push motivational factor. Iso-Ahola (1982) further theorised that tourism represents more of an escape-oriented activity than a seeking (or pull 
factor) for most people, which was confirmed by Fodness (1994). The motivation concept is, thus, based on the idea that people travel because they are pushed by intrinsic motivators and pulled by external forces of the destination attributes (Uysal \& Jurowski, 1994) and that the push factors dominate. With mass consumption, however, this distinction becomes mediated through holiday marketing and society (Prentice, 2004).

In fact, Goossens (2000) argued that frequently expressed holiday needs (such as escape and relaxation) represent culturally learned stereotypes for tourism behaviour. Gnoth (1997) states that these motives or psychological factors refer to tourists' longer lasting dispositions that recur with cyclical regularity, while the pull factors emphasize distinct situational parameters in which these motives are expressed. This literature has usually adopted a very individualistic orientation and does not take into account the social dimensions and dynamics present in groups like families (Pearce, 2005) or differentiate motivations between family members. Also, most research into motivations is based either on reasons for travel studies (behaviourist) or on destination attitude studies (cognitivist) (McCabe, 2000; Todd, 1999) with no link between motivation and actual behaviour (Mansfeld, 1992; Prentice, 2004) and satisfaction (Mannell \& IsoAhola, 1987). Structurally, research into expectations is similar to research into attitudes in that they are mainly cognitive (Gnoth, 1997) and can bridge the gap in motivation research. This can be addressed with a broader perspective that links motivations and expectations with the actual meanings gained from holiday experiences and takes into account all members of the family group.

The motivation literature often refers to the strengthening of family relationships and social interaction as a key motive for family travel (Crompton, 1979; Fodness, 1994; Pearce, 2005). In fact, 92\% of parents in a study of American travellers cited 'being together as a family' as their most important motivation (Makens, 1992), which can also include extended family (e.g., Crompton, 1981; Makens, 1992). Crompton (1981) recognised that the interactive nature of social groups reinforces, modifies, and moulds the motivations of its members. When looking at the motivation process of day visitors, McCabe (2000) found that the needsderived motivations of parents are intrinsic to the individual, whereas the more 
constraints-based motivations are made within the context of interpersonal (that is, family) relationships and are of a negotiated quality. Tourist motivations, thus, within a family are characterised by a combination of push and pull factors.

This, however, does not take into account the motivations of the children. In fact, there are few studies that examine children's motivations and needs, both in their own right (except Larsen \& Jenssen, 2004) and as part of the family unit (Carr, 2006). In fact, Carr found that there were differences in motivations between parents and their adolescent children which were less noticed by the parents. As children enter adolescence, they build their definitions of holidays with their own motives and expectations, which may differ from those of their parents (Decrop, 2006). Meeting or compromising the motivations of the children is then related to satisfaction with the holiday, as discussed later. What is needed, then, is research into the whole family holiday experience that studies children directly and links motivations with holiday outcomes, which has not been done yet (Carr, 2006).

There is, however, some interest in motivational studies from researchers working within a social science tradition who seek to understand the meaning and experience of travel (Ryan, 2002a). While there have been some studies that have interviewed participants before and after their holiday experience, such as Decrop (2005) for summer holidays, Heimtun (2007c) on single women's holidays, and Shaw et al. (2008) on family holidays, no longitudinal study has yet reported insights into the personal motivations of children for family holidays. There is evidence for gender differences when looking at personal motivators (Ryan, 2002a). For example, Anderson (2001) found that the main motivation of mothers was to ensure the happiness and safety of their families on holiday, while fathers were more focused on their individual needs and aspirations, yet most studies use gender in marketing with regards to what is purchased and how the decision is being made (e.g., Jaffé, 2007) rather than the underlying personal motives.

Most motivation studies are business orientated because sound market appraisals can be built on motivation scales or measures (e.g., Pearce, 2005), but such simplistic models and typologies can hide significant and complex patterns of gender relationships (Moscardo, 2008). It must be acknowledged that tourist 
motivation today is considered possibly so complex (in that the actual choice is a consequence of much wider experiences and outside influences) that traditional notions of motivation are perhaps no longer as relevant (McCabe, 1999; Prentice, 2004). Instead, motivation research needs to be seen as part of a broader framework and linked to the actual experience gained, centred on a particular holiday type, such as domestic family holidays, and the gender and generational influences of all the members in the social group. Thus, it becomes connected to outcomes, more focused and concerned with inside influences. For example, little is known about domestic tourism motivation such as national identity formation (Prentice, 2004), which seems relevant within the family context. Travel motivation, however, has been pointed out to be the stage that triggers the whole decision-making process and channels it accordingly (Mansfeld, 1992) which leads to the following discussion of the literature.

\subsubsection{FAMILY HOLIDAY DECISION MAKING}

For marketers, the issue of who influences purchasing is of great significance as parents are usually the primary decision makers and the role of the children in determining adult buying behaviour shows considerable market potential. Role taxonomy involves the empirical measurement of the relative influence of family members on purchases through conceptualising five kinds of role-related decisions: husband dominant, wife dominant, autonomic (eventual decision by one spouse), syncratic or joint (equal husband/wife), and paedonomic (child influenced). Jenkins (1978) was the first to apply the work on family buying behaviour to the study of family holiday decision making (Litvin et al., 2004). Most of the early research in the 1970s and 1980s emphasized the relative influence of husbands and wives on purchase outcome (e.g., Nichols \& Snepenger, 1988; Ritchie \& Filiatrault, 1980; Smith, 1979) or couples' involvement (Madrigal et al., 1992), but little attention was paid to the decisionmaking process itself (Bronner \& de Hoog, 2008; Commuri \& Gentry, 2000), and the child was marginalised (Lackman \& Lanasa, 1993; Seaton \& Tagg, 1995). Since that time various social and demographic changes have occurred in Western families which have affected the nature of decision making (Kang \& Hsu, 2005), such as women gaining more influence in all decision areas (Belch \& Willis, 2002) and the increasing influence of children (Shoham \& Dalakas, 2005). 
There has also been a shift from the command to the negotiation method for family decision making (Bronner \& de Hoog, 2008). These factors lead towards more joint decision making and increasing family democracy (Buttle, 1994; Litvin et al., 2004; Ndubisi, 2007) also in New Zealand (Lee \& Beatty, 2002), compared with Jenkins (1978) who found that most decision making was 'husband dominant'. While the overall holiday decision might be joint, when it is broken down into different stages women have a dominant role in the early stages which can make them the gatekeepers (Mottiar \& Quinn, 2004; Zalatan, 1998), and also have a prominent influence when deciding to purchase an activity (Howard \& Madrigal, 1990; Mowen \& Graefe, 2006), which highlights a gender perspective to the different roles in decision making. However, most research on family purchase behaviour has focused on heterosexual couples apart from one recent study on lesbian couples (Wilkes \& Laverie, 2007).

There are several studies that have explored gender differences in the decision making process including Darley \& Smith (1995), Koc (2002), and Jaffé (2007). These studies found that the male process for purchase decisions was quite clear and heuristic whereas for women it was an iterative and more comprehensive process that took into account interests of other family members. Others have pointed out that the consumer behaviour literature largely ignores the role of emotion and affect in family decision making in favour of more rational, problemsolving-based processes (e.g., Decrop \& Snelders, 2004; Park \& Tansuhaj, 1995). What is needed, then, is a consideration of both cognitive and affective processes when making family holiday decisions, and a gendered perspective to research that acknowledges the changing roles (Gentry et al., 2003; Labone \& Wearing, 1994). This, however, largely ignores the generational perspective that children bring to it.

Most studies into family decision making have focused on the husband and wife dyad, and relatively few investigations are done on the influence of children in the decision-making process (Howard \& Madrigal, 1990; Nanda et al., 2006). Originally ignored, and later dismissed as having little or no influence (e.g., Belch et al., 1985; Filiatrault \& Ritchie, 1980), children have since been recognised as playing an active part in family decision making by some studies 
(Gram, 2007; Shoham \& Dalakas, 2005; Thornton et al., 1997). Connell (2005) argued that children increasingly influence the choice of holiday destinations and their involvement increases during the holiday in terms of what families do (Decrop, 2006), such as holiday activities (Wang et al., 2004) and visiting attractions (Ryan, 1992). In terms of extent of influence exerted on holiday choice, research indicates that children influence more than half of all family travel decisions made by their parents (Yesawich et al., 2001). Tagg and Seaton (1994) found that the vast majority of Scottish and English children had been asked about holiday choice, indicating that children's opinions are important to parents, whereas Nanda et al. (2006) and Seaton \& Tagg (1995) suggested that the level of decision consultation increased with the age of children, which was confirmed with adolescent children (Lee \& Beatty, 2002). Thornton et al. (1997) found that the ultimate decision making remains with the parents but that parents rate satisfaction for their children more highly than that of themselves, which will be discussed later.

Most studies in decision making have focused on the distribution of roles within the household, but aspects such as group interaction, conflicts and power relationships have so far been neglected (Decrop, 2005). This can be addressed with a broader perspective that takes into account the whole family group, including the different roles each family member plays as well as an understanding of the actual experiences gained on holiday. According to Gram (2007), parents primarily want children to have fun on holidays, but this can only be fulfilled if children's desires are taken into consideration. Thus, family decision making becomes a two-way process, informed children versus supportive parents ensuring a peaceful holiday time without conflicts (Gram, 2007), but intergenerational differences in families may result in value conflicts (Decrop, 2006). Group decisions, then, are not as easy as individual ones because of divergent personal constraints and conflicting values or preferences (Decrop, 2005), which makes it a complex consideration of different family members' wants or duties (McCabe, 1999) and are characterised by a negotiated quality (McCabe, 2000). This social dimension to family holiday purchase behaviour makes it imperative to include children in the research process (e.g., Gram, 2007; Nickerson \& Jurowski, 2001) and to relate it to the on-site experience (Labone \& 
Wearing, 1994). Family decision making is an interactive and iterative process, and investigating only some family members at a certain time ignores the dynamic and longer-term nature of family influence. However, both decision making and life cycle approaches to family purchase behaviour have predominantly focused on the types of decisions made and who made them (Seaton \& Tagg, 1995) rather than the longer-term significance of these decisions.

The family life cycle (FLC) model has been deployed in studies that address the consumer behaviour of family members going on holiday (e.g., Bojanic, 1992; Landon \& Locander, 1979; Reilly et al., 1984). This model hypothesises that individuals pass through stages in their life, as single, married with small children, married with older children, etc., and that each phase is associated with distinct purchase patterns. This cyclical effect is mainly caused by the arrival and then dispersal of children (Lawson, 1991). The cycle phases full nest I, II, and III are those which involve families with children (Table 2.3). Compared with families with preschool children, full nest 2 families are less constrained and more active in their holiday behaviour (Lawson, 1991). However, changing family structures cast serious doubt on the future utility of this concept because it can result in classification problems (Oppermann, 1995b). Also, most studies using the FLC model focus on travel expenditure patterns (e.g., Hong et al., 2005; Tribe, 1999) or decision-making processes (e.g., Cosenza \& Davis, 1981; Fodness, 1992; Kang, 2002), and not on the significance of holiday experiences at different life stages. A notable exception is Blichfeldt (2006, 2007), who found that holiday experiences were connected to stages in the FLC with family holiday experiences for parents changing as the children grow older from 'smaller' to 'grander' family experiences. However, there is still an absence of the pre-teenagers' travel preferences in Blichfeldt's (2007) 'repertoire of experiencescapes' which is highlighted as stage 1 of the FLC comprising the first 25 years of life (Table 2.3) without including the children's experiences. This can be addressed with the children's perspective alongside the parents' when travelling as part of the same group and with a focus on the longer-term meanings gained, which is also true when considering satisfaction levels of families on holiday. 
Table 2.3 Family life cycle stages

\begin{tabular}{|l|l|}
\hline FLC Stage & Description \\
\hline $\mathbf{1}$ & Young single (under 25 years) \\
\hline $\mathbf{2}$ & Young couples (no children) \\
\hline $\mathbf{3}$ & Full nest I (pre-school children) \\
\hline $\mathbf{4}$ & Full nest II (school-age children) \\
\hline $\mathbf{5}$ & Full nest III (older children, possibly non-dependent) \\
\hline $\mathbf{6}$ & Empty nest I (still working, no children) \\
\hline $\mathbf{7}$ & Empty nest II (retired) \\
\hline $\mathbf{8}$ & Solitary survivor (retired) \\
\hline
\end{tabular}

Source: Lawson (1991, p. 13).

\subsubsection{FAMILY HOLIDAY SATISFACTION}

Customer satisfaction is one of the most important concepts of modern marketing thought and practice because it plays an important role in the survival and future of any tourism products and services (Neal \& Gursoy, 2008). However, very little research into satisfaction with family holidays has been carried out to date. The most comprehensive studies which have included children are by Seaton \& Tagg (1995), Thomas Cook (1983), and Nickerson \& Jurowski (2001). Seaton \& Tagg (1995) linked post-holiday assessment of the holiday with pre-holiday anticipation of holiday outcomes, as satisfaction is really the other side of motivation (Mannell \& Iso-Ahola, 1987). It can be concluded from these studies that most holidays make for happy children and that meeting the needs of the child may also account for satisfied adults (Ryan, 1992), although this has not yet been explored empirically. What has been established is that satisfying tourism experiences can provide a sense of wellbeing (Gilbert \& Abdullah, 2004) and can affect satisfaction with life in general (Neal et al., 2004) and, thus, holidays become an important component for a family. 
There are, however, differences in satisfaction levels between parents and children (Nickerson \& Jurowski, 2001). Carr (2006) states that parents of adolescents are often unaware of their children's desires, and while parents tend to prefer outdoororiented holidays, children prefer theme parks (Yesawich et al., 2001) like Disneyland (Thomas Cook, 1983). Also, children are more interested in holidaying with their friends than with parents (Yesawich et al., 2001) and this increases with age (Thomas Cook, 1983). However, assessments of holiday experiences are built on manufacturing logic in that they are supply-oriented, where the holiday is considered as a bundle of core and peripheral products and services (Gilbert, 1990; Gyimothy, 1999). This is incongruous with the demandoriented definition of the holiday being an extraordinary, holistic experience that only exists in the consumer's mind (Otto \& Ritchie, 1996).

A stream of research from the general marketing field has shown that subjective, affective, and experiential factors comprise a substantial portion of consumer satisfaction with their holiday services or attractions (e.g., Holbrook \& Hirschman, 1982; Lofman, 1991; McIntosh, 1999; Vitterso et al., 2000). It is through a qualitative methodology that understanding of the affective dimension of the tourist's motivations, experiences, and satisfactions is gained (Dann, 1996). According to Gyimothy (1999) the holiday experience represents a three-phase realisation of journey ideals, beginning with only a vague anticipation of a holiday ideal. This can be addressed with a holistic concept of the holiday experiences and hedonic ideals which include the pre-holiday anticipation of experiences, the onholiday experiences, and the remembering of experiences post-holiday, as well as an element of continuation to this process (Figure 2.3). This relates to Clawson \& Knetsch (1966) who divided a holiday into several phases. In light of the perspective that the core product of tourism is the experience gained (Prentice et al., 1998), an experiential and temporal dimension is adopted here for this study that provides understanding of the subjective tourist experiences. This, however, does not account for the social interactions and dynamics present on a family group holiday. Instead the multi-dimensionality of family holidays requires a different conceptual approach that links gender, generation, and group dynamics within an experiential framework over time. 
Figure 2.3 The holiday as a process of journey experiences and ideals

\begin{tabular}{|l|l|l|}
\hline $\begin{array}{l}\text { Pre-holiday phase } \\
\text { Motivation and } \\
\begin{array}{l}\text { anticipation of journey } \\
\text { experiences and ideals } \\
\text { What do they want? }\end{array}\end{array}$ & $\begin{array}{l}\text { Holiday phase } \\
\text { Experiences and realisation } \\
\text { of journey ideals }\end{array}$ & $\begin{array}{l}\text { Post-holiday phase } \\
\text { Follow-up of experiences } \\
\text { and journey ideals }\end{array}$ \\
\hline
\end{tabular}

Adapted from Gyimothy (1999, p. 69).

\subsection{THE EXPERIENTIAL AND TEMPORAL DIMENSIONS OF FAMILY HOLIDAYS - A CONCEPTUAL FRAMEWORK}

This section continues with a temporal exploration of holiday experiences before discussing the international tourism literature dealing with experiences from an individual, a dyadic partnership, and a triangular family group perspective which culminates in a conceptual framework (Figure 2.4). At the centre of the conceptual framework are the family holiday experiences, made up of a circular temporal dimension: pre-holiday anticipation, on-holiday experiences, and postholiday memories that feed into anticipation of future holidays. These can be explored from three experiential dimensions which encompass gender, generation, and group dynamics: one-dimensional individual, two-dimensional gendered approach, and three-dimensional family group. Any discussion of experiences usually begins with the individual tourist experience, because the primary goal of a holiday trip at an individual level is likely to be experiential (Botterill \& Crompton, 1996). Tourist experiences are believed to be dynamic, multi-faceted, and emerge through social interactions with others and the environment (Ooi, 2006; Prentice et al., 1998), and also involve multiple phases (Pritchard \& Havitz, 2006). The tourist experience can also be considered as an individual psychological process that concerns the anticipation of events, the actual holiday events, and the remembering of these events (Larsen, 2007). Yet, Ek et al. (2008) argue for a more dynamic framework of tourist experiences, as developed here, which includes relational and interactional processes as well as temporal perspectives of pre-, on-, and post-holiday. 
Figure 2.4 Conceptual framework: The experiential and temporal dimensions of family holidays

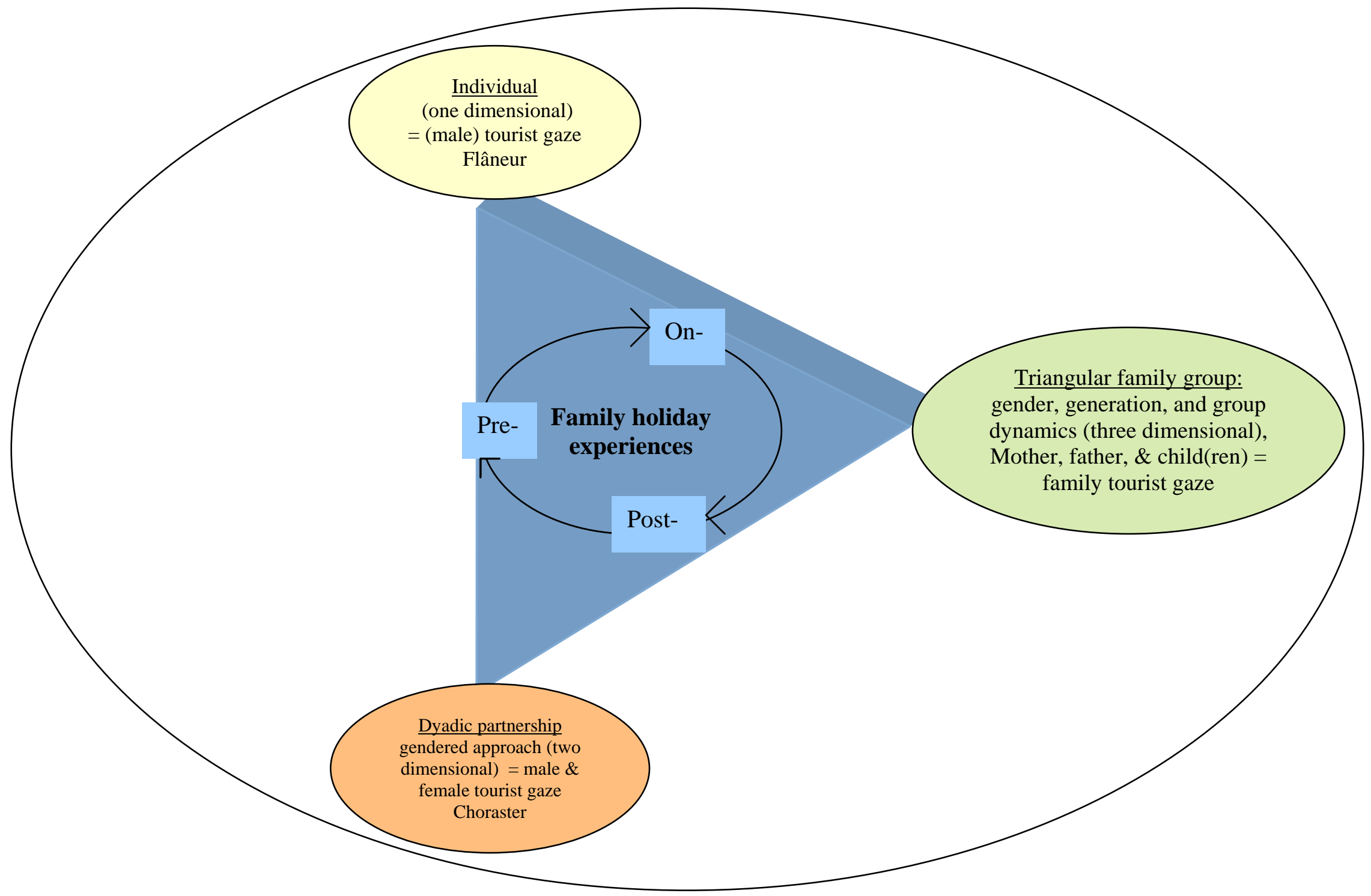


There have been some studies within psychology which have involved these three phases in the research process (e.g., Fredrickson, 2000; Mitchell et al., 1997; Wirtz et al., 2003) They have found that the processes of prospection and retrospection suggest that individuals are unlikely to revise the evaluations of certain events appropriately because they remember them more favourably, or more negatively, than they actually were. This is also aided by 'photoreconstructed' memories of predominantly positive emotions (Sutton, 1992) and supported by Lee et al.'s (1994) findings that the stressful experiences reported immediately after a leisure event did not emerge during the retrospective description. Tourist experiences, therefore, are functions of memory processes and can be defined as "past personal travel-related events strong enough to have entered long-term memory" (Larsen, 2007, p. 15) that can also predict future holiday choice (Wirtz et al., 2003). This makes the construction of longer-lasting memories a focus in studies of tourism experiences and emphasizes a temporal dimension to it. However, holiday experiences and memories of them can change considerably when the composition or dynamic of the travel group is taken into account alongside gender and generation. There is to date little work that has examined how social interaction within one's own travel party can diminish or heighten the tourist experience (Pritchard \& Havitz, 2006) and its longer-term effect on recollection. While gender, generation, and group dynamics are much neglected in tourism research they form the basis for the following discussion of a three-dimensional conceptual framework based on individual, dyadic, and triangular perspectives (Figure 2.4).

\subsubsection{THE INDIVIDUAL TOURIST PERSPECTIVE - A WESTERN MALE PERSPECTIVE}

The tourist experience is currently depicted as an obscure and diverse phenomenon, which is essentially constituted by the individual consumer (Uriely, 2005); (e.g., Botterill \& Crompton, 1996; Galani-Moutafi, 2000; Wickens, 2002). In fact, much of the initial research on tourism was concerned with the individual tourist and the part that holidays play in establishing identity and a sense of self (Wearing \& Wearing, 2001). The 'self' was male and tourism was seen in relationship to the workaday world (Wearing \& Wearing, 1996). Cohen \& Taylor (1976), for example, argued that holidays are culturally sanctioned escape routes 
for Western man. One of the problems for the modern traveller, in this view, is to establish identity and a sense of personal individuality in the face of the pressures in a global society (Wearing \& Wearing, 2001). A debate took place in the tourism literature about the authenticity or otherwise of this experience (Cohen, 1988; MacCannell, 1976), which objectified the destination as a place and presented it to the tourist for his gaze (Urry, 1990). Western philosophical discussion has been characterised by this rigid emphasis on the mind at the expense of the body. The pure Cartesian mind has remained an onlooker who sees how the things are and the sublime (male) gaze became a lonely gaze rather than a social gaze (Veijola \& Jokinen, 1994, p. 125). The social relevance of holiday experiences diminished as consumption and individualism came to dominate leisure and tourism research (Arai \& Pedlar, 2003). Tourism studies have, thus, tended to render the bodies and places of the (male) tourist gaze as exotic others and constructed tourism through difference and displacement (Johnston, 2001). This mind/body dualism has important associations with reason, masculinity, and a focus on the individual in tourism research.

The tourist became synonymous with the flâneur who travelled as a passive observer and who was generally perceived as escaping from his everyday world for an 'ephemeral' and 'fugitive' holiday experience (Rojek, 1993, p. 216). According to this view, the flâneur's freedom to wander at will on holiday is essentially a masculine freedom (Wilson, 1995). It can also include the motorized flânerie or glancing in a train or car that provides a different viewing position and visual experience than the static photographic gaze (Larsen, 2001). Post-1968 French feminism has criticised those historical masculine ways of thinking and knowing through the binary oppositions of mind/body, work/leisure, self/other, man/woman that have permeated philosophy and also leisure and tourism theory (Fullagar, 2002; Irigaray, 1993). Pritchard \& Morgan (2000) argued that this prevailing male bias in tourism research makes little allowance for gender difference and subsumes female experiences into those of the dominant male pattern, leading to analyses that are often partial and gender blind. The nongendered tourist simply becomes masculine by default (Johnston, 2001). For example, Rojek's (1995) analysis of the desire to escape through leisure travel relies upon a deterministic concept of commodification which assumes that men 
and women have the same desires. This type of generalised analysis offers a singular notion of the desire to travel that denies the possibility of gendered subjectivities, desires, and travel experiences (Fullagar, 2002). Thus, pluralizing depictions of the tourist experience which are sensitive to gender is needed (Uriely, 2005), which allows for a female tourist gaze alongside a male tourist gaze and is inclusive of embodiment alongside the mind, just as in a dyadic partnership (Figure 2.4).

\subsubsection{THE DYADIC PARTNERSHIP PERSPECTIVE - A GENDERED PERSPECTIVE}

Recognising a general absence of gender research in the tourism literature, researchers in the 1990s have sought to remedy the situation, examining impacts on host women, gendered guest-host relationships, employment of women in the tourism industry, and, to a lesser extent, women as tourists (e.g., Kinnaird \& Hall, 1994; Sinclair, 1997; Swain, 1995). Current gender research has largely focused on employment patterns and sex tourism, whilst too little work has focused on women's experiences as consumers rather than producers of tourism (Pritchard et al., 2007). The study of the behaviour and experiences of women as tourists is still in its incipient stages compared with other fields of study (e.g., geography and cultural studies) (Harris \& Wilson, 2007), and has been limited in contrast to gender analysis within leisure studies (Hall et al., 2003). A growing body of literature on the 'female travel experience' attests to the unique needs, motivations, and constraints that women face (Harris \& Wilson, 2007). However, little tourism research has employed true gender scholarship studying women's and men's travel experiences together by applying a holistic research approach as is the case here.

A number of authors have described five major stages in the development of gender research in general and tourism in particular (e.g., Henderson, 1994; Norris \& Wall, 1994). The first stage is where women are invisible (i.e., 'womanless'). Gender is neither examined nor acknowledged as influencing behaviour. In the second stage researchers attempt to compensate for the earlier lack of recognition of gender differences (i.e., 'add-women-and-stir'). This compensatory stage generally involves the identification of, and focus on, woman 
as a discrete group or type of 'other' and includes exceptional women who could be judged by men's standards (Swain, 1995). The third stage is concerned with dichotomous sex differences (i.e., 'sex differences') with statistical analyses seeking to determine the type and extent of male female differences. It overemphasized biological determinism and essentialism at the expense of a more rigorous acknowledgement and analysis of culturally constructed difference (Aitchison, 2001a). The fourth stage is based on the emergence of women-centred approaches or feminist scholarship (i.e., 'women-centred'). This tradition signals the emergence of social constructionism as a core paradigm proposing that behaviour and beliefs are the result of an individual's interaction with existing power structures (Moscardo, 2008). One danger here has been the construction of an essentialist universal female experience as a converse to the universal male (Swain, 1995) with little consideration given to the interactions between gender and other social roles.

This recognition of the intersection of gender, ethnicity, age, class, and personal experience leads researchers into the fifth stage of gender scholarship (Stewart \& McDermott, 2004) (i.e., 'true gender scholarship'). It moves to an interactional view of human expectations, behaviour, and power relationships (Swain, 1995) that allows a more holistic appraisal of gender relations (Aitchison, 2001a). From a gender perspective, researchers may study only one or both sexes together, theorising how behaviours and roles are given gendered meanings (Swain, 1995). To date, the objects of gender research have almost exclusively been women (rather than women and men) (Pritchard et al., 2007). Even so, Rosaldo (1980, p. 396) points out: "We will never understand the lives that women lead without relating them to men". As most tourism travel is still predominantly couple or small-group centred, true gender scholarship in tourism studies will need to investigate the dynamics between members of a travel group to understand the true nature of the travel experience (Gibson, 2001). Although Swain (1995) and Kinnaird \& Hall (1996) stated that men and women are involved differently in the construction and consumption of tourism, there is to date little true gender research to support this argument. Tourism needs to be considered not just as a type of business but as a powerful cultural process that both shapes and is shaped 
by gendered (re)presentations of places and people (Aitchison, 2001b). Gender considerations, therefore, have to be placed centrally within tourism research.

Historically the role of women as leisured consumers has been determined by traditional gender distinctions (Leontidou, 1994), such as staying closer to home (Enloe, 1989). Today, female travellers from Western societies comprise around half of both the business and pleasure travel market (Harris \& Wilson, 2007; Pennington-Gray \& Kerstetter, 2001) and enjoy unparalleled freedoms compared with earlier generations (Apostolopoulos \& Sönmez, 2001). It is vital to advance the understanding of women as 'gendered tourists' (Gibson, 2001) alongside male travellers. Studies on gender differences in tourism have found that men and women consistently differed in their holiday preferences, and men rated sports and adventure more significantly (Frew \& Shaw, 1999; McGehee et al., 1996) while women preferred shopping (Anderson \& Littrell, 1995; Timothy, 2005). Other quantitative studies support the notion that there are gender differences in tourist roles (Gibson \& Yiannakis, 2002), levels of expectations (Oh et al., 2002), constraints (Hudson, 2000), and purpose of travel (Collins \& Tisdell, 2002), with women generally placing more emphasis on family and kinship.

The female emphasis of socialising and interactions with others is highlighted by Chaplin (1999) compared with the male emphasis on action and self. Selänniemi (2002) concluded that women more often experience their holiday through relationships while men seem more likely to let go into a liminoid float, free of everyday demands. According to Wood (1994), gender differences could be interpreted as the expressions of femininity or masculinity in relation to social interactions. Other studies show that among younger tourists gender has little to do with activity and travel choice (e.g., Carr, 1999, 2000) but more with travel associations (Carr, 2001). In fact, younger men and women are increasingly not conforming to traditional gender roles on holiday (Carr, 2007). Rather than gender per se, it is the presence and absence of children and partners that has an impact on travel behaviour (Freysinger \& Ray, 1994; Lin \& Lehto, 2006), with women reporting more negative holiday experiences than men, due to the women's feelings of responsibility for others (Crawford et al., 1992). It is, thus, the social context that affects female travellers differently and warrants further discussion. 
Despite a lack of research dedicated specifically to female travellers (Bowen, 2005; Lin \& Lehto, 2006) there are some common themes. From a gendered perspective holiday leisure cannot be described as an escape from work when others (e.g., children) are involved. As discussed earlier, for many women the continuation of domestic and caring responsibilities is merely transposed from home to another location (see Bella, 1992; Deem, 1996a; Small, 2002, 2005b). Instead of a break from home, holidays for women contain obligation, work, social disapproval, and responsibility (McCormack, 1998).

Research into female independent travel relates the desire of women to challenge themselves, find a sense of freedom, and meet new people (e.g., Butler, 1995; Elsrud, 2006; Wilson \& Little, 2008). Women travelling solo only experience a 'relative escape' because they feel constrained by the social mores of home and destination and cannot fully escape being the object of the sexual 'male gaze' (Harris \& Ateljevic, 2003; Jordan \& Aitchison, 2008). The chance of a true escape may be more limited for women than for men (Harris \& Wilson, 2007). In effect, holidays for women are valued for their social opportunities (Pennington-Gray \& Kerstetter, 2001), for maintaining friendship and bonding social capital (Heimtun, 2007c), and achieving social connectedness with people (Small, 2003, 2005a). Instead of accepting male-defined uses of the tourism space, women are able to construct their own meanings and interact with others as active subjectivities rather than as objects of the gaze (Gibson, 2001). According to Chodorow (1989), it is this socially constructed embeddedness in interactions and personal relationships which differentiates women's lives from those of men and which acts as a filter on the tourist gaze. Also, separation from the domestic realm is much harder to achieve because the sense of place may be part of women's sense of place wherever they are (Massey, 1994). The importance of social relationships for female travellers, therefore, provides a gendered notion of space and time as well as a gendered gaze or female tourist gaze (Deem, 1996b).

In line with subjectivities and a feminised emphasis on interpersonal relationships, the idea of the holiday place as 'chora' is suggested as a space to be occupied and given meaning to by the people who use it (Grosz, 1995). This implies a shift from the basic conceptualization of the tourist as itinerant gazer to that of 
interacting person or 'choraster', which also points to a shift from holiday destination as a place to a more socially interactive space (Wearing \& Wearing, 1996), and a shift from the disembodied 'gazing' tourist (Veijola \& Jokinen, 1994) to a tourist that is feeling, touching, and, therefore, engaging with others and the chora. Thinking is, thus, moved towards a more feminised, person-centred approach, in which embodiment and emotionality are included along with the rational, mind oriented self (Wearing \& Wearing, 2001). Embodiment denotes the ways in which the individual grasps the world and makes sense of it in ways that engage both mind and body (Crouch, 2000), and offers insights of a feminine experience of the world alongside a more male perspective (Grosz, 1994). Essentially, embodiment insists that we reflect on the 'being, doing, touching and seeing rather than just seeing' (Crouch \& Desforges, 2003, p. 7; Edensor, 2006). This acknowledges that tourists as performers are gazers and active beings, such as in adventure tourism (Cater \& Cloke, 2007; Cloke \& Perkins, 1998). Embodiment introduces other senses into the study of tourism such as smell and scents (Dann \& Jacobsen, 2002) and taste and food (Everett, 2008; Richards, 2002), which involve aesthetic and sensual experiences (Wang, 2002). For example, Small (2007) reported that many women could still taste/smell/feel/hear/see and, as a result, relive the emotion and the sensations of recalled holidays at younger ages.

However, only through a feminised, gendered approach to tourism research can the body and all its senses be fully integrated and acknowledged (Wilson \& Ateljevic, 2008). Studying women and men in a dyadic relationship and their gendered holiday experiences by allowing for a female tourist gaze along with a male tourist gaze makes for true gender scholarship (Figure 2.4). It also opens the way for including the embodied experiences of the researcher and qualitative research strategies (Swain, 1995). Another implication is that research can become focused on gendered groups that have been marginalised, such as family groups and children. There is, therefore, a need to understand tourist experiences in a much broader sense than is generally reflected in the tourism literature, and in a way that also re-centres them as integral aspects of daily life (O'Dell, 2007). 


\subsubsection{THE TRIANGULAR FAMILY GROUP PERSPECTIVE -GENDER, GENERATION, AND GROUP DYNAMIC PERSPECTIVES}

A unit of three or more people is called a group, and this includes most families. Turley (2001) and Carr (2006) recognised that a more comprehensive and methodologically complex approach to tourism research is needed for family groups that triangulate the views of children and adults. Others have also pointed to this neglected area of research concerning gender, generation, and group relations/dynamics while families are on holiday (e.g., Chesworth, 2003; Norris \& Wall, 1994; Shaw et al., 2008). In effect, there is little research on how social interaction and travel party composition on a group holiday intersects with the holiday experience (Yarnal \& Kerstetter, 2005). This is surprising given that holiday spaces conducive to social interaction may be one of the primary meanings associated with the tourism experience (Pine \& Gilmore, 1998; Wang, 2000). Instead, existing research related to family travel is mostly focused on decision making (So \& Lehto, 2006) and, therefore, market-orientated, as discussed earlier. Other research is on the impact of tourism on families as hosts in developing countries (e.g., Archer \& Cooper, 1998; Kousis, 1989), on family tourism businesses (e.g., Getz \& Carlsen, 2005; Wilson, 1997), on work-family dynamics of tourism employees (e.g., Mulvaney et al., 2007), and on the impact of family tourism on relatives (Havitz, 2007). Apart from two recent studies (Gram, 2005; Shaw et al., 2008), there is little research into the impact of the family holiday experience on the whole family group (Chesworth, 2003). Instead, most research on family holiday experiences is from the mother's perspective or centred at particular attractions. To my knowledge, no tourism study has yet been carried out that includes all the different family members and the family unit covering an entire holiday, which takes full account of the social interactions between gender, generation, and group present in a whole-family study.

There is a lack of research in the tourism literature on motherhood (Small, 2005b), but a few studies are informed by a feminist research perspective and are, thus, focused on mothers' family holiday experiences. For example, Cerullo \& Ewen (1984) looked at American family camping holidays and confirmed earlier findings of women bearing the main domestic and caring responsibilities. This is 
supported by other tourism researchers (e.g., Anderson, 2001; Di Leonardo, 1992; Small, 2002), highlighting the never-ending physical and emotional work of motherhood both at home and when travelling. In ensuring the enjoyment of others, women sacrifice their own holiday time to plan activities that will create lasting memories (Davidson, 1996) and feel dissatisfied when conflicts and difficulties exist between family members on holiday (Deem, 1996b). Those studies identify a relationship between 'ethic of care', as discussed in the leisure literature, and motherhood and women's family holiday experiences.

It is also related to research that looks at the symbolic meaning of time use and links it to a person's identity. Thus, if women continue to do more housework while on holiday, the extent to which this is problematic varies with their desire to be doing something else (Thompson \& Bunderson, 2001). These findings imply that holiday time can be conceptualised as part of the work-family nexus. If so, the meaning and use of holiday time may differ by gender because of the relative weight that men and women place on their work and family identities (Maume, 2006). While enhancing family relationships is important to mothers on holiday, there is also literature that highlights women's need for a time and space of their own. In effect, freedom from family obligations is sought in a good holiday experience (Davidson, 1996) or an escape from the motherhood discourse (Small, 2005a, b). This is illustrated by a mother classifying a holiday with the children as a family adventure and without the children as a holiday (Buttle, 1994,b). Although these studies shed some light on women, they do not illuminate the experiences of the fathers and children.

In contrast to the established work on youth tourism, children have been neglected in tourism studies (Small, 2008). Little has changed since Graburn's (1983) observation of the absence of children in the tourism literature. Since then, the few studies have mostly been concerned with the impacts of tourism on the child as host in developing countries (e.g., Gamradt, 1995), while others have examined children's role in prostitution (e.g., Leung, 2003; Oppermann, 1998; Ryan \& Hall, 2001). Also, Richter (2005) discussed the role of travel policy in protecting children and Balkhy (2003) assessed the immunization status of travelling children. However, very few studies investigate the actual travel experience of 
children (Hilbrecht et al., 2008; Poria et al., 2005), which is surprising as tourism researchers acknowledge that the presence of children on holiday impacts on the adult holiday experience (e.g., Small, 2008; Thornton et al., 1997). Managers of some tourist attractions (e.g., theme parks, as discussed later) recognise that children are an important market segment as part of the family group (Cullingford, 1995; Ryan, 2002a), and also in their own right (Swarbrooke \& Horner, 1999), e.g., in organised educational tourism (Cooper \& Latham, 1988) or school trips (Larsen \& Jenssen, 2004), but there is also a need for a broader understanding of children as tourists that goes beyond a commercial focus.

Cullingford (1995) found that British children preferred beaches to cultural sightseeing when holidaying overseas. Most studies suggest that for children holidays are about physical activity, being involved and having fun rather than relaxing (Carr, 2006; Gram, 2005; Nickerson \& Jurowski, 2001; Small, 2008). A recent study by Hilbrecht et al. (2008) established that newness within a familiar environment and connections with social relations was important for children on family holidays. This confirms Small (2002) who found that for 12-year-old girls sharing holiday experiences with others, such as friends, makes for a good holiday experience. Small (2007) also highlights that the centrality of physical activity in girls holidays compares with its peripheral position in women's holidays, which reinforces findings from leisure studies that female participation in physical activity declines after childhood (Roberts, 1996). This introduces a gender perspective to the study of children in tourism which has largely been unexplored to date. There is also no known tourism study on the family holiday experience of fathers (Ryan, 2003), which is surprising given the increasing interest in fathers in the leisure and family literature as discussed earlier. This is a timely reminder that not only are children marginalised in tourism studies but also fathers are invisible apart from their joint parenting voice or as a vague comparison to that of mothers (Ryan, 2002a, 2003). Thus, while the male gaze is dominating for the individual experience within a family group the mother or female gaze is dominating the parent and family perspective.

With regards to family research carried out at tourism attractions, Johns \& Gyimothy (2002, 2003) found that there is a dichotomy between the 'fun' 
experienced by children at theme parks and the perceived penance or self-sacrifice of the parent. This research demonstrates potential tensions and generational differences within the family unit, again arguing for more studies of how family groups experience an attraction, a notion supported by Sterry \& Beaumont (2006) in relation to museums. Blud (1990) and Brown (1995) highlight gender and generational differences in the way families interact during a science museum visit. It appears that social interactions, rather than learning, have the most memorable effects on families in art museums (Sterry \& Beaumont, 2006). Christensen et al. (2007) found that compared with the art museum all senses were stimulated at the shopping mall and that children preferred more sensory experiences because they are 'wired differently' to adults. Instead, visits to the zoo are regarded as providing emotional connection between family members and enjoyable educational experiences for children and are, thus, redolent with purpose and meaning (Hallman et al., 2007). This also points to the wider meaning of the entire family holiday and broader societal attitudes.

There are tourism studies that have focused on the holiday experiences of economically and socially disadvantaged families (e.g., Hazel, 2005; Hughes, 1991; Smith \& Hughes, 1999) or visitor-related social tourism (Minnaert et al., 2006). Parents here reported the significance of 'change' and establishing relationships as meanings of family holidays. In France, family holidays are seen as an opportunity to (re)connect with extended family and as identity forming (Samuel, 1993). Yet, Rosenblatt \& Russell (1975) alluded to potential problems in family travel as families are typically better insulated from interpersonal problems at home than when they are together on holiday. While family holidays are seen as providing the opportunity for both revitalisation and family bonding, there is also the opportunity for serious interpersonal difficulties. However, the notion of families spending happy periods together is a persistent marketing image and has long been part of the 'mythology of tourism' (Seaton \& Tagg, 1995).

Additionally, Blichfeldt (2006) found that providing new experiences (such as holidays) is considered a critical element of good parenting. Research into mothers on family holidays found that there is a gap between the romantic view of holidays and the lived experience of motherhood which can lead to guilt and 
blame when there is conflict between family members (Davidson, 1996; Small, 2005b). Also, there are strong cultural constraints on expressing dissatisfaction with family holidays (Deem, 1996b). This reflects similar findings in leisure and family studies, as discussed earlier, which point to a dichotomy between the idealisation of family life (at home, at leisure, or on holiday) and the reality of it. So far, this tension is mainly based on mother's experiences rather than father's and children's experiences of family holidays.

A study by Gram (2005) identified an inherent dilemma on family holidays that because parents seek relaxation and children seek activities, the ideal of togetherness is hard to achieve. This is highlighted by Jepsen \& Blichfeldt's (2005) study at a caravan site where children were kept busy with activities which allowed adults to be passive and was, thus, found conducive to family togetherness. Both findings point to a pattern of separateness-connectedness that underlies all family interaction, as discussed earlier. In fact, a German study found that there is a schism between the wish by family members for togetherness and the need for personal space or separateness (Institut für Freizeitwirtschaft, 1999 in Gram, 2005). Interestingly Gram's (2005) and Jepsen \& Blichfeldt’s (2005) studies are based on Pine \& Gilmore's (1998) two-dimensional spectra of experiences (passive-active participation; absorption-immersion) which do not take into account the relational and interactive dimensions of gender, generation, and group dynamics needed for family studies. Also, Jepsen \& Blichfeldt (2005) were not focused on families and included no children, and while Gram (2005) interviewed the entire family, there are no individual voices of mothers, fathers, and child(ren), again suggesting a need for research into both the individual and collective experiences of whole families.

A study by Shaw et al. (2008) comes the closest to a whole-family study in tourism, but mothers still dominate and not all the children's experiences were included (see Hilbrecht et al., 2008). Apart from confirming gendered identities on holiday, this study found that the most important long-term meaning of family holidays for the parents was creating positive memories for their children that strengthen the family unit. It strengthens earlier findings in that holiday experiences are about memory construction (Larsen, 2007) and that family 
holidays carry more symbolism than other family times (Fiese et al., 2002), which puts more emphasis on continuity of meaning after the holiday. This is supported by other findings (e.g., Davidson, 1996; Lin \& Lehto, 2006) that families reminisce and romanticise about the trip (Noy, 2007) which helps reinforce the ideology of family holidays. It can be concluded that family holidays are underpinned by ideological notions such as media messages about 'good' parenting behaviour (Shaw, 2008) and societal expectations, just as family leisure and family time, and that there is a temporal dimension to it. Thus, family holidays are not only about the actual time spent together on holiday but also provide longer-term meanings like guiding the next generation and establishing social identities. According to Shaw et al. (2008), families differ from other tourists because of a strong parental focus on social aspects such as family togetherness, memory creation, and generativity (Erikson, 1950). There is, in fact, increasing literature on social experiences in tourism.

As discussed earlier, holidays are perceived more as spaces for maintaining social relationships for women travellers. This was also illustrated with regards to domestic tourism (section 2.2.3). In fact, the importance of social connectedness is prevalent throughout the broader literature associated with family travel (e.g., Arai \& Pedlar, 2003; Urry, 2003; Wearing \& Deane, 2003). Colton (1987) argued that meaning is derived through social interaction with 'others'. The key concept here is social capital, which is about reciprocity and generalised trust (Johnston \& Percy-Smith, 2003), and a label for the positive effects of sociality (Portes, 1998). This concept originated in Bourdieu (1984) and was popularised by Putnam (2000), and has been stretched from a property of individuals and families to a feature of communities, cities, and even nations (Portes, 1998). In tourism, however, social capital is mostly about being with friends and family (Heimtun, 2007a) rather than a source of network-meditated benefits beyond the immediate family. Larsen et al. (2007) argued that tourism research has neglected such issues of sociality and overlooked how more and more tourism is concerned with (re)producing social networks. Tourism often involves connections with, rather than escape from, social relations and the multiple obligations of everyday social life which is termed the ‘social turn' of tourism studies (Larsen, 2008). 
Indeed, the economic focus of much of tourism research coupled with a dominance of individual tourism pursuits means that the social dimensions in tourism research have largely been neglected. As posited above, social group holidays such as families are fundamentally different from individual tourists. This can be illustrated with regards to 'fun'. Podilchak $(1988,1991)$ argues that fun emphasizes a social emotional interaction process which means it is impossible to have fun by oneself. In fact, very few studies focus on family fun (Churchill et al., 2007) because social interaction and fun are seen as inferior to individual leisure and cannot be translated into monetary values. This is particularly relevant for family holidays with the emphasis put on fun, especially by children (e.g., Gram, 2005; Small, 2008), and can be addressed with research that is inclusive of children and the social dimensions present on holiday.

It is this additional social dimension that builds on the individualised male and feminised gaze by encompassing the whole interactive and embodied family group, thus including the gendered, generational, and group dynamic experiences of fathers, mothers, and child(ren), as established in the new conceptual framework (Figure 2.4). Research by Haldrup \& Larsen (2003) introduced the notion of the 'family gaze' that captures how family photography practices are socially organised and systematised. The family gaze is concerned with embodiment and revolves around producing social relations. While much tourism research is drawn to the spectacular and exotic, the family tourist gaze is concerned with the 'extraordinary ordinariness' of intimate family worlds. It, thus, sheds light on more 'mundane' and trivial types of tourism (Bærenholdt et al., 2004; Haldrup, 2004) which are embedded in everyday patterns of social life, family, and friendship (Larsen et al., 2007). This is part of the new mobility paradigm which means a rejection of disciplinary boundaries and the opposition of home/away (Hannam, 2008; Sheller \& Urry, 2006). This is best illustrated by Blichfeldt's (2008) finding that family holidaying at home is not so different from going away on holiday because it can be as simple as putting up a tent in the backyard. A focus on the social and temporal dimension in tourism experiences and the family gaze (Figure 2.4), thus, shows how tourism, leisure activities, and everyday life intersect in complex ways within the triangular family group. 


\subsection{Conclusion}

The research questions, as outlined in section 1.6, followed from the gaps identified in the literature. Most family tourism research is market driven with little emphasis put on the social and temporal dimensions of the experiences gained; instead, research into tourism experiences is predominately on the individual (male), while research on family holiday experiences lacks the father, child, and group dynamics perspectives. Family research in tourism, thus, is trailing recent developments in leisure and family literatures which reveal an increased focus on fathers, children, and societal influences within family studies. In New Zealand there is little understanding about the meaning and setting of holidays for families. These gaps are addressed by the conceptual framework (triangular family group perspective), a focus on the social experiences and phases of family holidays, and enquiry into the importance and definition of holidays for New Zealand families. This is based on the realisation that family holidays are primarily about group experiences, or the family gaze, with all members of the family contributing to the construction of its meaning, in this case mothers, fathers, and child(ren). This includes different phases of holiday experiences which are highlighted by the emphasis placed on holiday memories and generativity for the families. It combines the notion of temporality with the study of gendered, generational, and group dynamic experiences on family holidays.

It needs to be pointed out that while the family group dimension is based on current literature it does not need to be triangulated around the nuclear family and could include extended family (like grandparents) and friends holidaying together. As it stands, single parent and gay/lesbian families would require a more complex framework that might go beyond any triangulation. Richardson \& St. Pierre (2005) suggested the crystal as a central image for qualitative inquiry because it offers an infinite variety of shapes, multidimensionalities, and angles of approach. In many ways crystals can grow and change just like modern family forms. This would open many avenues for future research but goes beyond the scope used here. The discussion will now move to the methodology used for this study. 


\section{CHAPTER 3: RESEARCH PARADIGM AND}

\subsection{INTRODUCTION}

My philosophical perspective influenced the choice of methods which followed from the gaps identified in the literature and led to the conceptual framework and the research questions. This thesis accepts that family holidays are primarily about social interactions and relationships which can only be captured by a threedimensional approach to tourism research. It moves away from an individual (one-dimensional) research focus which dominates the tourism literature. Instead, the study builds on a two-dimensional (gendered) approach to tourism research by including children (generational) and social dimensions (group) into the research process leading to a focus on gender, generation, and group dynamics. It encompasses true gender scholarship that is inclusive of both the female and male perspective, and sociality of family groups that is inclusive of the generational and group dynamic perspective. Apart from the social dimension to family travelling there is also a temporal dimension which manifests itself in the symbolism attached to special family time, such as the longer-term meanings of memories and social identity formation.

In order to capture this temporal and social nature of family holidays, a holistic research approach was used within the interpretive research paradigm that links the phases of holidays with, first, the individual parent perspective and, second, family group interviews. A preliminary survey, which was mainly used as background to family holiday behaviour and basis for sampling, was linked with data triangulation of whole-family interviews over three time periods (Figure 3.1). This captured individual and group perspectives on family holidays while exploring temporal influences by longitudinal design. The emphasis is placed here on social interaction within a family group, which is encompassed by symbolic interactionism and informs the research through the grounded theory methodology (GTM). The research is grounded in the individual and social meanings that families derive from their holidays over time as proposed by the experiential dimension. It captures the anticipations, experiences, and recollections for the 
whole family and its individual members and allows for analysis according to generation, gender, and group dynamic perspectives relating to pre-, on-, and post-holiday stages (Figure 3.2). Qualitative research was used in a way that encompasses gender issues, multiple methods, embodiment, reflexivity, and situatedness, with 10 families forming this case study. This study, then, becomes an example of progressive research in tourism as proclaimed by Goodson \& Phillimore (2004). As a result, the analysis integrates gender, generation, group dynamics, social interaction, temporality, and context in developing small-scale theory regarding holidays by New Zealand families.

This chapter first outlines the research paradigm before detailing progressive qualitative tourism research practices, and the qualitative strategies of grounded theory, case study, and whole-family study used for this project. It then presents the methodological framework for this study including the multi-phase approach and linking the survey with data triangulation of whole-family interviews before detailing the four phases of methodology. This is followed by the analytical framework used and details of the data analysis, development of themes, and presentation of data. The chapter concludes with an evaluative and reflexive discussion of the research process and a bringing together of paradigm, methodology, and analysis. It provides a theoretical context for the research, understanding of the methods used and how the analysis was carried out and, thus, leads to an integration of the different phases of the methodology with analysis of the different perspectives resulting in a theoretical framework of the main themes.

\subsection{RESEARCH PARADIGM}

This section addresses the theoretical paradigm that informs this study and its related ontology, epistemology, methodologies, and methods. According to Denzin \& Lincoln (1994; 2008) and Hollinshead (1996), the researcher can be viewed as a bricoleur: an individual who pieces together sets of practices to solve a puzzle. In this sense, research is viewed as a creative and non-linear process, with the researcher seeking out different puzzle pieces until a point is reached when a picture as complete as possible can be presented. The messy research 
process is highly subjective not through choice but because that is the nature of social research. Researchers' actions are underpinned by a set of beliefs that define their worldview or paradigm (Goodson \& Phillimore, 2004). For this reason, an understanding of the research methods firstly requires an understanding of the theoretical paradigm guiding this research. There are three main elements of the research paradigm: ontology (the nature of reality); epistemology (how the world is known); and methodology (how knowledge is gained about the world) (Small, 1999). Within this, methods are merely tools which take on meaning according to the methodology within which they are employed (Silverman, 2000). Thus, the selection of research approaches is fundamentally a methods-level consideration of secondary concern to the initial paradigmatic determinations made vis-à-vis questions of ontology and epistemology (Hollinshead, 2004).

The overall paradigm guiding this study is interpretive, which influences the types of questions asked and the choice of research methods. This paradigm "assumes a relativist ontology (there are multiple realities), a subjectivist epistemology (knower and subject create understandings), and a naturalistic (in the natural world) set of methodological procedures" (Denzin \& Lincoln, 2000, p. 21). According to Hollinshead (2006), interpretivism is better suited than conventional positivist approaches for mapping the kind of contested and changeable realities which are increasingly encompassed in social encounters in tourism. Also, the insider's view provides the best lens through which to understand the longer-term social experiences of the case families. This emic perspective allows for the identification of multiple realities (Schwandt, 1994), as evidenced by the previously identified multi-dimensionality of family life. The methodological framework used was holistic within the interpretive research paradigm that links the parental survey with data triangulation of whole-family interviews (Figure 3.1), as discussed in more detail later. With this research approach, quantitative data are used to inform the primarily qualitative data and, thus, provide a more complete picture by noting generalisations and identification of individual parent themes along with in-depth knowledge of all family members' and collective perspectives over time. This produces a bricolage, that is, a pieced-together set of representations and interpretations that is fitted to the specifics of a complex situation (Denzin \& Lincoln, 2008) which is informed by symbolic interactionism. 
As the name suggests, 'symbolic interactionism' focuses on the connection between symbols (i.e., shared meanings) and interactions (i.e., verbal and nonverbal actions and communications) on which the GTM is based, as discussed later. The term 'symbolic interactionism' was coined in 1937 by Blumer (1969, p. 1) but the foundation of the perspective was established some 20 to 30 years earlier. This perspective has a strong conceptual heritage and research tradition in family research (LaRossa \& Reitzes, 1993). Symbolic interactionism's unique contribution to family research is, first, the emphasis it gives to the proposition that families are social groups and, second, its assertion that individuals develop both a concept of self and their identities through social interaction, enabling them to independently assess and assign meaning to their family activities (Burgess, 1926; Handel, 1985). It focuses on the nature of social interaction at a micro level or family group level.

However, according to Denzin (2002), symbolic interactionism must adopt insights from post structural philosophy and include gendered and critical interpretations. Alone, neither theory is sufficient to explain and account for the complexities that occur in gender and family relations. Thus, interactionism and post structuralism need one another (Denzin, 2001). While their underlying philosophies are different, there are areas of convergence which may include the concepts of reference groups such as families and the self within symbolic interactionism and ideological hegemony within critical perspective. By using a more pragmatic approach and combining symbolic interactionism with critical theories, both micro and macro levels come into focus and understandings across individual and societal levels can be gained (Burbank \& Martins, 2009). Such an approach appreciates that human agency and social structure exist in tension and that family members construct meanings with respect to certain events without loosing sight of the broader structures that shape meaning construction. It acknowledges that roles within the family such as fatherhood and motherhood must be understood within gendered and parenting ideologies in society. Implementing symbolic interactionism in this way for this research allows a focus on gender, generation, and group dynamics within the family holiday group.

Kelly (1994) argued that leisure is amenable to interpretive analysis and, in particular, the gendered nature of interaction processes. Learning the meaning of 
leisure and tourism activities and situations from other family members is encompassed by the tenets of this theoretical perspective (Colton, 1987). There are also several recent studies within leisure and tourism that have been informed by the tradition of symbolic interactionism (e.g., Dyck \& Daly, 2006; Jennings, 2005; Kyle \& Chick, 2007). This interpretive research approach, grounded in symbolic interactionism, suggests that the meanings family groups associate with their holiday experiences are the product of interactional processes involving the individual, time, and their social worlds. Symbolic interactionism, therefore, is particularly suitable for this project where the focus is on the longer-term social experiences and meanings of family holidaying, and as an interpretive paradigm for progressive qualitative tourism research.

\subsubsection{PROGRESSIVE QUALITATIVE TOURISM RESEARCH}

There is agreement that the majority of tourism research is positivist and that the interpretive approach is not common in qualitative tourism research (Lynch, 2005). Phillimore \& Goodson (2004) argued that, to date, qualitative tourism research has mainly used a set of methods rather than a set of thinking tools (paradigms) which enable researchers to consider different ways of approaching research. Tourism researchers, thus, need to become more sophisticated by encompassing epistemological notions of reflexivity and indeterminacy in their studies (Botterill, 2001). In fact, the influence of the full range of research paradigms is yet to emerge in practice (Goodson \& Phillimore, 2004). The continued growth of qualitative tourism research will be ensured by a need for deeper understanding (Riley \& Love, 2000). Tourism is an endlessly creative field of lived experiences that should be more deeply explored interpretively, and thereby 'qualitatively', especially in the light of new insights gained across social science disciplines (Hollinshead \& Jamal, 2007). Qualitative tourism research that utilises advances in social research praxis is, therefore, best positioned to uncover the interpretive understanding of family holiday experiences.

According to Phillimore \& Goodson (2004) there are five moments of qualitative research in tourism. The focus of this research is up to the fifth moment in line with current trends in tourism research. A brief discussion of these five moments 
is in order. The first moment is associated with positivism. The paradigm of symbolic interactionism is associated with the modernist period (second moment) which considers that there are multiple realities held by the inhabitants of the social world and that these can be reached by techniques such as in-depth interviewing (Denzin \& Lincoln, 1994). To take this approach further it is essential for this research project to blur the boundaries between different disciplines (third moment) and engage with gender issues/feminist debates, such as men's and women's differential holiday experiences. It also includes experimentation with more creative methods, such as photography and holiday scrapbooks used for this research. In addition, there has been the use of multimethod approaches such as the linking of both qualitative and quantitative methods (e.g., Marshall, 2001). The fourth moment requires greater reflexivity, embodiment, and personal biography of the researcher, whereby this researcher adopts the use of the first person to write herself 'into' the text. It acknowledges that there are multiple interpretations meditated by the personal biographies of researcher and their research subjects. Reflexive approaches to research have emphasized the subject-centred nature of all human knowing (Feighery, 2006) but has been seldom used in traditional approaches to tourism research (Ateljevic et al., 2005). The fifth moment makes this research project context specific (a 'snapshot' in time and space) and my voice as researcher one among many that influence the research process. Examples of fifth moment tourism research are only just emerging (e.g., Lynch, 2005). These moments have since been expanded to eight moments by Denzin \& Lincoln (2008) but have not yet been taken up by tourism researchers (Westwood et al., 2006). Jamal \& Hollinshead (2001) call for tourism scholars to acknowledge these issues and invoke new ways of interpreting and expressing the multi-vocality, textuality, and situatedness of participants.

A move away from positivism, the western hegemonic research paradigm, demonstrates deviance. This form of deviance can be perceived as affirmative for its innovation and progression in research practice (Jennings \& Junek, 2007). How these moments are applied to this research project demonstrates a form of affirmative deviance. The interpretive paradigm used here is associated with the second moment along with symbolic interactionism and the GTM. This is adapted through true gender scholarship, the linking of qualitative and quantitative 
methods, use of auto-photoelicitation and scrapbooks, and borrowing of the whole-family interview technique from another discipline (third moment). Reflexivity and personal subjectivity is acknowledged in the fourth moment. Focusing this study on New Zealand families and their domestic holidays makes this research context specific and part of the fifth moment.

There are many similarities with Jennings' (2005) research into experiences of ocean-cruising women. Apart from using the same paradigm and grounded theory, her research also links a survey with in-depth interviews and applies a gendered perspective and reflexivity. However, this project is a major departure from other tourism research in that it introduces the whole-family study borrowed from qualitative family research which allows for an investigation into gender, generation, and group dynamics on family holidays. Situating myself as an interpretive researcher using GTM clearly qualifies as a critical turn by not embracing the dominant research paradigms (Jennings \& Junek, 2007). Initiating whole-family studies as a new strategy in tourism research can also be interpreted as innovation and affirmative deviance as discussed in more detail next.

\subsection{QUALITATIVE RESEARCH STRATEGIES}

There are several qualitative research strategies used for this project that fit the progressive qualitative paradigm. These are GTM, case study inquiry, and wholefamily study. While grounded theory and case studies have been used in tourism research, no whole-family study has been reported in the leisure or tourism literature yet (see sections 2.4 .2 and 2.6.3). The width of scope and diversity of strategies and methods used for this research are shown in Table 3.1. The discussion now moves to the GTM before explaining the case study design used for this project and the relevance of whole-family studies within qualitative family research. The discussion, thus, progresses from the most widely used strategy in qualitative research to one of the least known, as whole-family studies are mainly used in family and health research. The methods are then explained in section 3.4. 
Table 3.1 Paradigm, qualitative strategies, and methods used for this research

Paradigms and perspectives Strategies of qualitative inquiry Methods

Largest

Progressive qualitative paradigm:

Interpretivism, up to five moment research

(a) Reality is socially constructed;

There are multiple realities.

(b) Researcher is part of research

settings.

(c) Investigation must be in reflexive,

self-critical, creative dialogue.

(d) Aim to problematise, reveal hidden

realities, initiate discussions.

\section{Grounded theory methodology (GTM):}

'Theory that is grounded in data

systematically gathered and analysed';

'Continuous interplay between analysis

and data collection' (Glaser \& Strauss, 1967).

\section{Case study:}

An in-depth, multifaceted investigation of a single social phenomenon like family holidays (10 families in this instance) (Orum, et al., 1991).

\section{Whole-family research:}

Research of whole families by including the perspective of each family member

(Handel, 1992).

\section{Smallest}

\section{Survey:}

Provide background and

themes for family interviews.

\section{Whole-family interviews:}

Family group interviews;

Individual interviews;

semi-structured interviewing.

\section{Photo-elicitation:}

Own photos as interview stimuli,

Auto-driven interview.

Holiday scrapbook:

Own diary as interview stimuli.

Source: adapted from Hollinshead (2004, p. 70). 


\subsubsection{GROUNDED THEORY METHODOLOGY (GTM)}

As mentioned earlier, the symbolic interactionist perspective, as applied here, forms the basis for grounded theory as a qualitative research methodology. Like symbolic interactionists, grounded theorists assume that people act individually and collectively (Bryant \& Charmaz, 2007) which fits with the whole-family study approach. The founders Glaser \& Strauss (1967), called the methodology 'grounded' because a theory systematically was obtained from a broad array of data through a rigorous process of constant comparison (see section 3.6.1). GTM was conceived as a way of generating theory through research rather than testing ideas formulated in advance of data collection and analysis (Dey, 2004). It is more likely to generate pattern theory that is sensitive to context rather than hierarchical theory. By definition, grounded theory is rooted in data, which in turn is rooted in persons, place, and time. This is a very different approach to most tourism and family research which is based on quantitative hypotheses testing (Gilgun, 1992; Hardy, 2005). Grounded theory is the most popular qualitative approach for family theorising (LaRossa, 2005) and generally in the social sciences (Bryant \& Charmaz, 2007), and is increasingly used in tourism research (e.g., Daengbuppha et al., 2006; Hsu et al., 2007; Woodside et al., 2004). It has also been used to research families within leisure and tourism (e.g., Churchill et al., 2007; Decrop \& Snelders, 2005; Johns \& Gyimothy, 2003), but not yet as a whole-family study.

Grounded theory can be of two general types: substantive and formal (Glaser, 1992; Glaser \& Strauss, 1967). In substantive grounded theory, the concepts and hypotheses that researchers develop are based on data drawn from one area of study. This is the aim of this research project focusing on New Zealand families on holiday at a specific time. Discovering similar concepts and hypotheses across areas of study, time, setting, and informants leads to formal theory. It entails Geertz's (1973) concept of 'thick description' as a process of elucidating a matrix of meaning which, when applied to families, leads to rich theory building with implications for family policy and practice (Gilgun, 1992). 
An inductive research process, such as GTM, is also needed for more theory creation in tourism (Connell \& Lowe, 1997; Hobson, 2003) and where no preexisting theory exists (Hardy, 2005), as in this case where there is a lack of theory about the three dimensionality of family tourism. GTM can offer a new level of understanding of tourists and their interactions within the tourism environment. It can generate explanations of events, processes, and relationships reflecting the lived tourist experiences of individuals and groups (Jennings \& Junek, 2007), which here is of the whole family. The aim is to develop a more complex and holistic analysis (Dey, 2004), as reflected in the approach taken here, leading to the construction of theory grounded empirically, conceptually, and holistically. It is, however, necessary that a more flexible constructivist GTM is applied (Charmaz, 2000) to allow for fifth moment qualitative research, as used by Lynch (2005) in hospitality research. Constructivist GTM assumes a relativist ontology with multiple realities based on a subjectivist epistemology, whereas objectivist GTM assumes a unidimensional external reality where a neutral observer conducts unbiased data collection (Schwandt, 1994). The constructivist approach adopts naturalistic methodological procedures focusing on meanings, values, and situations which are presented as interpretive case studies (Charmaz, 2000). The use of case studies is not only essential to GTM but has also been particularly important in the generation of new ideas and theories (Orum et al., 1991).

\subsubsection{CASE STUDY INQUIRY}

A case study inquiry is defined as an in-depth, multifaceted investigation, using qualitative research methods of a single social phenomenon (Orum et al., 1991). It is the preferred strategy when the focus is on a contemporary phenomenon within its real-life context (Yin, 2003). It permits the researcher to examine not only the complexity of life in which people are implicated but also the effect on beliefs and social interactions. The case study remains indispensable to the progress of social science research (Orum et al., 1991) and may incorporate several cases, that is, multiple case studies. Yin (2003) considers single- and multiple-case studies variants of research design, with both being included under the case-study inquiry, but with multiple-case designs increasingly being used. One strategy to strengthen the results of a single-case study is to use several case studies in a comparative 
framework, as applied by the GTM (Orum et al., 1991) and used here. In this research project the intensive case study is based on multiple cases (10 families) and the phenomenon is the holiday environment. Also, a case connotes a spatially delimited phenomenon observed at a single point in time or over some time period (Gerring, 2007), as used here over three times (before and twice after the holiday).

Case studies of families have been mainly based on interviews. One explanation is that very few researchers have managed to gain sustained observational access to families (Handel, 1991). The private nature of families and mobility on holiday does not allow for field observation in this case. Instead, 10 exploratory cases of whole families informed by in-depth interviewing make up this project. The aim is to treat each case (family) holistically rather than isolating variables, and to provide data about personal holiday experiences and their meaning from all family members in their own words. Case studies in tourism have been widely used but are usually geographically defined (e.g., Gios et al., 2006; Tovar \& Lockwood, 2008) or of other businesses (e.g., Daengbuppha et al., 2006; Schänzel $\&$ McIntosh, 2000). There are, however, case studies in tourism that have included families as part of travel parties (e.g., Woodside et al., 2004) or households (e.g., Decrop \& Snelders, 2005) but not a whole-family case study.

Family researchers usually base their studies on a small number of cases (Handel, 1991). The precedent is Hess \& Handel (1959), who selected five families with children between 6 and 18, so that all members could be interviewed several times. The researchers were concerned with developing a framework for understanding the family as a group, and their approach was exploratory and essentially inductive. According to Handel (1996) each family was studied as a functioning whole, a case. In each case the researchers tried to understand the meanings of each individual family member as well as the joint meanings which involved the interpretations of family relationships and interactions. In Handel's (1991) opinion the case study that aims at comprehensiveness is the best method for trying to understand the breadth of meaning that any family generates.

Other researchers such as Piotrkowski (1979), Speedling (1982), and Stacey (1990) have illustrated how whole-family methodology can be utilised in other 
areas. All of these studies assumed that the problem being investigated required an inclusive view of the family as a functioning group, but there are no established ways of looking at whole families (Handel, 1991). Murphy (1992) used two longitudinal studies of nine and eight families to study sibling-infant relationships. Sufficient work has been done to show how whole-family case studies can be adapted to examine diverse problems and situations (Handel, 1996). Although there is no whole-family case study in leisure and tourism as yet, Harrington (2001) based her research of family leisure on 10 families and Shaw et al. (2008) interviewed 15 families before and after their summer holiday. All this indicates that the selection of 10 families for this research sits well within the parameters set for a whole-family case study and allows for 1-2 families to fall away due to unforeseen circumstances. It has to be remembered that all families (20 parents and 20 children) were interviewed three times individually and together, resulting in 148 interviews ${ }^{1}$. The discussion now moves to the relevance of whole families within qualitative family research.

\subsubsection{WHOLE-FAMILY RESEARCH}

Families are a distinctive focus of research which differs from research of individuals, as outlined earlier. Qualitative research is particularly amenable to the study of this social group. In keeping with Weber's (1947) Verstehen tradition, qualitative methods are best suited for understanding the meanings, interpretations, and subjective experiences of family members (Daly, 1992). Burgess (1926) formulated the concept of "the family as a unity of interacting personalities". Mead (1934) argued that although the self is developed in a social process and reflects the group, each member has an individual perspective. Those concepts together form a charter for the study of whole families by including the perspectives of each member (Handel, 1965, 2001), as carried out by Hess \& Handel (1959) on nuclear families. However, most family research investigates only one of the component relationships in a family (Handel, 1996). Obviously in today's context the concept of whole families takes many forms. This increased variety of forms constitutes a continuing rationale for studying whole families, whatever their form (Handel, 1992).

\footnotetext{
${ }^{1}$ Two children were not interviewed in phase 4 of research. See section 3.5.2.3.
} 
Families are social groups, and the adult, parent-child, and possible sibling relationships need to be understood concurrently in their group context as mutually influencing and as resulting in individual and group holiday experiences. It is, thus, necessary to collect multiple forms of family data, including both individual and group data (Murphy, 1992). Mothers are often sources for explaining families' realities while fathers are difficult to recruit, although the value of multiple-member perspectives is paramount in most family research (Daly, 1992; Lareau, 2000). No single family member is a sufficient source of information for their family as a family constructs life from the multiple perspectives of its members and an adequate understanding requires that those perspectives be obtained from their multiple sources (Handel, 1996). Compared with most quantitative research which takes the individual as the unit of analysis, qualitative research can accommodate multiple perspectives and can better deal with families and internal relationships as units to enable richer accounts of lived family experiences (Handel, 1992). Qualitative methods, designed to capture emergent and emic meanings, are well suited to the study of a wide range of family experiences from multiple perspectives (Daly, 1992), such as the wholefamily cases of the family holiday, as discussed later.

Qualitative family research has been sidelined by family scholars for a long time (Ambert et al., 1995; LaRossa \& Wolf, 1985) even though there has always been a tradition of qualitative research in family studies (Gilgun, 1999), as established by Thomas \& Znaniecki (1927). The legitimization of qualitative methods in recent times has been remarkable (Bengtson et al., 2005) as it is significant in advancing family theory and for deepening our understanding of the often hidden realms of meaning related to family life experiences (Gilgun, 1999). Also, different research paradigms can be successful in answering different kinds of questions about families, thereby producing a greater variety of family research (Ambert et al., 1995) such as in this case researching the meanings of family time on holiday, which is novel to family studies. Underlying the qualitative wholefamily study is the GTM which is well suited to studies of groups and conceptual questions regarding differing family meanings and interactions (Murphy, 1992). For this reason, this project uses the GTM for its multiple whole-family case studies and, consequently, brings together GTM, case study, and whole-family 
study as its research strategies. The discussion now moves to the methodological framework and the different phases used for this research.

\subsection{METHODOLOGICAL FRAMEWORK}

The methodological framework uses a holistic research approach within the interpretive research paradigm, as outlined earlier, and which informs the discussion here (Figure 3.1). It is made up of two key components, the linking of the parental survey used for background with whole-family interviews, and data triangulation of whole family interviews aided by auto-photoelicitation (APE) that leads to three phases of qualitative data collection and exploration along three perspectives (gender, generation, and group dynamics). Taken together this resulted in four phases of methodology which are discussed later in this chapter before discussion of the analytical framework used, including the process of the GTM, and evaluation of the subjective and reflexive elements of this research. I first discuss the linking of quantitative with qualitative methods within the interpretive and longitudinal research design.

\subsubsection{LINKING OF SURVEY WITH WHOLE-FAMILY INTERVIEWS}

According to Bryman (2006), research that involves the integration of quantitative and qualitative research, and which is variously called mixed methods or multimethods, has become common in recent years, as advocated by McIntosh (1998) for research into experiential tourist dimensions. It is argued here that this should be thought of more in terms of 'meshing' or 'linking' rather than 'integrating' data and method. Mason (2006), in particular, notes the value of mixed methods approaches in studies about social experiences and lived realities like family and interpersonal relationships. While the quantitative data are more effective in providing "breadth", e.g., statistical analysis of family travel behaviour, the qualitative data is ideal for addressing "depth", e.g., capturing each family member's point of view. The strengths of both qualitative and quantitative data can be enhanced by linking them which provides a way to generate more information about the breadth and depth of the topic under study (Henderson \& Bedini, 1995). Mason (2006) suggests that 'qualitative thinking' is a useful starting point for mixing methods, but it is more helpful to think in terms of multidimensional research strategies that transcend any qualitative-quantitative divide. 


\section{Figure 3.1 Methodological framework}

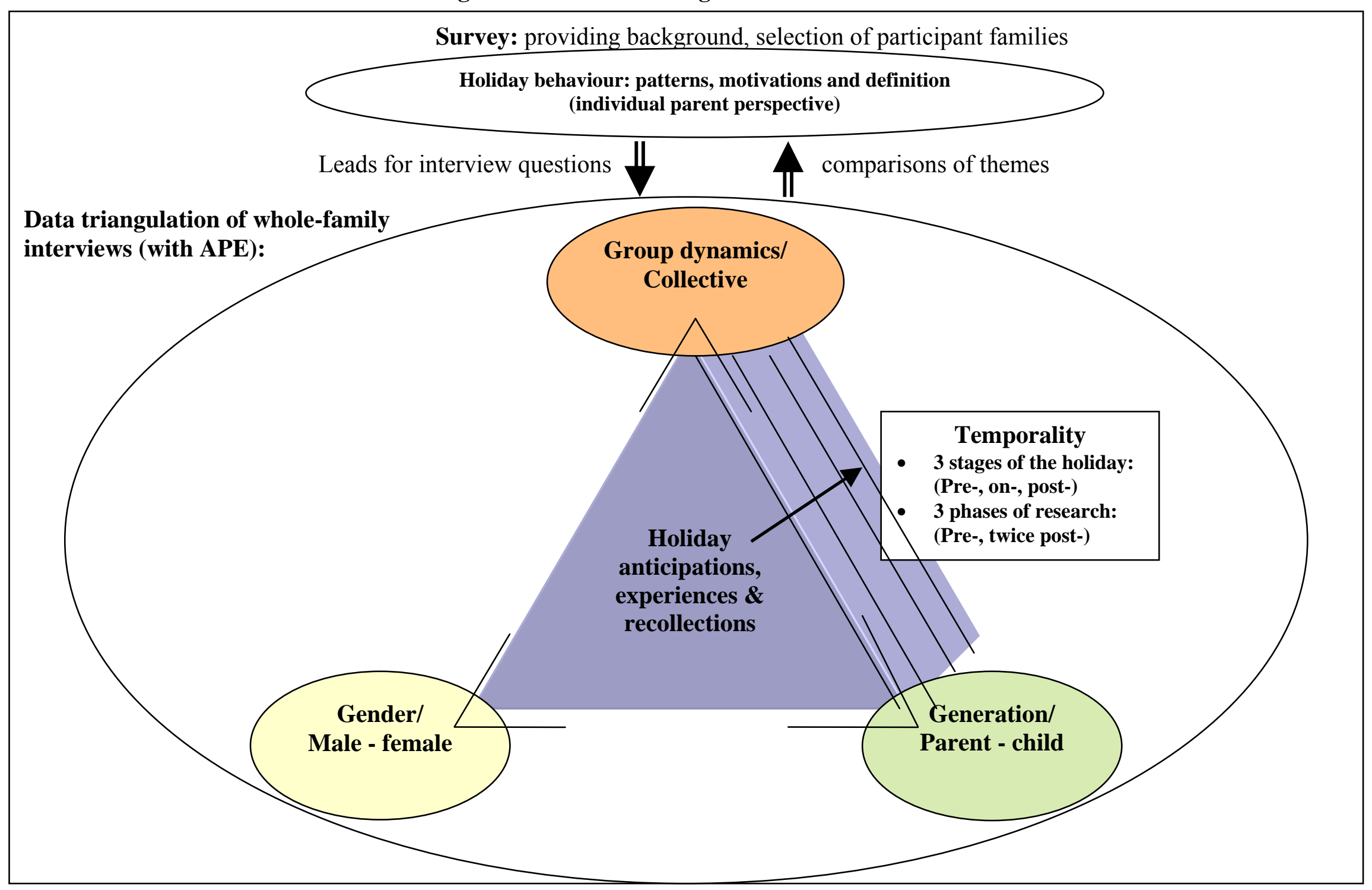


A qualitatively or interpretively driven approach to mixing methods offers enormous potential for generating new ways of understanding the complexities and contexts of social experience and for exploring its multi-dimensionality (Mason, 2006). Because surveys can only capture a single perspective or dimension of research (individual parent perspective in this case), the quantitative method was linked with three phases of whole-family interviews to explore gender, generation, and group dynamics over time (multiple perspectives of the whole family group and its individual family members).

According to Brannen (1992), when a quantitative method is subservient or subsidiary to qualitative methods, it tends to fulfil certain functions: a survey provides background data in which to contextualise this small-scale intensive study and also provides a basis for the selection of cases (families here) which form the intensive study. This explains why a survey was conducted before the main qualitative study rather than at the end. This form of linkage is done where a study is primarily qualitatively driven but quantitative data are collected for background (Henderson, 2006; Henderson \& Bedini, 1995). Collecting the quantitative data was also important here because the area of family holiday experiences has not been extensively studied. The survey information provided a basis for exploring issues in greater depth and leads to the first round of qualitative family interviews within the iterative research design. The study, thus, accepts a more flexible, innovative approach to qualitative thinking that recognizes the validity of different research methods and celebrates complexity, richness, and depth (see Mason, 2006). This fits not only with a more reflexive approach taken by the fourth moment of qualitative research but also a more creative approach to knowledge as proclaimed by Goodson \& Phillimore (2004) and Botterill (2001). It means that the strength of this multi-method approach lies in adding breadth and depth to this research and is not for the purpose of pursuing 'objective' truth (Fielding \& Fielding, 1986, p. 33). This explains why the survey lies outside of the data triangulation of whole-family interviews (Figure 3.1). 


\subsubsection{DATA TRIANGULATION AND WHOLE-FAMILY RESEARCH}

The crucial component of triangulation as a research approach is that each measure needs to be interrelated, meaning they all have to relate to the same triangle in question (Oppermann, 2000). Denzin (1978) distinguished between a number of different 'triangulation' approaches, namely data triangulation (DT), investigator triangulation, theory triangulation, and methodological triangulation. However, according to Oppermann (2000) a multi-method approach should not be referred to as methodological triangulation, as it is virtually impossible to obtain the 'truth' from both quantitative and qualitative methods. The term triangulation, instead, should be used only for DT as a form of 'within method' triangulation. DT has the closest resemblance to the origins of the term triangulation because all measurements are of the same kind and based on the same ontology and epistemology (Blaikie, 1991). It refers to using the same approach for different sets of data in order to verify or falsify generalisable trends detected in one data set (Oppermann, 2000). The aggregation from different data sources will not necessarily add up to produce a more complete picture. Indeed, the differences between types of data can be as illuminating as their points of coherence (Fielding \& Fielding, 1986). In fact, Perlesz \& Lindsay (2003) argue that given the multifaceted context and intimate subject matter in family research, there is a high likelihood of dissonant findings when working with triangulated data.

According to Denzin (1978), DT may include (1) time triangulation, exploring temporal influences by longitudinal design; (2) space triangulation, taking the form of comparative research; and (3) person triangulation, variously at the individual level, the interactive level among groups, and the collective level. This research uses DT of whole-family interviews and more specifically: time triangulation (longitudinal, corresponding with the three phases of the research) and person triangulation (in terms of different family perspectives: generation, gender, and group dynamics). Three phases of whole-family interviews were conducted (once before and twice after the summer family holiday), all centred around the same triangle of family holiday anticipations, experiences and recollections for the whole family and its individual members (see Figure 3.1). This approach aids the multi-dimensional nature of this research (the multiple 
experiential and temporal realities) and also adheres to true triangulation in that at least three data sets are used (Oppermann, 2000). It has been used in tourism by Oppermann (1995a), Decrop \& Snelders (2004), and Belhassen \& Santos (2006), all stating the usefulness of DT in contributing to various dimensions of the research process which can be congruent with an interpretive paradigm.

In particular, Decrop \& Snelders (2004) used DT, person, and time triangulation, together with the GTM, which meant that key variables could be compared at different times and at different levels. For this research, using DT and GTM meant that the successive phases of research involved the concurrent collection and analysis of data informing the next phase or constant comparative analysis (Glaser \& Strauss, 1967). Key grounded themes initially generated from the data were elaborated and modified as incoming data from the next phases were meticulously compared against them. The aim of this iterative research design is to refine themes and ideas or theoretical sampling, not to increase the size of the original sample (Charmaz, 2000). Theoretical sampling was used here by modifying data collection procedures, in this case the interview questions, as outlined later, as the study progressed in line with Glaser's (1987) recommendations. Theoretical sampling, therefore, can be viewed as a technique of data triangulation: using different data sources to get a better understanding on something that is only partially known. Another technique used in DT, person triangulation, is at the heart of the whole-family interview.

A whole-family interview is defined as a method of data collection where all members of the family unit are involved in a group setting specially designed for the purpose of gathering information, or group interview (Astedt-Kurki \& Hopia, 1996). Families represent more than a set of individuals and a family is more than a sum of its individual members. In a whole-family approach, as is the case for this project, the family is seen as a unit of analysis. Multiple family members as informants were used both together (concurrent) and one at a time (sequential) (Astedt-Kurki et al., 2001). In order to capture shared meanings, the whole family was interviewed together. However, to guard against the possibility of one family member dominating the conversation, and to give individual family members the opportunity to describe their own experiences without the scrutiny of the rest of 
the family, sequential interviews were also necessary. The group interviews complemented the individual interviews (Morgan, 1997). This allows for DT into the familial perspectives of generation, gender, and group dynamics.

With regards to the generational perspective, there has been an increase in the demand for children's voices to be heard in matters that affect their lives, but few studies are based on children's accounts of their everyday lives (Morrow \& Richards, 1996), such as family holiday experiences. Contemporary social research presents children as actors in their own right with diverse and often divergent views about their everyday worlds (Matthews et al., 1998). This shift has involved repositioning children as the subjects rather than objects of research, and presents new possibilities for children as competent participants in research (Farrell, 2005). This, however, required special methodological considerations regarding children. New 'methodologies of representation' have been developed to enable children to communicate through, for example, drawing, photography, or diaries with the aim of being inclusive and building rapport with participants (Barker \& Weller, 2003). Qualitative methods, in contrast to quantitative methods, can be used for those aged under 11 years as well as older children (Miers \& Murphy, 2004). Using open-ended questions has been shown to increase the accuracy of information elicited (Krähenbühl \& Blades, 2006). Time is also of importance to allow a relationship to develop between researcher and the participants, as children need some familiarity with the researcher (Morrow \& Richards, 1996). For this reason, whole-family interviews with open-ended questions were conducted three times and several projective techniques were used.

One technique used here in conjunction with the interviews to particularly engage children and enhance participant involvement is auto-photoelicitation (APE). The term 'auto' indicates that the interview is driven by the participants who are reflecting on their own photographs (Heisley \& Levy, 1991). Harper (2002) advocates the use of photo elicitation because images evoke deeper elements of human experiences than words alone. Yet, few studies have employed visual data that have been generated by tourists themselves (e.g., Garrod, 2007). It is especially useful in tourism research since taking photographs is such an integral part of holidays (Andersson-Cederholm, 2004) and because "travel becomes a 
strategy for accumulating photographs" (Sontag, 1977, p. 9). Photographs are an under-used but powerful qualitative tool particularly with respect to determining the 'holistic' tourist experience (Willson \& McIntosh, 2007). APE is used as a technique for triggering responses, for making the respondent feel comfortable in the interview (Andersson-Cederholm, 2004), and to explore tourists' experiences from their own point of view (Botterill \& Crompton, 1987). Research becomes a collaborative process whereby the researcher listens as the participants interpret their photographs (Loeffler, 2004). It is also useful in bringing out gender differences in photographic depictions (Clancy \& Dollinger, 1993). Other projective techniques used were daydreaming and family holiday scrapbooks, which are explained in section 3.5.2, but the photographs proved the most valuable. The photographs and scrapbooks also introduced an on-holiday element to this study, as used for analytical purposes later. Table 3.2 links this to the temporal dimension of the methodological framework (Figure 3.1).

Table 3.2 Temporal dimension for methodology and analysis

\begin{tabular}{|l|l|}
\hline \multirow{2}{*}{ Stages of the holiday } & Phases of methodology \\
\hline \multirow{2}{*}{ Pre-holiday } & Pre-holiday survey \\
\cline { 2 - 2 } & Pre-holiday interviews \\
\hline \multirow{2}{*}{ Post-holiday } & (Photographs and scrapbooks) \\
\hline & Post-holiday interviews (short-term) \\
\cline { 2 - 2 } & Post-holiday interviews (long-term) \\
\hline
\end{tabular}

Families' own photographs have been used in tourism research before, but not child-taken photographs. Haldrup \& Larsen (2003) and Larsen (2005) brought family photography into tourist studies through the notion of 'the family gaze' (see section 2.6.3), which stresses the sociality, reflexivity, and embodied performances of family photographs. They employed it as a particularly effective tool in capturing the social, personal, and affective side of holiday experiences. Hallman et al. (2007) found that family holiday photographs become souvenirs of 
quality family time, depicting the time and emotional investment made in the social relations captured in the images. Decrop (2005) and Gram (2005) used the APE interview in their research with families. The difference for this research is that each family member, including children, chose their own photos, as opposed to the family (Gram, 2005) or only one adult family member (Decrop, 2005). In this case, disposable cameras were given to children and child-taken photographs were used at interviews as employed by Cunningham et al. (1996), Grant (2006), and Dean (2007). Also, scrapbooks were used as a form of diary and for children's drawings (e.g., Murphy, 1992). Using child-taken photography and art signifies an alternative way of getting children to express their feelings and engaging them in the research process.

Accepting an interpretive paradigm draws attention to the need to understand children from their own perspective and to recognise that they may gain different meanings than adults. Rather than assuming children know less than adults it is suggested that they may know something else (Matthews et al., 1998). Interviews can be problematic for children (Clark-Ibáñez, 2004) and special methodologies need to be considered that include other aspects of children's communication (such as art and photography). There is a sense that children need to be seen to be understood and researchers need to be sensitive to the different ways in which children express themselves (Matthews et al., 1998). A combination of techniques enables the data generation process to be more interesting and fun for participants as well as effective in generating useful data (Punch, 2002). Children become empowered and provided with opportunities to express themselves in ways they find interesting and appropriate to their level of competence (Matthews et al., 1998). The use of such participatory and sensory devices in the data collection fits in with fifth moment qualitative research which foregrounds the 'situated researcher' and which encourages greater participant involvement and reflexivity (Westwood et al., 2006), as advocated by this study. Research paradigms which draw on innovative and interpretive methodologies can provide insights into understanding tourism consumption as holistic experiences for everyone involved. Also, linking the survey with the DT of whole-family interviews makes up the four phases of methodology. 


\subsection{PHASES OF THE METHODOLOGY}

This research is primarily qualitative focusing on the phenomena of domestic family holidays informed by multiple family case studies using constructivist GTM. Each of the ten families was studied as a functioning whole, as a case. To understand the social experiences and meanings when a family goes on holiday it is necessary to gather data from the whole family. This is based on two premises:

1. Conceptualising families on holiday as groups of interacting members,

2. Obtaining data from each member of the families studied.

Taking account of multiple members' perspectives, including those of children, is not amenable to quantification and statistical analysis (Handel, 1996). Nonetheless, a survey, used as background and basis for sampling, was linked to the whole-family interviews resulting in a holistic research approach within the interpretive research paradigm.

A holiday involves several phases, as outlined in the previous chapter (see Clawson \& Knetsch, 1966; Gyimothy, 1999), and can essentially be seen as a process of journey experiences and ideals (Figure 2.3). It involves a pre-holiday phase, on-holiday phase, and post-holiday phase, along with ongoing reflections. Yet, it is the importance and symbolism placed on memories that not only influences future holiday behaviour (see Larsen, 2007; Wirtz et al., 2003) but also is particularly significant for families in manifesting family togetherness and establishing social identities (see Shaw et al., 2008). The emphasis placed on the recollection process together with an inability to conduct longitudinal wholefamily studies that include an 'on-holiday' phase meant that a 'before' and 'after' holiday design was chosen. It has to be remembered that the majority of the case families were touring on their holiday and it would have been unfeasible to follow them around for interviewing (see Table 3.7).

Based on these reasons, a decision was made to conduct a longitudinal study that included one initial survey phase and three interview phases: to interview families before their summer holiday (the period when most New Zealanders take their main holiday) (anticipation phase), straight after (short-term recollection phase), and then some time after the holiday (long-term recollection phase). The parental 
survey was distributed through schools and 10 whole-family interviews were conducted in 2006 before the summer holidays, and two rounds of 10 wholefamily interviews were conducted in 2007 after the summer holidays. Taken together, those four phases covered the span of about one year in the holiday life of 10 New Zealand families. The different phases of methodology and their relation to the research questions were outlined in chapter 1 (Figure 1.1), but the methodological details follow next.

\subsubsection{PHASE 1: SURVEY THROUGH SCHOOLS}

The purpose of the survey was primarily to recruit families for later interviewing, acquire a demographic profile of families, provide a snapshot of the holiday behaviours of New Zealand families, and develop a preliminary definition of family holidays that would inform the family interviews. It was determined that access through a school system was the best way to contact a broad range of families across socio-economic lines in common with previous studies (e.g., Carr, 2006; Zabriskie \& McCormick, 2003). The primary schools chosen were from the Wellington region and in the vicinity of my place of residence to ensure that the families could be interviewed in their homes during later phases. The survey was distributed to five state-funded primary schools in the city of Lower Hutt. Questionnaires were only distributed to the year 3 to 6 classes (age 7-11). This age criterion provided not only for some homogeneity in terms of family life cycle (full nest II; Table 2.3), but also under 12 year olds have not yet reached the age at which independent peer leisure starts to dominate over family activities (Shaw \& Dawson, 2001). This stage of family life is also when children are a key preoccupation and when a wide range of children's activities are available (Shaw et al., 2008). Table 3.3 provides a profile of the schools. The number of eligible students was requested from the school administrators. The questionnaires were then delivered to the school and given out by the teachers at the end of the day for the students to take home to their parents/guardians with an accompanying letter that had completion instructions (see Appendix A). The data collection took place before the summer holidays in November/December 2006. 
Table 3.3 Profile of schools and survey response rate

\begin{tabular}{|l|c|c|c|c|}
\hline School & Decile & $\begin{array}{l}\text { Number of year } \\
\text { 3 to 6 students }\end{array}$ & $\begin{array}{l}\text { Survey } \\
\text { responses }\end{array}$ & Response rate \\
\hline A & 10 & 123 & 21 & $17 \%$ \\
\hline \hline B & 10 & 60 & 16 & $27 \%$ \\
\hline C & 10 & 240 & 60 & $25 \%$ \\
\hline D & 4 & 130 & 10 & $8 \%$ \\
\hline E & 1 & 127 & 3 & $2.5 \%$ \\
\hline Total & & 680 & 110 & $15 \%$ \\
\hline
\end{tabular}

Some difficulties were experienced during the data collection that related to school access and parental cooperation. In order to provide a representative crosssection of families, a range of different decile schools was sought. The decile rating is meant to reflect the income of a selection of residents in the school's catchment area with decile 1 representing lowest income and decile 10 representing highest income. Out of the 10 schools contacted four were high decile, four were middle decile, and two were low decile. Identifying middle to low decile schools that allowed me access to their pupils proved to be a difficult exercise, with the majority of those schools declining to participate. After some negotiation with the school principals, three high decile, one middle decile, and one low decile school were included in the study (Table 3.3).

The high decile schools had a response rate of about $23 \%$ which is in line with Board of Trustees survey return rates as reported by one school official. The middle to low decile schools had a low $(8 \%)$ to very low $(2.5 \%)$ response rate, which means that the results are skewed towards families at schools with higher average incomes. This is reflected in 38\% of annual household incomes of respondents being over $\$ 100,000$, whereas only $6.4 \%$ had a household income of $\$ 20,000-40,000$ (Table 3.4). The average annual household income in New Zealand at the time was $\$ 68,692$ (Statistics New Zealand, 2006b). However, 
Lawson et al. (1997) already identified that the family group represents the highest income segment of all New Zealand travellers.

The total response rate was about $15 \%$, with 680 questionnaires delivered to the schools and 110 completed questionnaires received (Table 3.3). It has to be remembered that the response rate is difficult to determine because of siblings in the same family receiving multiple questionnaires. Children might also have been absent on the day of distribution and questionnaires could have been misplaced, resulting in not all allocated students bringing home a questionnaire to their parents. This means that the actual response rate could be much higher. To improve the response rate a reply paid envelope addressed to the researcher was attached to the questionnaires and the option was offered to enter a prize draw for a $\$ 30$ book voucher per school. The gender, age, income, ethnic, and family characteristics of the 110 respondents are shown in Table 3.4. The results show that the majority $(81 \%)$ of parents who completed the survey were females.

Table 3.4 Characteristics of survey respondents

\begin{tabular}{|c|c|c|}
\hline$(n=110)$ & & Percent \\
\hline Gender & $\begin{array}{l}\text { Male } \\
\text { Female }\end{array}$ & $\begin{array}{l}19.1 \\
80.9\end{array}$ \\
\hline Age (years) & $\begin{array}{l}25-34 \\
35-44 \\
45-54 \\
55-64\end{array}$ & $\begin{array}{r}8.0 \\
61.0 \\
30.0 \\
1.0 \\
\end{array}$ \\
\hline Household income (\$) & $\begin{array}{l}20,000-40,000 \\
40,001-60,000 \\
60,001-80,000 \\
80,001-100,000 \\
100,001+ \\
\text { Not disclosed } \\
\end{array}$ & $\begin{array}{r}6.4 \\
9.0 \\
11.0 \\
20.6 \\
38.0 \\
15.0 \\
\end{array}$ \\
\hline Ethnicity & $\begin{array}{l}\text { NZ European/New Zealander } \\
\text { Maori } \\
\text { Asian } \\
\text { Other }\end{array}$ & $\begin{array}{r}86.3 \\
6.4 \\
5.5 \\
1.8\end{array}$ \\
\hline Family structure & $\begin{array}{l}\text { Two parent/guardian } \\
\text { Single parent }\end{array}$ & $\begin{array}{l}93.6 \\
6.4\end{array}$ \\
\hline Children & $\begin{array}{l}1 \\
2 \\
3 \\
4+\end{array}$ & $\begin{array}{r}11.0 \\
50.0 \\
30.0 \\
9.0\end{array}$ \\
\hline
\end{tabular}


This bias reflects a major difficulty associated with collecting data from all adult family members, as identified by Carr (2006), namely how to actively involve fathers in the data collection process. The majority of respondents were from a two parent/guardian households (93.6\%), which could include blended families, in the 35-44 age bracket (61\%), classified themselves as NZ European/New Zealander (86.3\%), and had 2 children $(50 \%)$.

The questionnaire contained eight sections that were divided into cover letter, introduction, family holidays, family holidays since October 2005, the main family holiday since October 2005, upcoming summer holiday, personal details, and optional contact details (see Appendix A). The purpose of the cover letter and questionnaire introduction was to familiarise the participant with me as a parent, identify a need and outlet for this research, provide reasoning and incentive for participation, and give logistical and ethical details. At the end, the optional contact details had the purpose of recruiting families for the follow-up research, as well as the prize draw and survey feedback. In terms of human ethics approval, this survey was not necessarily anonymous because participants had the option of leaving their contact details. However, the contact details were on a separate piece of paper that was removed after the selection of the interview respondents and prize draw. Informed consent was implied by voluntary participation in filling out the questionnaire. Thus, the survey was confidential in terms of the reporting of the data as no individual person or family was identifiable.

The open and closed questions (see sections B to F in Appendix A) established the nature, frequency, and length of holidays by New Zealand families divided into general definition, past and upcoming travel behaviour. The results were used to develop a working definition of family holidays in New Zealand and leads for the next phase of family interviewing. Section B contained open-ended questions with the purpose of establishing a preliminary definition of family holidays as closed questions do not allow tourists to define the nature of their holiday themselves (McIntosh, 1998). It aimed to clarify whether Kiwi family holidays only entail travelling with the immediate family as put forward by Lawson et al. (1997) and/or can include holidaying at home as stated by Blichfeldt (2008). The aim was, thus, to establish if family holidays fall outside the general definition of 
tourism (see Leiper, 1979). It further identified key aspects of ideal family travelling and determined the minimum holiday duration in the New Zealand context.

Sections $\mathrm{C}$ to $\mathrm{E}$ had the purpose of establishing a snapshot of travel behaviour of New Zealand families. Section C contained closed questions about the general family holiday behaviour over the previous year, such as trip frequency, destinations (domestic and overseas), and non-family trips, along with an open question about reasons for not travelling. Section $\mathrm{D}$ and $\mathrm{E}$ compared the characteristics of the main family holiday in the past year and an upcoming summer holiday. Both sections contained closed questions about destination, VFR travel, business travel, accommodation, length, month of travel, and travel party as well as an open question for motivations. Despite the potential incompatibility of mechanistic approaches to motivations and behaviours with symbolic interactionism, there were methodological reasons for using these terms as they are widely understood by respondents and represent desires, drives, impulses and actions that are fundamental to human agency. The response options on accommodation were developed after consulting the Tourism Research Council (2006) website in order to establish accommodation patterns. The questions on VFR and business travel were used to clarify the definition of family holidays and those questions on travel party identified the range of family forms. Details on the upcoming summer holiday also served in the selection of participating interview families. In total, the questionnaire contained six open-ended questions to identify a definition of family holidays based on motivations and key characteristics for family travel, and reasons for not travelling. This qualitative data was coded for key themes with multiple themes established per answer. Those key themes informed the next phase of interviews as leads for questions and are explained in section 3.5.2.1.

The aim of section $\mathrm{F}$ was to gain demographic details to profile respondents. The questions on gender and age were in line with standard practices. Question 28 on ethnic group was derived from the census (Statistics New Zealand, 2006a) but combined all Pacific Islanders into one category. Question 29 on employment status was in line with Shaw (1992) and question 20 offered income brackets to 
allow comparison with the literature including an option of non-disclosure. In terms of ordering, the demographic questions were placed towards the end due to their sensitivity. Instead, the questionnaire began with open-ended questions to engage the interest of the participants, encourage them to complete (Sapsford \& Jupp, 2006), and to get their initial ideas on the definition of family holidays. The design of the questionnaire went through some rounds of testing with friends and fellow researchers who were parents. During this process of refining the questionnaire some questions became more open-ended and the general flow of sections became more streamlined, logical and engaging. The selection process of the 10 different participant families is explained in more detail next.

\subsubsection{PHASES 2-4: WHOLE-FAMILY INTERVIEWING}

The study employed a purposive sampling technique using specific criteria, including the presence of at least one child 7-11 years old, firm plans for a domestic summer holiday, and male and female parents. This gave the sample some homogeneity in terms of family life cycle (e.g., Harrington, 2001), focused on an under researched area of New Zealand tourism (Ministry of Tourism, 2007c), and allowed research into the familial perspective that is inclusive of parental gender differences (Figure 2.4). With regards to recruiting families for the next three phases of interviewing, from the 110 questionnaires returned, 34 families were willing to participate. Of those, seven were not eligible due to travelling overseas for the summer holidays, not having any firm travel plans, or there not being both a male and female parent in the household (Table 3.5). Twenty-seven eligible participants volunteered for the qualitative phases of the research.

It was necessary to move beyond convenience or opportunity sampling and identify the most appropriate participant group. Consistent with the tenets of purposive sampling in GTM, information rich cases were sought that manifest the phenomenon of interest (Morse, 2007). For this research a variety of different domestic holiday experiences was sought in the sample. Sixteen willing participants from four different schools were contacted via phone with 10 recruited and six declining due to time constraints or some family crisis. One of 
those willing families was used as a pilot family for this study as they were acquaintances. As a result, 10 two-parent, middle to high-income families in the Wellington region were involved in these three qualitative phases of the study. A demographic profile of the families is provided in Table 3.6. This means that the families selected were urban residents, nuclear families, NZ European or of European origin, and belonging to a higher income group, which is not necessarily representative of all New Zealand families

Table $3.5 \quad$ Recruitment process of interview families

\begin{tabular}{|l|c|c||c|c|c|}
\hline School & Decile & $\begin{array}{l}\text { Families } \\
\text { willing }\end{array}$ & $\begin{array}{l}\text { Families } \\
\text { eligible }\end{array}$ & $\begin{array}{l}\text { Families } \\
\text { contacted }\end{array}$ & $\begin{array}{l}\text { Families } \\
\text { recruited }\end{array}$ \\
\hline A & 10 & 7 & 5 & 4 & 3 \\
\hline \hline B & 10 & 7 & 5 & 5 & 3 \\
\hline C & 10 & 19 & 16 & 6 & 3 \\
\hline D & 4 & 1 & 1 & 1 & 1 \\
\hline E & 1 & 0 & 0 & 0 & 0 \\
\hline Total & & $\mathbf{3 4}$ & $\mathbf{2 7}$ & $\mathbf{1 6}$ & $\mathbf{1 0}$ \\
\hline
\end{tabular}

Although the requirement for two parents to give a gender perspective on parenthood allowed for step-parents, no blended families volunteered, meaning the sample is made up of 10 sets of biological parents and their children. The children ranged in age from 6 to 16 years, with one to three children in each family. The majority (five families) had two children, which corresponds with the size of the average family (Statistics New Zealand, 2005) (Figure 2.1). Altogether there were 20 adults and 20 children (11 boys and 9 girls) in the study. The families were relatively diverse in terms of employment. Most of the families had incomes over $\$ 100,000$, which matches findings by Lawson et al. (1997), although three families had lower income levels. In the majority of families both parents worked, but in one family the mother stayed at home and in another the father stayed at home. Most families were NZ European but there was also one immigrant family of European descent. This means that some variations of 
holiday experiences were expected that reflected the different socio-demographic profiles of the families. Table 3.7 presents the travel characteristics of the case families. There were, thus, one or two families that portray a different holiday characteristic from the majority. For example, while the majority stayed at a campground for at least part of their holiday, some families stayed at a motel, hotel, or on their private boat.

While one family had a toddler, who was not included, all the other children were six or over. The age limit for the children was set on practical grounds because very young children require specialised non-verbal interview techniques (Hess \& Handel, 1959). It is widely regarded that five/six is the youngest age at which interviews can be readily conducted, as confirmed by other studies (e.g., Cullingford, 1995; Matthews et al., 1998). Children are taken to include every human being below the age of 18 years (see UN Convention on the Rights of the Child) but the term 'child' masks a wide range of categories and diversity of children (Morrow \& Richards, 1996). The accounts that children give of themselves are affected by a range of variables such as gender (Stafford et al., 2003), age (variations according to chronological and developmental age) (Mahon et al., 1996), and other personal characteristics of each child. The language used for the questions had to reflect these variations and be clear, unambiguous, and specific to the child's experience (Miers \& Murphy, 2004).

The concept 'child' also denotes a relationship (child as parents' offspring) (Morrow \& Richards, 1996) and introduces a generational perspective to this study. Also, children want to be taken seriously and ideally there should be a form of incentive (Stafford et al., 2003). Because of the need for special methodological considerations regarding children (see section 3.4.2), projective techniques (e.g., APE, scrapbook) were used and tangible rewards for participation were offered (e.g., disposable cameras, box of 'goodies').

Qualitative family research is almost always conducted in the home (LaRossa et al., 1994), as was the case here, because it ensures that the family members are in their natural environment and more willing to participate (Astedt-Kurki et al., 2001). In order to get behind the happiness façade (Astedt-Kurki \& Hopia, 1996) 
Table 3.6 Demographic profile of the family case studies

\begin{tabular}{|c|c|c|c|c|c|c|c|}
\hline $\begin{array}{l}\text { Family name } \\
\text { (Pseudonym) }\end{array}$ & $\begin{array}{l}\text { Number of children/ } \\
\text { ages/gender }\end{array}$ & $\begin{array}{l}\text { Age of } \\
\text { parents }\end{array}$ & $\begin{array}{l}\text { Number of } \\
\text { family } \\
\text { participants }\end{array}$ & Household income & \begin{tabular}{|l|} 
Employm \\
Father \\
\end{tabular} & $\begin{array}{l}\text { status } \\
\text { Mother }\end{array}$ & Ethnic group \\
\hline Fantail & \begin{tabular}{|l|}
1 girl: \\
10 years old
\end{tabular} & $45-54$ & 3 & $\$ 100,000+$ & Full-time & Full-time & NZ European \\
\hline Goldfinch & $\begin{array}{l}1 \text { girl: } \\
10 \text { years old }\end{array}$ & $35-44$ & 3 & $\$ 100,000+$ & Full-time & Part-time & South African \\
\hline $\begin{array}{l}\text { Hoiho } \\
\text { (pilot) }\end{array}$ & $\begin{array}{l}2 \text { boys: } \\
8 \text { and } 11 \text { years old } \\
\end{array}$ & $45-54$ & 4 & $\$ 60,000-\$ 80,000$ & Full-time & Part-time & NZ European \\
\hline Kakariki & $\begin{array}{l}2 \text { children: } \\
6 \text { years old boy } \\
8 \text { year old girl } \\
\end{array}$ & $35-44$ & 4 & $\$ 40,000-\$ 60,000$ & At home & Full-time & NZ European \\
\hline Kea & $\begin{array}{l}3 \text { girls: } \\
7 \text { and } 10 \text { years } \\
(+1 \text { year old })\end{array}$ & $35-44$ & 4 & $\$ 40,000-\$ 60,000$ & Full-time & Part-time & NZ European \\
\hline Kereru & $\begin{array}{l}3 \text { boys: } \\
10,13,16 \text { years }\end{array}$ & $35-44$ & 5 & $\$ 100,000+$ & Full-time & Full-time & NZ European \\
\hline Pukeko & \begin{tabular}{|l|}
2 boys: \\
11 and 13 years \\
\end{tabular} & $45-54$ & 4 & $\$ 100,000+$ & Full-time & Full-time & NZ European \\
\hline Takahe & \begin{tabular}{|l|}
2 children: \\
10 year old girl \\
12 year old boy
\end{tabular} & $45-54$ & 4 & $\$ 100,000+$ & Full-time & Part-time & NZ European \\
\hline Tui & $\begin{array}{l}3 \text { children: } \\
8 \text { and } 11 \text { year old boys } \\
14 \text { year old girl }\end{array}$ & $35-44$ & 5 & $\$ 100,000+$ & Full-time & At home & NZ European \\
\hline Weka & $\begin{array}{l}2 \text { girls: } \\
7 \text { and } 8 \text { years old }\end{array}$ & $45-54$ & 4 & $\$ 100,000+$ & Full-time & $\begin{array}{l}\text { Part-time } \\
\text { student }\end{array}$ & NZ European \\
\hline $\begin{array}{l}\text { Total/Analysis: } \\
\text { 10 Families = } \\
40 \text { Participants }\end{array}$ & $\begin{array}{l}20 \text { children: } \\
11 \text { boys, } 9 \text { girls } \\
\text { Age range: } 6 \text { to } 16\end{array}$ & $\begin{array}{l}\text { Age range: } \\
35-54\end{array}$ & $\begin{array}{l}\text { Majority with } 4 \\
\text { participants } \\
\text { (6 families) }\end{array}$ & $\begin{array}{l}\text { Majority } \\
\$ 100,000+ \\
(7 \text { families })\end{array}$ & \multicolumn{2}{|c|}{$\begin{array}{l}\text { Majority both parents } \\
\text { working } \\
\text { (8 families) }\end{array}$} & $\begin{array}{l}\text { Majority NZ } \\
\text { European } \\
\text { (9 families }) \\
\end{array}$ \\
\hline
\end{tabular}


Table 3.7 Travel characteristics of family case studies

\begin{tabular}{|c|c|c|c|c|c|c|c|}
\hline & General tra & el behaviour & Summer holiday & $2006 / 2007$ & & & \\
\hline $\begin{array}{l}\text { Family name } \\
\text { (Pseudonym) }\end{array}$ & $\begin{array}{l}\text { Past over- } \\
\text { seas travel }\end{array}$ & $\begin{array}{l}\text { Domestic summer } \\
\text { travel }\end{array}$ & $\begin{array}{l}\text { Destination } \\
\text { (see Figure 4.1) }\end{array}$ & Length & Accommodation & Transport & Scrapbook \\
\hline Fantail & no & $\begin{array}{l}\text { Same regional } \\
\text { location each holiday }\end{array}$ & $\begin{array}{l}\text { Marlborough } \\
\text { Sounds }\end{array}$ & 10 days & Private boat/yacht & boat & $\begin{array}{l}\text { Partially by } \\
\text { daughter }\end{array}$ \\
\hline Goldfinch & yes & $\begin{array}{l}\text { Different locations } \\
\text { each holiday }\end{array}$ & $\begin{array}{l}\text { Auckland, } \\
\text { Northland, } \\
\text { Hamilton }\end{array}$ & 12 days & $\begin{array}{l}\text { Private friend's home } \\
\text { Campground/motel }\end{array}$ & car & no \\
\hline $\begin{array}{l}\text { Hoiho } \\
\text { (pilot) }\end{array}$ & yes & $\begin{array}{l}\text { Different locations } \\
\text { each holiday }\end{array}$ & $\begin{array}{l}\text { Auckland, Great } \\
\text { Barrier Island, } \\
\text { Eastland }\end{array}$ & 21 days & $\begin{array}{l}\text { Campground/tent } \\
\text { Motel }\end{array}$ & car & $\begin{array}{l}\text { Mainly by } \\
\text { mother }\end{array}$ \\
\hline Kakariki & yes & $\begin{array}{l}\text { Different locations } \\
\text { each holiday }\end{array}$ & $\begin{array}{l}\text { Wanganui, } \\
\text { New Plymouth }\end{array}$ & 7 days & Motel & car & $\begin{array}{l}\text { Partially by } \\
\text { daughter }\end{array}$ \\
\hline Kea & yes & $\begin{array}{l}\text { Different locations } \\
\text { each holiday }\end{array}$ & New Plymouth & 8 days & $\begin{array}{l}\text { Campground/tent/ } \\
\text { motor home }\end{array}$ & car & $\begin{array}{l}\text { Combined by } \\
\text { the family }\end{array}$ \\
\hline Kereru & no & $\begin{array}{l}\text { Same location each } \\
\text { holiday }\end{array}$ & $\begin{array}{l}\text { Coromandel } \\
\text { Peninsula, } \\
\text { Rotorua }\end{array}$ & 12 days & $\begin{array}{l}\text { Rented holiday home/ } \\
\text { bach } \\
\text { Motel }\end{array}$ & car & no \\
\hline Pukeko & yes & $\begin{array}{l}\text { Different locations } \\
\text { but involving family }\end{array}$ & $\begin{array}{l}\text { Hawke's Bay, } \\
\text { Gisborne }\end{array}$ & 18 days & $\begin{array}{l}\text { Private family home } \\
\text { Campground/tent }\end{array}$ & car & no \\
\hline Takahe & yes & $\begin{array}{l}\text { Different locations } \\
\text { each holiday }\end{array}$ & Hawke’s Bay & 5 days & Campground/motel & car & $\begin{array}{l}\text { Mainly by } \\
\text { mother }\end{array}$ \\
\hline Tui & yes & $\begin{array}{l}\text { Different locations } \\
\text { each holiday }\end{array}$ & Wairarapa & 7 days & $\begin{array}{l}\text { Campground/cabin/ } \\
\text { tent }\end{array}$ & car & $\begin{array}{l}\text { Mainly by } \\
\text { mother }\end{array}$ \\
\hline Weka & yes & $\begin{array}{l}\text { Different locations } \\
\text { but involving family }\end{array}$ & $\begin{array}{l}\text { Hamilton, } \\
\text { Auckland }\end{array}$ & 12 days & $\begin{array}{l}\text { Private family home } \\
\text { Apartment hotel }\end{array}$ & car & no \\
\hline $\begin{array}{l}\text { Total/ } \\
\text { Analysis: }\end{array}$ & $\begin{array}{l}\text { Most travel } \\
\text { overseas } \\
\text { (8 families) }\end{array}$ & $\begin{array}{l}\text { Most travel to } \\
\text { different locations } \\
\text { each holiday } \\
\text { ( } 8 \text { families) }\end{array}$ & $\begin{array}{l}\text { Most tour within } \\
\text { North Island } \\
\text { ( } 9 \text { families) }\end{array}$ & $\begin{array}{l}\text { Range of } \\
\text { length: } \\
\text { 5-21 days }\end{array}$ & $\begin{array}{l}\text { Most stay at a camp } \\
\text { ground, at least part of } \\
\text { the holiday } \\
\text { ( } 6 \text { families) }\end{array}$ & $\begin{array}{l}\text { Most travel } \\
\text { by car } \\
\text { ( } 9 \text { families) }\end{array}$ & $\begin{array}{l}\text { Most filled out } \\
\text { by mothers and } \\
\text { daughters }\end{array}$ \\
\hline
\end{tabular}


or ideological constraints on expressing dissatisfaction with holidays (Deem, 1996b), a long interview approach (e.g., Gram, 2005; Riley, 1995) and several interviews over a period of about one year were conducted. This gradually built up trust and rapport with the family members (e.g., Smith \& Hughes, 1999) and allowed them to talk more freely about their feelings (e.g., Astedt-Kurki et al., 2001). However, while family interviews are particularly amenable to getting a close-up look at family experiences and meanings, there were secrets and loyalties that probably remained inaccessible to me (e.g., Daly, 1994), such as details of tensions on holiday, which were alluded to only in passing.

All three phases of in-depth whole-family interviewing consisted of collective family group interviews/focus group with all family members and sequential interviews with all the individual family members in private. This ensured that multiple forms of family data were gathered to inform the methodological framework (Figure 3.1). It further ensured that the individual perspectives of fathers and children were collected, which are largely absent in tourism studies, and to safeguard against one family member dominating the family group interview. The family group interviews usually preceded the individual interviews to guarantee confidentiality and reduce any tension, particularly in interviewing children. Also, a level of familiarity was reached with me and the collective memory was boosted before the children were interviewed in private. However, due to circumstances outside of my control, such as phone interruptions, the order of interviews was changed at times (see Tables 3.8-3.10 for research reflections on the interviews). Additionally, given the typical open-plan layout of modern housing, it became difficult to maintain individual privacy. When comparing group with individual interviews, little systematic research has been carried out (Morgan, 1997). Kitzinger (1994, p. 117) concluded that comparisons of individual and group interviews are about context rather than validity, as "all talk through which people generate meaning is contextual, and that the contexts will inevitably somewhat colour the meaning". It was found that whichever form of interview came first usually provided more detail. Overall, regardless of their order, family interviews brought out the group dynamics whereas the individual interviews were more concerned with a personal perspective. 
Semi-structured interviewing using interview schedules allowed for adaptation of the content and flow of the interview to each participant or family group, without forcing interviewees into preconceived answer patterns. There was more room for discovering particular situations and atypical behaviours, which is important for theory generation (Rubin \& Rubin, 2005). The very essence of such semistructured interviews is the establishment of a relationship with the respondents and the desire to understand rather than to explain (Fontana \& Frey, 2005). Gubrium \& Holstein (2002) urged researchers to be reflexive not only about what the interview accomplishes (the substantive findings) but also about how the interview is accomplished (the context and manners of the interview process), thereby uncovering the ways in which text is created. With the interviewees' permission, interviews were recorded on tape and transcribed; field observation notes were written down after each interview. Such notes described the setting, relationships between the family members, issues of privacy, and personal feelings (Tables 3.8-3.10). The evaluation of the interview process and reflexive thoughts are elaborated on later in this chapter. The discussion now moves to the consent process and the first phase of family interviewing.

\subsubsection{Family interviews pre-holiday}

Once the 10 participating families were recruited via phone, a time was arranged to meet with the whole family in their home in December 2006/January 2007, shortly before their summer holiday. This proved difficult because pre-Christmas is very busy for families. Once at the house, information letters provided details about the purpose of the study, the types of data that would be collected, and family members' roles and choices. Daly (1992) and Astedt-Kurki et al. (2001) advised that for whole-family interviews it is necessary to ask separately for the consent of each and every family member. Consent was sought from all family members: written for the parents, verbal and written for the children depending on age (see Appendix B). This process recognised that children have a status in their own right (Stafford et al., 2003) and safeguarded against one family member consenting but not passing on all the information to the rest of the family. Three families opted to have at least one parent present during the individual interviews with their children (see Hilbrecht et al., 2008) (Table 3.8). Combined with a 
general lack of privacy in modern housing, this meant that confidentiality of individual interviews was hard to achieve. The whole-family interviews, thus, were neither anonymous nor confidential for all three phases of interviewing.

One family known to me was used as a pilot in terms of testing the interview schedule (Table 3.7). Pilot studies can be used for pre-testing a research instrument (Van Teijlingen \& Hundley, 2001). Piloting the questions resulted in streamlining some questions and cutting down on possible repetitions, as the pilot participants felt that the interview was too long. The data from the pilot study were included in the main study because the content of the questions did not change, only the flow (see Van Teijlingen \& Hundley, 2001). Piloting with a familiar family helped in testing the process of interviewing children and using certain projective techniques, i.e., daydreaming (see Decrop, 2005). This involved asking the interviewed family members to close their eyes and to describe in their own words how they see one ideal day out of the next summer holiday. Each family was given a blank book for anecdotal notes and children's drawings, as a holiday scrapbook. At the end of the project, the book remained the permanent property of the family but photocopies were made of the entries (Murphy, 1992).

Additionally, disposable cameras were handed out to all children participating and to parents that did not own their own cameras to let them take holiday photos. The reward was getting their own disposable cameras and one set of copies of the photos afterwards. Both children and adults were specifically asked to take photos that were related to their positive and negative holiday experiences, including travel to and from the destination(s). The scrapbook and photographs were treated as field data and for APE during the two interview phases after the holiday.

The interview schedule used for this pre-holiday interview (see Appendix C) followed on from the key themes identified in the survey to establish the social experiences and meanings sought in a family holiday from generation, gender, and group dynamic perspectives. As a result of GTM, a key emergent theme from the survey was the importance of visiting friends and family on holiday (see section 4.2.1) which was addressed as interview questions. As an icebreaker and to build rapport with the families, I introduced myself and showed them some of 
Table 3.8 Research reflections on family interviews pre-holiday (Dec 2006-Jan 2007)

\begin{tabular}{|c|c|c|c|c|c|c|c|}
\hline $\begin{array}{c}\text { Family } \\
\text { name }\end{array}$ & $\begin{array}{l}\text { Interview } \\
\text { order }\end{array}$ & $\begin{array}{c}\text { Time pre- } \\
\text { holiday }\end{array}$ & Space $^{*}$ & $\begin{array}{l}\text { Other persons } \\
\text { present }\end{array}$ & $\begin{array}{l}\text { Behaviour of } \\
\text { participants }\end{array}$ & $\begin{array}{l}\text { Inter- } \\
\text { ruption }\end{array}$ & Comments \\
\hline Fantail & $\begin{array}{l}\text { Family then } \\
\text { Individual }\end{array}$ & 7 days & open & no & Very supportive & no & $\begin{array}{l}\text { Some questions did not apply } \\
\text { due to different kind of } \\
\text { holiday (boat) }\end{array}$ \\
\hline Goldfinch & $\begin{array}{l}\text { Family then } \\
\text { individual }\end{array}$ & 4 days & open & $\begin{array}{l}\text { Everybody around for } \\
\text { individual interviews }\end{array}$ & $\begin{array}{l}\text { Parents making } \\
\text { comments, supportive }\end{array}$ & no & $\begin{array}{l}\text { Close family with no privacy, } \\
\text { expecting second child }\end{array}$ \\
\hline $\begin{array}{l}\text { Hoiho } \\
\text { (pilot) }\end{array}$ & $\begin{array}{l}\text { Family then } \\
\text { individual }\end{array}$ & 39 days & open & $\begin{array}{l}\text { Parents for children's } \\
\text { interviews }\end{array}$ & Children restless & no & $\begin{array}{l}\text { Some repetition in interview } \\
\text { due to pilot, long family } \\
\text { interview }\end{array}$ \\
\hline Kakariki & $\begin{array}{l}\text { Family then } \\
\text { individual }\end{array}$ & 27 days & open & $\begin{array}{l}\text { Family around for } \\
\text { individual interviews }\end{array}$ & $\begin{array}{l}\text { Children shy and not } \\
\text { much contributing, } \\
\text { parents commenting }\end{array}$ & no & No real privacy, supportive \\
\hline Kea & $\begin{array}{l}\text { Family then } \\
\text { individual }\end{array}$ & 6 days & closed & $\begin{array}{l}\text { Youngest daughter } \\
\text { (toddler) }\end{array}$ & $\begin{array}{l}\text { Younger child shy, } \\
\text { very supportive }\end{array}$ & no & Relaxed atmosphere \\
\hline Kereru & $\begin{array}{l}\text { Family then } \\
\text { individual }\end{array}$ & 21 days & open & $\begin{array}{l}\text { Family around for } \\
\text { individual interview }\end{array}$ & $\begin{array}{l}\text { Parents making } \\
\text { comments }\end{array}$ & no & $\begin{array}{l}\text { No real privacy, eldest son } \\
\text { joining later, supportive }\end{array}$ \\
\hline Pukeko & $\begin{array}{l}\text { Family then } \\
\text { individual }\end{array}$ & 13 days & open & $\begin{array}{l}\text { Parents in the kitchen } \\
\text { listening at times }\end{array}$ & $\begin{array}{l}\text { Entire family very } \\
\text { supportive }\end{array}$ & no & Relaxed atmosphere \\
\hline Takahe & $\begin{array}{l}\text { Family then } \\
\text { individual }\end{array}$ & 1 day & open & no & Supportive, relaxed & no & In holiday mode \\
\hline Tui & $\begin{array}{l}\text { Family then } \\
\text { individual }\end{array}$ & 16 days & open & no & Father taciturn & no & $\begin{array}{l}\text { Some disharmony, appeared } \\
\text { that father was not informed } \\
\text { about the interview }\end{array}$ \\
\hline Weka & $\begin{array}{l}\text { Family then } \\
\text { individual }\end{array}$ & 6 days & open & $\begin{array}{l}\text { A friend and child } \\
\text { present }\end{array}$ & $\begin{array}{l}\text { Parents somewhat } \\
\text { distracted, relaxed }\end{array}$ & yes & $\begin{array}{l}\text { Not expected by the family, } \\
\text { father forgot to tell. Family } \\
\text { interview over dinner }\end{array}$ \\
\hline
\end{tabular}

* Open space denotes open-plan living, while closed space means a separate room. 
my family holiday photos. The first set of questions got all family members to define and describe a family holiday, which allowed comparisons with the survey.

The next set of questions was about the anticipations for their upcoming holiday and sought to establish the social experiences and meanings family members seek from their holiday. A differentiation was made between generalised intentional responses (reasons for travelling) and more situational responses (decision making) to elicit intrinsic motivations along with motivations that are made within the context of interpersonal relationships (see McCabe, 2000). The positive and negative aspects of family holidaying were probed. The schedule of questions for the individual interviews was a replication of the group interview questions, but with a focus on personal experiences as opposed to collective experiences. The aim here was to explore differences and similarities between a collective and individual perspective of family holidays, as used for all three interview phases.

The interview analysis and interpretation was based on the GTM, which is discussed in section 3.6.1. Procedures in GTM include the concurrent collection and analysis of data and the constant comparison of data and emerging interpretations which influenced the interview schedule for the next phase of family interviews. See Table 3.11 for a thematic development of interview questions through the research phases using the GTM. The themes that emerged from the data coding process pertained to the anticipated holiday experiences of the whole family. These included the importance of fun for children, the change from normal routine, and the relationship between own time/relaxation and togetherness/family time (chapters 5 and 6). Thus, the analysis of the multiple forms of data from different family members informed theory development (through emergent themes and patterns) and was refined for the next phase.

\subsubsection{Family interviews post-holiday (short-term)}

The first post-holiday family interviews were scheduled within 1-3 months after their return with the aim of establishing the social experiences and meanings family members derive from their holiday in the short term. The aim of interviewing the families within one month of their holiday had to be extended 
due to unforeseen circumstances. Facilitating the holiday photos for APE meant getting all the disposable cameras back, developed, and returning one set of copies of photos to the families. Since not all disposable cameras were full after the holiday extra time was needed to complete the film. Of the 26 cameras handed out, 21 were eventually returned, one lost, and four not used. Two families also used their own photos (Table 3.9).

The families were very busy in these summer months and with the beginning of the school year. When arranging dates for the family interview with one parent via phone I asked if every family member could choose 5-6 photos (not necessarily their own) they particularly liked or thought were important to them. Another unanticipated difficulty was that the pilot family was the last to return from their holiday but was used again as the first interview family. The testing of the data collection techniques again helped streamline the questions, eliminated possible repetitions, and familiarised me with APE in a supportive family. The photos corresponded directly with events on holiday which, due to the delay in interviewing, made them even more important. These photos were then used as prompts throughout the individual interviews, which proved particularly successful when children could elaborate on their own photos. Thus, the ease and excitement of disposable cameras for children was paramount and worked well. Copies of the chosen photos were then kept to illustrate the findings.

The other projective technique of using a scrapbook proved less reliable within a domestic family holiday context. Of the 10 books handed out, 4 were not used, 5 were partially filled out, and only one was completed (Table 3.7). This is in contrast to Heimtun's (2007b) research of using holiday diaries of solo women. The use of diaries in tourism research has been limited but is valuable in revealing information regarding the holiday longitudinally and from the participants' perspective (see Markwell \& Basche, 1998; McIntosh \& Zahra, 2007). The scrapbooks for this research were filled out mostly by women or girls and the domestic holiday presented additional challenges. Some families reported that domestic travel does not warrant a scrapbook as opposed to going overseas. Others thought it resembled school work from which they wanted a break. A few families liked the idea of scrapbooks and had used it in the past, but none of them 
had boys. Scrapbooks, thus, became optional and were used to remind some families about their holiday before the interview rather than at the interview which explains their limited role in the findings. The scrapbooks were also intended to engage the children and stimulate conversation rather than becoming a chore.

The interview schedule used here (see Appendix D) followed up key themes established in the survey and pre-holiday interview after their holiday was over (in the short term). It again began with the family group interview and opened with an icebreaker compiling a list of things on holiday they enjoyed or were fun, which could include reference to the photos and scrapbook. Several questions then incorporated key themes established earlier (Table 3.11), such as the importance of VFR and togetherness (both from survey), the importance of fun, relaxation, and compromises, and elimination of conflicts through planning (all from preholiday interview), along with probing questions on negative aspects of holidaying to identify possible sources of conflict. The next set of questions established the notion of anticipations over time and followed-up from the preholiday interview to allow for comparison between before and after the holiday. The last set of questions tried to establish the importance of the New Zealand holiday setting for the whole family and compare this with overseas holidays.

The individual interview questions again replicated the group questions but with the emphasis put on a personal perspective. The questions in conjunction with APE were used to probe the notion of own time on holidays further. This is largely absent in the family tourism literature. It incorporated earlier themes of relaxation, VFR, togetherness, and compromises as well as establishing more negative and contentious aspects of holidaying in a family group. A differentiation between family time on holidays and the individual need for own time was further elaborated on before the last phase of interviewing. The meaning of family holidays in a New Zealand context was expanded. This interview phase straight after the holiday aimed to capture the more immediate experiences and meanings of family holidaying before the next interview phase explored them retrospectively. Both post-holiday phases provide an understanding of the shortand longer-term importance of reminiscing about particular events and about the place of holidays in the everyday life of families. 
Table 3.9 Research reflections on family interviews post-holiday (short-term) (March-April 2007)

\begin{tabular}{|c|c|c|c|c|c|c|c|}
\hline $\begin{array}{c}\text { Family } \\
\text { name }\end{array}$ & $\begin{array}{l}\text { Interview } \\
\text { order }\end{array}$ & $\begin{array}{c}\text { Time post } \\
\text { holiday }\end{array}$ & Space & $\begin{array}{c}\text { Other persons } \\
\text { present }\end{array}$ & $\begin{array}{l}\text { Behaviour of } \\
\text { participants }\end{array}$ & $\begin{array}{c}\text { Inter- } \\
\text { ruption }\end{array}$ & Comments \\
\hline Fantail & $\begin{array}{l}\text { Family then } \\
\text { Individual girl } \\
\text { then family } \\
\text { then individual }\end{array}$ & 2 months & open & no & $\begin{array}{l}\text { Some distraction } \\
\text { with the phone calls }\end{array}$ & yes & $\begin{array}{l}\text { Phone call for father, } \\
\text { interrupted the order of the } \\
\text { interview, only used their } \\
\text { own photos }\end{array}$ \\
\hline Goldfinch & $\begin{array}{l}\text { Family then } \\
\text { individual }\end{array}$ & 3 months & open & $\begin{array}{l}\text { Everybody around for } \\
\text { individual interviews }\end{array}$ & $\begin{array}{l}\text { Parents making } \\
\text { comments }\end{array}$ & no & $\begin{array}{l}\text { Close family with no privacy, } \\
\text { expecting second child }\end{array}$ \\
\hline $\begin{array}{l}\text { Hoiho } \\
\text { (pilot) }\end{array}$ & $\begin{array}{l}\text { Family then } \\
\text { individual }\end{array}$ & 1 month & open & $\begin{array}{l}\text { Parents for children's } \\
\text { interviews }\end{array}$ & Children restless & no & $\begin{array}{l}\text { One son not feeling well, time } \\
\text { pressure }\end{array}$ \\
\hline Kakariki & $\begin{array}{l}\text { Family then } \\
\text { individual }\end{array}$ & $\begin{array}{l}1 \frac{1}{2} \\
\text { months }\end{array}$ & open & $\begin{array}{l}\text { Family around for } \\
\text { individual interviews }\end{array}$ & $\begin{array}{l}\text { Children shy, } \\
\text { parents making } \\
\text { comments }\end{array}$ & no & No real privacy \\
\hline Kea & $\begin{array}{l}\text { Family then } \\
\text { individual }\end{array}$ & $\begin{array}{l}21 / 2 \\
\text { months }\end{array}$ & closed & $\begin{array}{l}\text { Youngest daughter } \\
\text { (toddler) }\end{array}$ & $\begin{array}{l}\text { Children distracted } \\
\text { by younger sibling }\end{array}$ & yes & $\begin{array}{l}\text { People coming to the front } \\
\text { door }\end{array}$ \\
\hline Kereru & $\begin{array}{l}\text { Family then } \\
\text { individual }\end{array}$ & $\begin{array}{l}1 \frac{1}{2} \\
\text { months }\end{array}$ & open & $\begin{array}{l}\text { Family around for } \\
\text { individual interview } \\
\text { (having breakfast) }\end{array}$ & $\begin{array}{l}\text { Parents making } \\
\text { comments }\end{array}$ & yes & Phone call, no real privacy \\
\hline Pukeko & $\begin{array}{l}\text { Family then } \\
\text { individual }\end{array}$ & $\begin{array}{l}2 \frac{1}{2} \\
\text { months }\end{array}$ & open & $\begin{array}{l}\text { Parents in the kitchen } \\
\text { listening at times }\end{array}$ & $\begin{array}{l}\text { Parents making } \\
\text { comments }\end{array}$ & no & $\begin{array}{l}\text { One son not feeling well, also } \\
\text { used their own photos }\end{array}$ \\
\hline Takahe & $\begin{array}{l}\text { Individual then } \\
\text { family then } \\
\text { individual }\end{array}$ & 2 months & open & no & $\begin{array}{l}\text { Parents awaiting } \\
\text { arrival of their son }\end{array}$ & yes & $\begin{array}{l}\text { Son was found after some } \\
\text { phone calls, interrupted the } \\
\text { order of interviews }\end{array}$ \\
\hline Tui & $\begin{array}{l}\text { Family then } \\
\text { individual }\end{array}$ & $\begin{array}{l}21 / 2 \\
\text { months }\end{array}$ & open & no & Father taciturn & yes & $\begin{array}{l}\text { Phone call, mother and } \\
\text { daughter leaving, father } \\
\text { unaware of my arrival }\end{array}$ \\
\hline Weka & $\begin{array}{l}\text { Individual then } \\
\text { family then } \\
\text { individual }\end{array}$ & 2 months & open & $\begin{array}{l}\text { Real estate agents } \\
\text { and friends }\end{array}$ & $\begin{array}{l}\text { Parents somewhat } \\
\text { distracted }\end{array}$ & yes & $\begin{array}{l}\text { House just sold, changed the } \\
\text { order of the interviews }\end{array}$ \\
\hline
\end{tabular}




\subsubsection{Family interviews post-holiday (longer-term)}

Family interviews were scheduled within 7-10 months after the return from their holiday (Table 3.10) with the aim of establishing the social experiences and meanings family members derive from their holiday in the longer-term. A letter was sent out to the 10 families 1-2 months before the interviews were arranged as a reminder of this project, their possible scrapbooks and with instructions for each family member selecting a few photos (not necessarily their own) of memorable incidents to discuss with the rest of the family. The main reason to use the photographs at this phase was to stoke the memories and aid in the conversation. This interview phase was intended within 6-8 months after their family holiday but outside circumstances extended this research period. Most notable was one family having moved over $500 \mathrm{~km}$ away, which required extra funding and planning to visit them. Another family was on an extended overseas holiday, some family members were sick, and other families were extremely busy with work and sport commitments making it difficult to find a time with all family members present. For these reasons this phase of the research took longer than anticipated.

A property dispute was preoccupying the pilot family which meant that their willingness to participate in this research was dampened. The interview still went ahead but with some time pressure put onto me which resulted in less probing than anticipated. The pilot, nevertheless, helped in streamlining the questions and eliminating repetition between the family and the individual interviews while maintaining a collective and individual perspective on the major themes. While all 10 participating families were retained for this final round of interviewing, two family members were absent. One teenager was asleep at the time of interview and it was decided by the parents not to disturb him. In another family, the youngest child played up and his family decided that this behaviour did not merit his participation.

Retaining all 10 families despite several complications meant a strong commitment on behalf of the families but also highlights the importance of allowing sufficient and flexible time for scheduling of the interviews. As a researcher I had to fit my time and prospects around the busyness and tribulations 
of contemporary family life and with that came some concessions. As a result, managing to get 10 entire families to participate three times over the time span of nearly one year can be fraught with difficulty and might partly explain why families, fathers, and children are so little represented in tourism research.

The final interview (see Appendix E) with the whole family focused on their last summer holiday, even though they may have taken a holiday since, which was represented through their photographs and possible scrapbooks. Most families relied on the photographs from the disposable cameras although other photographs were allowed. Only two families also had other photographs available and two families had no photographs due to disorganisation (Table 3.10). In a digital age most families had no hard copies of their own photographs but only images on the computer, which made the use of the developed prints from the disposable cameras even more valuable for this project. As an icebreaker a question was posed regarding what everyone remembered positively and negatively about the summer holiday, also prompted by the photographs, which was useful in collectively stoking their memories. The themes from the first two rounds of interviewing were then further refined to ask questions regarding the social aspects of togetherness and (re)connecting with people as well as the constraints of this. Also, questions were asked that allowed comparisons between everyday and holiday routines to get at the theme of change of routine (Table 3.11). Other questions that came out of the second round of interviewing focused on creating memories and generativity. The next set of questions linked the anticipations over time and compared them not only with future holidays but also with other holidays in the meantime. This connected anticipations to the actual meanings derived from the holiday experiences including overseas holidays.

The individual interview followed on from the collective interview with a focus on the personal perspectives of the themes. The photos remained available for the participants to discuss. The questions refined the theme of relaxation and whether there are generational or gender differences to own time, and compared with family time. They then took on themes that arose from the second round of interviewing (see Table 3.11) regarding the importance of couple time, children time, and generativity along with compromises made by both parents and 
Table 3.10 Research reflections on family interviews post-holiday (longer-term) (August-November 2007)

\begin{tabular}{|c|c|c|c|c|c|c|c|}
\hline $\begin{array}{c}\text { Family } \\
\text { name }\end{array}$ & $\begin{array}{l}\text { Interview } \\
\text { order }\end{array}$ & $\begin{array}{c}\text { Time post } \\
\text { holiday }\end{array}$ & Space & $\begin{array}{c}\text { Other persons } \\
\text { present }\end{array}$ & $\begin{array}{l}\text { Behaviour of } \\
\text { participants }\end{array}$ & $\begin{array}{l}\text { Inter- } \\
\text { ruption }\end{array}$ & Comments \\
\hline Fantail & $\begin{array}{l}\text { Family then } \\
\text { individual }\end{array}$ & 8 months & open & no & $\begin{array}{l}\text { Very supportive, } \\
\text { relaxed }\end{array}$ & no & Had some of their own photos \\
\hline Goldfinch & $\begin{array}{l}\text { Family then } \\
\text { individual }\end{array}$ & 10 months & open & $\begin{array}{l}\text { Baby around and cared } \\
\text { for. Family around for } \\
\text { individual interviews }\end{array}$ & $\begin{array}{l}\text { Parents listening and } \\
\text { making comments, } \\
\text { supportive, relaxed }\end{array}$ & yes & $\begin{array}{l}\text { Family moved away from } \\
\text { Wellington, had a baby in the } \\
\text { mean-time. Holiday influenced } \\
\text { the move. Used own photos }\end{array}$ \\
\hline $\begin{array}{l}\text { Hoiho } \\
\text { (pilot) }\end{array}$ & $\begin{array}{l}\text { Family then } \\
\text { individual }\end{array}$ & $\begin{array}{l}61 / 2 \\
\text { months }\end{array}$ & open & $\begin{array}{l}\text { Parents for children's } \\
\text { interviews }\end{array}$ & $\begin{array}{l}\text { Children restless, } \\
\text { father controlling, } \\
\text { mother supportive }\end{array}$ & no & $\begin{array}{l}\text { Some time pressure, reluctance by } \\
\text { one son and father to take part, } \\
\text { outside stresses on family }\end{array}$ \\
\hline Kakariki & $\begin{array}{l}\text { Family then } \\
\text { individual }\end{array}$ & 8 months & open & $\begin{array}{l}\text { Family around for } \\
\text { individual interviews }\end{array}$ & $\begin{array}{l}\text { Children no longer as } \\
\text { shy, supportive, } \\
\text { relaxed }\end{array}$ & no & No real privacy \\
\hline Kea & $\begin{array}{l}\text { Family then } \\
\text { individual }\end{array}$ & 8 months & closed & no & $\begin{array}{l}\text { Very supportive, } \\
\text { relaxed }\end{array}$ & no & Youngest daughter asleep \\
\hline Kereru & $\begin{array}{l}\text { Family then } \\
\text { individual }\end{array}$ & 8 months & open & $\begin{array}{l}\text { Family around for } \\
\text { Individual interview }\end{array}$ & Supportive, relaxed & no & $\begin{array}{l}\text { No real privacy, oldest son } \\
\text { (teenager) asleep and not } \\
\text { participating }\end{array}$ \\
\hline Pukeko & $\begin{array}{l}\text { Family then } \\
\text { individual }\end{array}$ & $9 \frac{1}{2}$ months & open & $\begin{array}{l}\text { Some coming and } \\
\text { going with family }\end{array}$ & Supportive, relaxed & no & $\begin{array}{l}\text { Family very busy, photos could } \\
\text { not be found }\end{array}$ \\
\hline Takahe & $\begin{array}{l}\text { Individual then } \\
\text { family then } \\
\text { individual }\end{array}$ & 8 months & open & no & $\begin{array}{l}\text { Very supportive, } \\
\text { relaxed }\end{array}$ & yes & $\begin{array}{l}\text { Son was with friends and needed } \\
\text { to be collected, interrupted the } \\
\text { order of interviews }\end{array}$ \\
\hline Tui & $\begin{array}{l}\text { Family then } \\
\text { individual }\end{array}$ & $\begin{array}{l}91 / 2 \\
\text { months }\end{array}$ & open & Youngest son & $\begin{array}{l}\text { Relaxed but not } \\
\text { overly talkative apart } \\
\text { from mother }\end{array}$ & no & $\begin{array}{l}\text { Youngest son played up and } \\
\text { ended up not participating }\end{array}$ \\
\hline Weka & $\begin{array}{l}\text { Family then } \\
\text { individual }\end{array}$ & 9 months & open & $\begin{array}{l}\text { Girls playing in the } \\
\text { background }\end{array}$ & Supportive, relaxed & no & $\begin{array}{l}\text { Family moved house, still } \\
\text { unorganised and photos not found }\end{array}$ \\
\hline
\end{tabular}


children. For that the individual questions were split into separate questions for parents and children to get at generational and gender differences with respect to group dynamics. The questions on memories and meanings allowed comparisons of longer-term reflections with short-term recollection and elucidated the importance of the collective dimension compared with the individual dimension. The next questions elaborated on individual comparisons of everyday life with other holidays. The last set of questions compared personal anticipations over time to track any changes and refine the social theme of family holidays. With that, all the different themes that came out of the different phases of research (Table 3.11) were followed up from an individual and collective perspective resulting in theoretical saturation. The processes of the GTM used for this research are explained after the analytical frameworks are presented next.

\subsection{ANALYTICAL FRAMEWORK}

The analytical framework followed from the conceptual framework and methodological framework in that the whole family experiential dimension is embedded in the family holiday behaviours through the iterative research design (Figures 3.2 and 3.3). The analytical framework for family holiday behaviours combines the parental perspective from the survey with the familial perspective from the family interviews to result in a family holiday definition. It marries the analysis from the closed and open survey questions with the broader experiential dimensions by developing themes through the GTM (as discussed in the next section; Table 3.11) that feed back into the definition, as indicated by the double arrows (Figure 3.2). The complexity and importance of the whole family experiential dimensions within the analytical framework is elaborated on in Figure 3.3. It combines the multiple perspectives of generation, gender, and group dynamics with three stages of time (pre-, on-, and post-holiday) and the two dominant themes of family time and own time that resulted from the GTM process. Together these form a cube with three axes: perspectives, temporality, and themes which are addressed in turn; 
- The three perspectives of generation, gender and group dynamics were developed from the literature as a new approach to family tourism research that encapsulates the social dimension (Figure 2.4, conceptual framework).

- The three temporal stages are pre-, on-, and post-holiday capturing the family holiday as a longitudinal process (Figure 3.1, methodological framework). It is based on the anticipation of experiences from the first two phases of research (survey and pre-interviews), the actual holiday experiences as captured by the photographs and scrapbooks, and the recollection of experiences from the two phases of research after the holiday (post- and final interviews). The temporal dimension corresponds with the stages of a family holiday rather than the different phases of data collection (Table 3.2).

- Two overarching themes (family time and own time) and their sub-themes (see Figure 4.7, theoretical framework) emerged through theoretical saturation as a result of the GTM (see next section). The main point is that in family time one is connected to family while in own time one seeks freedom from commitments.

The frameworks, thus, operate along multiple perspectives, and a temporal and experiential dimension while incorporating the fundamental tensions between individual and collective demands and interests. The data are presented in the following chapters along the definitional elements and dominant themes.

\subsubsection{ANALYSIS OF PHASES THROUGH THE GTM}

The approach to grounded theory taken here is built upon a constructivist grounded theory (see section 3.3.1), as advocated by Charmaz (2000, 2002), which defines what is happening in the data, rather than discovers it. This calls for intimate familiarity with respondents and their world, thus seeking meaning rather than an objective truth (Charmaz, 2000). As a result, $a$ world is made real, rather than the world, which is situated in the thoughts, the language, and the actions of the participants. It acknowledges that GTM is an emergent and iterative process that requires the researcher's interaction within the field and the data. Instead of 'truth' and 'validity', Jamal \& Hollinshead (2001) propose the alternative 
Figure 3.2 Analytical framework for family holiday behaviours

\begin{tabular}{|c|}
\hline Parental perspective on \\
family holiday behaviour \\
(Survey) \\
$-\quad$ Travel patterns \\
$-\quad$ Motivations \\
\hline
\end{tabular}
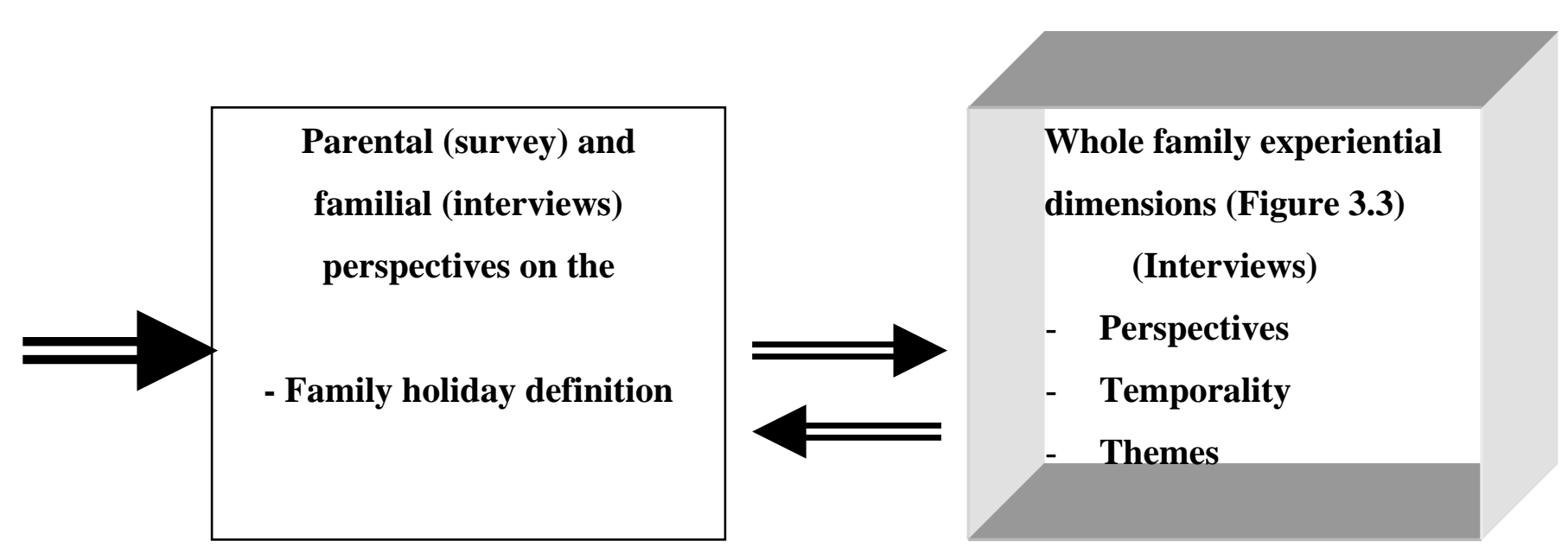
Figure 3.3 Analytical framework for whole-family experiential dimensions

THEMES

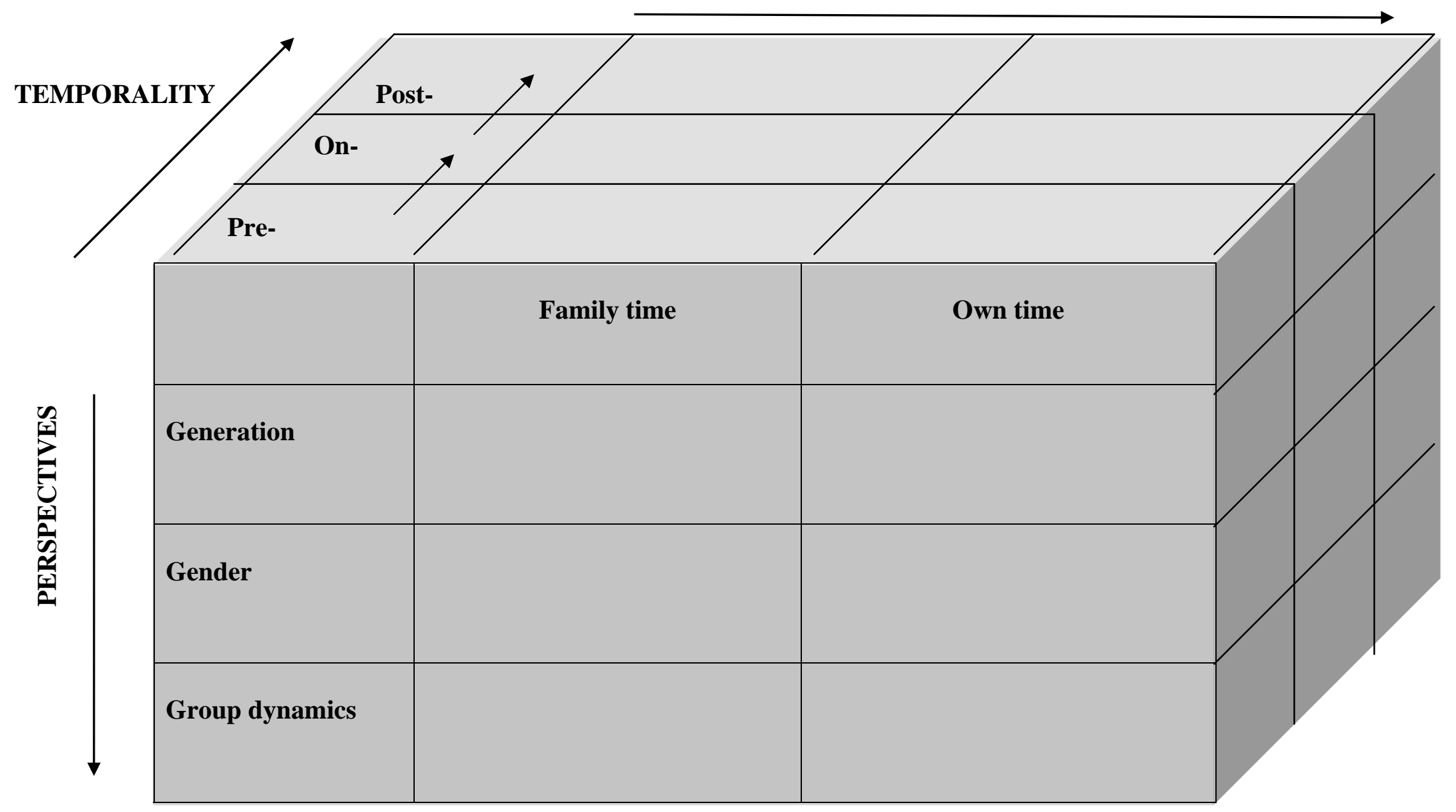


Table 3.11 Development of interview questions regarding themes through the research phases using the GTM

\begin{tabular}{|c|c|c|c|c|c|c|c|c|c|}
\hline Themes & $\begin{array}{l}\text { VFR/ } \\
\text { (re)connect- } \\
\text { ing }\end{array}$ & $\begin{array}{l}\text { Holiday } \\
\text { at home }\end{array}$ & $\begin{array}{l}\text { Fun/ } \\
\text { enter- } \\
\text { tainment }\end{array}$ & $\begin{array}{l}\text { Change } \\
\text { (difference) } \\
\text { to normal } \\
\text { routine }\end{array}$ & $\begin{array}{l}\text { Relaxation } \\
\text { / } \\
\text { Own time }\end{array}$ & $\begin{array}{l}\text { Together- } \\
\text { ness/ } \\
\text { Family } \\
\text { time }\end{array}$ & $\begin{array}{l}\text { Couple } \\
\text { time/ } \\
\text { Children } \\
\text { time }\end{array}$ & $\begin{array}{l}\text { Constraints/ } \\
\text { conflicts/ } \\
\text { compromise }\end{array}$ & $\begin{array}{l}\text { Creating } \\
\text { memories/ } \\
\text { generativity }\end{array}$ \\
\hline $\begin{array}{l}\text { Phase } 1 \\
\text { Survey (closed } \\
\text { questions) }\end{array}$ & $\sqrt{ } *$ & $\sqrt{ }$ & $X$ & $X$ & $X$ & $X$ & $X$ & $X$ & $X$ \\
\hline $\begin{array}{l}\text { Phase } 1 \\
\text { Analysis (open \& } \\
\text { closed questions) }\end{array}$ & $\sqrt{ }$ & $\sqrt{ }$ & $X$ & $\sqrt{ }$ & $\sqrt{ }$ & $\sqrt{ }$ & $X$ & $X$ & $X$ \\
\hline $\begin{array}{l}\text { Phase } 2 \\
\text { interview } \\
\text { questions }\end{array}$ & $\sqrt{ }$ & $\sqrt{ }$ & $X$ & $\sqrt{ }$ & $\sqrt{ }$ & $\sqrt{ }$ & $X$ & $X$ & $X$ \\
\hline $\begin{array}{l}\text { Phase } 2 \\
\text { Analysis }\end{array}$ & $\sqrt{ }$ & $X$ & $\sqrt{ }$ & $\sqrt{ }$ & $\sqrt{ }$ & $\sqrt{ }$ & $X$ & $X$ & $X$ \\
\hline $\begin{array}{l}\text { Phase } 3 \\
\text { interview } \\
\text { questions }\end{array}$ & $\sqrt{ }$ & $X$ & $\sqrt{ }$ & $\sqrt{ }$ & $\sqrt{ }$ & $\sqrt{ }$ & $X$ & $X$ & $X$ \\
\hline $\begin{array}{l}\text { Phase } 3 \\
\text { Analysis }\end{array}$ & $\sqrt{ }$ & $X$ & $\sqrt{ }$ & $\sqrt{ }$ & $\sqrt{ }$ & $\sqrt{ }$ & $\sqrt{ }$ & $\sqrt{ }$ & $\sqrt{ }$ \\
\hline $\begin{array}{l}\text { Phase } 4 \\
\text { interview } \\
\text { questions }\end{array}$ & $\sqrt{ }$ & $X$ & $\sqrt{ }$ & $\sqrt{ }$ & $\sqrt{ }$ & $\sqrt{ }$ & $\sqrt{ }$ & $\sqrt{ }$ & $\sqrt{ }$ \\
\hline $\begin{array}{l}\text { Phase } 4 \\
\text { Analysis }\end{array}$ & $\sqrt{ }$ & $X$ & $\sqrt{ }$ & $\sqrt{ }$ & $\sqrt{ }$ & $\sqrt{ }$ & $\sqrt{ }$ & $\sqrt{ }$ & $\sqrt{ }$ \\
\hline $\begin{array}{l}\text { Comparative } \\
\text { analysis }\end{array}$ & $\sqrt{ }$ & $\sqrt{ }$ & $\sqrt{ }$ & $\sqrt{ }$ & $\sqrt{ }$ & $\sqrt{ }$ & $\sqrt{ }$ & $\sqrt{ }$ & $\sqrt{ }$ \\
\hline
\end{tabular}

* $\sqrt{ }$ theme present; $X$ theme not present 
measures of transparency and reflexivity for fifth moment qualitative research. For this reason, details are provided here on how emerging themes necessitated a change in interview strategies in each phase of analysis while also mapping the influence of literature to the development of theoretical concepts (see Draucker et al., 2007). The temporal and conceptual development of the main theoretical themes to emerge through the GTM is explained here to provide transparency to the analytical process. Reflexivity will be elaborated on in the next section.

Central features of the GTM include the method of theoretical sensitivity, theoretical sampling, constant comparative analysis, and theoretical saturation (Glaser \& Strauss, 1967). Theoretical sensitivity draws upon a wide range of literature also outside the field of study to inform the analytical encounter with the data (Dey, 2004; Glaser, 1987). This was acquired by conducting an extensive literature review that encompassed the wider family literature which led to the conceptual and methodological framing of this research. The analysis of data also happened alongside emerging tourism literature rather than just resulting from it (see section 2.6.3).

Theoretical sampling, the process of data collection directed by evolving theory, is preceded by selective sampling. Selective sampling is the identification of populations and settings prior to data collection, which in this study was the survey distributed through five schools and resulting in 110 parental responses. These data was entered into SPSS and frequencies, percentages, cross-tabulations, and comparisons of means were conducted in line with the smaller sample size. For this the quantitative data were broken into categories (e.g., accommodation type) which allowed comparisons between the different holidays (e.g., past and upcoming travel) and resulted in summary tables (see Table 4.1) and graphs (see section 4.2) which informed the family holiday definition.

The survey also contained open-ended data on motivations and family holiday characteristics which was manually coded before being entered on SPSS alongside the other quantitative data. For example, one respondent's motivations: "time with children; break from routine - everyone can relax" were coded for the three themes of 'time together', 'break away', and 'relaxation' which resulted in a 
variety of 15 motivations emerging for family travel. Another example is for one respondent's family holiday definition: "One where all members of the family spend time together doing things other than they would normally do - usually away from home" was coded for the three characteristics of "time together/whole family', 'different activities', and 'away/break from home'. This resulted in a variety of 10 different characteristics to a family holiday definition. Thus, coding according to the GTM occurred before SPSS was used as a quantification tool rather than an analytical tool. This allowed the codes emerging from the survey to be counted to create a definition of family holidays based on prevalence and to present them in graphs (see Figures 4.4 and 4.5). The resulting main themes then informed the first interview schedule and linked the open and closed questions in the survey to the interviews with the 10 families. These initial themes were then tracked over time and further refined in the three interview phases concurrent with the analysis phases (Table 3.11).

The data collected via selective sampling refers to a tentative categorisation from which to begin theory development (Draucker et al., 2007). Sampling was sequential beginning with selective sampling and moving into theoretical sampling when themes began to emerge, such as the theme of togetherness that emerged in the survey and then evolved in the interview phases. Theoretical sampling was used by modifying interview schedules to gain specific information regarding an emerging theme as the study progressed. For example, fun emerged as a theme in phase 2 analysis and was followed up in the subsequent interview phases. Table 3.11 illustrates how interview schedules were modified and demonstrates how additional questioning increased the complexity of the analysis.

Theoretical sampling is closely tied to grounded theory coding which is based on at least a two-step process: (a) initial or open coding, and (b) selective or focused coding. For example, the initial coding of time with non-family became part of the main theme of own time. Through the process of constant comparison analysis, the concurrent collection and analysis of data informing the next phase, these initial codes were collapsed into core themes and integration of the theoretical framework was achieved. This means that coding progressively distils events and meanings without losing their essential properties (Charmaz, 2002). The third step 
of coding as introduced by Strauss \& Corbin (1990), axial coding, was deemed unnecessary because it adds complexity with little benefit to the analysis (see Charmaz, 2000; Glaser, 1992). Theoretical saturation is presumed to be achieved when new data fit into the themes already devised (Morse, 1995). In practice, saturation tends to be an elastic category that contracts and expands to suit the researcher's definitions rather than any consensual standard (Charmaz, 2002). After the comparative analysis of the four phases of research was completed, all the data fitted into the theoretical framework (see Figure 4.7) and theoretical saturation was deemed achieved.

Analysis was based on verbatim transcriptions by me of the 148 recorded interviews. The coding process was carried out manually in that data were initially coded by reading through the transcripts several times while making notes on a large piece of paper which was then sorted into themes and integrated into a theoretical framework. According to Lincoln (1998) in Charmaz (2000), part of interpretive work is gaining a sense of the whole body of data, all interviews and all stories. For this it was necessary to have the data organised initially by the different phases and then by family while simultaneously planning to assemble the parts in the form of themes. Only after the core themes were established was selective coding applied using the computer program NVivo 8. This program proved especially helpful with managing the volume of data. Other advantages of computer coding included the ability to do multiple searches using more than one code/theme simultaneously and according to the perspectives (e.g., generation). The code and retrieve method supports the emergence of theory by searching the data for specific codes/themes or attributes and assembling ideas (see Charmaz, 2002). The management of the parts in NVivo was, thus, superseded by nuanced manual interpretive analysis which signifies a more holistic approach to the GTM.

The analysis can be illustrated using an example of one initial theme: VFR (Figure 3.4). In phase 1 survey VFR was included in the form of closed and open ended questions. Phase 1 analysis encompassed the quantitative data on VFR and the qualitative coding of time with friends and relatives for every participant mentioning friends or relatives (definition and motivation) including visiting or spending time with extended family (see sections 4.2 and 4.3). After entering the 
codes in SPSS and comparing their frequencies with other codes it became a theme. This theme of importance of friends and relatives was included in phases 2-4 of interview questions after it continued to be relevant in the analysis phases (Table 3.11). Larsen et al.'s (2007) work helped the naming of this theme in phase 3 of analysis into time for (re)connecting and social obligation. The comparative analysis allowed these themes to be increasingly refined over the different phases and led to social support emerging as an additional theme from the data which was absent in the literature. These themes were then collapsed and integrated into the sub-theme of social connectedness/VFR which is part of the main theme of family time (see Figure 4.7). This also contributed to the development of the subtheme of cooperation which is part of the internal dynamics. It became apparent that these themes transcend the temporal dimension of the phased approach.

Through the longitudinal approach different themes emerged that did not correspond with the phases of methodology but instead had an all encompassing presence like change of routine and relaxation. This meant that the temporal element was not as strong in the analysis because family holidays were part of a familiar routine or tradition (see section 6.7). Themes emerged in the analysis that were then taken up in the modified interview schedules (Table 3.11). While some themes were named after literature that was emerging at the time, e.g., generativity (Shaw et al., 2008), most themes were named by the participants (e.g., the two main themes) or directly emerging from the data (e.g., peer time).

The comparative analysis of all four phases of research resulted in collapsing of the initial themes into core themes and integration into the theoretical framework (see Figure 4.7). This meant a reorganisation of the themes into family time, own time, and internal dynamics, development and naming of new sub-themes such as cooperation as well as refinement of existing sub-themes such as change of routine. Thus, the presentation of the data in the findings chapters is now organised along the main themes and sub-themes (see section 4.5). The thematic or theoretical framework that resulted from the iterative grounded theory process of refining, extending, challenging or superseding the extant concepts is then used to illustrate key findings regarding the different generational, gender and group dynamic perspectives in chapter 7 . 
Figure 3.4 Illustration of the development of initial theme VFR through the GTM

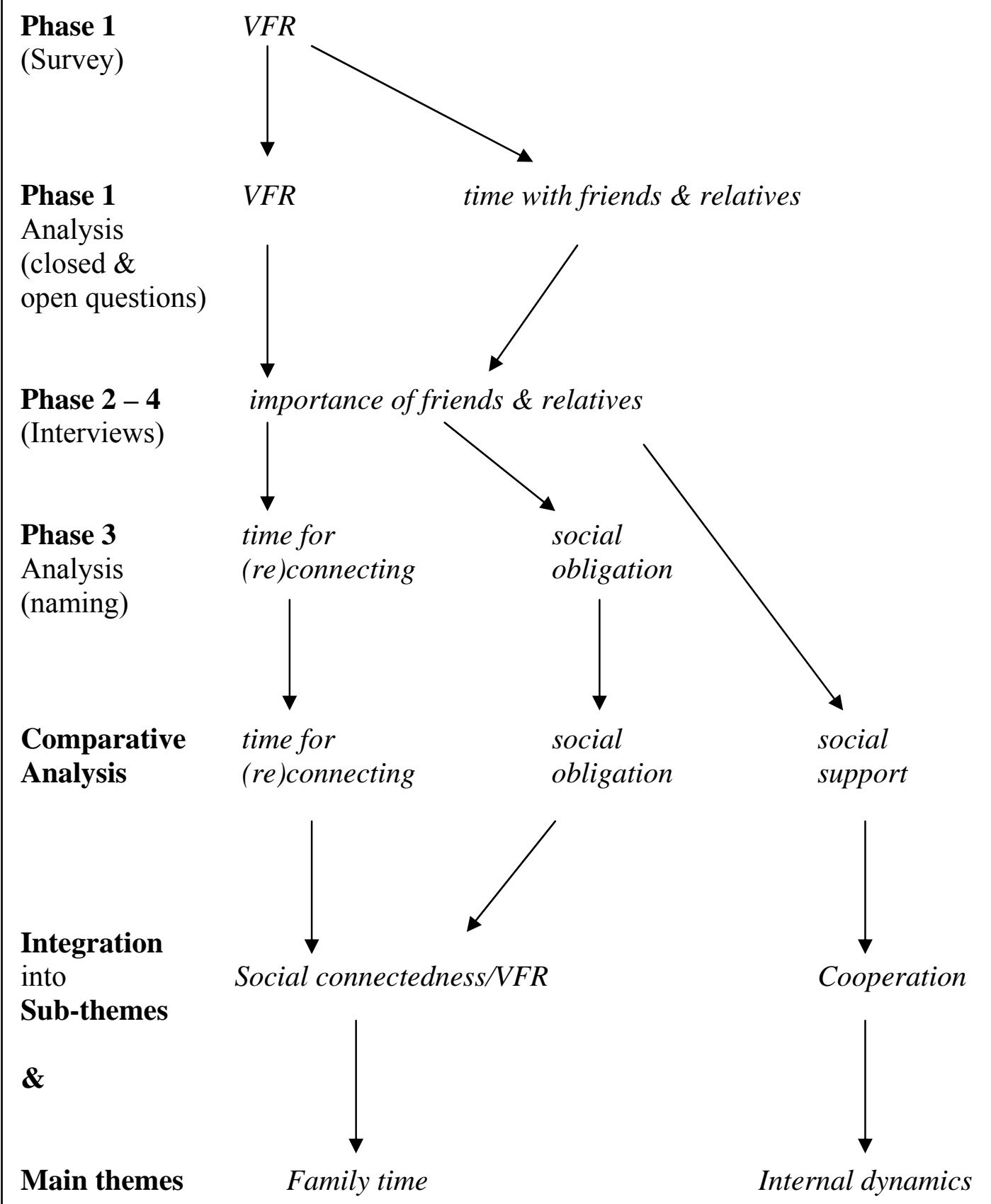


The model in Figure 7.1 presents a summary of the main findings based on the holiday experiences of the whole family or the group perspective. The Figures 7.3-7.5 present findings based on family holiday experiences from generational perspectives (children and parents) and gender perspectives (mothers, fathers, girls and boys). Thus, those figures provide an application of the theoretical framework (Figure 4.7) with regards to the different perspectives and represent theoretical outcomes or models according to gender, generation and group dynamics. The naming of the concepts in Figure 7.1 and 7.3-7.5 arose directly from the themes articulated in chapters 5 and 6 as well as by referring back to the literature in chapter 7 . When a concept existed in the literature such as social capital (Bourdieu, 1984) or purposiveness (Shaw \& Dawson, 2001) for what was intrinsically in the data than the theme was named accordingly to allow for a more theoretical interpretation of the findings.

Regarding the presentation of the data in the findings chapters, selected quotations are used to illustrate key points. Because of the nature of the family interviews longer exchanges are included to demonstrate interactions and family dynamics. The different travel and family characteristics (see section 3.5.2) make each family relevant for at least some themes and provide an overall balance in the discussion of themes. Yet, every theme is not discussed for each family as the GTM is about multiple realities that can highlight differences rather than a single reality that applies to all families. Selected photos are used as illustrations of the quotations and when integral to the interviews as intended by the APE technique (see section 3.4.2). Specific consent was obtained from families for inclusion of the photos in the thesis as family members can be identifiable to readers who already know them. In order to protect the family names when reporting the data, New Zealand bird names were given (Tables 3.5 and 3.6) alongside their positioning in the family, e.g., Kea mum and Kea girl 1 (eldest daughter). The age of the children is given when first recruited. When personalised data are used in the quotations, the relation to that person is given, e.g., <wife>. For methodological reasons, indication is given if the data are from the family group or individual interview along with the temporal element (pre-, post-, and final). The discussion now provides further transparency to qualitative research. 


\subsubsection{EVALUATION AND REFLEXIVITY}

In order to increase the integrity and trustworthiness of qualitative research it is necessary for researchers to evaluate how intersubjective elements influence data collection and analysis (Finlay, 2002). In being reflexive, I become the bricoleur who understands that research is an interactive process between myself and the participants requiring a process of 'getting entangled' in different forces and constraints (Ateljevic et al., 2005). Ultimately, research is seen as a dynamic, unpredictable, and often messy process (see section 3.2), making this section part of fourth moment research. My subjectivity is situated in my biography: a white, middle-class, immigrant, Western woman and mother, with a background in European family holidaying along with holidays with my own children in New Zealand who ended up studying white, middle-class, nuclear families and their holiday behaviours. My own situatedness is both a strength and limitation for this research. On the one hand, the relative homogeneity of the families made them more comparable and easier for me to connect with them; on the other hand, it left out non-European and non-nuclear families which made the study less diverse. My upbringing in Europe also means I did not grow up with New Zealand family holiday traditions, although I am developing these with my own children.

There are tribulations and constraints when doing longitudinal family research that involves a multi-method approach. It meant, first, the combination of positivistic and interpretive approaches and, second, getting access to entire families. The most valuable result to come out of the survey was the qualitative content, but getting initial access through schools and reaching parents was taxing along with the way relationships between variables were mainly quantified rather than explained. While the linking of quantitative and qualitative methods is part of third moment research it required me to combine different ways of thinking. The survey proved effective in providing background information to family holiday behaviours, but my primary incentive as a qualitative researcher was to find the stories behind the numbers. Getting permission to interact with families proved the most challenging part of the research, but sharing their stories was the most rewarding. 
The other difficulty was reaching families in their homes and maintaining contact with them, as they were generally very busy (see section 2.3.1) and also mobile (two families moved house). I found calling families to arrange dates challenging, as potentially any time was inconvenient and some parents sounded stressed. I resorted in the last interview phase to contacting parents via email which proved a less intrusive way of communicating with families. During interviews at their homes, normal family life continued despite my presence, such as phone calls and visitors arriving (Tables 3.8-3.10). This required flexibility in the research process, such as conducting interviews over dinner and waiting for teenagers to arrive. Also, the open-plan layout in modern housing combined with the fluidity of living arrangements made privacy for the individual interviews virtually impossible. I had to follow the lead of the participants in choosing an interview space they felt comfortable with, which usually was the kitchen/dining table. This meant that other family members could listen and make comments during individual interviews at times. It has been suggested with regards to teenagers to explicitly ask parents to stay out of the common room during the interview (Bassett et al., 2008), but because of the age span of the children I did not feel comfortable doing so. This would have raised ethical issues regarding child safety. It did, however, put me in a position of compliance with their family lives rather than being able to follow my research script.

Furthermore, I need to acknowledge that my own gendered experience as a mother made me an insider with regards to family dealings and relating to parents. I started the interview process by introducing my own family through family holiday photographs. As a result, mutual understanding and shared identities were usually implied especially with the mothers. Most family interviews finished with informal conversations about schools and other concerns related to children. Gender studies have regarded interviews as a positive way for women to tell their own stories (Puwar, 1997), which was the case here. However, I have to wonder whether societal expectations of family holidays and the prevalence of an ethic-ofcare for mothers (see section 2.6.3) had an influence on their responses. With regards to researching fathers, there is the possibility that my position as a mother and the ideology of involvement (see section 2.6.3) influenced their responses, a point also raised by Lareau (2000). It would be interesting for future tourism 
research into fathers to have male interviewers conducting the research, as no real comparisons are available yet. Instead, it could be argued that an ethics-of-care approach rooted in social contexts, as identified by Gilligan (1982), is dominating family concerns, which might have underplayed a more individualistic, male approach. With regards to the children, I think being a mother made it easier for younger children to relate to me, but with older children an outsider perspective might have been preferable. This relates to the fact that children increasingly with age draw away from their parents and external interests take over; being a parent might then no longer be an advantage.

Interviewing children proved a challenge at times as some younger children were shy and not forthcoming, but interviewing over three rounds was successful in that it built up their rapport with me (Tables 3.8-3.10). There were noticeable gender differences in that most girls were verbally more assertive than the boys (see Stafford et al., 2003), but this was compensated in boys making more succinct comments at times. Overall, it was less the gender of the child than their age that affected their contribution. I found a good age range was 8-12 years with younger children often shy and teenagers sometimes becoming self-conscious and less willing to speak their mind. The photographs from the disposable cameras worked well in engaging all the children as they could relate to them. Also, providing rewards like a box of 'goodies' worked well for the younger children while a different prize would have been preferable for the teenagers.

In general, it was difficult catering to a 10-year age range between the children in language comprehension (regarding the questions posed), attention spans (regarding the family interviews), and engagement with the topic. This meant that the questions had to be rephrased and simplified at times, some abstract concepts such as relaxation were lost to younger children, and some children grew restless at the end of the family interview. I had to strike a balance between keeping it simple and everyone engaged while covering the main themes and encouraging thoughtful answers. It was interesting to see the different family forms within the context of this research, with some families being quite close and controlling and others more open and independent, reflecting Olsen's Circumplex Model (Olsen \& Gorall, 2003) (see section 2.3.1). Families with traits of the former tended to 
have the parents around for the individual children interviews, which might have inhibited the children's individual contributions.

While finding time to schedule interviews was difficult, once I was at their home the families were generous with their time and interested in the topic. This led to situations where it became difficult to find the right moment to leave. In many ways, I was a guest in their home and treated with all the courtesy awarded to visitors. I was offered drinks and food which I always accepted as sharing them is a way of making visitors comfortable. This also enabled me to have a sip of a drink while waiting for interview answers and break any uncomfortable silence. I became an observer of family habits which provided me with a snapshot into their lives. The use of the family home as a research site, thus, reflects how everyday family life plays out and can be in contrast to this study of holiday experiences. It also means that I entered and was affected by the families' worlds, which is in line with the constructivist GTM taken (see Charmaz, 2002). Overall, maintaining interviews with 10 families over three rounds despite some obstacles ensured that theoretical saturation was achieved and that the data is comparable.

\subsection{CONCLUSION}

The methodology used for this study developed from the conceptual framework which introduced gender, generation, group dynamics, and a more holistic approach to research. It is about addressing gaps in tourism research by, first, finding out more about New Zealand families' holiday behaviour through a parental survey and, second, through longitudinal whole-family interviewing which is inclusive of all family members' voices. Placing the project within the interpretive paradigm and five moments of research allowed for the linking of quantitative with qualitative methods, the initiation of whole-family studies to tourism, and the novel use of APE with regards to children on holiday. This made for a more inclusive, critical, and original study. It also allowed me to acknowledge my situatedness as a woman, mother, and New Zealand European.

This research was based, initially, on 110 individual parents, from which 10 families (20 parents and 20 children) elected to participate in three phases of 
whole-family interviewing. This resulted in 140 participants contributing to this research. While the survey aimed for a diversity of families through distribution in schools with a range of decile rankings, the families for the interview phases ended up more homogenous for conceptual and methodological reasons but also as a result of the response rate. This means that the strength of this research is the relative comparability of the interviewed families and the inclusion of the fathers, children, and whole family group perspectives. It also means that the sample did not include a range of families that more accurately reflects New Zealand's multicultural society. Studying the holidays of a more diverse array of families is beyond the scope of this thesis and will have to be the focus of future research.

The analytical process of using the GTM resulted in the theoretical framework with its two overarching themes that govern the remaining chapters. The theme of family time signifies a continuation of the social dimension presented in the literature and the methodology of whole-family interviews used, whereas the theme of own time corresponds to the more individualistic elements in the literature and research methods represented by the individual interviews. The remaining five chapters discuss the findings from the study. Chapter 4 presents the development of a definition of family holidays that began with the survey and then continued with the whole-family interviews, thus, amalgamating the individual and social group elements of this research. The next chapter also presents an overview of the main and contextual themes which emerged through the GTM. The findings, therefore, follow the process of the methods and analytical frameworks used by discussing the parental survey first before adopting a more holistic and experiential approach and including the perspectives and meanings of all family members. 


\section{CHAPTER 4: $\quad$ DEFINING THE FAMILY HOLIDAY: BACKGROUND AND THEMES}

\subsection{INTRODUCTION}

This chapter links the parental survey with the whole-family interviews by establishing what family holiday behaviours and the key themes associated with them are. It combines the parental perspective from the survey used for background with the familial perspective from the interviews to first, establish a definition of family holidays (see Figure 3.2) and second, outline the key themes and contextual factors resulting from this process. In order to establish a family holiday definition, travel patterns, motivations, and definitional characteristics based on the parental surveys are discussed before they are combined with some key themes from the whole-family interviews. This establishes a definition of family holidays that encapsulates the notions of togetherness, purpose, change of routine, fun, length, balance, individual pursuits, compromise, and conflict. This chapter further discusses contextual factors that are more peripheral to this study and presents an overview of the key themes that resulted from the GTM process. It outlines themes according to time spent together as a family and time away from family commitments, including the resulting internal dynamics between these two overarching notions of time (see Figure 4.7). The survey, as discussed here, provides background to family holiday behaviours and a parental perspective on a definition of family holidays which informed the development of the key themes in the whole-family interviews. Thus, apart from presenting the results from the survey and establishing a definition of family holidays based on the perspectives of all family members, this chapter introduces the main contextual factors and key themes as related to the family holiday behaviours. It, therefore, provides a New Zealand context for this study before discussing the findings from the whole family experiential dimensions in the remaining chapters.

\subsection{BACKGROUND TO FAMILY HOLIDAY BEHAVIOUR}

This section discusses travel patterns of New Zealand families and motivations for family holidays based on the parental survey distributed through five primary 
schools in the Wellington region before the summer holiday of 2006/7. See section 3.5.1 for details on the survey and the 110 participants. The respondents were mainly mothers (81\%), with high household incomes (59\% with \$80,001+), were from two parent/guardian households (94\%) and NZ European (86\%) (Table 3.4), reflecting a socio-economic group of families with children at higher decile schools but not necessarily representative of New Zealand's diverse society. The analysis provides a snapshot of past and upcoming holiday patterns of New Zealand families and parental perspectives on motivations for family holidaying. It presents a context for this study and contributes to a working definition of family holidays.

\subsubsection{FAMILY TRAVEL PATTERNS}

The survey collected behavioural data which presents a snapshot of family holiday activities by these 110 New Zealand families. It compared past holiday behaviour and main past family holiday characteristics with upcoming holiday behaviour. Of the respondents, $88 \%$ had been on a family holiday in the previous year with the majority (62.5\% of respondents) having had their main holiday in New Zealand. When surveyed in December 2006, 82\% of families had already decided to go on a holiday in the forthcoming summer with the vast majority (79\%) planning to travel in New Zealand with the rest travelling overseas (3\%). Table 4.1 presents the main travel patterns for the previous year, the main past holiday, and the next summer holiday. The holidays will be discussed in that order, then the main findings are compared and summarised.

\section{Family travel patterns in the previous year}

In the past year, $28 \%$ of respondents had one domestic holiday while $15 \%$ had four or more domestic holidays (Table 4.1). This means that for the majority of respondents who take multiple annual holidays there can be a main holiday as well as other holidays. The most popular domestic holiday destinations were Wairarapa (20\%), Hawke’s Bay (15\%), and Lake Taupo (14\%), signifying the popularity of holiday destinations within 1-4 hours driving distance from the Wellington region (Figure 4.1). These figures, however, do not reveal whether the families visited the same destination more than once. 
Table 4.1 Selected travel patterns for past and upcoming family holidays

\begin{tabular}{|c|c|c|c|}
\hline & $\begin{array}{l}\text { Previous year } \\
(n=110)\end{array}$ & $\begin{array}{l}\text { Main past holiday } \\
(n=110)\end{array}$ & $\begin{array}{l}\text { Next summer } \\
\text { holiday }(n=110)\end{array}$ \\
\hline Not travelling & $12 \%(n=13)$ & $12 \% \quad(n=13)$ & $18 \%(n=20)$ \\
\hline $\begin{array}{l}\text { Domestic } \\
\text { holiday }\end{array}$ & $88 \%(n=97)$ & $62.5 \% \quad(n=69)$ & $79 \%(n=87)$ \\
\hline $\begin{array}{l}\text { Number of } \\
\text { holidays }\end{array}$ & $\begin{array}{l}1 \text { holiday }=28 \% \\
2 \text { holidays }=27 \% \\
3 \text { holidays }=18 \% \\
4+\text { holidays }=15 \%\end{array}$ & & \\
\hline $\begin{array}{l}\text { Top } \\
\text { destinations } \\
\text { (Figure 4.1) }\end{array}$ & $\begin{array}{l}\text { Wairarapa }(20 \%) \\
\text { Hawke’s Bay(15\%) } \\
\text { Lake Taupo }(14 \%)\end{array}$ & $\begin{array}{l}\text { Eastland (10\%) } \\
\text { Lake Taupo (9\%) } \\
\text { Bay of Plenty (7\%) } \\
\text { Hawke’s Bay (7\%) } \\
\text { Manawatu (7\%) } \\
\end{array}$ & $\begin{array}{l}\text { Nelson }(12 \%) \\
\text { Eastland }(9.5 \%) \\
\text { Auckland (8\%) } \\
\text { Manawatu }(6 \%)\end{array}$ \\
\hline $\begin{array}{l}\text { Main } \\
\text { accommodation }\end{array}$ & & $\begin{array}{l}\text { Campground }(28 \%) \\
\text { Home of FR }(22 \%) \\
\text { Holiday home }(22 \%) \\
\text { Motel }(10 \%) \\
\text { Hotel }(6 \%)\end{array}$ & $\begin{array}{l}\text { Campground (34.5\%) } \\
\text { Home of FR }(24 \%) \\
\text { Holiday home }(21 \%) \\
\text { Hotel }(7 \%) \\
\text { Motel }(6 \%)\end{array}$ \\
\hline $\begin{array}{l}\text { Main months } \\
\text { of travel }\end{array}$ & & $\begin{array}{l}\text { December (42\%) } \\
\text { January }(27 \%)\end{array}$ & \\
\hline $\begin{array}{l}\text { International } \\
\text { holiday }\end{array}$ & $35 \%(n=38)$ & $25.5 \%(n=28)$ & $3 \%(n=3)$ \\
\hline No. of holidays & $\begin{array}{l}1 \text { holiday }=82 \% \\
2 \text { holidays }=16 \% \\
3 \text { holidays }=2 \%\end{array}$ & & \\
\hline $\begin{array}{l}\text { Top } \\
\text { destinations }\end{array}$ & $\begin{array}{l}\text { Australia (59\%) } \\
\text { Fiji (19\%) } \\
\text { Europe (11\%) }\end{array}$ & $\begin{array}{l}\text { Australia (40\%) } \\
\text { Fiji (22\%) } \\
\text { Canada/USA(11\%) } \\
\text { Europe (11\%) }\end{array}$ & Australia (67\%) \\
\hline $\begin{array}{l}\text { Main } \\
\text { accommodation }\end{array}$ & & $\begin{array}{l}\text { Home of Friends \& } \\
\text { relatives (43\%) } \\
\text { Hotel (38\%) } \\
\text { Holiday home (7\%) } \\
\text { Motel (4\%) }\end{array}$ & $\begin{array}{l}\text { Home of Friends \& } \\
\text { relatives }(100 \%)\end{array}$ \\
\hline $\begin{array}{l}\text { Main month of } \\
\text { travel }\end{array}$ & & $\begin{array}{l}\text { September }(18 \%) \\
\text { October }(18 \%) \\
\text { December }(18 \%) \\
\end{array}$ & \\
\hline $\begin{array}{l}\text { All holidays } \\
\text { (domestic \& } \\
\text { international) }\end{array}$ & $88 \%(n=97)$ & $88 \%(n=97)$ & $82 \%(n=90)$ \\
\hline $\begin{array}{l}\text { Other travel } \\
\text { party }\end{array}$ & & $\begin{array}{l}\text { Extended family \& } \\
\text { friends }(27 \%)\end{array}$ & $\begin{array}{l}\text { Extended family \& } \\
\text { friends }(28 \%)\end{array}$ \\
\hline $\begin{array}{l}\text { Visited friends } \\
\text { \& relatives }\end{array}$ & & $65 \%$ & $65 \%$ \\
\hline Length & & Median 11 nights & Median 10 nights \\
\hline
\end{tabular}


Figure 4.1 Map of regional destinations in New Zealand

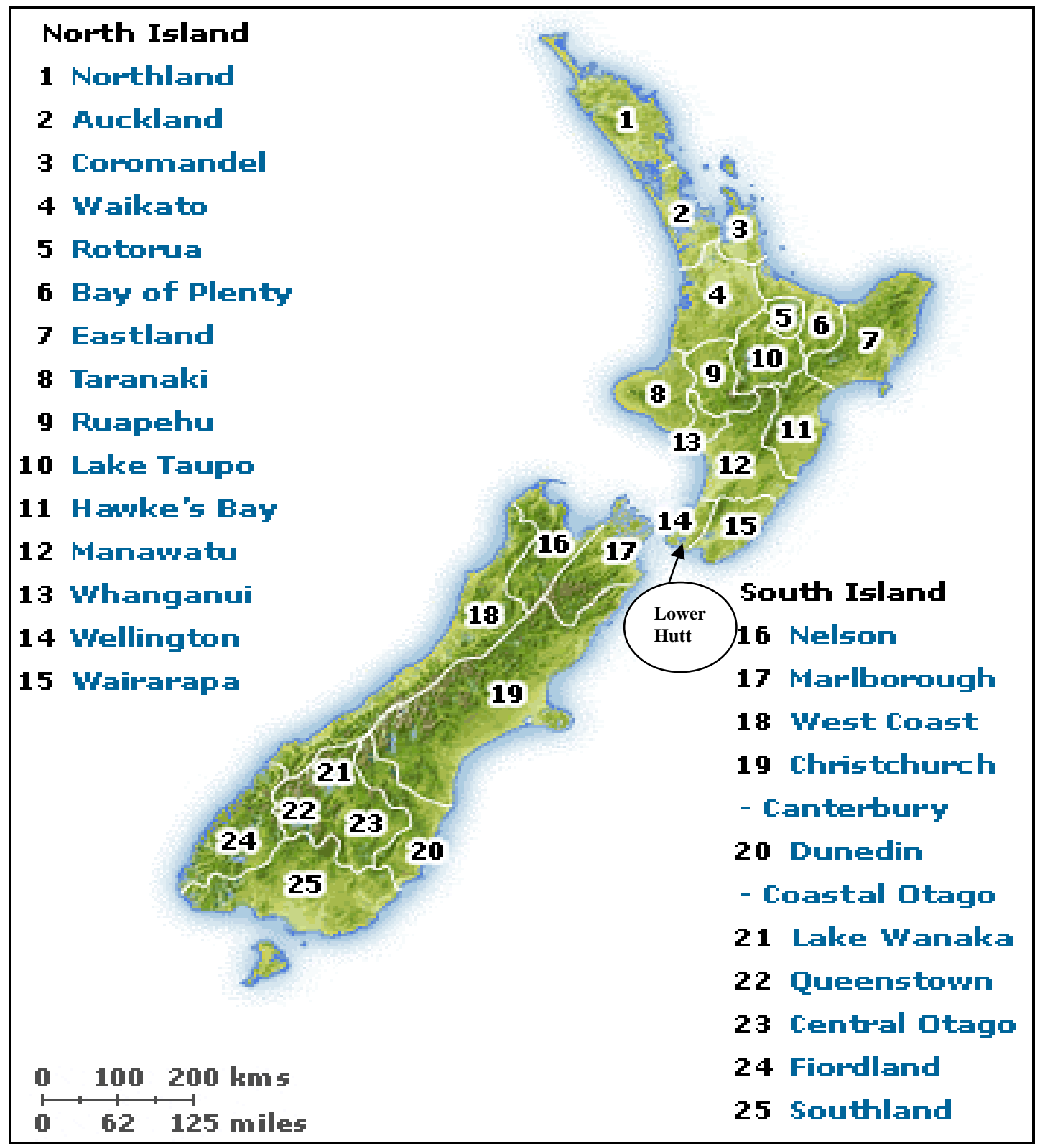

Source: Tourism New Zealand (2008).

In the past year, $65 \%$ of respondents had no overseas holiday. Of the families who holidayed overseas $(n=38)$, the majority $(82 \%)$ had one holiday with Australia being the most popular overseas destination (59\% of overseas holidays) followed by Fiji (19\%). The popularity of Australia confirms previous research (see section 1.5). Of the $12 \%$ of respondents who did not go on a family holiday at all, lack of money was given as the main reason (67\% of these respondents). Additionally (and not in Table 4.1), 63\% of all respondents noted that some members in their family took a non-family holiday in the past year, with children taking most of 
those trips (24.5\%), followed by parents (22\%), and fathers and mothers separately (19\% each). This suggests that apart from family holidays, children and parents also frequently go on holidays separately.

\section{Main family holiday in the previous year}

The survey then asked respondents to identify the holiday they considered to be their main family holiday in the previous year and asked a series of questions about it. For their main past family holiday, $25.5 \%$ of participants travelled overseas with Australia the most popular destination (40\% of overseas holidays), followed by Fiji (22\%), and Canada/USA and Europe (11\% each) (Table 4.1). The key domestic family holiday destinations were Eastland (10\%) and Lake Taupo (9\%), with the top five regional destinations all located in the North Island (Table 4.1; Figure 4.1). This indicates that for their main holiday families travel further away than the one-hour drive to the Wairarapa (Figure 4.1), which was the most frequent domestic destination for all previous holidays.

The main domestic accommodation types were campgrounds (28.5\%), followed by homes of friends and relatives and holiday homes (22\% each) (Table 4.1). This indicates that staying with friends and relatives on holiday (especially overseas where, $43 \%$ of holidays included this accommodation) is integral to family travelling. Camping holidays do not feature overseas, where hotels (38\%) are the second preferred option. In terms of travel party for the main past holiday, most families travelled with their immediate families while $27 \%$ of families also travelled with extended family and friends. Additionally, 65\% of families indicated that they visited friends and family on this holiday. This implies that friends and relatives are visited, travelled with, and stayed with on family holidays, a point that will be elaborated on later.

The length of their main past family holiday ranged from 2-42 nights with 10 nights proving the most common (15\%) for all holidays resulting in a median length of 11 nights. Summer travel dominated: December (42\%) and January (27\%) were the most popular months of the year to begin the main past family holiday to domestic destinations (Table 4.1; Figure 4.2). Of overseas holidays, $64 \%$ took place between June and October. In terms of month of travelling, it can 
be concluded that most families travel domestically during the summer holidays and take advantage of warmer weather conditions overseas during the winter (June/July) and spring (September/October) school breaks.

\section{Figure 4.2 Month of travel for main past holiday}

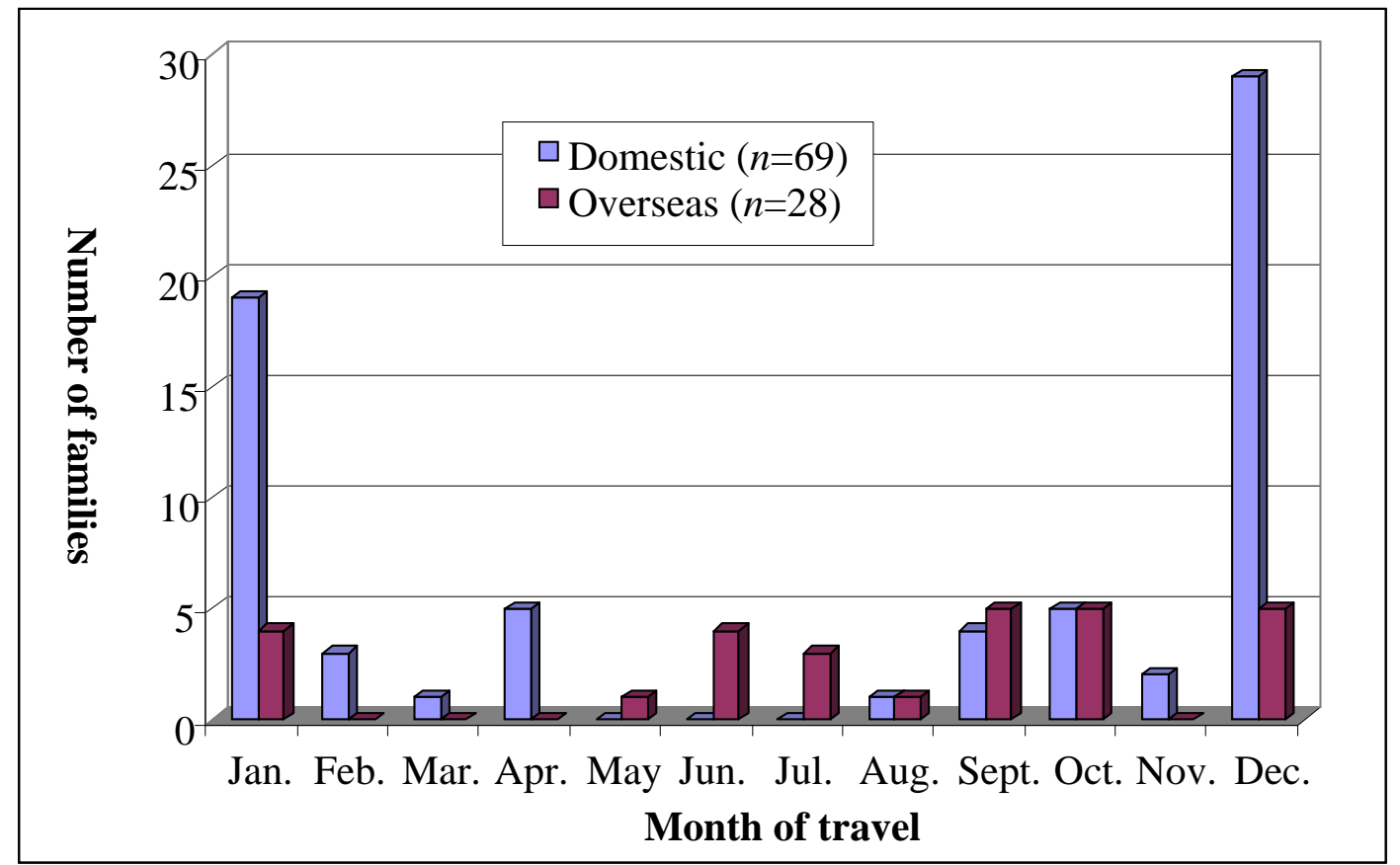

\section{Next summer holiday}

Domestic destinations dominated for this holiday with $79 \%$ of respondents planning to travel within New Zealand compared with 3\% overseas and 18\% not travelling or undecided (Table 4.1). In terms of domestic regional destinations, Nelson was favoured by $12 \%$ of families planning to travel in New Zealand, followed by Eastland (9.5\%), and Auckland (8\%) (Figure 4.1). With regards to accommodation types for this upcoming domestic summer holiday, campgrounds were preferred by $34.5 \%$ of those families, followed by the homes of friends and relatives (24\%), and holiday homes (21\%). Apart from staying with friends and relatives, $28 \%$ also reported travelling with extended family and friends and $64 \%$ of all travelling families planned to visit friends and relatives on this next holiday (Table 4.1). This means that the upcoming family holiday includes extended family and friends by travelling, visiting, and staying with them. The median length for this holiday was 10 nights. 


\section{Comparing holiday patterns}

The following discussion compares the main past holiday with the upcoming holiday, as similar data were gathered about both, to look for differences and similarities. In terms of domestic destinations there are few correlations, which identifies a trend for variety (Figure 4.3). Apart from Eastland, which features highly for main past (10\%) and upcoming holidays (9.5\%), immediate past travel behaviour did not match future travel intentions. The time of year for travelling could account for the differences. For the upcoming holiday, Nelson in the South Island dominated (12\%) (Figures 4.1 and 4.3) which in comparison rated only $4.5 \%$ for the main past holiday. However, apart from Nelson, the favourite regional holiday destinations past and future were in the North Island.

Figure 4.3 Top seven domestic regional destinations for upcoming holiday compared with main past holiday

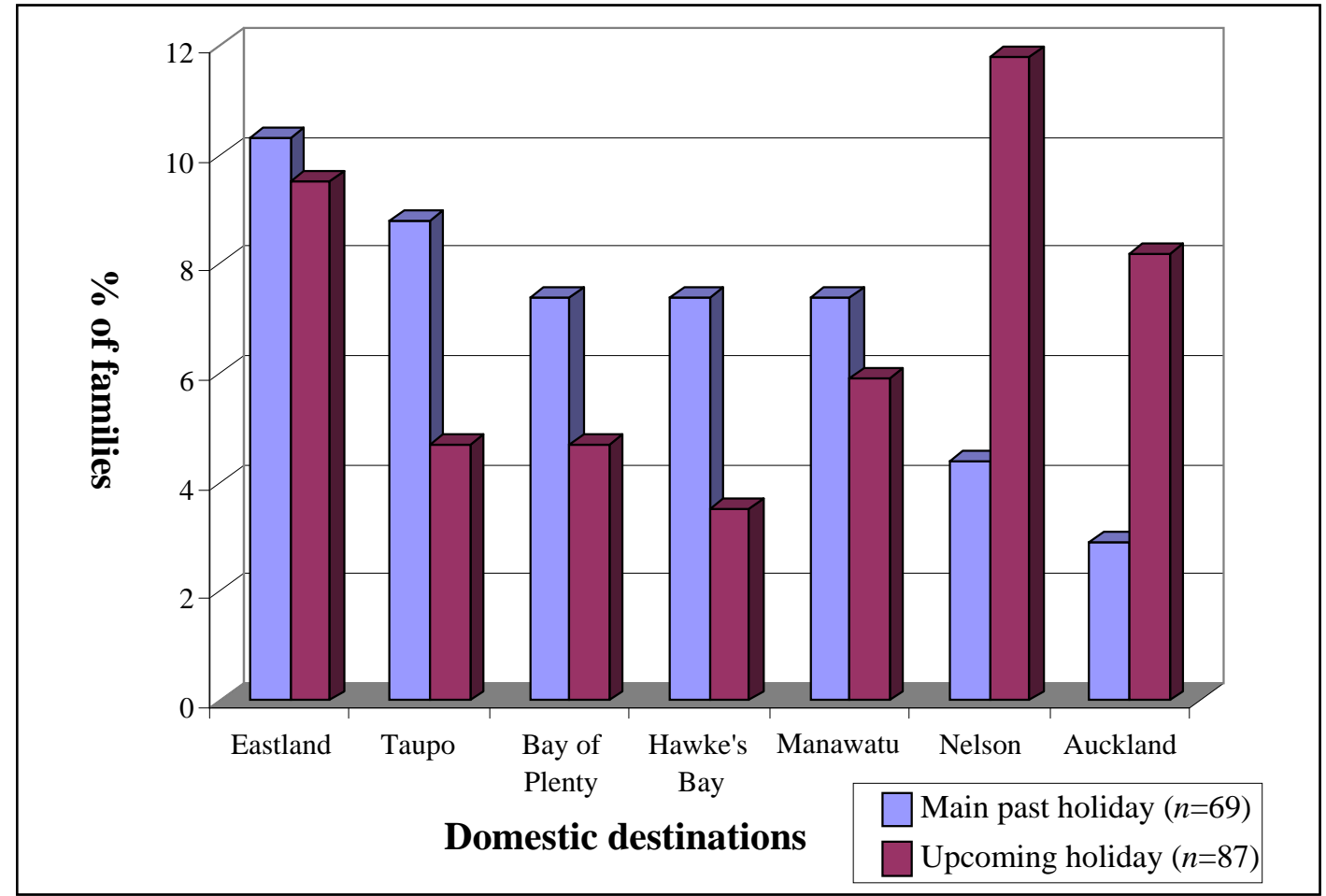

When comparing accommodation types for main past and upcoming holidays, it becomes evident that camping grounds dominate within a domestic context but do not feature on overseas holidays (Table 4.1). Instead, accommodation for overseas holidays is marked by staying with friends and relatives, which ranks higher than for domestic holidays. VFR overseas might be more prevalent than within New 
Zealand as the strengthening of family ties provides more of a motive for travel when geographically distanced (see Morrison et al., 2000) and could also be linked to cost saving. Also, it appears that $10-11$ nights is the most popular length of all family holidays (Table 4.1).

In summary, it can be concluded that most participants embark on one to two family holidays a year with an average length of 10-11 days for their main holiday. Also, for these New Zealand families, domestic family holidays predominate over travelling overseas. Domestic travel from the Wellington region is to a variety of regional destinations mainly in the North Island. The most common accommodation types for domestic holidays are camp grounds, especially for the summer months. The results confirm that the domestic camping holiday features highly for New Zealand families (see section 2.2.3). Children and parents also travel independently from each other throughout the year.

Significantly, for many families, visiting, travelling with and staying with friends and relatives is part of their family holidays. Thus, apart from spending time with the immediate family, visiting or meeting up with friends and kin is an integral part of family holidaying both domestically and internationally. Currently, this overlap may not be evident in tourism statistics. For example, the DTS treats holidays and VFR as separate categories (Ministry of Tourism, 2007a). This leads to a significant underestimation of the VFR market when using traditional measurements (Brocx, 2003) which in part depends on whether VFR refers to accommodation or motive. It also undermines Lawson et al.'s (1997) assertion that Kiwi family holidays only entail travelling with the immediate family and highlights the underestimation of the VFR market both domestically and overseas (see section 2.2.3). The importance of spending time with extended family and friends is also reflected in the motivations for family travelling, as discussed next. 


\subsubsection{PARENTAL PERSPECTIVES ON MOTIVATIONS}

This section reports on the open-ended questions regarding the main motivations for family travel both for their main past holiday and their upcoming holiday. By including some open-ended questions in this survey, data can be generated that broaden theoretical understanding around the issue of parental motivations for travel. Multiple codes were assigned to responses about their motivations for these family holidays. From these responses common themes were coded by way of the GTM and then counted (see section 3.6.1). This resulted in seven motivations for family travel dominating for the parents (Figure 4.4). This quantification of the coded responses is capable of incorporating multiple motivations for family holidays and allows numbers to "speak" in order to establish their prevalence. Thus, unlike the subsequent analysis of the interview data, the frequency of coded themes is important.

\section{Figure 4.4 Main parental motivations for past and upcoming holidays *}

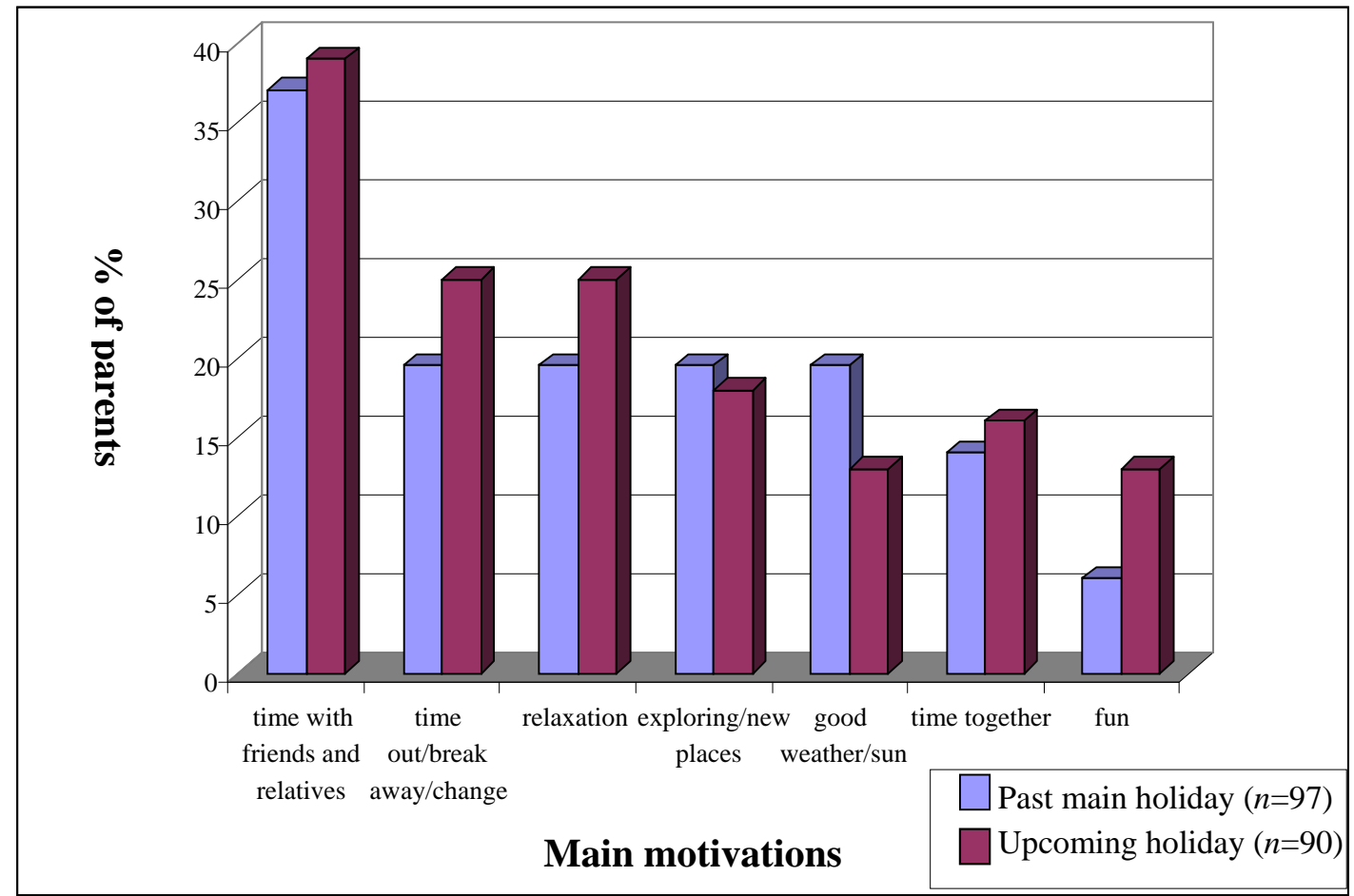

* Total responses do not equal $100 \%$ as multiple motivations could be reported.

When comparing the main motivations given for past main holiday with those for upcoming holidays, to establish a trend, several similarities present themselves (Figure 4.4). The key motivation for both is 'time with friends and relatives' (37\% 
past and 39\% upcoming holiday), followed by 'a time out/break away/change' and 'relaxation' (20\% and 25\%), 'exploring/new places' (20\% and 18\%), ‘time together' (14\% and 16\%), and 'fun' (6\% and 13\%). The higher rating of 'time out/change', 'relaxation', and 'fun' for the upcoming holiday may reflect the immediate needs for travelling compared with recollected motivations. Dividing the responses by gender, the motivation 'exploring/new places' was rated consistently higher for the fathers (34\% past and 42\% upcoming holiday) than the mothers (12\% and 15\%), which confirms earlier discussions on gender differences (see section 2.3.1). Relaxation as a prime motivation for upcoming family travel rated higher for the mothers (29\%) than the fathers (6\%). This confirmed the work of Ryan (2002a) in that women place more value on using holidays to relax physically and emotionally. However, it needs to be acknowledged that the data for the fathers relies on a smaller number $(n=18)$ than the mothers $(n=87)$.

Only $7 \%$ of respondents specified there was a work/business component to their family travelling in the previous year. This indicates that family holidays are primarily about spending leisure time together with the immediate family, extended family, and friends, and is motivated by a change/break away, relaxation, exploring new places, good weather, and maybe fun. Thus, a motivational pattern presents itself that is signified by similarity or continuity across the different holidays past and future. These findings are now combined with a discussion on a definition of family holidays.

\subsection{DEFINITION OF FAMILY HOLIDAYS}

The establishment of a definition of family holidays was based first on the parental survey and second on the whole-family interviews. This meant that a working definition resulted from the parental survey responses which were combined with the perspectives of the whole family experiential dimensions (Figure 3.2). As a result, the definition was progressively refined into a familial definition of family holidays by incorporating the findings of the interviews into the parental definition from the survey. Rather than relying on the survey responses from parents alone, this research highlights the need to include children 
in the research process and for longitudinal family research to more realistically reflect gender and generational differences present in this travel group. Combining the parental definition of family holidays with a familial definition allows for the incorporation of the perspectives of all family members before and after the holiday took place.

\subsubsection{PARENTAL DEFINITION}

This section reports on the open-ended questions from the survey by analysing the multiple characteristics of family holidays, their length, and the notion of having a holiday at home. These findings are then combined with other already reported findings from the survey to progressively build up a working definition of family holidays which is then compared with definitions in the tourism literature. When questioned at the beginning of the survey on how to describe or define a family holiday, multiple codes were assigned to their responses (see section 3.6.1). Seven main characteristics emerged for a family holiday definition (Figure 4.5), demonstrating where the emphasis for parents/guardians lies when holidaying with their child(ren). The most frequently mentioned characteristics were 'a time spent together or with the whole family' (84\% of respondents) and 'a time away/break from home' (67\%). Thus, a family holiday is essentially 'a time spent together away from home with the whole family' or 'a break from home together with the whole family'.

Twenty percent of respondents included extended family in their definition of family holidays (Figure 4.5), and it was reported earlier that $65 \%$ of families intended to visit friends and family on their next summer holiday (Table 4.1). Together with the main motivations established earlier (Figure 4.4), 'spending time with or visiting friends and family' becomes an integral element of family holidays. It also introduces a purpose to family holidaying. This study’s initial definition of family holidays is therefore: 'a purposive time spent together with the whole family (which may include extended family) away from home’. 
Figure 4.5 Main characteristics of a definition of family holidays $(n=106) *$

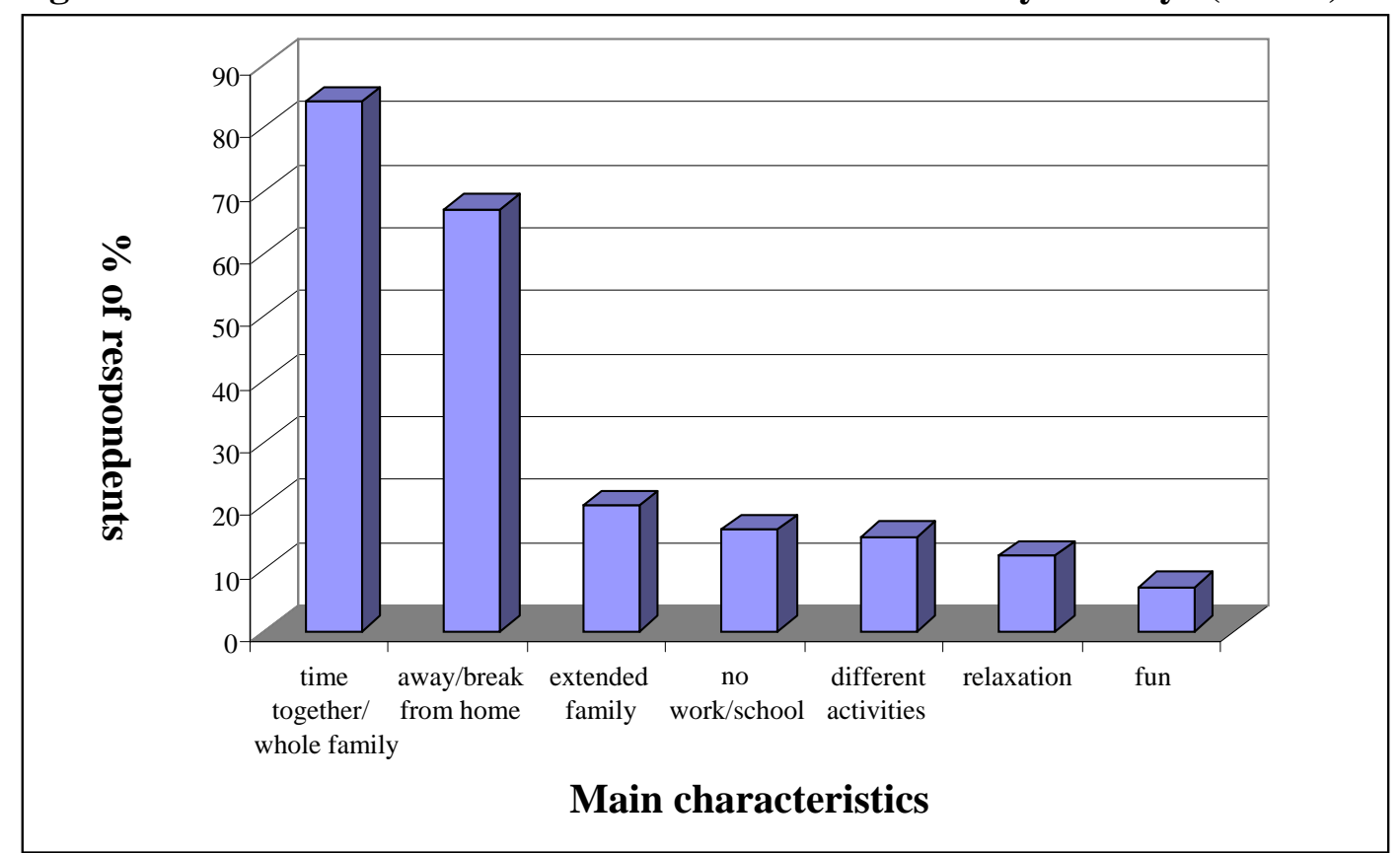

* Total responses not $=100 \%$ as multiple characteristics could be reported.

Accepting that the focus of family holidays lies in spending time together as a family explains why $54 \%$ of respondents agreed that it is possible to have a holiday at home. Here are some examples from respondents' prompted explanations:

"A family can do things they wouldn't normally do using home as a base rather than going away"

"Planned activities (list of things to do on the fridge) which are different from normal day to day activities”

"It's more about the quality time together rather than where it is".

They all share in common that home can be used as a base and that family holidays can include holidaying at home. Family holidays basically mean spending time together as a family and, if not away from home, then doing activities different to normal routine. This is supported by $15 \%$ of respondents stating in their definition that family holidays involve different activities (Figure 4.5). What this means to the definition of family holidays is that 'away/break from home’ could imply a break from normal home routines rather than necessarily an overnight trip away from home. 


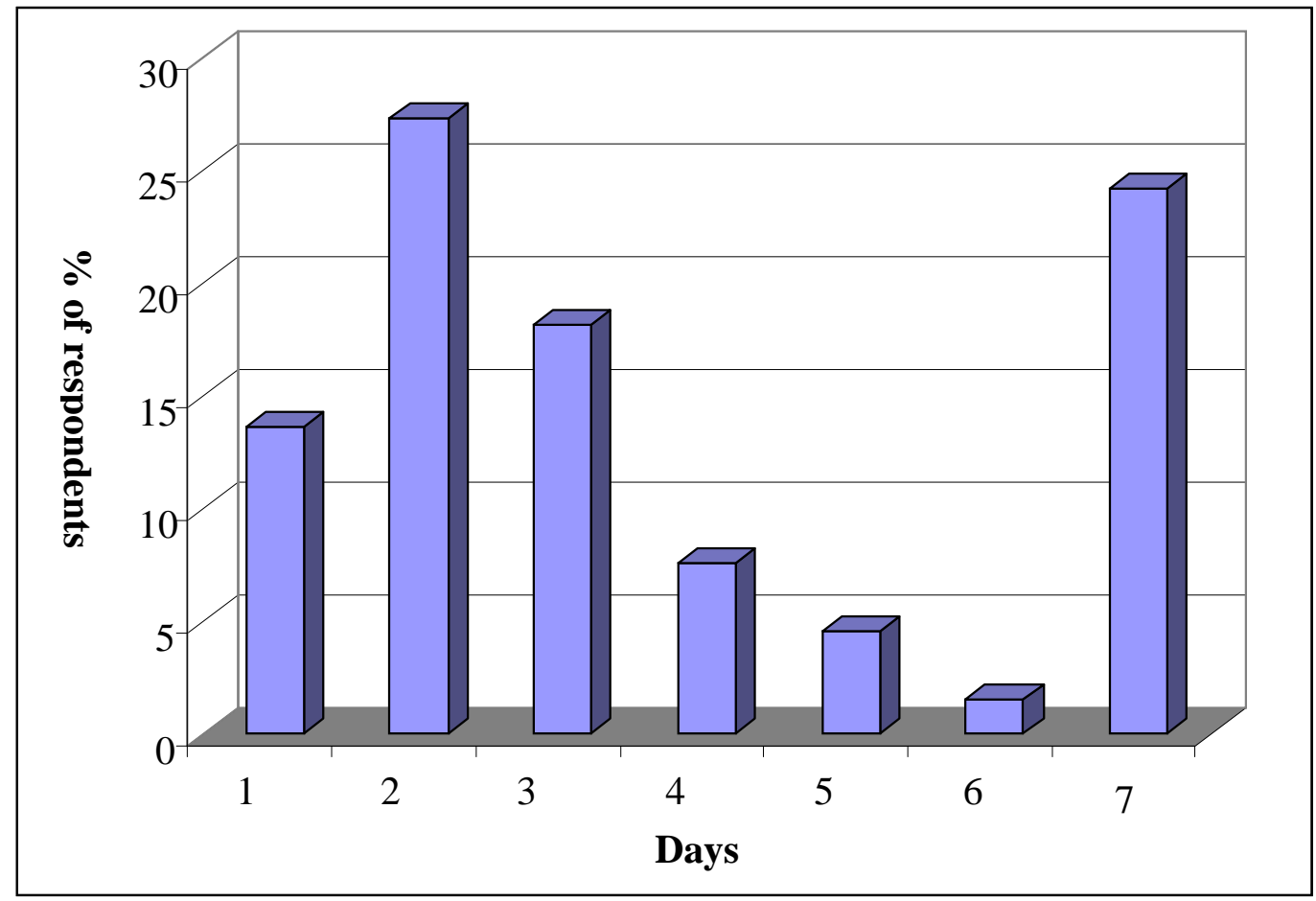

Over and above where the family holiday is spent, there was also a question on the length of family holidays, with $61 \%$ of respondents stating that there was a minimum length. This ranged from 1-7 days, with a peak around 2-3 days (45\%) and another peak at 7 days (24\%) (Figure 4.6). While the findings are not completely conclusive it could be stated that a (long) weekend counts as a minimum for a family holiday. A refined definition of family holidays is therefore: A purposive time spent together with the whole and extended family doing activities different from normal routines for at least a weekend.

The main conclusions that can be drawn from the survey are that family holidays are primarily about spending time together 'with' the family rather than just an escape or break 'from' home routines. This might even mean a 'holiday at home' as long as it involves activities different from normal. Spending time with the family must be seen in the wider sense in that it is not limited to the immediate family. Family holidays, consequently, may fall outside the general definition of tourism as established by Leiper (1979) in that day trips become as much an element of family holidays as overnight trips. It confirms Blichfeldt's (2008) notion of a holiday at home within the context of families. With regards to a break 
'from' routine, this has already been established in the literature (Crompton, 1979; Iso-Ahola, 1982), and is not unique to family holidays but is a key travel motivation (McCabe, 2000). This desire to escape through leisure travel might represent culturally learned explanations for tourism behaviour (Goossens, 2000) and has been argued from a male individual perspective (see section 2.3.9), but it does not account for the social dimension of a family group holiday.

The strengthening of kinship relationships has been referred to in the literature as a key motive for family travel (e.g. Crompton, 1981). It is this opportunity for interpersonal relationships or social connections across multiple generations that differentiates family holidays from most other holidays (see Shaw et al., 2008). By taking an interactionist perspective, family holidays are not an escape from the everyday life but an escape to a social space which allows a focus on interpersonal interactions (Wearing \& Wearing, 1996, p. 229). This is supported by Larsen et al.’s (2007) argument that tourism often involves connections with, rather than an escape from, social relations and that social obligations and the need for proximity to significant others generates tourism. It introduces family holidaying as purposive in that the time together is used to develop a sense of family (Shaw \& Dawson, 2001). It allows people to (re)connect through tourism and can be seen as a social practice that involves networking and social obligations (Larsen et al., 2007) for at least a weekend.

This results in a working definition of family holidays that encapsulates the notions of togetherness, plurality of families, purpose, change of routine, and length. It does not reflect stressful experiences, as previously identified by Lee et al. (1994) with regards to a definitional perspective. However, this definition is solely based on the perspective of parents (mainly mothers) and does not include the characteristics or motives that the entire family would bring to it. To allow for the generation, gender, and group dynamic perspectives it is necessary to include the views of all family members before and after the holiday. This working definition of family holidays based on the parental survey is extended and further refined through the whole-family interviews as discussed next. 


\subsubsection{FAMILIAL DEFINITION}

The interviews with all family members (group and individual interviews) took place once before and twice after their summer holiday to account for the generational and gender differences in experiences as well as group dynamics over time. The value of including children conceptually and methodologically in the research was confirmed in the characteristics that they brought to a definition of family holidays (Figures 2.4 and 3.1). The whole-family interviews also provided an independent voice to the fathers, who are currently missing in tourism research (see section 2.6.3). The longitudinal whole-family research, thus, added to the definition experiential characteristics that are based on fun for the children, a need for individual pursuits, and tensions between the family members.

When asked in the survey only $6 \%$ of parents included fun as essential when defining family holidays (Figure 4.5) but this did not correspond with the children's interviews. For example, an 8 year old (Hoiho boy $2^{2}$ ) said: “It is not a holiday if it is not fun. If it is fun then it is a holiday." This sentiment about fun being essential for family holidays was echoed by all the other children (see section 5.3.2). Thus, by including the children's voices in the research process, fun becomes another definitional characteristic. During the family interviews parents and children also discussed their need for individual experiences and some of the negative and positive characteristics of family holidays. It emerged that having a balance of time for individual pursuits as well as compromise and conflict are important themes which had not appeared in the parental survey. This meant that for a harmonious family holiday a balance of family time and own time was needed for all family members. This represented a freedom from obligatory aspects in family time to pursue interests alone or with peers (see chapter 6), as exemplified in this response by Goldfinch mother on her anticipations in the individual interview:

"Having the family together but also to have some time for myself."

Kereru boy3, 10, confirmed these anticipations in his individual interview:

"Having the family all together but still doing some things separate and having a big rest. Just like having fun ourselves."

\footnotetext{
${ }^{2}$ For same gender siblings, the number denotes the position in the family with 1 being the eldest.
} 
The more prevalent theme of compromise emerged mainly in the parents' responses (see section 6.6.2) while the more concealed theme of conflict emerged mainly in the fathers' and children's responses (see section 6.6.3). Examples of compromise included Takahe mother in the individual interview before taking her children to a water theme park:

"I do not mind Splash Planet. I will be bored but I can take something and talk to the other parents, that is fine. I do not want to go down all the slides myself and stuff. It is a bit of a compromise."

Goldfinch father commenting on sacrifices in the final individual interview:

"To be honest during a holiday everyone sacrifices here and there with three people and we are all different. But we continuously did it."

Examples of conflict on holiday included Hoiho father in the individual interview on what to expect on holiday:

"There will be some stresses from time to time if the children do not cooperate. I can imagine myself getting into disputes and yelling at the kids and so on which happens on holiday sometimes."

Conflict was illustrated by an exchange between Pukeko parents reflecting on their holiday.

Father: "There were some tense moments but then again we are not used to living in close quarters to everybody for that many hours in a day every day of the week. Some of us escape to work or school."

Mother: "That would be a fair comment. The half heart about a family holiday is that we actually all get on really well when the boys go to school, $<$ dad $>^{3}$ goes to work and we all...but 2 weeks together!”

Children also discussed conflict such as Tui girl, 14, in the individual interview reflecting on her siblings:

"I don't enjoy it. My brothers basically ruin it because youngest brother is always in a bad mood and grouchy and annoying. He actually kind of ruins it for me."

It becomes evident from the family interviews that the group dynamics can lead to compromise and conflict (see section 6.5) and that family holidays are not always all harmony (Gram, 2005). By including the perspectives of all family members in the research process, fun, balance, individual pursuits, compromise, and conflict

\footnotetext{
${ }^{3}$ The position in the family is used in $<>$ when person was referred to by name.
} 
become added definitional characteristics alongside an experiential notion to difference (see section 5.3.1). As a result, the definition of family holidays developed by this research is:

A purposive time, at least a weekend, spent together with the whole and extended family having experiences different from normal routines that are fun. This centres on a balance of time that includes individual pursuits and which may involve compromise and conflict.

In conclusion, the above definition establishes that family holidays have a purpose of spending time together 'with' the family (including extended family) rather than just an escape/break 'from' normal routines. Family holidays, then, offer a social time to (re)connect with people and for parents to spend quality time with the child(ren) for at least a weekend. This might not involve overnight trips but using the home as a base for experiences that are different to normal, which extends family holidays beyond the general definition of tourism. Including children in the research process highlights fun as essential to family holidays. Allowing for the perspectives of all family members over time has ascertained that individual pursuits, compromise, and conflict are as much a part of family holidays as the social and fun aspect. This definition emphasizes the overall importance placed on balancing the social and experiential dimensions of holidays while also revealing the underlying dynamics that family members bring to it. It, thus, speaks to themes that are developed later in this study. These internal dynamics are also influenced by external factors that provide a context to the family holiday.

\subsection{CONTEXTUAL FACTORS}

The contextual factors discussed here frame the internal relationship between the time the family wants to spend together and the time individual family members want to spend away from family commitments. There are five main contextual factors that were mentioned by all the families (destination choice, finances, weather, accommodation space, and length of holiday) and other factors (such as noisy neighbours) that were specific to only some families. These factors positively and negatively surround and influence the internal family dynamics. 
Thus, when these contextual factors have a negative effect on families (such as lack of choice or bad weather) they act as constraints on the family group dynamics but are not the result of the interactions between the family members (Figure 4.7). In this sense, the contextual factors only come to the fore when they impinge on the families and serve as context to the main themes that will be discussed later. Yet, there are also contextual factors such as the ideology of family life, which is driven by media representations and dominant discourses, as emerged from the literature review. These ideological factors can have an influence on family behaviour and practice on holiday, as discussed in the findings chapters, but have not been mentioned directly by the participants.

\subsubsection{DESTINATION CHOICE}

Decisions about the holiday destinations were largely made jointly by the parents, with little consultation with the children but following the overall purpose of family holidaying as discussed later:

“The kids just go where we go.” (Kea mother, pre-family interview)

"No part [in decision], just mum and dad. Do not mind, have never been there.” (Pukeko boy1, 13, pre-individual interview)

Most children were content with their lack of destination choice but it became a problem for one girl and negatively influenced their family dynamics:

"I only go because I have to. If I had the choice I stayed here." (Fantail girl, 10 , final family interview)

However, the following responses revealed that children's involvement in decision making increased with regards to specific attractions visited at or en route to the destination like theme parks which supports Decrop (2006).

"It was kind of decided we are going there. Me and <brother> were told that we are going to Rainbow's End and stuff and we also wanted to go to Splash Planet and so that came in later." (Hoiho boy1, 11, pre-individual interview)

"We asked <the son> if you wanted to go to Splash Planet and you said yes.” (Takahe father, pre-family interview)

Two families had been following traditions and holidayed at the same destination for a number of years (Keruru and Fantail). The other eight families holidayed at 
various destinations around the North Island (Table 3.3) with reasons for choosing a location being proximity to relatives, difference of location, ease of access compared with the South Island, and family budget, as reflected by this respondent:

"A discussion and we thought we try something different...We are limited in Wellington, you can only go North without it to cost megabucks by going on the ferry. So it is only Hawke's Bay or Taranaki if you do not want to travel too far.” (Kea mother, pre-individual interview)

Other responses echoed the sentiment of choosing a destination for its difference:

"We always like to go somewhere different. We haven't actually been to Gisborne as a family.” (Pukeko mother, pre-family interview)

The main positive reason for some families was because of family ties:

"Because relatives are there, the defining thing is that. That is why we go to that particular destination because otherwise we could go anywhere." (Weka mother, pre-family interview)

With regards to domestic holiday destinations, it became apparent that parents mainly made decisions themselves based on family traditions, where relatives live, where they have not been before, and practicalities such as ease of access combined with finances, as discussed next. The sub-themes of traditions (see section 5.5), social connectedness/VFR (see section 5.4) and change of routine (see section 5.3) were reflected in the destination choice, which was interspersed with entertainment aspects and preferences of the children (see section 5.3.2). Thus, destination choice provided a context for discussing the main themes in the next two chapters in that mutually favourable decisions allow for balanced family time and own time. However, a perceived lack of choice could lead to constraints within the internal family dynamics, a theme revisited in section 5.6.

\subsubsection{FINANCES}

The cost of a holiday was not perceived as a deterrent. In fact, all of the families had annual domestic summer holidays and some had also been on overseas holidays. The finding is a reflection of sampling families with above average household incomes (Tables 3.2 and 3.3). Domestic holidays were perceived as cheaper and better value for money than overseas holidays, especially if travelling in the North Island. 
"There is another thing: the cost of going to New Plymouth for 10 days was about half the price of going to Australia for the same amount of time. You could say, hey, we can do two of those holidays." (Kea father, final individual interview)

Travel to the South Island was considered to be more expensive (see previous section). Thus, finances were related to destination choice but were not a matter of whether or not to go on holiday. Generally the available finances for holiday travel were connected to proper planning rather than income levels:

"It is a matter of planning. It is not expensive to do. You can do it in an expensive way but you can see New Zealand really cheaply as a family. And I like my kids to know that." (Kea father, post-individual interview)

"And you have money because you plan for it." (Goldfinch father, postfamily interview)

It also became evident that for some, finances had a male gender role:

"What I like to do with these guys [family], just follow them around and hand over the cheque book. Pay for things is a very important role of mine."

(Weka father, pre-family interview)

The financial cost of a holiday is considered in the tourism literature as a crucial factor in holiday taking (see Schänzel et al., 2005) but had few implications amongst these more affluent families within a domestic context. Finances can have an influence on the type of holiday, thus, indirectly constraining family relationships by way of destination choice.

\subsubsection{WEATHER}

The weather, good and bad, was mentioned variously throughout the interviews. The expectation before the holiday was generally for good weather especially because the spring weather was particularly changeable that year:

“To be sunny, nice weather, not like here.” (Pukeko boy1, 13, pre-individual interview)

While very hot weather was mentioned as a negative experience, it was usually rain and cold which characterised bad weather. It was generally agreed that even bad weather could be alleviated through good planning and facilities available at the destination:

"You can't help the weather but you can, coming back to having some ideas and some preparation. We took games. We played card games and a couple 
of board games. Also being in a city there is a lot more to do.” (Kea father, post- individual interview)

"Even when it was raining I was swimming and didn't feel the rain." (Kakariki girl, 8, post-individual interview)

It also depended on the right attitude, as exemplified by this respondent:

"Even when it is raining and the worst conditions there is an expression: a bad day on holiday is better than a good day at the office." (Fantail father, final family interview)

Some even favoured rainy weather at times because of the alternative activities it created:

"It is just nice and cosy inside the boat (when it is raining) and it is not that nice and cosy when it is sunny. It is like having the whole family down below reading books and play card games or board games.” (Fantail girl, 10, post- individual interview)

"I don't even mind if it rains. It is quite often a good excuse to stay in the tent and just read for the day. As long as it is not for a week, one day is fine." (Pukeko father, pre-individual interview)

The extent and duration of bad weather, however, meant that eventually it could constrain the family dynamics and leave a lasting negative memory of the holiday.

Bad weather was commonly mentioned about things not liked on holiday and also dreaded in anticipation:

"I could imagine if it rains for four days in a row and everything gets wet than tempers will start to fray a bit." (Hoiho father, pre- family interview)

"It was cold and we were waiting for the summer holiday to start. I vaguely remember you [son] getting grumpy at some stage." (Pukeko mother, final family interview)

Considering the emphasis that was given to good weather (warm and sunny) on summer holidays it was somewhat surprising how little was remembered more than half a year after the holiday in the final interview phase. Unless the weather was particularly bad and maybe aggravated through other factors (for example, noisy neighbours, as discussed in section 4.4.6), for most participants negative weather experiences played a small role in their overall recollection and only improved over time. The temporal dimension and its influence on memories about weather and other examples will be discussed in section 6.7. 


\subsubsection{ACCOMMODATION SPACE}

Holiday accommodation as a contextual factor exemplified the possible constraints on personal space and, thus, anticipated the relationship between family time and own time with regards to space. Although not as dominant a factor as the themes discussed in the following chapters, accommodation in relation to space and comfort was important to all the families. Some families had deliberate plans by trying to accommodate every family member's need for individual space and commented positively on this, such as using separate tents for their children:

"The fact that we had the cabin and the kids had the tents that way I didn't have the: 'you get out of my room'. I didn't hear that because they had their own bedrooms per se." (Tui mother, post-individual interview)

"We had a good camp set up this year. We had a big tent and the boys had a little pup tent each. So they had their own space and we a gazebo." (Pukeko father, post-family interview)

In contrast, other family members struggled with the perceived confinement and loss of personal space on holiday, especially as everyone had their own room at home. When children had to share a room on holiday this could create constraints on the families. In the Takahe post-individual interviews both father and 10 year old daughter separately discussed the shared accommodation arrangements:

Father: "The other thing was that the kids had to share a room and sometimes that doesn't work out so well these days."

Girl: "I like having a bit more of my space."

After more than half a year this had become a negative memory for the mother:

"It was a bit claustrophobic in that small unit." (Takahe mother, final family interview)

Even a single child could feel the lack of personal space:

"Spending the whole time on the boat which is just a wee bit bigger than this room. It is quite cramped and you get quite bored easily." (Fantail girl, 10, final individual interview)

However, some younger children also treasured sharing a room on holiday as a novelty. For example, in the Kakariki family, the children enjoyed it but the parents perceived it as a negative experience: 
"It is more fun because we get to stay up talking. At home we are in separate rooms and we can't do that." (Girl, 8, final individual interview)

"Putting the kids to bed. Just because all of the places they slept in the same room (and they have two rooms here). So they settle down a lot quicker here." (Mother, post-individual interview)

Cleanliness and the odour of an accommodation was a prime concern for the families, and children particularly remembered the smell of a place as part of a negative experience. An exchange from the two Pukeko brothers (11 and 13 years old) at the pre-family interview illustrated this:

Boy2: "We do not like really dirty camping grounds."

Boy1: "What was that one where there was that horrible smell all the time?"

What became apparent was that the sharing of a smaller living space on holiday could be perceived as confining and negative, especially retrospectively. The perceived lack of personal space, thus, foretold the perceived lack of own time as will be discussed with regards to the temporal dimension in chapter 6 .

\subsubsection{LENGTH}

The discussion on the length of the holiday determined an ideal length of time, with a holiday that was too short or too long constraining the internal family dynamics. The quotations mostly originated from the family interviews before the holiday, where they were asked directly about holiday length. The ideal length of a holiday was mentioned as between 10-14 days, which reflects the average length of holidays taken in the survey results (see section 4.2.1).

"Probably 10 days to two weeks would be the ideal time but you do not always have that time. It is nice to come home too." (Kea father, pre-family interview)

"We can be routinely away for two weeks and that is quite busy and usually after that time we are quite happy to go home." (Tui mother, pre- family interview)

Ideal length depended on what kind of holiday, with overseas holidays needing to be longer.

"But overseas it has to be a minimum of 10 days. We went for a week once and that was not really that suitable as we only just settled in and then had to think about leaving.” (Weka mother, pre- family interview) 
It also depended on the activities available, particularly for the children.

“About two weeks if it is good." (Hoiho boy2, 8, pre-family interview)

"You do not want to go for too long because otherwise you run out of things to do." (Takahe boy, 12, pre- family interview)

This also meant that a holiday could be too short because it took a few days to get into a holiday frame of mind and not feeling rushed doing different activities:

"Although it was short it felt quite condensed and quite a bit packed in. I would have liked to stay and done a few other things." (Takahe mother, post- individual interview)

"It has got to be a minimum. I think it takes me three days to just unwind. I sleep for the first couple of days." (Kereru father, pre- family interview)

“To actually relax you need a week or more.” (Pukeko mother, pre- family interview)

Mostly it was the holidays that were too long that could be constraining to the family relationships.

"I can go with that for a week or 10 days but if it was any longer than I would start to struggle. And as a family that is probably the maximum amount of time that we go away where we are doing things together all the time." (Pukeko father, post- individual interview)

"Maybe not going for too long because we did that one year. It is good going three weeks but we went for about four weeks...it was too long because they <sons> actually didn't get on very well with each other at the time." (Hoiho mother, pre- individual interview)

Another factor was that home, pets, and friends were missed when staying away for too long.

"It can be too long because you do actually miss your home after four weeks.” (Goldfinch mother, pre- family interview)

"We miss the cats.” (Pukeko mother, pre- family interview)

From the interviews it became apparent that the families knew what suited their family relationships and planned accordingly. However, internal group dynamics could be constrained, in particular, when going on family holidays for too long. 


\subsubsection{OTHER FACTORS}

Other contextual factors that were mentioned in the interviews as generally not liked on holiday were accidents, travel delays, break downs, motion sickness, and illnesses, but because no specific examples were given by the families these cannot be discussed further. However, the potential impact of other contextual factors can be illustrated by the Pukeko family who endured noisy neighbours in a campground in the form of drunken and rude teenagers in conjunction with a cold weather patch (see section 4.4.3), which constrained their family dynamics and ultimately affected their holiday memories. Here are recent recollections from the family members in their post-individual interviews:

"They [the teenagers] were swearing, they kept us awake, they were loud and they had really yuck music on.” (Boy2, 11)

"The shenanigans going on next door for the first couple of days. Everybody got a bit tense and terse with each other. It is just people invading your space a bit.” (Father)

"Without harping on too much about the teenagers, they had the potential to ruin it, they really did.” (Mother)

Yet with the hindsight of time in the final family interview the children at least could also see the humour:

Boy1, 13: "That was funny when they got kicked out. All the girls swearing and saying: 'no, you can't do this to us'."

Mother: "I don't think it was funny. It was better that we avoided it."

This hinted at the temporal dimension which will be discussed in section 6.7 in that negative experiences were more persistent for parents than for children. Also, the notion of space seemed particularly important with regards to these contextual factors, as a perceived lack of personal space could be affected by noisy neighbours, too long a holiday, persistent bad weather, and shared accommodation facilities. These directly mentioned or personal factors and other ideological or societal factors provide a context to family holidays highlighting that there are micro and macro environments for families, as elaborated on later. The family group holiday itself, however, is signified by the main themes of family time and own time that comprise the theoretical framework and is presented next. 
Figure 4.7 Theoretical framework of the main themes on family holidays

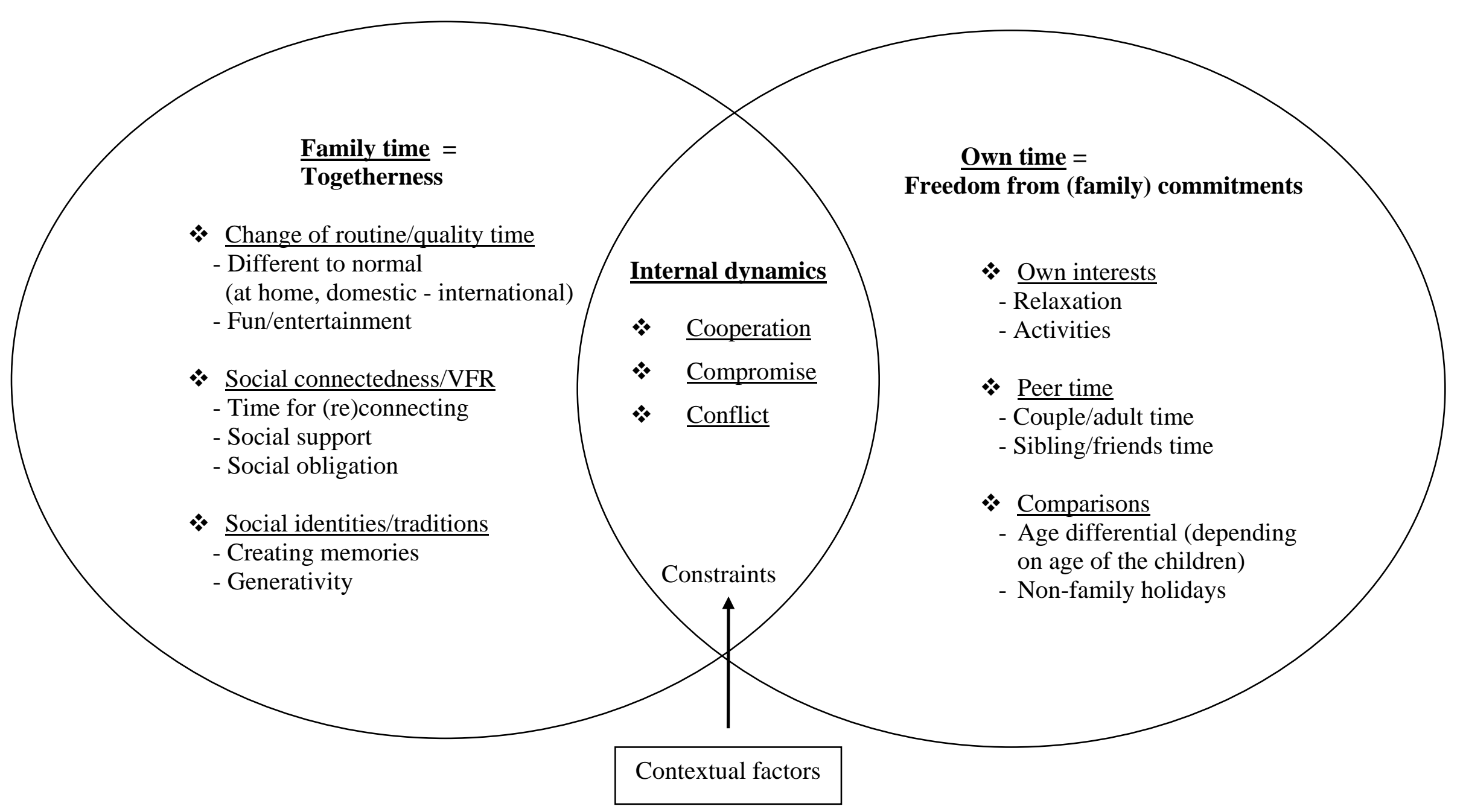




\subsection{OVERVIEW OF THE THEORETICAL FRAMEWORK OF THE MAIN THEMES}

The theoretical framework of the main family holiday themes followed from the GTM process and the incorporation of the survey results into the first phase of whole family interviews (Table 3.11). It deepened the analysis of family holiday behaviours based on 110 parents to a whole family experiential dimension based on 10 entire families. This resulted in the development of two overarching themes of family time and own time that overlap to reveal the internal dynamics, and these are further divided into 9 sub-themes. Family time encapsulates the time spent together with the immediate and extended family and includes idealised notions of change of routine, social connectedness, and social identities. In contrast, own time encapsulates freedom from those family commitments to pursue own interests alone or with peers, which includes comparisons with nonfamily holidays and earlier family holidays. The relationship between family time and own time leads to the internal family group dynamics of cooperation, compromise, and conflict. The contextual factors when negative (e.g., bad weather) can lead to constraints as explained earlier. Figure 4.7 models the main themes and the internal dynamics and contextual factors present on holiday. This theoretical framework will be used to structure the next two findings chapters of family time and own time on holiday according to generation, gender, and group dynamics. The internal dynamics of cooperation, compromise, and conflict are part of family time but will be discussed under own time as they are more aligned with the pursuit of individual interests.

\subsubsection{FAMILTY TIME: TIME SPENT TOGETHER}

Togetherness signifies the time spent with the whole and extended family. This social theme is divided into three sub-themes;

* Change of routine is about doing activities that are different from normal and that qualify as quality time with the children. There is a difference between at home, domestic, and an international holiday in that overseas is perceived as more different than New Zealand and going away on a domestic holiday as more different than home-based holidaying. An 
* Social connectedness centres on establishing social relationships with loved ones, including VFR, and is a time for (re)connecting as well as providing support for each other. It can also contain elements of social obligation in that this is tied to responsibilities rather than free choice.

* Social identities are established through shared memories and through guiding the next generation. Family holidays are part of this tradition of generativity and creating positive collective memories.

\subsubsection{OWN TIME: FREEDOM FROM FAMILY COMMITMENTS}

Own time signifies time to pursue one's own interests away from family commitments. This more individual theme is divided into three sub-themes:

* Own interests are about spending time alone doing activities that are relaxing and that one is passionate about.

* Peer time is about spending time amongst the peer group and within one’s generation: couple time and time with other adults for the parents, and time with their siblings and friends for the children.

* Comparisons have two components: it is about comparing the amount of own time and one's sense of entitlement relative to the age of the children and compared with non-family holidays. This means that both parents and children make demands for having their own time as the children get older. Thus, in comparisons, own time is linked to an age differential of the children and to non-family travelling.

* Cooperation, compromise, and conflict are part of the internal group dynamics resulting from negotiations between the main themes but more closely connected with the independent interests sought in own time. Cooperation is facilitated mainly through the social support network of extended family as one way to allow parents and children to pursue their own interests independently from each other. Compromise signifies the relationship between the main themes in that both notions of time are regularly sought. Accommodating both notions of time can lead to conflict if there is an imbalance for some family members, such as if own time is sought while being pressured by the demands of the rest of the family. 
The contextual factors like weather can accentuate or minimise these internal dynamics. They were discussed earlier as possible constraints that are external rather than central to the family group dynamics. The core aspects of internal dynamics (cooperation, compromise, and conflict) are, then, discussed in chapter 6 and all internal dynamics are revisited in chapter 7. The temporal dimension of pre-, on-, and post-holiday (Figure 3.3) is discussed at the end of chapter 6 after the analysis of the findings according to themes (main and sub-themes) and perspectives (gender, generation, and group dynamics). Temporality as a longitudinal element to family holidays is signified more by a continuation of the main themes and perspectives than distinctions between the stages. This made its overall importance less dominant and more constant than the primary discussion of the thematic and familial perspectives in chapters 5 and 6.

\subsection{CONCLUSION}

This chapter has provided an exploration of New Zealand family holiday behaviours and related whole family experiential themes across the different methods used. Family time became the main purpose of holidaying, linking parental ideals reflected in the survey with those in the interviews. The addition of children in the interviews extended this theme to include having fun. The family interviews also revealed the internal group dynamics of compromise and conflict. Together they established a definition of family holidays. The broader contextual factors provided a frame in which family holidays occur, such as bad weather can impinge on the internal family dynamics. The development of the themes based on a deepening analysis from the survey to the experiential familial dimension revealed own time as a key theme reflecting realities on holiday compared with the more idealised theme of family time. In effect, family life is about realising ideals of togetherness while in reality family members also require time that is free from those commitments. This reflects the thematic dualism of family time and own time that overlaps to reveal the internal dynamics (Figure 4.7). Differentiation according to the main and sub-themes, the familial perspective, and the longitudinal element of the research, thus, provide an understanding of the thematic dynamics between generation, gender, and group over time. Findings 
according to the thematic, familial, and temporal dimensions are presented in the next two chapters to reveal the complexity of family living on holiday. It also represents a shift towards the contributions of the participants in their own words. 


\section{CHAPTER 5: FAMILY TIME ON HOLIDAY}

\section{$5.1 \quad$ INTRODUCTION}

Family holidays are about spending time with the family; at least, this is the more public side discussed here. The other side is own time, which will be discussed in the next chapter. Family time for the parents has the purpose of socially connecting with the (wider) family, generating a social identity, and spending quality time together that is different from normal routines. The meanings for the children can be more hedonistic and focused on the self, which emphasizes generational differences. Apart from possible divergences between the generations there are also gender differences present on holiday. The perspectives of generation, gender, and group dynamics will be demonstrated throughout this and the next chapter and then brought together in chapter 7. The focus in this chapter is on the theme of family time and its sub-themes as outlined in the theoretical framework (Figure 4.7). The discussion lets the participants present a journey in their voices from an idealised notion of family time as change of routine through to facilitating social connectedness and leading to establishing social identities, although this can result in enforced family time when needs for own time are ignored or imbalanced. Family time is the more accentuated and visible part of holidaying, as illustrated with the family photos used throughout the discussion, whereas own time is more private and concealed. The temporal dimension relating to both family time and own time is examined after the thematic discussion in chapter 6.

\subsection{IDEAL OF FAMILY TIME}

As reflected in the survey (see section 4.2.2), family holidays were about spending time together as a family, which is supported by the interview responses. Anticipations and recollections highlight an ideal of family time that becomes untangled as the discussion develops and culminates in enforced family time (see section 5.6). Yet, to begin with and as a lasting memory, family holidays were mainly about family time: 
"But the most important aspect about this holiday and any other holiday is spending time with the family." (Weka father, post-individual interview)

For those who work full-time, it was a time away from work and extended time with the family:

"Just having a break from work as we had quite a busy year, and just a family time.” (Fantail mother, pre-individual interview)

"To relax and de-stress from work, recovery time for me and time with the family I scrimp on during the year." (Kereru father, pre-individual interview)

This was particularly highlighted by a working mother where the father stayed at home:

"I hear a lot of stay-at-home mothers say I would love to go away without the kids but no, I want to go away with the kids. Maybe that is the person I am and not because I work. So holidays are my time to spend some time with them." (Kakariki mother, final individual interview)

For a full-time mother it was about a break from normality:

"For me it is a distraction away from life, actually just spending time together being somewhere doing whatever with family members." (Weka mother, post-family interview)

The time spent together was also attached to values. It is not just about the quantity of time but it also has to be good and fun. The notion of family time as being 'good' and enjoyable is, however, predominantly a parental concept:

"Just to relax and have good family time together and spend time with each other and do things that we don't normally do when we are at home." (Goldfinch mother, post-individual interview)

“Enjoy each other’s company.” (Kea mother, pre-family interview)

The notion of family time as being fun was more prevalent in fathers and children than mothers, which could indicate that mothers perceive it as less pleasurable:

"It is mainly for family rather than me, just to have some family time together, just have some fun and have a good time." (Takahe father, preindividual interview)

“Going out, having some time together and having fun.” (Tui girl, 14, prefamily interview) 
The importance of fun for children has already been emphasized in relation to establishing a definition of family holidays (see section 4.3.2) and will be explored more later. From a parental perspective, family holidays have an idealised value of goodness attached to family time that reflects the Western discourse (see section 2.3.1). At the same time, what was also sought was a break from family commitments, which was then perceived as relaxing. The notion of relaxation within own time will be explored in the next chapter (see section 6.3.2). The following response exemplified this dual meaning of family holidays:

"A good family time, time together and time to relax." (Hoiho mother, final individual interview)

The children's perspective on family holidays was more hedonistic and focused on the self. Their ideal was primarily about having fun:

"Just to get out of Wellington and have some fun." (Kea girl1, 10, postindividual interview)

These responses outline the broader themes about what is important to family members on holiday which govern the discussion of the findings: the ideals of family togetherness and fun are presented in this chapter and own time in the next chapter. From a parental perspective family time is idealised, driving not only the main motivations for family holidays but also distilling the social dimension as its main meaning. Children are more self-interested and hedonistic in desiring fun on holiday. When the family dynamics are taken into account it emerges that, apart from family time, family members also desire their own time away from family commitments, which will be discussed in the next chapter. However, the ideal of family time is very much linked to collective quality time.

\subsection{CHANGE OF ROUTINE/QUALITY TIME}

The importance of change of routine from whatever was considered normal life (home, work, or school) was echoed throughout the interviews and across generation and gender. It mirrored findings in the parental survey as the second most important characteristic in a definition of family holidays and a key travel motivation (see section 4.3.1). Holidays also offered children an element of escape: 
"It [holiday] felt like a nice way to get out of the house, get away from everyday life." (Tui girl, 14, post-individual interview)

"It [holiday] is a change of routine, of everything and scenery." (Pukeko boy2, 11, final individual interview)

This meant a suspension on holiday of routines which are valued by children in regular daily life (see Christensen, 2002). Mostly the responses mentioned an element of 'difference' from normality or everyday life and also included elements of 'fun' and entertainment. For the parents, family holidays were more purposeful in that they had the value of quality attached to it:

"On holiday everyone is in a good mood and you get to spend quality time." (Kakariki mother, pre-individual interview)

"We certainly spend a lot more quality, quantity time absolutely than a normal day or week-end.” (Weka father, final individual interview)

"It is different [on holiday] because there is more quality time and you are more relaxed and you can spend a longer time with your family. A lot of things are different. We eat different food and stuff we normally don't eat. You are more relaxed. Everything is different, we dress differently, more shorts and T-shirts and stuff." (Goldfinch father, final individual interview)

Family holidays, then, were perceived as 'quality time' which has become part of the cultural discourse of what it means to be a 'good' parent (Snyder, 2007) including offering different fun activities for the children. The last response draws attention to the element of difference from normal routine, including food and dress style. The meaning of difference is discussed next, first generally and then in relation to 'at home', and compared with domestic and international holidays. The discussion then moves to fun and entertainment as important elements of that change of routine, particularly with regards to children.

\subsubsection{DIFFERENT FROM NORMAL}

The notion of difference could have a variety of connotations from being different from normal routine at home to being different from normal holidays. The meaning of difference on family holiday was, thus, on a continuum from holidaying at home to exotic overseas holidays. For the majority of respondents difference meant a different holiday each year, but at the lowest denominator it was about being different from normal routines as epitomised by these responses: 
"My boss asked me at a training course to describe what is your perfect holiday and I said different. I did not mean different each year but I meant different from what I do normally. And normally it is schedules, running backwards and forwards, do this and do that, go up, I got to do that...adopting a different rhythm and if you miss it is not critical.” (Kereru father, final individual interview)

"It [holidays] is just different I guess. I've said that a lot but something different is always good if you do the same thing every day then something different is good.” (Takahe boy, 12, pre-family interview)

This meant that difference was essentially compared with everyday life rather than other holidays, which also contained elements of being a more concentrated time, expansion of the mind as well as stress reduction:

"It is just a concentrated time. In my mind you can spend a week on holiday and it is like six months at home in terms of the concentration of time and effort, energy and good times, cheering and stuff." (Weka father, final individual interview)

"And you need to go away to do something different. And to do something different expands everybody. You taste, try and do different things and you behave differently. That is a good learning experience for the boys and for us too. Otherwise you get into a rut that is the motivation.” (Pukeko mother, post-individual interview)

Holidays can, thus, help in achieving a balance in life by going away from home (see Zabriskie \& McCormick, 2001). The fact that the parents felt more relaxed on holiday was reflected in this response which illustrated the perceived difference in other family members and the meaning of difference for the children:

"Mum and dad are more relaxed for one thing. They are not screaming at you: 'go and do the dishes'. Yes they were but they are more relaxed. Not having to go to school is good, not having to wake up in the morning is good, sleeping in is good.” (Pukeko boy1, 13, final individual interview)

For many families difference also meant different or novel holidays each year (see section 4.4.1):

"We did want to go somewhere different, somewhere we hadn't been before." (Hoiho father, post-family interview)

Different food or meals in a different setting from normal became an important topic for all the family members and was often mentioned as a family highlight. These different experiences were also shared experiences and centred on the 
collective enjoyment of difference. Photographs provided an on-holiday element here (Table 3.2). Family members were asked to take photos of positive and negative holiday experiences. A selection of their own photos was then used during the interviews as prompts (see section 3.5.2), and is presented here when the respondents talked about them.

"I wouldn't normally take photos of the food. But definitely shots where it is something different. I think it is getting less and less that kids are having fish and chips in a tent." (Kea father, postindividual interview)

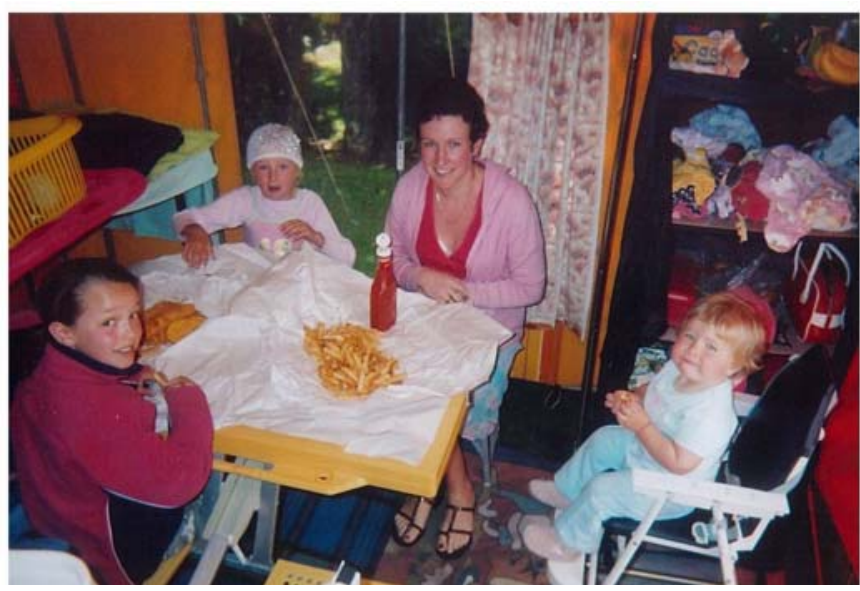

"Having friends up there and sitting around with candles going in the evening on the deck and chatting and having a meal, having an entrée of smoked mussels that I caught on the rocks." (Kereru father, final individual interview)

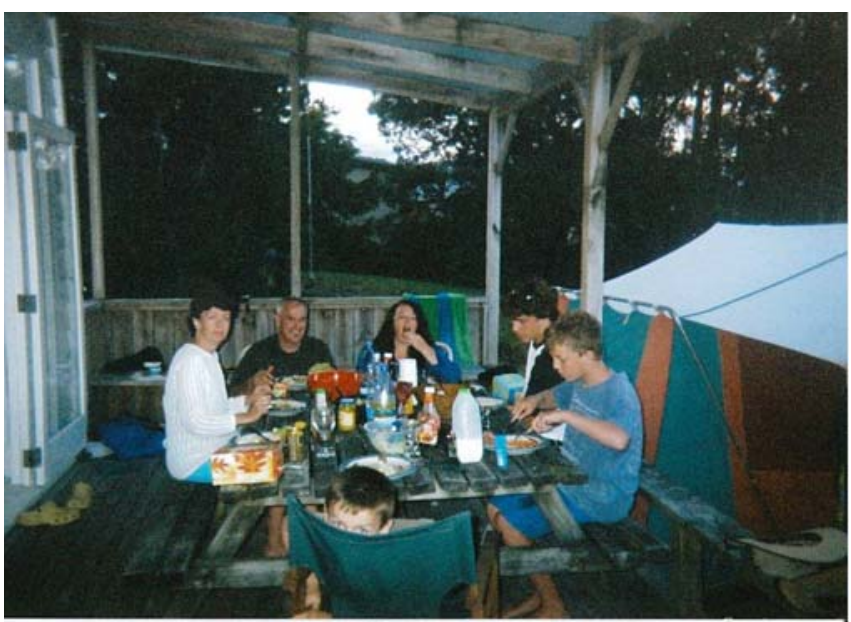

Doing different activities from home, such as card and board games, was linked to relaxation (see section 6.3.2):

"We make time in the evenings to play games which we don't get around to doing at home. So card games and monopoly and things like that and she [daughter] really enjoys that. It is definitely good quality time." (Fantail mother, final individual interview)

"Just after meal time we play cards by campfire torch that we would not normally do at home. We would not normally sit around and play 500 or something but we do that when we go camping." (Pukeko father, final individual interview)

Also important were activities such as horse riding, fishing, kayaking, boogie boarding, and swimming in the sea, which were not normally done at home: 
"Probably trying something that is out of the usual that we do not normally do like walking on the beach, horse riding, snorkelling, going for a walk in the bush." (Tui mother, pre-family interview)

"Fishing because we do not do much of that and have not done it for years." (Pukeko boy1, 13, pre-individual interview)

What stood out as family highlights were also chance encounters and events because they were novel and unexpected, such as a beauty pageant:

"I think we all enjoyed at the time the Mrs and Miss Arataki show because it was quite funny with the little kids running around and some running away and not really doing the show. That was quite unusual because I don't think we've ever had anything like this before." (Takahe mother, post-family interview)

Not having technology on holiday was also considered different and desirable in that it meant distancing oneself from technology that could distract from family time:

"I like not having the computer. When the computer is here the kids use it but it is great not having it. And not having Sky so they can't just sit and watch TV. They actually did get out and played." (Kakariki mother, postindividual interview)

It also meant bringing back a simpler way of life and constitutes an inversion from everyday urban life, as mentioned previously with regards to second-home tourism (see section 2.2.3). With regards to different roles on holiday, there were gendered domestic elements that remained on holiday. Most noticeable was the preoccupation with planning meals and providing nutritious food that continued for most mothers on holiday:

"We only have to do our clothes and food but then that all comes back to me. I kind of try with the food to plan ahead because I do not want have to buy everything when we get there. If I can plan the meals, just an idea of meals anyway, that will take the pressure off while I am there." (Kea mother, pre-individual interview)

"And there was just food always constantly at the back of your mind because there were no facilities." (Tui mother, post-family interview)

However, it was also acknowledged that holidays provided a role reversal with regards to cooking in that men enjoyed cooking on the barbecue or women cooked who usually did not: 
"That is just <husband> doing the cooking and that is something I really appreciate. He does the barbecuing here but it is a bit different when we are camping. He can do more on that and he takes more responsibility than he would at home. Which is nice, it is a break for me.” (Kea mother, post-individual interview)

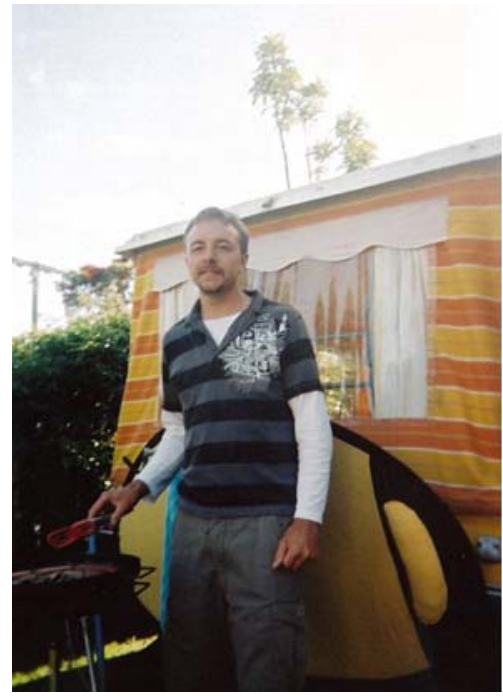

" $<$ Husband $>$ does a lot of cooking during the year and I do all the cooking on holiday. I don't know why that is. Routines are changed." (Fantail mother, final family interview)

What remained for the fathers on holiday was the domestic responsibility of organising, packing, and unpacking of the gear:

"At the end there [photo] I am the one responsible for putting things together again. There are things that come out that need to be washed and then they have to be put back for next time. It is a small responsibility, just different aspects."

(Kea father, post-individual interview)

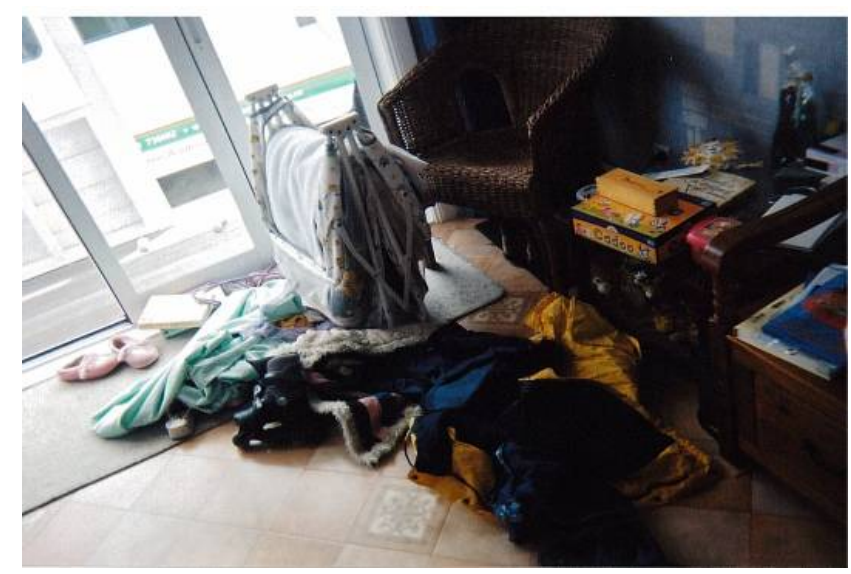

Fathers were also actively involved in setting up the camp site:

"I always enjoy putting up the tent and setting up home when we get where we are going." (Pukeko father, post-individual interview)

This signified a continuation from their usual responsibilities for home spaces (see Allen \& Daly, 2005). What emerged was that gendered domestic roles largely remained on holiday but some role reversals took place. Getting a break from these home routines and domestic commitments was particularly sought by the mothers and will be discussed later (see sections 5.4.3 and 6.3.2). 
Other examples were seeing and exploring different things from normal:

"You see different things but when you are at home you have been to most of the places. But then on holiday we haven't seen anything there until we actually go.” (Kakariki girl, 8, final individual interview)

"Just finding new places, seeing new things, experiencing things that are different from what you have got around from where you live. Exploring is a very broad definition. I think it covers anything that is a bit different from your everyday activities at home.” (Hoiho mother, final family interview)

Holidays, then, were generally about a different routine and environment, some role reversals, a break from technology, doing things different from normal in which mealtimes and novel food experiences played an essential part. This also introduced the importance of a sensual and embodied experience to family holidays in the way of different things affecting the human senses (see section 2.6.2). Embodiment proved particularly important for the children, especially with regards to touching animals and new taste sensations, and remained in their longer-term memory (see section 4.4.4 with regards to smells):

"And there were curly fries, they were yummy and some of them were like springs." (Weka girls, 7 and 8 , final family interview)

"And me and dad went across the road from where we were staying and there were all these horses. And every day we fed the same horse a carrot because the horse every time came up." (Takahe girl, 10, final family interview)

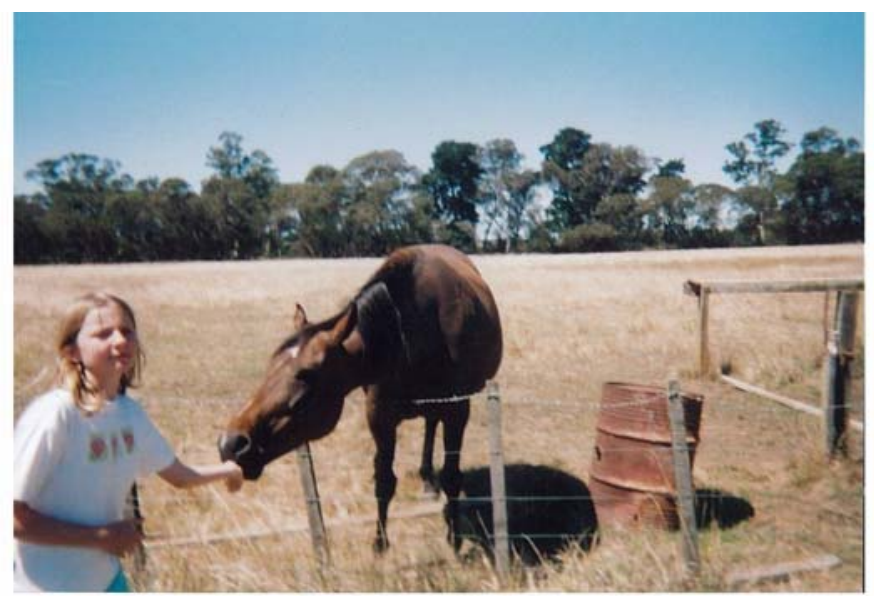

Regarding memory, what was often remembered long after it happened were events, activities, and meals that contained an element of surprise or discovery:

"But thinking about some of the highlights from the other holidays, actually when we come back from holiday often the things we will repeat and tell others about will be days when we actually went on some kind of adventure, discovered something new or did something really different." (Hoiho mother, final family interview) 
The sub-theme of different from normal, thus, applied to all family members; for full-time working parents it was away from work, for part-time working and stayat-home mothers it was away from home routines, whereas for children it was a break from school routines. Holidays were also about experiencing different activities and food, especially embodied experiences for the children. The different experiences from normal in family time are fundamental to family members' understanding of a holiday and included elements of the unexpected and novel which could lead to memorable experiences. In terms of the spectrum of difference from the norm, those experiences could range from at home to domestic to overseas holidays. The emphasis is here on family time at different locations. For most, a holiday at home was not considered sufficiently different from normal which, meant that family holidays were usually taken domestically and internationally, with overseas holidays deemed more different than New Zealand holidays.

\section{Holiday at home}

As identified earlier in the survey, when defining family holidays, it can also involve holidaying using the home as a base (see section 4.3.1). However, when queried at the family interviews there was usually no consensus amongst the family members to what the notion of holiday at home means. What emerged was that theoretically and with good planning a holiday at home was possible because it forms the base for different experiences. Practically this was not considered a family holiday because a change from normal routine was too hard to achieve, as demonstrated by this exchange at the Pukeko pre-family interview:

Boy2, 11: "It is not a holiday if it is at home."

Father: "Important message, can you have a holiday at home? No, there are too many chores to do to be considered a holiday because you would be doing things.”

Some families also had work and care-giving commitments that made holidaying at home difficult to achieve:

"We do have other commitments here especially with my mother when we are here." (Fantail father, final individual interview) 
"It [holiday at home] is pretty difficult for us because of our work. Work in real estate, so if people know that you are at home they will ring you. So it would not work." (Kereru mother, pre-family interview)

Going away on holiday was considered preferable to holidaying at home and was also what was generally meant in the term family holiday:

"Obviously you could be on holiday [at home] but would not call it a family holiday unless you spend at least a night away. It needs to be longer time and further away.” (Hoiho mother, pre-family interview)

"For me a holiday is really when I am away from home." (Kea father, prefamily interview)

Domestic, work, and care-giving commitments made it practically difficult to consider staying at home on holiday. Instead, holidays away from home were preferred for providing a further degree of difference from normal, with domestic holidays considered more novel than holidaying at home.

\section{Domestic holiday}

Holidays within New Zealand were generally considered as special with regards to what the different destinations had to offer, especially over the summer months:

"It is pretty idyllic. There are probably some overseas places that would be nice to go but I think it would be hard to find a combination, not the crowds and expense. The nice unspoilt beaches are really special." (Kereru mother, pre-individual interview)

"We are just very fortunate because it [Marlborough Sounds] is one of the nicest boating areas probably in the world. And we are just very fortunate to have it on our door steps. And it is nice to be able to make the most of it because not many New Zealanders actually do." (Fantail father, postindividual interview)

For most families domestic summer holidays were about experiencing different aspects of New Zealand, exposing and teaching the children about different parts of the country, which was linked to national identity and generativity as will be discussed in section 5.5:

"We have had a lot of holidays in New Zealand. We have been down to Queenstown, Nelson, and all sorts of places. It is important because the kids need to know their own country." (Kea mother, pre-family interview)

For other families it was the closeness to extended family and friends which made domestic holidaying different from normal: 
"It was important [to holiday in New Zealand] because we had to see our relatives and they are here and we wanted Christmas with them." (Weka mother, post-family interview)

Domestic holidays were also considered as requiring less organisation, less expensive (see section 4.4.2), and generally less stressful than overseas holidays:

"Travelling in New Zealand is so much easier and there is anything you want in New Zealand apart from coconut palms. You can achieve that in two days travel.” (Tui mother, post-individual interview)

In general, domestic holidays, especially over summer, were perceived by the parents as offering a variety of different experiences that were agreeable, accessible, affordable, family orientated, and part of New Zealand culture and heritage, including catching up with relatives:

"I think New Zealand has heaps of places to holiday that are just as good or nearly as good as overseas.” (Hoiho father, post-individual interview)

"I like to think half the holidays are here and half the holidays are overseas. But most of them are here. I think it is important because it is part of our heritage and culture. And hopefully when the kids are older they will go back to New Plymouth and they can understand and remember it more." (Kakariki father, post-individual interview)

For the children, domestic holidays were more about the different activities on offer and having fun, rather than the destination:

"Just to see that there are great things that you can do in New Zealand, that you do not have to go out of the country is good." (Takahe boy, 12, postfamily interview)

"Doesn't really bother me as long as it is fun I don't mind where we are going.” (Kereru boy1, 16, post-individual interview)

For some children, especially girls, it was more about staying in the country to be able to catch up with extended family (see section 5.4.1):

"I like overseas but I actually prefer staying here and seeing my cousins. I think that is the best type of holiday for me." (Tui girl, 14, final family interview)

The responses confirmed a strong domestic summer holiday tradition (see section 2.2.3), especially for the parents, which was also tied to VFR (see section 5.4). Domestic holidays were perceived as providing enough variety and different experiences for everyone: children were more interested in fun activities and 
social experiences whereas parents also had more deliberate motives such as national identity and traditions (see section 5.5) which differed from overseas holidays.

\section{International holidays}

Compared with domestic holidays, overseas holidays were desired more for different reasons, such as escape in winter, VFR, excitement, interest, and for variety. By going overseas the spectrum of difference from the norm expanded to the more unknown and exotic.

"We normally go somewhere hot in winter [overseas] and then in summer on a [domestic] road trip.” (Weka mother, pre-family interview)

"[Going overseas] is not a question of better. It is just a question of different because I like the stimulation of going to different places, different things all the time." (Takahe father, post individual interview)

International holidays were also perceived by the parents to be more stressful, hectic, and needing more planning than domestic holidays, which means that facilitating difference can come at a cost to the parents:

"If we go overseas then we always do pack in a lot." (Pukeko father, prefamily interview)

"Going overseas is more intense. It is not necessarily a holiday per se. It is a lot more relaxing going to [my] Auntie [in NZ].” (Weka mother, final family interview)

Some families also had plans to expose their children to the exotic end of the spectrum of difference, as these responses demonstrated:

"My ideal would be going to Vietnam and seeing something completely different because the holidays we have done have been fairly unadventurous." (Pukeko mother, pre-family interview)

"Now that they are getting older we will take them to like Egypt is actually my favourite place in Africa or Zimbabwe. But we want them to be older...I think that will give them much more life skills." (Weka mother, final individual interview)

Awareness of the level of difference, including sensory experiences, on overseas holidays in children was linked to international travel exposure, as this exchange 
between the 8 and 11 year old Hoiho brothers (who had travelled to Vanuatu and Australia before) at the post-family interview demonstrated:

Boy1: "Fiji or Australia because I like to go overseas.”

Boy2: "Me too."

Boy1: "Totally different animals, totally different plants."

Boy2: "Insects and sounds and sights."

Boy1: "When you go somewhere in New Zealand there are a lot of trees and bush and sea and streams. But I like to go somewhere completely different. I do not know what other places there are that is why I like to go and see."

And another example:

"It is fun to go overseas because it is a different culture, different experiences and all that. And there is a different way in how people live. Like we went to Fiji and it was just like everybody is living in tin huts, everything. I enjoyed seeing how other people live." (Pukeko boy1, 13, postindividual interview)

However, overseas holidays were essentially still about family time:

"Every holiday is different anyway in terms of organisation but the common theme is spending time with the family as long as that is a relaxing time." (Weka father, post-individual interview)

International holidays emerged as part of the spectrum of difference that begins with holidays at home and centres on the ideal of family time. For the parents, holidaying overseas was perceived as more work than domestic holidays but considered an important part of good parenting by offering 'grander' experiences (see Blichfeldt, 2006, 2007) and a variety of experiences to their children. Interest in overseas holidays for children was linked to their travel career in that children with previous international travel exposure expressed stronger desires to travel further, particularly the boys. Girls were more connected to extended family. Children in particular mentioned the different embodied experiences that overseas had to offer which were also considered fun. Difference, and especially the shared experience of difference, then becomes an important dimension of family holidays regardless of where they are taken (at home, domestically or internationally).

\subsubsection{FUN/ENTERTAINMENT}

The importance of fun for the children has been argued earlier (see section 4.3.2) and is expanded here. While fun is considered a hedonistic concept it is central to 
the understanding of family holidays as a collective pursuit. Photos and, ultimately, memories revolved around capturing 'fun' holiday moments, especially for the children. Parents also liked to choose photos depicting 'good times' where the children, at least, enjoyed themselves. This perpetuated the image of fun and therefore 'good' holidays linked to good parenting and creating positive family memories (see section 5.5.1) but might hide any compromises or sacrifices made to ensure the children were entertained (see section 6.6):

"This to me illustrates the family photo, the family all together having fun on the beach." (Hoiho father, final family interview)

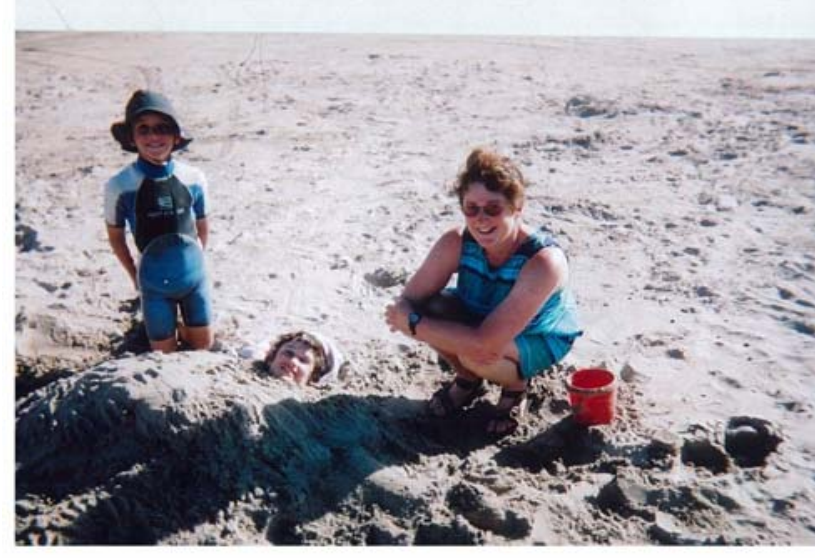

"Those are the photos that I chose. Why? I guess the kids seem to be having fun $I$ suppose, so kids in the foreground. I think that sums it up the children are important for the holiday." (Kakariki father, final individual interview)

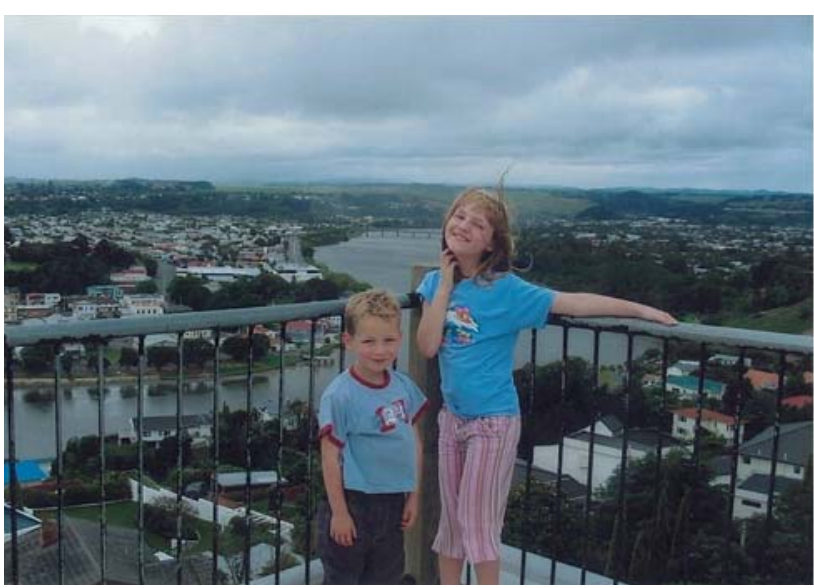

For the children fun was consistently mentioned as essential to holidays and was also reflected in their highlights and their favourite photos chosen. Theme parks (e.g., Rainbow's End and Splash Planet), animal parks (e.g., Marineland and Kelly Tarlton's), and other attractions catering towards children's interests (see section 6.3) were rated highly by those children who experienced them as part of their holiday:

"The Sky Tower was really fun, probably the Sky Tower and Rainbow's End were the funnest. But the rest was fun too. I think that was the highlight because at Rainbow's End there are so many things to do you never know when you are done or if there is something more to do." (Goldfinch girl, 10, final individual interview) 
A family highlight that was considered fun could also simply be playing cricket in the evening, as illustrated by the Tui family in their final family interview:

Mother: "<Daughter> got the cricket game going."

Girl, 14: "Yes, that was so much fun. You guys didn't want to do it at first because I really like playing cricket especially when it is with family, not really competitive teenagers but just a nice relaxed game with everyone else..."

Mother: "But we enjoyed those."

Girl: "I enjoyed the game of cricket more than the cards because you are actually doing something rather than sitting around."

Fun was very much tied to activities, to doing things, and also retrospectively, the selected photos reflected moments that were considered funny:

"This [photo] was at Anaura Bay and we got the kayak trolley and this plank and we tied it together and dad tried to carry us around... and this was funny." (Hoiho boy1, 11, final family interview)

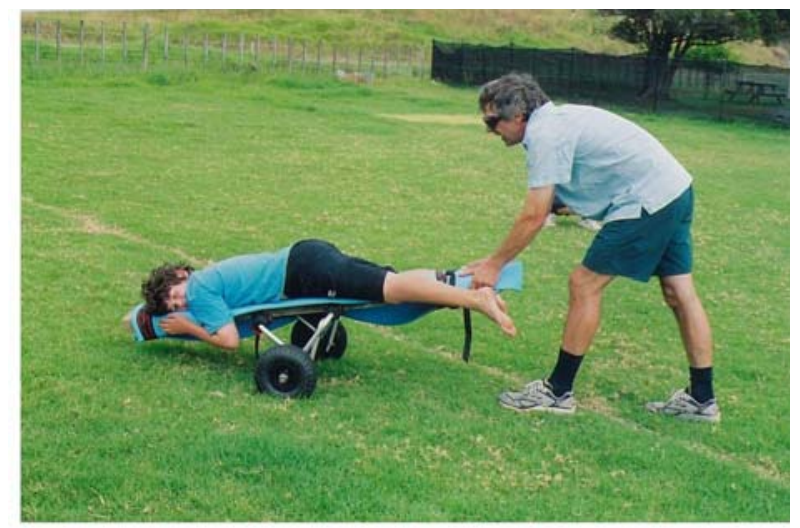

"We have a photo and it is us in the pool and it is really funny. <Sister> thinks it is weird because she is leaning like that and I am like that...taking a breath and it is really funny." (Kea girl2, 7, final individual interview)

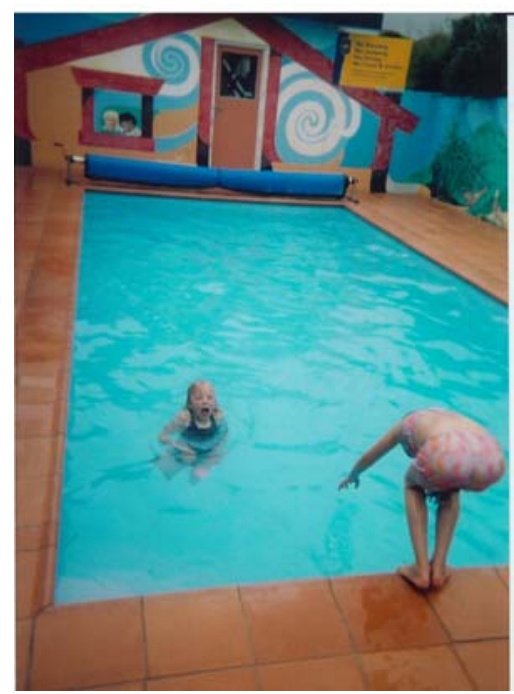


"I like the [photo] of the swing bridge because daddy looks funny.” (Kakariki girl, 8, final individual interview)

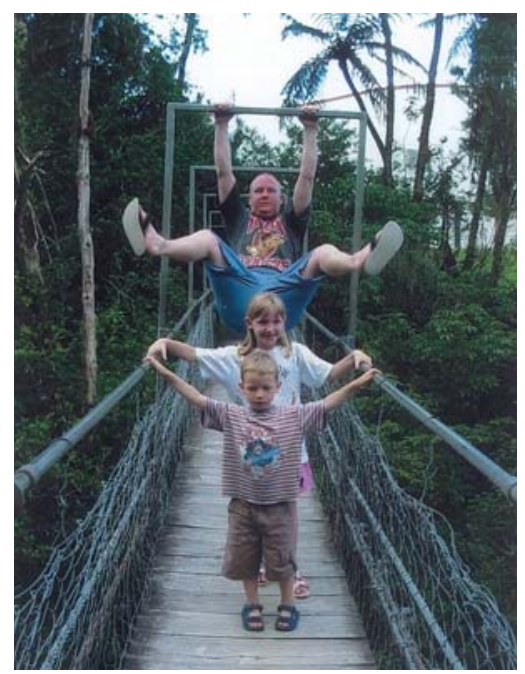

Memory for the children was mostly connected to photos portraying fun or funny moments, thus perpetuating the image of holidays as fun:

"Most of these [photos] are just fun times with the family, doing fun stuff." (Tui girl, 14, final individual interview)

While fun was central to children on holiday it was also connected to other people. The best fun to be had for children was with others, which could include friends (see section 6.4.2):

"Splash Planet was probably the best thing we did because I had friends there as well. I could hang out with them and it was probably the funnest thing." (Takahe boy, 12, final individual interview)

For the parents fun was more connected to providing entertainment. For example, when taking the children to theme parks this involved compromises for the parents (see section 4.3.2) rather than reflecting their interest. This was particularly true for the mothers, as fathers were generally more content to be actively involved, as illustrated by the Hoiho family:

Father (post-family interview): "I did a lot of rides [at Rainbow's End] with the children. I was not a spectator so I accompanied the children on those rides. So I enjoyed those days as well because the children were enjoying themselves and just for their own sake. They were quite fun too."

Mother (final individual interview): "And there are certain things that I don't enjoy as much but I would do anyway. It is not that I hate them because if my kids are enjoying it then that is enough. Things like Rainbow's End do not particularly appeal to me at all.” 
It emerged that the meaning of providing active fun as part of entertainment was more prevalent for the fathers, who also considered it more their responsibility than the mothers:

"I suppose at those campgrounds I would be happy to just sit in the chair and read but I realise that it is important for them particularly to be entertained and have fun with me and do these sort of activities when I would personally be just as happy sitting and reading because $<$ wife $>$ tends to spend time during the term with dealing with the children while I am at work. I feel it is important for me to spend that time with the children." (Hoiho father, final individual interview)

Additionally for the parents, especially the mothers, it was important watching and knowing children were having fun rather than being actively involved. Fun family time, then, entailed more than physically doing things together and also encompassed the mental realm which was also perceived as relaxing (see section 6.3.1):

"Going to the aquarium and going to Marineland they [children] seemed to be quite taken with [animals], that was quite fun. And that is relaxing too because you are watching a show and you are not monitoring and trying to entertain. It has been done for you, so that is easy." (Takahe mother, final individual interview)

"Watching everyone having fun like at the luge together as a family and having <oldest son> involved as he gets older he is not around as much." (Kereru mother, final individual interview)

For the children, family time was about having active fun which constituted their primary 'purpose' of family holidays (Hilbrecht et al., 2008). This means that children want to have fun, parents want to see their children having fun (and perhaps participate in that fun) and capture that fun on film, thus, shaping future memories and perpetuating the image of happy family holidays. Fun has an element of spontaneity to it: sometimes it just happens and cannot be engineered. Fun for children is a product of collective moments and social interaction whereas for parents it can also entail the role as provider of fun that brings contentment rather than fun for themselves. For fathers it means a more active involvement and responsibility in providing fun whereas mothers prefer a more passive involvement and relinquishment of the entertainment role. For parents the provision of fun within family time sometimes involves making compromises and sacrifices to ensure the children are having fun (see section 6.6). 


\subsection{SOCIAL CONNECTEDNESS/VFR}

Family holidays were primarily about maintaining social relationships where meaning was derived through social interaction within the nuclear family, extended family, and friends. The social dimension on family holidays encompassed positive and negative elements; extended family could provide support as well as become an obligation. Issues of sociality were paramount to family holidays (see section 2.6.3) and were supported by photographic images. While social connectedness was sought on holidays it also provided the family group with the necessary cooperation to allow for individual own time (see section 6.6.1). The choice of photos for the parents was mainly about reproducing social relations, which is also about creating memories (see section 5.5.1):

"[Chose photos, as illustrated below] because I quite like photos with people in them, always have done rather than landscapes. I thought they were quite representative of us all together having a nice time and some of the things we did." (Takahe father, post- individual interview)
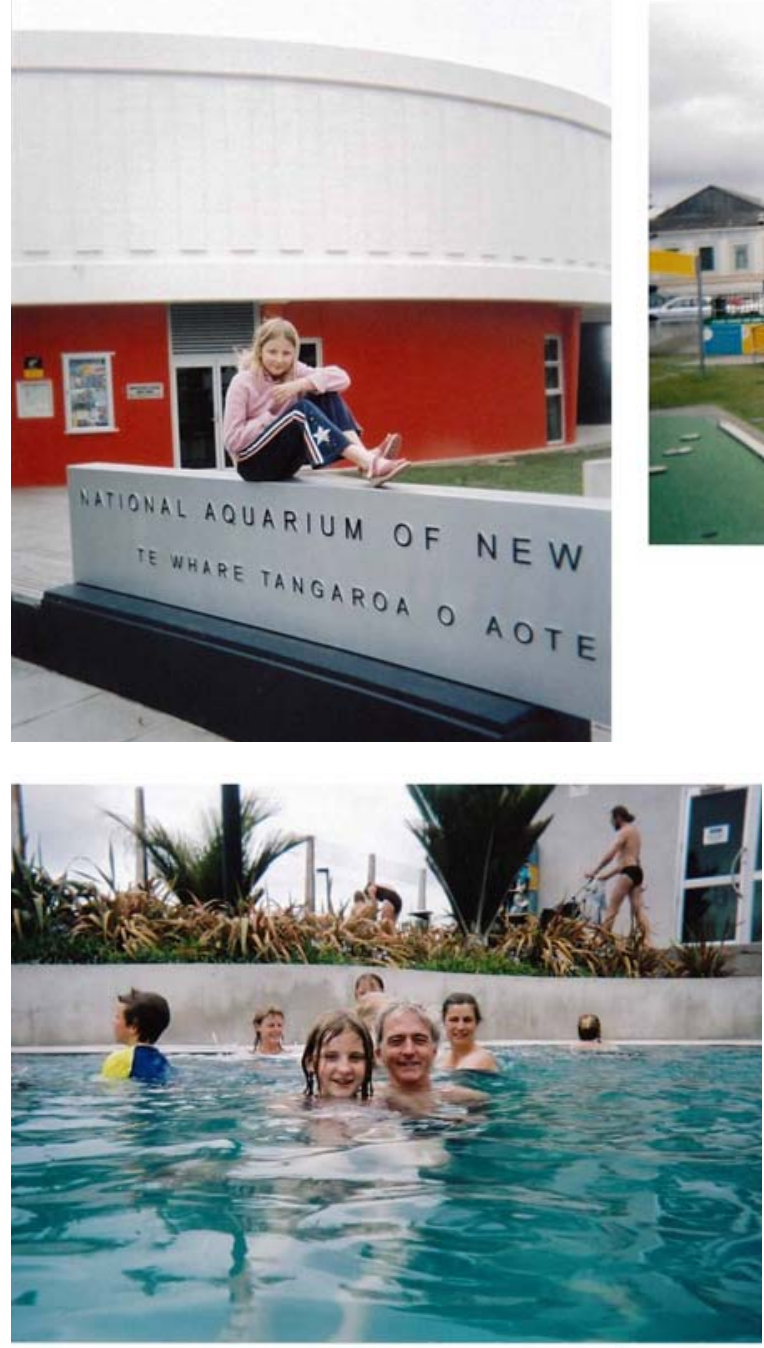
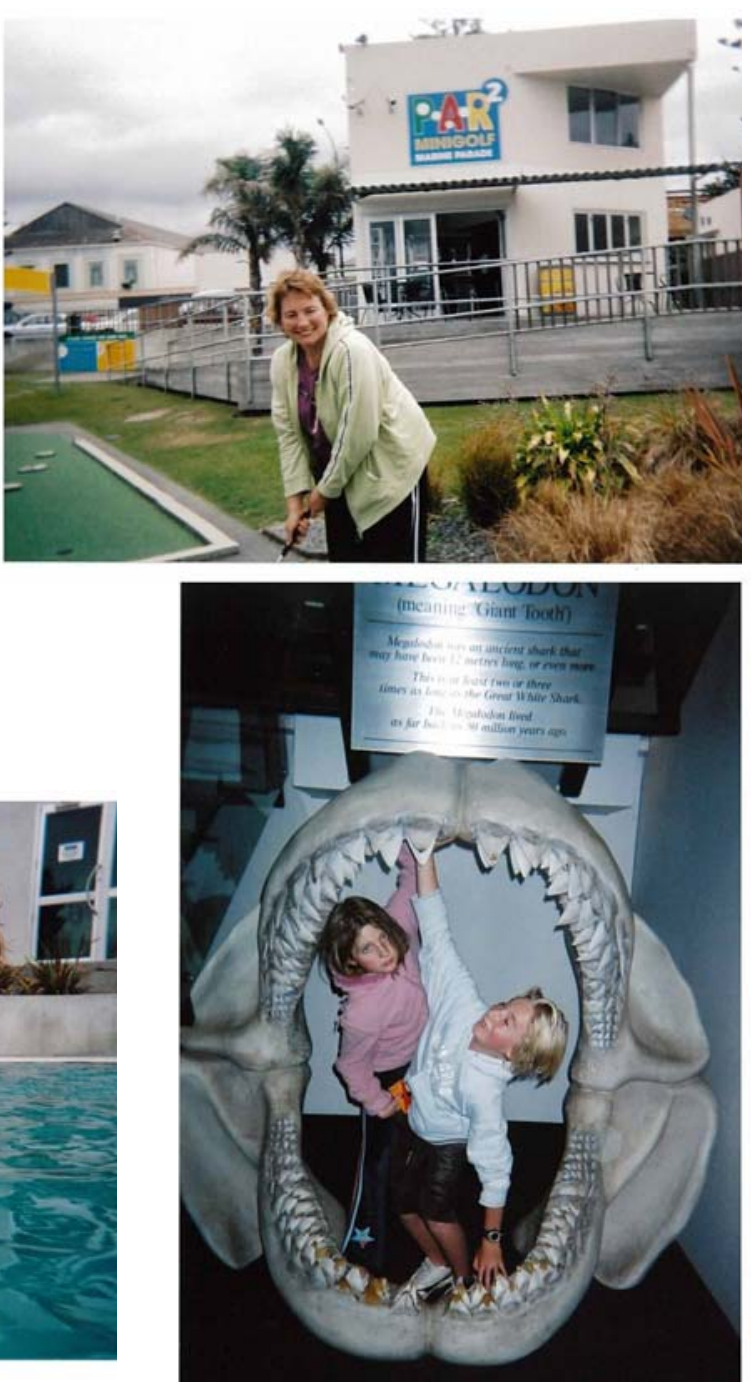
"These are all photos that mean something to me. There is one of the family with the kids. In all of them there is at least one in them [family member]." (Kea mother, post-individual interview)

"I only picked those photos because they have got my kids in them or my [extended] family.” (Weka mother, post-individual interview)

These images were all part of the family gaze (see Haldrup \& Larsen, 2003; Larsen, 2005). Social connection, which was represented through the photos that ultimately influenced the memory formation, centred on the nuclear and the extended family but could also include friends, as friends could become like family in the absence of an extended family network. Tourism often involves (re)connections with social relations and can include social obligations. However, family holidays are also about providing social support for the family members.

\subsubsection{TIME FOR (RE)CONNECTING}

All the families on their summer holiday stayed with, visited, or had family and friends coming along on holiday. In a domestic context, VFR, thus, played an important role for families to (re)connect with social relations:

"We tend to do a bit of a meander around to catch up with people, very much the same way continuing contacts and renewing friendships." (Tui mother, final family interview)

In the first instance, for the parents (re)connecting was about bonding and getting to know their own nuclear family again through spending time together, which is connected to establishing social identities (see section 5.5):

"It can be a time of reflection but also a time of being together with our family because the time leading up to Christmas especially we are all so busy and I work nights as well. There can be a real gelling again." (Kea father, final individual interview)

"I would say it drew us much closer. You really get to know, it sounds funny, but about what they like and what they don't like and things that you maybe didn't realise." (Goldfinch mother, final family interview)

It was also about spending time with the individual children, especially in the case of siblings, which was probed in the final interviews: 
"It is nice to have the one on one time with each of them even if it is just a short little jaunt somewhere." (Kea mother, final individual interview)

"It is good to spend time with them individually because each likes completely different things. You always end up doing different things with each of them." (Takahe father, final individual interview)

Differences between the children were particularly noted with regards to gender:

"Daughter...she likes her comfort activities whereas son likes quite vigorous activities. But they both like the animal ones." (Takahe mother, final individual interview)

"It is different because <daughter> is so studious like we talk about books and she likes learning whereas <son> is rough and tumble and wants to jump and wrestle." (Kakariki mother, final individual interview)

Generally, holidays for the parents were more about spending time with all the children rather than individually:

"We didn't tend to separate off, we tended to be together." (Tui mother, final individual interview)

In the second instance, for the parents, and especially mothers, it was about (re)connecting with the extended family:

"I like [holidays] because we see all the family and I think we should see them more. I like it because of that aspect. You are so far away nowadays you just don't get that involvement." (Weka mother, post-family interview)

In the third instance, it was about (re)connecting with friends who were considered part of the family, as the immigrant Goldfinch family, who have no family living in New Zealand, demonstrated at the final family interview:

Mother: "And they are the kind of friends who became like family. I am 100\% sure that both the families [we visited] will be friends for the rest of our lives."

Girl, 10: "We are so close that I call them my New Zealand cousins."

Holidays also enabled children to spend more time with their parents in a less stressed way, especially if the parents were working full-time:

"I have more time to spend with dad because he is at work from about 6 or 7am until we have dinner and then I go to bed. So it is really nice seeing dad more and mum not stressed about work. It is just seeing everyone and like talking more.” (Pukeko boy2, 11, final individual interview)

"It does give you a lot more opportunity to catch up like be with them and spend time with them which you don't get to do that much at home because I 
have got a lot of other things to do.” (Takahe boy, 12, final individual interview)

In general, for the children it was less about the quantity of time but more about how parents were spending their time with them, confirming the findings of Galinsky (1999) and Christensen (2002). There were noticeable gender differences in what the children did with their mothers or fathers, which reflected differences in personal interests (see section 6.3):

"With mum it is more relaxing like playing card games; with dad it is more sailing and fishing." (Kereru boy3, 10, final individual interview)

"Mum doesn't really like running around and sports things. She is more of an organised, relaxing person. And dad is more of a fun, sporty type person. So I like going with dad because I like running around." (Kea girl1, 10, final individual interview)

"With my dad we do really rough things like we go on Fearful which is this thing where you go up and then you fall down...whereas me and my mum are more gentle. We sit and chat and talk and laugh.” (Goldfinch girl, 10, final individual interview)

This confirmed earlier findings that mothers seek a more emotional involvement with their children whereas fathers are more active and physical in their interaction (see section 5.3.2). It supports the notion that fathers take on a more active role in entertaining children on holiday.

For some of the children, and particularly the girls, holidays were predominantly about (re)connecting with the extended family like grandparents and cousins rather than the nuclear family:

“Just grandparents and cousins make the holiday for me I reckon.” (Tui girl, 14, final individual interview)

"Seeing all the relatives and having fun with them as well, particularly [my] cousin.” (Weka girl1, 8, post-family interview)

Building up social connections and maintaining them was particularly important for the female members of the family. For the fathers it was more about the immediate family, whereas the mothers were more deliberate in establishing wider social relationships. There were noticeable gender differences in the way individual parents spent time with their children: for mothers it was more about 
connecting emotionally whereas fathers connected more through physical activities. Children were more interested in doing things with their parents and their extended family; especially girls with their cousins (see section 6.4). Holidays, then, represent the main opportunity for the family, especially children (Havitz, 2007), to connect with their extended family. VFR, thus, is intricately integrated with family holidays, which can turn to social obligation when there is a lack of choice.

\subsubsection{SOCIAL OBLIGATION}

The opportunity to visit or travel with friends and relatives on holiday can also become an obligation, as the Goldfinch family experienced. This affected their future plans for VFR travel:

Mother: "I realised this is not going to work and we already made arrangements to go to them for a couple of days. But I felt we couldn't cancel it because the husband is actually really nice and the children. And we felt we should just push through. But that was not enjoyable at all. It was really stressful and I couldn't wait to get away. That is definitely something I won't do again if I don't know people just to go on the holiday. You are locked in and you don't really know how to get out of it again." (Post-individual interview)

Girl, 10: "Because the woman said she hated children.” (Final family interview)

Other dutiful social experiences that involved the extended family were captured in the following responses:

"At [my father's] farm for me it is quite tiring because I cook and I clean and I do all sorts of stuff. It is not a holiday for me. It is lovely, don't get me wrong. I love dad but that is my chance to see that everything is fine with him. And I still have to do everything, in fact even more, because a 92 year old' kitchen is quite a challenge to produce a Christmas lunch for everybody." (Pukeko mother, post-individual interview)

"The next [holiday] is purely because we have to see the family again. It is more a chore rather than a holiday." (Tui father, final individual interview)

While (re)connecting with social relations was sought on family holidays there were also social connections that were viewed as obligations. For the parents, these responsibilities were accepted when part of care giving and looking after the extended family. In the case of non-core friends those responsibilities were 
preferred to be relinquished. When social obligation did not involve the next of kin it was considered to be a matter of choice:

"For me I sometimes like the freedom of not calling on other people but it is nice to have the option to do that." (Takahe mother, pre-family interview)

Social obligation, therefore, was linked to personal choice and closeness to the social relations.

\subsubsection{SOCIAL SUPPORT}

Holidaying or staying with extended family or friends could also add another dimension to family holidays in that the social relations provided support to the functioning of the family group:

"I think just being with the [extended] family [on holiday] and having all that support around which I don't have here [at home].” (Weka mother, final individual interview)

Mothers, in particular, mentioned and appreciated the domestic help that social relations brought to holidays:

"And <friend> cooks. He cooks really nice meals. I love it when he comes." (Kereru mother, pre-family interview)

"When I go and hang out at [my] auntie's that is a holiday. They cook and clean and do the washing." (Weka mother, final individual interview)

The other social support mentioned was providing child-care and entertainment of the children:

"[When] we have family somewhere like in Hastings, often we leave the kids for the afternoon and we go off and that is quite good." (Kea mother, final individual interview)

"One of the things with [extended] family holidays and Christmas we were with people we trust. So the girls were well looked after and we did go out for a few hours one time shopping or something." (Weka father, final individual interview)

Travelling to and with extended family and friends, then, could provide practical and logistical support for the parents in the form of domestic help and entertainment responsibilities and is linked to cooperation, which is part of the internal dynamics (see section 6.6). 


\subsection{SOCIAL IDENTITIES/TRADITIONS}

Identity and traditions were both linked to domestic tourism behaviour and social connectedness. The first was about a national identity and the latter was about a family identity, while together they were about social identities and perpetuating family rituals in the form of a holiday tradition. Family holidays signified a continuation of a tradition passed down from generation to generation as exemplified in these responses:

"I like the idea of having a family holiday every year. That seems to be a good Kiwi thing to do. I grew up with it so it is nice to pass that on to the kids." (Kea mother, final individual interview)

"For me it is a continuation of letting the children enjoy a summer beach holiday which is something of a privilege I had a as a child.” (Kereru mother, final family interview)

Within the tradition of family holidays there were also distinct rituals, such as family song and a log book, which reinforced the symbolic nature of holidays:

"And get in the car and we have this family song that we normally sing. It is such an annoying song and we scream it out when we go in the car. You can ask <husband $>$ to sing it, it is Afrikaans and we made it up ourselves before we had <daughter $>$. It is like, we are on holiday, we are on holiday, yip, yip, hooray!” (Goldfinch mother, pre-individual interview)

" $<$ Wife $>$ keeps a journal of the things that happened on the way and all the adventures and what time we were at such and such a place. Yes, we do have them going back to years and it is quite funny to take them all with you and read them on the way." (Kereru father, pre-individual interview)

For the parents the symbolism of maintaining a family tradition was linked to creating positive memories, which was part of a concern for establishing and guiding the next generation or generativity (Erikson, 1950; Shaw et al., 2008). The themes in this section were mainly probed in the final interview phase as identified by the GTM (Table 3.11).

\subsubsection{CREATING MEMORIES}

Parents used holidays as an opportunity to create memories which were part of generating a social identity in its family members. The memories centred on special moments that were considered different from everyday life (see section 5.3.1): 
"And it is so special and it is memories that you will get that no one can take away from you. And it draws everyone in the family closer, those special moments that you share." (Goldfinch mother, final individual interview)

Memory creation through family tales and lore were exemplified by an incident of dolphins that were mistaken as sharks from the final Kereru family interview:

Mother: "The dolphins."

Father: "The non-sharks."

Boy3, 10: "The ones you [family] thought were sharks."

Mother: "A family legend."

Holiday memories had an intangible character that could be easily forgotten:

"It is all enjoyable at the time but a lot of it is not tangible but obviously we still enjoy it. But everyone can forget quite easily." (Kakariki father, final family interview)

A generation later and over time, holidays became a general enjoyable memory interspersed by highlights:

"If I look back to my childhood and all the years we went to our holiday place that was all a blur as well. It is just a general memory of a nice pleasant holiday. And I guess there are some things that stand out and actually they were all incidences." (Fantail mother, final individual interview)

Photos in general helped in stimulating and creating the holiday memory. They became the tangible element of otherwise intangible and unreliable memories and, thus, perpetuated the tradition and symbolism of family holidays. For parents this was deliberate whereas for the children it was more incidental:

"And because the kids are young and we might forget we do take lots of photos as well to jolt the memory quickly." (Kakariki father, final family interview)

"With things you don't remember you can look at the photos." (Weka girl1, 8, final family interview)

For children the memories were mainly about activities that were novel or unexpected (different from normal) or related to other people such as friends and relatives. Their memories generally faded over time and in the process became 
more positive (see section 6.7.3). These were responses to the question of why and what they remembered:

"Because they [activities] were fun and I don't get to do them much. So that was kind of a first opportunity thing." (Kea girl1, 10, final individual interview)

"I think I will remember the show that we [cousins] performed in front of the adults and how we made it and collecting all the money of the adults." (Weka girl2, 7, final individual interview)

Holiday memories had perpetuity to them, possibly ranging several generations from parents' childhood memories to children in the future passing on memories to their children. In this way parents seek to recreate their memories of childhood holidays experiences for their children (see Kyle \& Chick, 2004; Small, 2008) and maintain a family tradition over time. The holiday memories got reconstructed through photos which constituted a more positive retelling and a (re)production of an idealised family time. For parents this production of memory stories was part of a deliberate desire to provide meaning, permanence, and social belonging that was captured by the family gaze (see Haldrup \& Larsen, 2003). For children the memories centred on unusual experiences and social relations while their purposive meanings were not recognised at the time.

\subsubsection{GENERATIVITY}

For some parents holidays provided a conscious opportunity for guiding their children (or generativity) by instilling values, traditions, and skills, whereas for other parents it was a continuation of what they usually did:

"I don't think holidays as any different from the general during the year when we try and instil values and skills and so on." (Hoiho father, final individual interview)

"I think it [holiday] is a very important time to teach your children and that is something I remember from my childhood...We did those things and they were fun and maybe you hope that they are doing it for their children. There are lots of skills that I am hopefully passing on to the girls." (Kea father, final individual interview)

Domestic holidays were also about fostering an appreciation of New Zealand or national identity in the children by showing them around the country: 
"I guess almost the educational aspect of [holidays] as well. That is our opportunity to teach the kids holidays around New Zealand, to teach them about New Zealand and for us to learn as well." (Kakariki mother, final individual interview)

"New Zealand is stunning and we need to expose our boys to a number of places in New Zealand so they have an appreciation of it...We want them to know and love home. We want them to have that and then go overseas but we want them to go overseas knowing that they have a beautiful place to come back to and to let other people know that it is great. We would actively encourage them to go overseas but they also need to know what New Zealand is first." (Pukeko mother, post individual interview)

Holidays were also about teaching family-specific skills and encouraging personal interests that reflected gendered pastimes (see section 6.3.1) such as sailing, riding motorbikes, archery, and lighting fires outside the normal urban environment, as the Pukeko family at the pre-family interview demonstrated:

Mother: "We are all pyromaniacs, my dad is very happy that they all jointly build great bonfires, well supervised."

Boy 1, 13: "It is a lot of fun."

Father: "And it is not something you can do around here."

Mother: "Not ever, but it is a really neat way to learn on how to do all of that what is sensible and what can be done and how to keep it under control. And they are lucky enough that they can ride motorbikes on the farm."

Holidays also provided an opportunity for character development in the children by overcoming challenges and learning social and practical skills, which reflected the importance placed by the parents on acquiring general life skills:

"There are life skills everywhere, particularly on holiday because you are in a different environment and that is when their upbringing comes into play with the choices they can make." (Pukeko father, final individual interview)

"It was good seeing the boys going into a new situation like doing the zorb, having to do it on their own and go off with strangers and a vague idea of what is going to happen." (Kereru mother, final family interview)

"They [children] learn the value of looking after and empathy for each other and everyone has needs." (Kakariki father, final individual interview) 
For the parents, especially mothers, holidays were also about heritage and belonging to an extended family:

"It adds a different dimension. Also it really helps the kids perhaps reinforce who they are and their heritage gets kind of passed on which to me is important that it reinforces them as a member of this family." (Tui mother, post-family interview)

"The values on family holidays are to teach them about [extended] family and how good that all is.” (Weka mother, final individual interview)

As a result, several mothers mentioned that their children grew up more during the holidays:

"The more experiences we have, they [children] learn something and you come back and find that they are not necessarily more mature but their knowledge has expanded. Their view of the world is expanded and they have grown up a little bit more.” (Pukeko mother, final individual interview)

All these responses demonstrated the parents' deliberate efforts in generativity by transmitting family-specific skills and establishing family values, either as a continuation from home, mirroring other findings in family leisure research (e.g., Harrington, 2001), or opportunistic to the holiday. However, generativity is not just one-sided, as holidays also provided opportunities for parents to learn about their children, especially for the fathers:

"Not so much learning from her but I am always amazed at her capabilities and the things she can do that I don't get to see sometimes during the year. I might be a bit too busy or not taking notice." (Fantail father, final individual interview)

“There are big chunks of their [sons'] life and our lives that you don't have much input. You can certainly see that on holiday because you are with them a whole day. You get to see how they behave and how they interact with other people." (Pukeko father, final individual interview)

Generativity, then, must be understood as a two-way process: an exchange between the generations or bidirectionality (Lollis \& Kuczynski, 1997). Mothers were more aware of changes in their children before and after the holiday, whereas for the fathers holidays provided more a time of (annual) evaluation. For the children, learning was usually related to specific activities and social relations:

"I am gradually learning about fishing and sailing, slowly but not specifically and learning a bit more about birds and stuff that are sometimes there.” (Kereru boy2, 13, final individual interview) 
"How fun it is to spend with [extended] family and friends because I didn't want to go first. I changed my mind when we got there.” (Weka girl1, 8, final individual interview)

Learning was generally not expected from the parents at specific attractions, as reflected in this response:

"I always just assumed that they would learn something. I haven't really expected that they had to. I try and think of it as a holiday first and foremost." (Takahe father, final individual interview)

Attractions, thus, were less about education and more about entertainment (see section 5.3.2). Instead, generativity was more related to skills which reflected family values and establishing traditions that shape the family's social identities. The purposiveness was deliberate by the parents but remained unrecognised by the children. Social identity formation encompassed all the family members as generativity proved to be a two-way process. Holidays for the fathers provided more a time of evaluation of this process, whereas mothers were more aware of their children's progress throughout the year. Also, for the fathers, family identity was derived more from acquiring skills whereas for the mothers it was more about connecting with social relations. Holidays, then, were considered a symbolic time out of the normal that warranted remembering and was used for generating social identities in its family members. The social identity encompassed belonging to the immediate and extended family, to a nation, and, ultimately, to a society. However, the purpose and symbolism of family time on holiday could lead to enforcement when confined to a shared space and time.

\subsection{ENFORCED FAMILY TIME}

Crompton (1979) claimed that the enhancement of kinship relationships on holiday was facilitated on long car rides because family members were forced to interact with each other. In fact, this enforced family time on car and boat journeys with no-one else around and no physical escape could reveal internal family dynamics or social tensions (see Small, 2005a) and highlighted gender and generational differences on holiday. All the children reported not liking the journey, finding it boring, annoying, and tedious: 
"Travelling in the car is boring." (Kakariki girl, 8, pre-interview family interview)

Boys, in particular, suggested novel ways of escaping this enforced time together through air travel or involving futuristic technology:

"We'll get a helicopter and you guys [parents] can take the car." (Pukeko boy1, 13, post-family interview)

"Being teleported from one activity to the other with no travelling." (Hoiho boy1, 11, pre-family interview)

The mention of car travel brought out family dynamics in that fathers mostly liked driving, mothers were more pragmatic, and children absolutely resented it, as in the following exchange at the Pukeko post-family interview:

Father: "It was a good drive up there. I enjoyed the drive from Napier to Gisborne."

Mother: "I thought it was beautiful."

Boy 2, 11: "I thought it was horrible, boring and I hated it."

Boy 1, 13: "The only reason why you [dad] like it is because you are driving and we are sitting in the back."

In fact, most fathers did all the driving out of enjoyment and own interest (see section 6.3.1), as well as a sense of responsibility:

"Loved it, did nearly all of the driving. It is actually relaxing. It relaxes me because it keeps me busy. I can't just sit in the car." (Goldfinch father, postindividual interview)

"They [family] can make fun of travelling and getting there safely but it is an important part of the responsibility if you are the driver or the dad or if you happen to be all the above." (Pukeko father, post-individual interview)

This included the journey on the boat:

"I enjoy the sailing experience. The crossing as well as in the Sounds and just sailing the boat that is what I really enjoy. That is the main personal enjoyment.” (Fantail father, post-individual interview)

These stood in contrast to the mothers' responses:

"I don't like it [the drive]. I used to do it all the time." (Weka mum, postindividual interview)

"The long car trips are not good, although I quite enjoyed the scenery on the way. I find it quite tiring." (Hoiho mother, final individual interview) 
Sitting in a car together involved finding ways to entertain the children and when the use of modern technology was desired (compared with section 5.3.1):

"It [the drive] is just pretty much sitting there and playing I spy and I listened to some music on my MP3 player." (Hoiho boy1, 11, postindividual interview)

"I watched a movie on my PSP half the way but the other half I got really, really bored. The PSP ran out of batteries." (Pukeko boy2, 11, final individual interview)

Car and boat travel highlighted how enforced nuclear family time over a prolonged time and in a confined space could lead to tensions, with fathers acknowledging the stresses involved:

"Travelling in the car for long times can be stressful." (Takahe father, prefamily interview)

"The travelling, that can be quite a challenge. That has been a challenge in the past and as to deal with that." (Hoiho father, pre-family interview)

Such enforced family time is the antithesis of being able to be free from family commitments:

"Just doing what I want to do, and relaxing when I want to relax and going wherever I want to go and not having to travel by car." (Hoiho boy2, 8, pre-individual interview)

It also became evident from 10 year old Fantail girl, a single child, that travelling on a boat excluded her from social opportunities with peers and pursuing her own interests in the company of friends, to the point of not wanting to go (see section 4.4.1):

"I prefer actually not to go on it [boat] ... because all my friends are back here and I can go horse riding up on the hill and stuff." (Pre-individual interview)

"It was a bit boring not seeing anyone my age apart from a couple of days when we met up with mum and dad's friends." (Final individual interview)

Holidays, then, were about striking a balance between family time and own time. Children, in particular, relished the opportunity to spend time with their peers, which became even more important in the absence of siblings (see section 6.4.2). 
However, going to isolated places for an extended time with children that did not get on with each other could be just as challenging (see section 4.4.5):

"I think there is probably not enough variety. I think you actually need other people as well. I am not sure that I do but I think the others do. Maybe $<$ husband> doesn't but the kids do." (Hoiho mother, final individual interview)

These responses and family exchanges all highlighted the underlying group dynamics at play in that the whole family was forced together in a shared or isolated space which primarily suited one or both parents but not the children. Fathers, especially, could enjoy their interest in driving or sailing while the rest of the family were unable to escape and pursue their own interests. Peer time in the form of other people became an important ingredient that was missing when prolonged family time proved challenging. While the use of modern technology helped children in pursuing an interest, it did not detract from the unwanted nature of the situation. Thus, while family time on holiday is generally sought, there are also family times that are enforced which can lead to conflicts. Children, in particular, prefer the company of their peers and all family members need to be able to pursue their own interests at times. This emphasized the need for own time as a time away from family commitments as being necessary for all family members.

\subsection{CONCLUSION}

As a basic requirement, family time on holiday needed to be different from home, which committed the parents to values and purposes for its achievement. Family holidays for the parents became about providing quality time, social connectedness, and establishing social identities, and not just as having fun together. This reflected a hegemonic and idealised view of family holidays in Western society as highly beneficial to family functioning and parent-child relationships (Hilbrecht et al., 2008) but disregarded the needs of the individual family members. Mothers put particular emphasis on social identity development whereas fathers put more emphasis on practical and physical skills. Both reflected obligatory aspects of holidaying as a taken-for-granted aspect of parental 
responsibility and mirrored other findings in family leisure research (see section 2.4). It became evident that family times on holidays were not 'holidays' in the sense of freedom from commitments or unobligated time, but they provided relief from normal routines. While children did not realize the parental purposive component to holidaying, they sought meaning by having fun and connecting with social relations. What emerged was that all family members sought respite from the obligatory commitments of family life in the form of having their own time, either alone or with peers, to pursue their own interests. The discussion on the notion of own time, as related by the participants alongside family time, and a requirement for all family members in a balanced holiday follows in the next chapter. 


\section{CHAPTER 6: OWN TIME ON HOLIDAY}

\subsection{INTRODUCTION}

The attention in the literature, media (see chapter 2), and the families themselves was placed on time together rather than time away from family, which was demonstrated with the purposefulness of family time in the previous chapter. Despite or maybe as a result of the hegemony of family time, individual needs for own time as freedom from family commitments to pursue own interests alone or with peers were mentioned throughout the interviews, especially those interviews closest to the actual holiday. Thus, the mundane and temporal reality of day-today family holiday living emerged as a continual struggle with the symbolic ideology of family time, as shaped by social norms and values. Although every family member straddled this need for own time, there were gender and generational differences in its meaning and the way it was experienced.

The focus in this chapter is first, on the theme of own time and its sub-themes as outlined in the theoretical framework (Figure 4.7) and second, the temporal dimension (Figure 3.3). The discussion is presented as a reflection on the significance of own time, or not-with-whole-family time, for own interests, time with peers, compared with non-family holidays and earlier family holidays. The internal dynamics of cooperation, compromise, and conflict further highlight the function of own time on holiday. Subsequently, both notions of time are revisited pre-, on-, and post-holiday. This temporal dimension provides an understanding of the relationship between anticipated and remembered holiday ideals and the realities of on-holiday experiences. As a result, own time emerged as essential for a more balanced and realistic family holiday presentation while family time encompassed more idealised notions.

\subsection{BALANCE OF TIME}

The existence of tension between the obligation towards family time and individual desires for own time was exemplified in this response: 
"And then me having a bit of time somewhere in that day also just relax and read a book and not have to deal with anyone else...It is quite nice having a bit of time without the children during the holiday but that usually does not happen much. I suppose it is not that important because the main reason to go on holiday is to be all together. So the time we are separate we do another time." (Hoiho mother, pre-individual interview)

What emerged was that while the focus remained on family time, particularly in the anticipation and recollection phase, on holiday an internal equilibrium was needed by having time out from those family commitments:

"If we all have some time out...For me, I cannot be 24/7." (Weka mother, post-individual interview)

This meant that for harmonious group dynamics a state of balance or homeostasis was needed between the obligatory aspects of family time and the perceived freedom from those commitments in own time (see section 4.3.2).

Individual family members might have different requirements for own time with one possibly needing more than the other:

"I suppose I need a bit more personal space than the rest of the family which is why I go off and do some of the stuff [shopping]. <Husband> never feels that much of a need and the kids not so much." (Takahe mother, final individual interview)

Holidays also exemplified a time of prolonged togetherness that can be found challenging compared with everyday life:

"Like I said before you get to spend 24/7 with family and I don't normally. I am out the door to work and on the weekends we are off doing different activities. And I am a person who needs a bit of solitude. I don't actually enjoy living in somebody's pocket all the time. I am quite happy to go for a wander by myself or go for a run in the morning or just a bit of time on my own. I think we are all like that but me in particular. I don't need someone around all the time." (Pukeko father, final individual interview)

Younger children usually did not realise the need for time out by their parents because they were engaged themselves with social relations who provided cooperation (see section 6.6.1), whereas older children could be more circumspect and aware of their own and parents needs:

"We [children] needed our time away and they [parents] needed theirs. They just needed a break from us once in a while that was all good." (Takahe boy, 12, final individual interview) 
"I didn't mind it because I just spend time with grandma and grandpa." (Tui girl, 14, final individual interview)

What became apparent was that apart from family time all family members also desired some time on their own or with their peers rather than just the family:

"We [couple] were together but we had our own space as well. The kids were off doing different bits and pieces and left us to it sometimes which was nice." (Kea mother, post-family interview)

Homeostasis, then, signified the ability of the family group to regulate its internal dynamics by seeking a balance between the demands of family time and the perceived freedom from these allowed by own time. Individual family members had differing needs for their personal own time which reflected more personality than gender for the parents. Among the children there were differences according to age and family composition, which will be discussed later.

\subsection{OWN INTERESTS}

There was a wide range of personal interests, from the more physical which are discussed under activities below to the more restful which are discussed under relaxation. Own interests were also linked to family time in that children, in particular, were able to pursue personal interests, such as animals, as part of family entertainment (see section 5.3.2).

"I think seeing animals was really good because I have seen the Auckland Zoo programmes that <father $>$ has recorded. And I always wanted to go there." (Hoiho boy2, 8, post-family interview)

"I really liked the aquarium. I thought that was really cool. All these amazing fish and there was even a crocodile and sharks because I really like marine life." (Takahe boy, 12, post-individual interview)

This highlighted the potential self-sacrifice of parents in providing children's interests at the expense of their own interests. Parent's own interests could also be sacrificed when taking children along and, then, not being able to fully enjoy the experience:

"Probably going up Mt Taranaki would be a highlight. There are lots of walks. It is pretty difficult with young children, they do not last that long."

(Kakariki father, pre-family interview) 
It could also mean being unable to pursue one's interests because of conflicting family interests and willingness to compromise (see section 6.6.2):

"Actually there were a couple of things that I wanted to do. One in particular was the transport thing. I suppose that is the guy thing kicking in. I suppose we could have sacrificed the gardens to go to the museum. I didn't go there and I heard it was really good." (Kea father, post-individual interview)

All of these responses made own time for parents even more important. Pursuing own interests in one's own time was then considered relaxing compared with catering to other family members' needs and desires.

The best combination of own interests with family time came when all family members shared the same interests. This could become a highlight, as exemplified by a walk over an island which was enjoyed by the entire Hoiho family:

"I agree with the scenery that is one of the reasons why tramping is so good because <husband> and myself have done tramping throughout our lives. I like the thought that gradually the kids are able to do more even though we haven't done a lot for various reasons. But to do things like that more with them and enjoy the same sort of things. And it is great to have them really enjoy, even so sometimes they are not so keen to go walking they usually do and really enjoy it." (Mother, final family interview)

However, pursuing own interests largely revolved around having time on your own or in the company of peers. The main denominator here was that it involved a form of freedom from commitments for both children and parents. For parents it meant not having to actively care for their children, and for children it meant not being obligated to their parents.

\subsubsection{ACTIVITIES}

There were some marked gender and generational differences with regards to pursuing own interests in activities. For the fathers the activities mentioned centred more on individual physical activities involving a form of challenge:

"Individually best day probably the day we went kayak surfing that was the most exciting and fun day...I suppose it was the most fun for me because it was the limit of what I can actually kayak surf...It was definitively a challenge to actually try to keep the kayak under control and keep surfing and when I couldn't to just fall out and that was a heap of fun." (Hoiho father, post-individual interview) 
"It is the sailing that is good sport. You try and make the boat go and just the challenge of making the boat work and sail and get where you want to go." (Kereru father, postindividual interview)

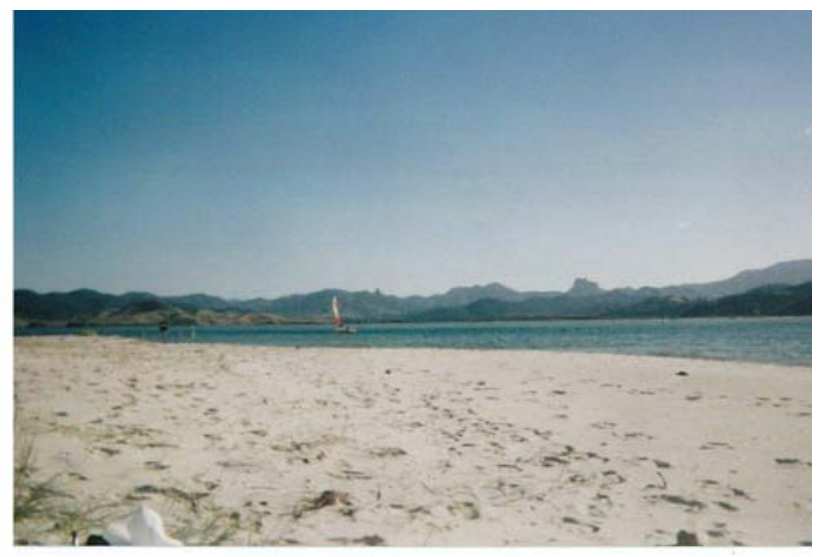

Other challenges could be building or erecting structures, as this Pukeko exchange at the pre-family interview exemplified, regarding staying at a bach:

Mother: "Here is in reality what would happen. <Husband> would look at the bach and think, being the engineer that he is, that is not very good let's just go up and fix that. And he would start rebuilding the bach, erecting all sorts of structures all around the place, chopping some wood. He would recreate it into a nice little city until it is time to go."

Father: "That would still be my ideal holiday. I am not someone who can sit and do nothing. I would be bored out of my brain."

Gendered interest in physical activities was also reflected in holiday wishes:

"What I like for an ideal family holiday is not what $<$ wife $>$ would like. Personally I would love to go on a tour of Tasmania on a bicycle in a group or stuff like that." (Goldfinch father, pre-individual interview)

Another interest for the fathers was providing for the family:

"I do not do it particularly successfully but going out to catch your own food and just that aspect of it and being able to prepare a meal, the hunter gatherer. I only go fishing on holiday.” (Kereru father, pre-individual interview)

Fathers also often mentioned an interest in exploring in the car or boat as part of their holiday experience which was linked to enforced family time (see section 5.6):

"I am a bit different from the others. I don't mind getting in the car and going other places and exploring. I am not one for sitting around doing nothing." (Pukeko father, post-individual interview)

For the mothers, own interest activities such as shopping were often mentioned which could become a sacrifice when not being able to pursue them (see section 
6.7.3). Shopping was usually not shared as an interest by the rest of the family, which led to compromises (see section 6.6.2):

"I just like looking around and see how the town has developed. I always like looking at shops. I went to my wool shop." (Takahe mother, postindividual interview)

"You [family] do not like as much shopping as me." (Weka mother, postfamily interview)

Other activities particularly favoured by mothers were animals (see section 6.7.2) and also gambling:

"On New Year's Eve we went to the casino. And I always win lots of money and I did it again.” (Weka mother, post-individual interview)

For the mothers, physical activities were also mentioned such as tramping (see section 6.3), boogie boarding, kayaking, walking, and swimming, but this was less prevalent than for the fathers and usually involved shared activities with the family (see section 5.3.1) or couple time (see section 6.4.1):

"We only have two boogie boards so two of us will do it and then we swap over. It is just good fun. There is a bit of competitiveness about who gets the best wave." (Pukeko mother, final individual interview)

"I love swimming with the kids and watching the kids swim, I love it." (Kakariki mother, post-individual interview)

Activities for children were mainly water-based, for fun (see section 5.3.2), especially swimming pools and the sea. Other activities were riding a bike, roller skating, scooting, and play grounds. Ease of access to these activities was considered especially important:

"I think the best thing was the swimming pool because we did not actually have to drive to it but could just walk to it." (Kea girl1, 10, post-individual interview)

"It was also fun playing on the beaches, bodysurfing and surfing on boogie boards." (Hoiho boy2, 8, final individual interview)

This meant a chance to participate in some familiar holiday activities that children valued (Hilbrecht et al., 2008). While in family time novelty or difference from normal was sought, own time revolved around personal interests which were more familiar. Own time also revolved around physical activities that were only 
undertaken on holiday which could be linked to teaching family-specific skills such as motor biking and archery (see section 5.5.2):

"My favourite was probably the farm because of the motorbike and riding around on all the paddocks. I have my own motorbike." (Pukeko boy2, 11, post-individual interview)

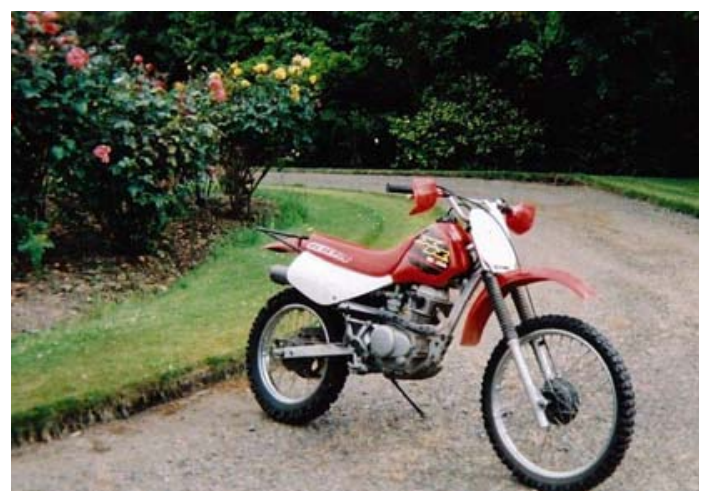

Or those holiday-only activities could be linked to time with friends (see section 6.4.2):

"Fishing not a lot but I was with my friend and we took a photo of me fishing and I caught $a$ kahawai.” (Tui boy2, 8, post-family interview)

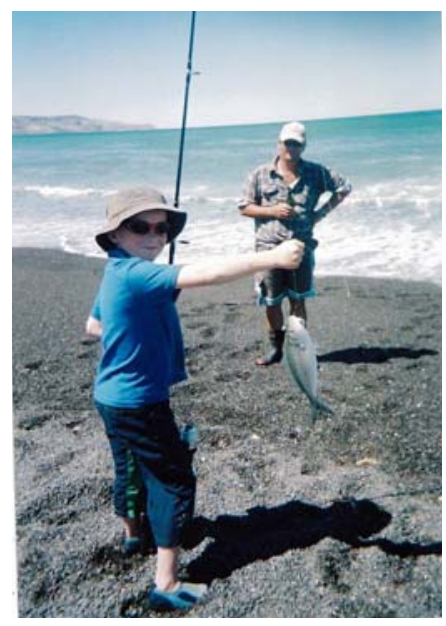

Gender differences in the children also emerged with regards to ideal activities, as 10 year old Takahe girl exemplified:

"I probably would go shopping and I might go to a beauty spa and a normal spa. And if I was staying at a hotel I think I just stay at the hotel and do stuff like go to the pool and order room service.” (Post-family interview)

Children particularly treasured the freedom from parental restrictions on holidays to pursue their own interests:

"[Prefer] going on holiday because then we can have fun and do all those other stuff and play at the playground and go to the pool whenever we want to and just ride our bikes wherever and don't really have to ask mum or dad because they are mostly resting." (Kea girl2, 7, final individual interview)

"We [brothers] could go on our own boat. We had more freedom and we could go wherever we liked. I guess that was a major part as well, the freedom to go anywhere we liked. That was good." (Pukeko boy1, 13, final individual interview) 
For the fathers, being independently active and involving a form of mental or physical challenge was more paramount than for the mothers who sought out fewer physical and more shared activities. Some of these gender differences filtered through the generations in that boys generally preferred more adventurous physical activities than the girls, who also mentioned pampering. These activities implied a continuation of familiar interests rather than novel experiences as sought in family time. By pursuing their own interests, parents relished the freedom from family commitments while children treasured the freedom from parental restrictions. This meant that everyone had some control over their own time, which eased pressures on the family dynamics.

\subsubsection{RELAXATION}

What was perceived as relaxing differed for the genders, at least for the parents; for the fathers it also included being physically active as long as it provided a break from work routines, while mothers sought out more restful activities:

"Because I sit in an office I find doing physical work, I wouldn't say it is a holiday but I enjoy it. I find it more relaxing than sitting around. You just feel like you have achieved something if you physically do something and go out there. Just because it is different from what I do here, the routine." (Pukeko father, post-individual interview)

"I got my relaxation because I was away from home, stop thinking about work, stop doing things, could focus and enjoy whatever the family was up to. That really helped the relaxing." (Weka father, post-individual interview)

Reading and doing mental problem solving was often mentioned by the fathers:

"Reading, I guess holidays are always a good time to catch up on some reading. It is nice to be able to do that when you do not always have the time during the year. And crosswords and sudokus and things like that. I did those until I got bored of them.” (Fantail father, post-individual interview)

For fathers a drink and a nap was also mentioned as relaxing:

"So to go away and recharge and sleep in the middle of the afternoon if you felt like a sleep in the middle of the afternoon. And lie back and have a nice cold beer when you felt like a cold beer." (Kereru father, post-individual interview)

Other relaxing activities mentioned by the fathers were watching others or TV, looking out at the view, or doing nothing: 
"I would just sit at a comfy chair with a wine or a beer in the sun and watching people go by." (Kea father, post-individual interview)

"And once they [children] are in bed there is nothing to do around the motel unit. So there is either watching TV or read a book or lie there do nothing. So there is plenty of doing nothing." (Kakariki father, postindividual interview)

For the mothers reading was the most prevalent form of relaxation:

"I really enjoyed reading. I got lots and lots of reading done that is my form of relaxation.” (Fantail mother, post-individual interview)

"I liked having the time and space to be able to read my book actually. It was good." (Kea mother, post-individual interview)

The notion of relaxation was also connected with fewer domestic commitments

(see 5.3.1) and an increased sense of entitlement for own time on holiday:

"I think every mum has to think because the kids want to be fed three times a day. So that whole thing changes. You obviously have to plan ahead. But if the clothes are filthy it doesn't really matter. I feel like I have more right to say: 'I am not cooking, I am reading'. And now that they are big enough I can say: 'rustle up your own meal if you want'." (Tui mother, final individual interview)

"I also read a book and I had time for myself which was really good. And like we bought a lot of takeaways, easy food, so it was really good for me to relax. They did not expect me to do the things that I usually do at home. And I really enjoyed it." (Goldfinch mother, post-individual interview)

For the mothers, the level of relaxation was particularly linked to the safety of their children; the safer the children the more relaxed they felt. It was about enjoying own time while knowing family members were safe and content in their activities:

"Being at a camping ground and know that the kids are safe. They could run and meet some friends and we didn't have to worry about them." (Kea mother, post-individual interview)

This confirmed the work of Anderson (2001) in that women are primarily concerned about the safety and happiness of their families. Relaxation, however, could also be linked to staying at one place rather than moving around:

"I like relaxing, usually just staying in one place rather than travelling around a lot." (Takahe father, pre-family interview) 
"It would be great if on our next holiday we could plan an extra 3-4 days just to stay at the same place because sometimes you do get tired of going out every day." (Goldfinch mother, post-individual interview)

Relaxation for the parents could also be combined with family time, by reading together (see below) or by becoming a family highlight as a boat trip was for the Goldfinch family:

"That was quite relaxing I think because you didn't have to do anything. You had no responsibilities. You could just enjoy yourself and do whatever you want to do and I that was very nice to relax. I think it was so relaxing." (Mother, final individual interview)

In general, parents were content with their amount of relaxation on holiday but there were also some imbalances. Even though Takahe mother perceived her husband to have little need for personal space (see section 6.2) this was not his opinion:

"I don't think that I ever feel that I've had enough time for myself."

(Takahe father, post-individual interview)

The entertainment imperative of Hoiho father (see section 5.3.2) compared with his wife illustrated the compromises made on behalf of spouses (see section 6.6.2):

"I really appreciate <husband> going off and doing things with the kids because that gives me a bit of time out when I am with them more the rest of the year." (Hoiho mother, final individual interview)

This highlighted that some sacrificed their own needs, especially fathers, in order to cater for the perceived higher needs of their spouses. For both mothers and fathers relaxation was linked to the ages of the children, as discussed in section 6.5.1; normally, the older the children the more relaxing the holidays:

"Every year is easier as the family gets older. It was harder when they were younger but now it is a real holiday for me too." (Kereru mother, final family interview)

For the children relaxation also often involved reading books or magazines: 
"This [photo] is of my favourite seat at the bach. I stayed there for ages and I read lots because it was in the sun and I could wear a hat so it just goes over my eyes. That was probably one of the spots I was in most times for the longest except for my bed." (Kereru boy3, 10, final family interview)

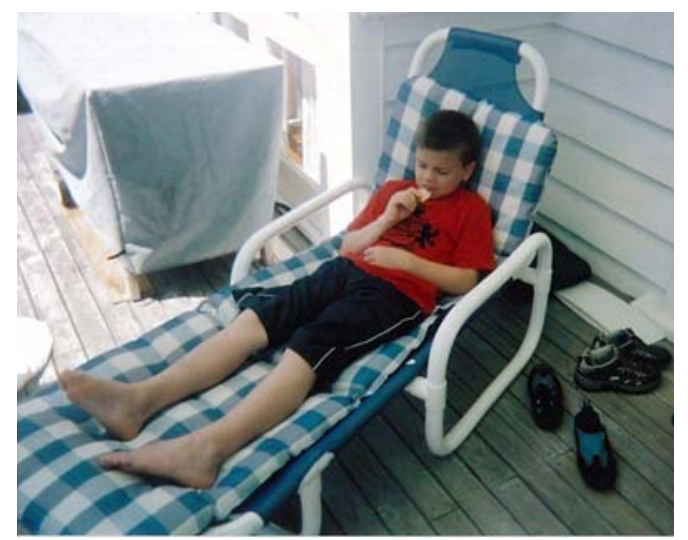

Other relaxing activities mentioned by the children were drawing, sunbathing, listening to music, dozing, watching TV, and playing with toys:

"I do have lots of drawing stuff, so I do drawing and reading quite a lot." (Fantail girl, 10, pre-individual interview)

"I had some books to read and sometimes I just lied down and snoozed." (Pukeko boy1, 13, post-family interview)

Relaxation for the children, especially girls, was also connected to family time (see section 5.3.1) or sibling time (see section 6.4.2), such as playing games or reading in the company of others:

"I would listen to my iPod or play games like Cadoo with <sister> and dad.” (Kea girl1, 10, post-individual interview)

"I really like sitting in the shade reading a book with family. We spent ages just doing that.” (Tui girl, 14, post-individual interview)

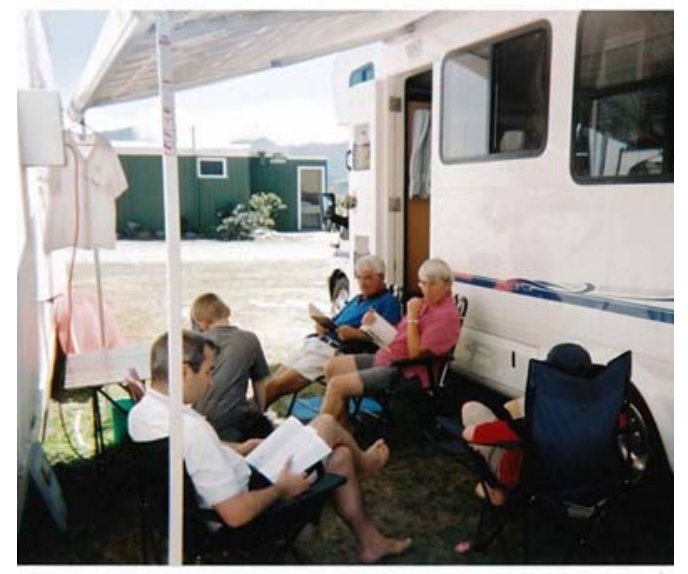

Relaxation was more diverse for the fathers than for the mothers. For the fathers it included both being more physically active and not doing anything, whereas for the mothers it centred mainly on reading. It emerged that for the mothers reading provided justification as their right for own time on holiday, which was even measured in the number of books read. Relaxation for the fathers was achieved 
through a break from work routines; for the mothers it was linked to a break from domestic routines or the motherhood discourse (see Small, 2005b). Reading was the most popular form of relaxation for all family members. Girls achieved relaxation more in the company of others than boys. The common denominator for relaxation was a freedom from responsibilities, which included not having to move frequently. Relaxation for the parents was also linked to keeping the children occupied. In particular, there were some sacrifices of men's own time to allow more relaxation for their spouses.

\subsection{PEER TIME}

The importance of socialising with other people on holiday manifested itself from the responses, as already mentioned in the previous chapter (see section 5.6) and as related to cooperation (see section 6.6.1). For the parents, peer time was about spending time as a couple or with friends and relatives whereas for the children it was about spending time with sibling(s) or friends and cousins. This meant that family holidays generally involved other people:

"Try and go with another family or other people that we can socialise with." (Hoiho father, post-individual interview)

"One of the things that were nice about it was that that we met up with friends there. So we had a day at Splash Planet where we met up with them and the kids had an opportunity to play with their friends. I thought that was quite nice although it is nice to have some family time. It is also nice to have some time with other friends so that the kids have a chance to spend a bit of time with them.” (Takahe father, final individual interview)

While the importance of the peer group for teenagers is not surprising, it became obvious that the popularity of time with peers extended across the age spectrum. The meaning of peers differed at times in terms of new and familiar peers. In general, children desired more peer time than their parents (see section 5.6):

“Mum and dad like it all quiet. I like it more with people." (Fantail girl, 10, final family interview)

Peer time, then, included the own family, social relations, and new and established friends across the same generation. 


\subsubsection{COUPLE/ADULT TIME}

Couple/adult time was divided into first, time for the parents with each other and second, time with other adults such as friends or relatives. For some parents couple time was an important aspect of holidays, as this exchange at the Pukeko post-family interview demonstrated:

Mother: "We went to the beach for a walk and talked. We talked more than we normally talk here. And we talked about things that were actually important and we don't always get a time to do that at home. While it wasn't lazing about and relaxing ... When you go on holiday and you get a time to plan for the next year or reflect on the year that has just been, that is the advantage of a holiday and that is what we did."

Father: "Very true, walking on the beach was good."

For other parents, couple time was not as important on holiday or simply not achievable. For those parents there was a consensus that couple time was more attainable at home:

"[Couple time] is good but it is not essential. We are always thinking how we should do more of that throughout the year. And in some ways it is almost easier to do that at home, organise a babysitter and go off." (Hoiho mother, final individual interview)

For some parents the emphasis was on time alone rather than shared own time:

"I think it is great to spend time with [husband] although I must say I would like some time for myself." (Goldfinch mother, final individual interview)

Adult time could include meeting new people or social relations and was linked to social connectedness (see section 5.4):

"We met some neat people, really interesting people as you always do when you are camping. We met a couple in the two places where we camped. I think that is something about camping. You can have wine at 9pm at night and it is okay, different people and just no expectations. They just happen to be your neighbours. You know you are only going to meet them for 1-2 nights and so we just met lovely people and had a couple of really good nights together.” (Pukeko mother, post-individual interview)

While couple time was more important for some parents than for others and was also dependent on other factors such as independence of the children (see section 6.5.1) and social support (see section 5.4.3), there was a general consensus that holidays were about family time and making sure the children were happy: 
"I mean spending time with my wife is important but the holidays are more about families in my mind." (Weka father, final individual interview)

"But it is always that juggle act because you are on holiday but feel like you should be spending time with your kids." (Pukeko mother, final individual interview)

It was revealing that no photos were selected for the interviews that portrayed just the parents. Thus, for the parents, holidays were more about the children than themselves, even though couple time could help to enhance marital communication. Also, some parents preferred individual own time rather than shared own time. However, there were no obvious gender differences present.

\subsubsection{SIBLING/FRIENDS TIME}

Sibling/friends time was divided into first, time for the children with their sibling(s) and second, time with other children like friends or cousins. Holidays could be important for children in terms of getting to spend extra time with their sibling(s), especially if they were not usually around, such as teenagers (ages are included here as it highlights some differences between younger and older children):

"We were playing cards with $<$ oldest brother $>$ and that was quite good because he had his toy gun on the table that he had been shooting us a lot with. We were playing poker with his gun sitting on the table." (Kereru boy3, 10, postindividual interview)

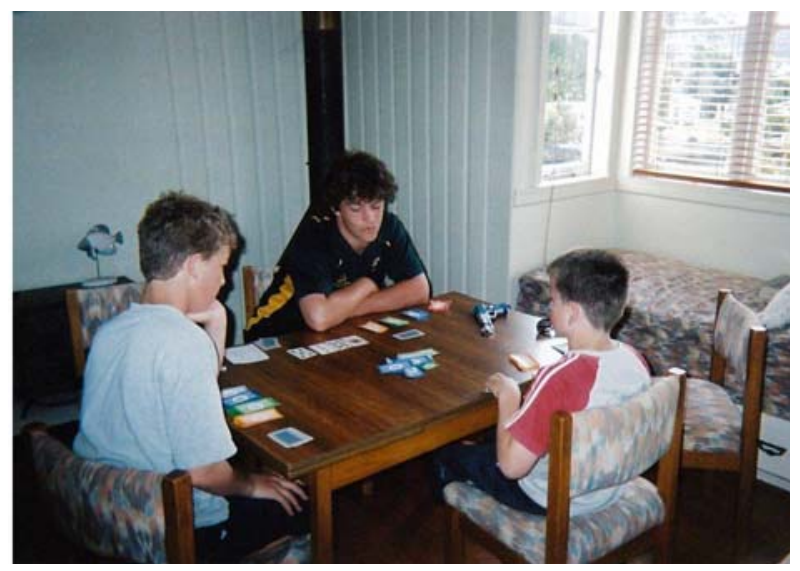

"And that one [photo] because on holiday I hang out with sister more than I do at home. I don't get a lot of time to hang out with her at home." (Takahe boy, 12, final individual interview)

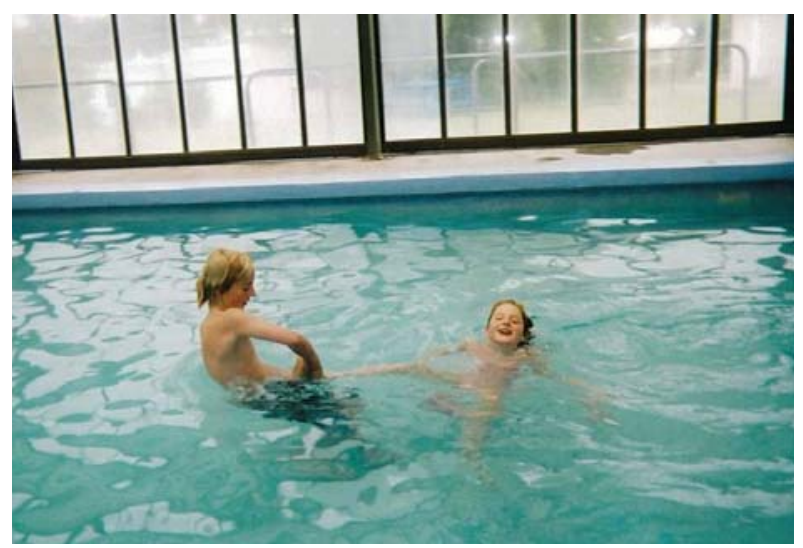


For some children extra time with siblings was not desired on holiday because of the conflicts it created (see sections 4.3.2 and 6.6.3):

"I see him [brother] every single day. So no need especially as most of the time we are arguing." (Pukeko boy1, 13, final individual interview)

"I am actually trying to spend time without them because we seem to get into arguments.” (Tui boy1, 11, final individual interview)

In the absence of siblings (see section 5.6) and when there were tensions amongst the siblings, time with friends became particularly important. This was linked to either social reconnecting or to making new friends on holiday. The first was more related to deliberately connecting with cousins and known friends while the second was more incidental. Both fulfilled the purpose of entertaining children to allow the parents some free time themselves and making sure the children were happy (see section 5.3.2):

"We like to meet up with other people mainly because it is nice for $<$ daughter $>$ to have other children to play." (Fantail mother, post-family interview)

"So I guess, and probably <wife> as well, would have preferred that there are other children around that our children could be with and therefore we would not need to actually entertain them quite as much as we do when there are no other children around." (Hoiho father, pre-individual interview)

For the children it provided a meaningful experience in terms of having their own time amongst their peers, establishing new friendships or maintaining old ones, which provided them with a break from family life:

"I met a girl called [name] and she came over to our motel and played stuff in Kerikeri. But now they went back to Australia but I got their email. She emailed me twice and I emailed her once. When we were in Kerikeri me and [name] met because I was looking for a friend." (Goldfinch girl, 10, postfamily interview)

"We were spending a lot of time alone and doing stuff within the family and that was good but it was good to have a break from that and catch up with $<$ friend $>$ and chat together and do things together." (Hoiho boy1, 11, postfamily interview)

Peer time for younger children might be more about making new friends whereas for teenagers it was more about established friends/cousins, but it became 
important across the age ranges. While the meaning of peer time for older children revolved more about old friends, holidays for younger children offered more of an opportunity to make new friends. Peer time, then, served the dual purpose of keeping the children happy for the parents to enjoy their own time and to allow the children some time out from their family commitments. It became a way to appease all family members and ease pressures on the internal group dynamics. Peer time, therefore, mirrored the function of cooperation (see section 6.6.1) in allowing an escape to peers which signified freedom from certain responsibilities.

\subsection{COMPARISONS}

Parents made comparisons with regards to the different ages of their children and holidays without the children. There was consensus about the correlation that with increasing age of the children came more personal own time. The desirability of non-family holidays was, however, dependent on personal desires of the parents. Children made comparisons with regards to the different ages of their siblings and holidays without the parents. This highlighted the fact that with age of children came increasing independence and desire for more own time. The comparisons made allowed for a contrast with family holidays when the children were younger and non-family holidays.

\subsubsection{AGE DIFFERENTIAL}

For those parents who had older children there were marked differences in their children's independence compared with when they were younger. Having older children was then perceived as more relaxing (see section 6.3.2):

"It is very different with the boys being older, every year seems to be better and more enjoyable because they are just so self-contained. Particularly $<$ youngest son> reads now. When everyone else was reading except him it wasn't so good. Now he is a great reader so they all just settle down after lunch and relax. There is no one pestering you to play. It is a whole new experience.” (Kereru mother, post-individual interview)

"I guess that is just the stage they are at when they are not quite so dependent. So holidays are not quite as demanding on your time as they were when they were small. They can go off and have a shower and do the things they need to do. Definitively more relaxing from that point of view." (Pukeko father, post-individual interview) 
That age of the children made a difference to the overall harmony and quality of the family holiday was also mentioned by a teenager with regards to his brothers:

"When my brothers were smaller it was more difficult because they were really annoying and I was annoying them. But now that they have grown up it is a lot more fun. An older family is quite good for a family holiday. Age does make a difference.” (Kereru boy1, 16, pre-individual interview)

Having older children meant also having less of a routine which was then perceived as more of a break (see section 5.3):

"Especially with a two year old, to fit life around a two year old. She just eats and sleeps. The routine becomes more flexible all the time with the older ones. We are not so big with having to be in bed at a certain time...The meal times are not quite so rigid for the older ones." (Kea mother, final individual interview)

There was consensus amongst the parents with teenagers that there will not be many family holidays in the future where the teenagers want to take part:

"We just make the most of the holidays that the kids still want to come with us. Probably not that many more at the age that <oldest son, 13> is at." (Pukeko father, post-individual interview)

"<Oldest son $>$ is turning 13 tomorrow so you kind of know your days are numbered really with family holidays, just the family." (Takahe mother, post-individual interview)

This reflected a sense of urgency among the parents (Shaw, 2008). The age of the children was related to an increase in the level of their independence which was then perceived by the parents as increasing the parent's own time and feeling of relaxation. There was recognition from the parents about the changing composition of the group in that children will eventually outgrow the family holiday and pursue 'own time' outside the family.

\subsubsection{NON-FAMILY HOLIDAYS}

As identified in the survey (see section 4.2.1), parents and children also went on holidays separately, which provided a contrast with family holidays. It was generally agreed for the parents that non-family holidays provided more 'own time’ or freedom from responsibilities, as this exchange at the Pukeko pre-family interview demonstrated: 
Mother: "That was fun. We would like to do that one again. It was $<$ husband's> 40th birthday and we went over to Melbourne with some friends."

Father: "That was quite good."

Mother: "That was hilarious but you wouldn't want to do that too often, that would not be good for our livers. It was a very adult holiday."

Father: “The freedom, the less responsibility. You don't have to plan. You can get up early, you can stay up late. You do not have to plan what food you are going to have."

Non-family holidays also provided parents with the opportunity for increased couple time and allowed mothers a break from their domestic role, which was desired in a good holiday (see Davidson, 1996):

"I think it would be lovely to have a holiday by myself actually. We had, $<$ husband $>$ and I had gone on holiday as a couple and with a friend. It is different because I do not have three children and I do not have to think about food and school and laundry and all that stuff. For me it is actually a holiday from my job as being a mother. And for <husband $>$ and me it is actually a chance just to talk and not being interrupted.” (Tui mother, prefamily interview)

Holidays without the children could provide everything sought in own time on family holidays and, thus, provided a contrast to family time. However, it also meant some parents missed their children and preferred the commitments of family time:

"We do not go away together (the two of us) because we only end up missing the kids, so what is the point? So we just spend the whole time like on a business trip pathetically pining after our kids. So what is the point if we are not enjoying it anyway?” (Kakariki mother, pre-family interview)

The conflict between more own time but no family was exemplified in this response:

"So you do miss the family but you get the benefit of doing your own thing." (Takahe father, pre-family interview)

Children also made comparisons between family and non-family holidays:

"I think it is pretty different because there are things that you want to do and there are things that the rest of the family wants to do. But if it is just you and another person you do different things to what you do on a family holiday. It is just not as busy, it is a bit more relaxing when you go on your own.” (Takahe boy, 12, pre-family interview) 
This replicated sentiments shared by the parents in that non-family holidays provided more time to pursue own interests, which was perceived as more relaxing. It could also mean that non-family holidays were preferred (see section 5.6):

"It [non-family holiday] is a lot more things to do because you are always doing something whereas on the boat you more try and find something to do, unsuccessfully usually. And I think I prefer the pony club and it has got horses.” (Fantail girl, 10, final individual interview)

The comparisons with non-family holidays provided a counterbalance to family holidays. In the absence of the ideology of family time, holidays without children or parents were signified by an emphasis placed on 'own time'. In the case of enforced family time (see section 5.6) the non-family holiday could be preferred. The comparisons made emphasized that increasing age of children was correlated with increasing independence and needs for own time. Yet, it also highlighted a conflict in that own time came at the price of missing the rest of the family, which could make family holidays preferable. Preferences for non-family holidays might be more related to personality, family form (see Olsen \& Gorall, 2003) and ages of the children rather than gender or generational differences. In terms of group dynamics, non-family holidays provided relief from internal tensions in that certain family obligations were absent, and children's growing up eventually meant a change to family holidays. After the discussion of family time and own time the overlap between the two reveals the internal dynamics as core aspects in the negotiation between togetherness and more individual pursuits (Figure 4.7).

\subsection{INTERNAL DYNAMICS}

As mentioned throughout the findings and partly in section 4.3.2, the family group dynamics revolved around cooperation, compromise, and conflict at times. These core internal dynamics are discussed here, whereas the more external constraints were discussed in chapter 4 . Cooperation was implicitly linked to social support provided by extended family and friends (see section 5.4.3) as allowing for individual own time. Compromise was explicitly mentioned in that catering towards individual family member's needs often required a compromise or sacrifice from other members of the family. Conflict was more concealed and 
surfaced only with probing. Compromises were also more accepted across the generations and genders. However, there were more pronounced gender and generational differences with regards to reporting of conflicts amongst family members, which revolved around disagreements between individual family member's interests. On a scale from positive to negative internal dynamics, cooperation was positive, compromise was neutral, and conflict was negative. While cooperation was desired in a harmonious holiday, compromise was taken for granted, and conflict was to be avoided, which was linked to the ideology of family time.

\subsubsection{COOPERATION}

The incorporation of other people, especially close friends and family, was perceived as breaking up the intensity of the internal family group dynamics. This allowed for cooperation between the social relations and sharing of responsibilities which then freed up the individual family members:

"When you are with the family you are just with the family and that can get quite intense. But if you are with other people it changes the nature of the conversation, perhaps it changes what you do. It is an opportunity to share your experiences with other people immediately and it also gives the kids a chance to be with other people their own age." (Takahe father, final individual interview)

"We do try and incorporate, especially if we are going away for quite a long time, we try and incorporate other people in some ways because it is too intense with just the family. Usually there is a combination of a bit of family and a bit of friends if we can." (Hoiho mother, final family interview)

An example of cooperation between the extended family was given by a child:

"When we went to Hamilton zoo [with cousins and their aunt] dad stayed at home with uncle and auntie and mum went shopping." (Weka girl1, 8, final individual interview)

Family holidays were about an escape to social connections which allowed for an escape from the family commitments. This involved escape to the extended family and close friends in order to escape from the nuclear family, which was perceived as too restrictive at times. The wider social networks, thus, provided freedom from family commitments by relieving tensions on the internal family group dynamics. The cooperation provided by social relations then served the function 
of balancing family time and own time on holiday which could be appreciated by all family members: mothers the domestic help, fathers the entertainment assistance, and children the (re)connecting with friends and relatives. The ability to have own time is, thus, dependent upon the actions of others, cooperation within the extended relations, and compromise within the immediate family.

\subsubsection{COMPROMISE}

It emerged from the responses that a level of compromise was expected from every family member on holiday. Parents made compromises on behalf of their children (see section 4.3.2):

"I think the whole holiday is all about them [children]. If we talk about sacrifice that is if we go out for dinner we go to kid friendly restaurants. It is all about them really. I mean even when we book motels we go let's try one with a swimming pool because that is what they enjoy." (Kakariki mother, final individual interview)

Parents, especially fathers, also made compromises on behalf of their spouses (see section 6.3). Children also made compromises to meet the needs of their siblings or parents:

"It was kind of hard because we had to be quiet when <youngest sister> was sleeping while they [parents] were resting there. So we had to be really quiet and I drew a picture and played with my toys." (Kea girl2, 7, final individual interview)

This resulted in a give and take for all family members:

"The kids had to put up with some things they probably wouldn't want to put up with but we enjoy and we had to do the same." (Kakariki mother, postfamily interview)

Compromises, then, revolved around catering to the interests of all family members, such as entertaining the children (see section 5.3.2), doing what the rest of the family wanted, or less own time than desired.

"We probably compromise all the time. I would have probably taken a longer time to walking around those gardens but we were aware that they [children] were getting bored. The more interesting it is to adults, the less interesting it is to children, seems to be anyway." (Kea mother, final individual interview)

"Spending time that was family orientated rather than myself looking around shops or an art gallery. But they are just not interested so I didn't get to do that much." (Takahe mother, final individual interview) 
These responses highlighted that compromises were about balancing gender and generational differences because what one or some family member(s) wanted was not necessarily what the rest of the family desired. This amounted to constant work by the family members in achieving a balance between family time and own time:

"I suppose time and energy to keep coming up with ideas and things for them [children] to do and things for us to do.” (Kea father, final individual interview)

"I agree having a balance of things that we all like doing." (Hoiho mother, post-family interview)

This could also include extended family, which made the balancing of three generations even more demanding:

"I am in the middle very much when <wife> can have her moments with my father and I feel like I am in charge as I am on holidays, it is fair to say, head of the house or whatever. And with my parents as my wife said: 'two more children to look after.' We have five people to consider and I know them all well. It is quite stressful and it is a balancing act." (Kakariki father, final individual interview)

This highlighted that constant compromises could lead to stresses and possible conflicts. While compromises were common amongst all family members, they were generally more accepted by the parents than the children. This might explain why continuous compromising or balancing of different interests was perceived as more arduous by the parents. There were some gender differences noticeable in that men were more amenable to compromise for their wives. Compromise brought out the internal group dynamics of balancing different family members' needs and desires, which could become more strenuous with an increase in number of family members and generations involved. Compromise was, therefore, associated with balance and constancy which had more neutral connotations.

\subsubsection{CONFLICT}

Conflict mainly emerged through probing and could arise on holiday out of an imbalance of different needs and desires. Some reasons for stresses and tensions were not having enough own time, insufficient cooperation between the family members (see section 4.3.2), or one family member continually pursuing own interests: 
"It is quite stressful isn't it? Once again you don't have your own rooms and your own space necessarily." (Kea father, final individual interview)

"One of the things that you have to be careful when you are on a family holiday is spending a lot of time together, the arguments can sometimes start. We find the boys either the first week or the last week there are usually niggles. It doesn't usually go the whole time." (Pukeko mother, final family interview)

Conflicts could also arise out of clashes of interests, as this exchange between Takahe mother and 12 year old son at the final family interview demonstrated:

Mother: "I didn't really enjoy walking on Westshore beach which is very notoriously dangerous and I told the kids and so <son> had to go and have a try and walk right by the waves."

Boy: "I wasn't anywhere near the waves. I was the whole room away from the waves. You were having a panic attack."

What emerged was that safety concerns proved particularly taxing for the mothers in that children wanted to pursue their interests but mothers were anxious about their well-being (see section 6.3.2). Mothers were also more emotionally affected by the unhappiness of their children:

"As a parent when the children are not enjoying themselves that to me affects all of us." (Hoiho mother, final family interview)

"I didn't enjoy my daughter not enjoying the walk because she has a way of picking on everyone." (Fantail mother, post-family interview)

For fathers, conflicts arose more through active forcefulness (see section 4.3.2):

"They [children] are also at an age where you have to be quite firm with them. It is a fine line between being the grouch and having a good time and this is always difficult when you are the one laying down the law. But these guys hit the boundaries too.” (Pukeko father, final individual interview)

For children, conflicts could arise for different reasons, one being sibling rivalry (see sections 4.3.2 and 6.4.2) and another, tensions with their parents:

"Sometimes I argue with my brother but it is not serious. It is little things but it turns into big things and then we get told off." (Pukeko boy2, 11, final individual interview)

"We get into trouble from mum when we have to pack and then we get into trouble when we get on the road." (Hoiho boy1, 11, pre-family interview) 
There were some noticeable generational and gender differences. Conflicts between the parents were not reported but featured between the children. For the parents, conflicts arose out of differences between their interests and the children's interests. For the mothers, conflicts were more emotionally felt and also connected to safety. For the fathers, conflicts were more actively handled and connected to disputes. Children reported conflicts with their parents and their siblings. Cooperation, compromise, and conflict, thus, highlighted positive, balanced and negative internal dynamics affecting the family group and the diverse effects they could have on the different family members. They also reflected the realities of family living on holiday, which are contrasted with more ideological notions of family time in the temporal dimension.

\subsection{TEMPORAL DIMENSION}

The dimension discussed here relates to the three temporal stages: pre-holiday, on-holiday, and post-holiday (Figure 3.3). The traditional mode of temporality follows a linear procession of holiday anticipation, experiences, and recollections. The findings showed that the temporal dimension is comprised more of a circular continuation of family ideals (pre- and post-holiday) and realities (on-holiday) than distinctions between the stages (Figure 6.1) which extends holiday experiences over time (Figure 2.4).

Figure 6.1 Circularity of temporal dimension of family holidays

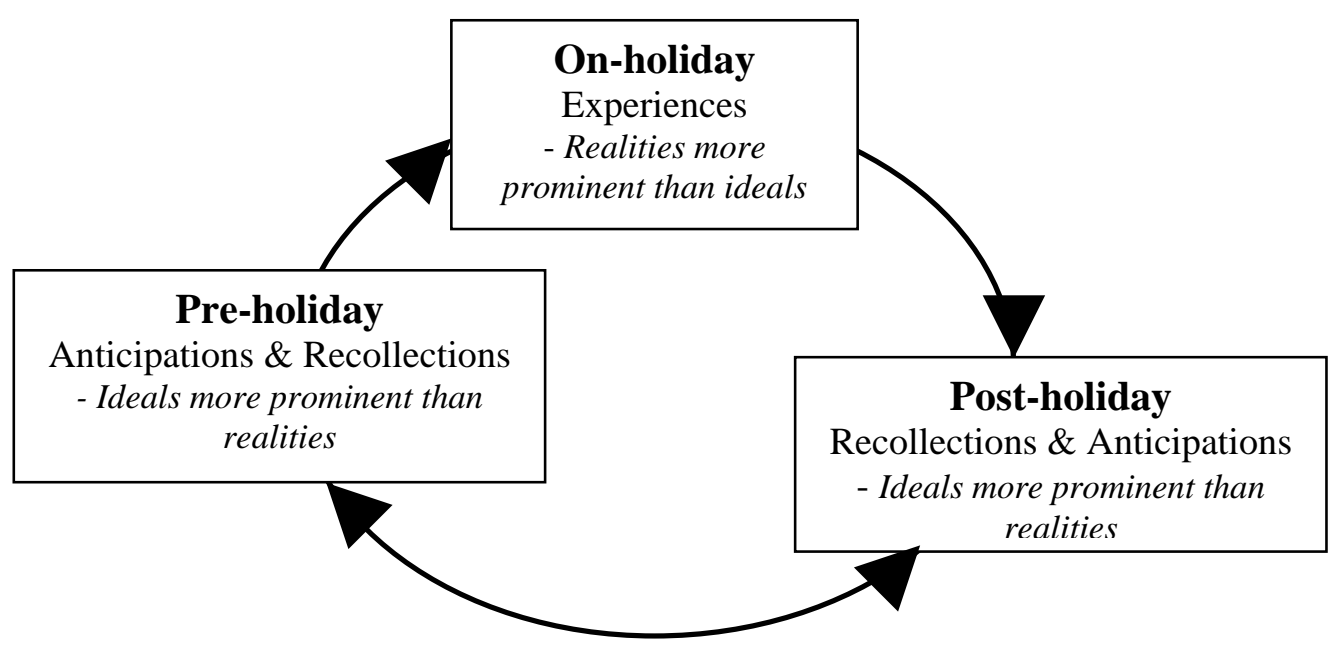


Temporality is represented more by a continuation of family habits and traditions on holiday, which made the staged approach more arbitrary. In many ways, the thematic dimensions of family time and own time and their internal dynamics were taken on holiday and played out at a different location but represented an extension from home and a continuation from other holidays. While time together as a family was anticipated and remembered before and after the holiday, family members also had their own agendas on holiday, as everyone wanted to pursue their own interests, just as at home. The following discussion tracks these elements over time and refers to other past holidays as a reflection of the continuation of the themes and perspectives, with temporality itself playing a secondary role.

\subsubsection{PRE-HOLIDAY: ANTICIPATIONS AND RECOLLECTIONS OF IDEALS}

The period before the holiday was characterised mainly by low expectations and a vague anticipation of a holiday ideal (see Gyimothy, 1999). This might reflect the regular holiday behaviours of these families, where holidays have become an established part of their everyday life worlds (McCabe, 2002). The general ideal or purpose was spending quality family time together and a change of routine (see chapter 5). For the parents, the destination and specific activities then became secondary to the paramount notion of family time:

"The expectations are not huge, per se, other than just spending time with the family." (Weka father, pre-individual interview)

"I don't really mind where we go as long as we can have family time again.” (Goldfinch mother, post-individual interview)

Apart from family time being 'good' there were no concrete expectations other than weather, which was mentioned by parents and children alike (see section 4.4.3):

"I like there to be nice weather and spend some good time together." (Kakariki mother, pre- individual interview)

Children had even fewer expectations because their lack of choice in the destination (see section 4.4.1) meant they knew little about where they were going: 
“No idea what to expect from Great Barrier Island.” (Hoiho boy1, 11, preindividual interview)

The children mainly anticipated having fun and sociality. Even though motivations and expectations pre-holiday were signified by vagueness, they nevertheless anticipated the core thematic developments governing the other temporal stages. The main purpose for the parents was having a good family time, for children this included having fun together. Thus, before the holiday the notion of family time already became imbued with values, meanings, and idealisations, as discussed in chapter 5 .

\subsubsection{ON-HOLIDAY: EVERYDAY EXPERIENCES}

Time and space became inseparable dimensions of the actual holiday experiences, especially having your own time and space (see section 4.4.4). Within the holiday environment a break was sought from the purposive nature of family time, as discussed earlier in this chapter:

"I liked having the time and space to be able to read my book actually." (Kea mother, post- individual interview)

Pursuits of own interests came to the forefront such as the individual highlight of surf kayaking (see section 6.3.1) or the watching of seals.

"I am an animal nut. So seeing the seals is like <husband> is going: 'when are we going?' and I am: 'soon'. I could sit here all day and watch the seals." (Tui mother, postindividual interview)

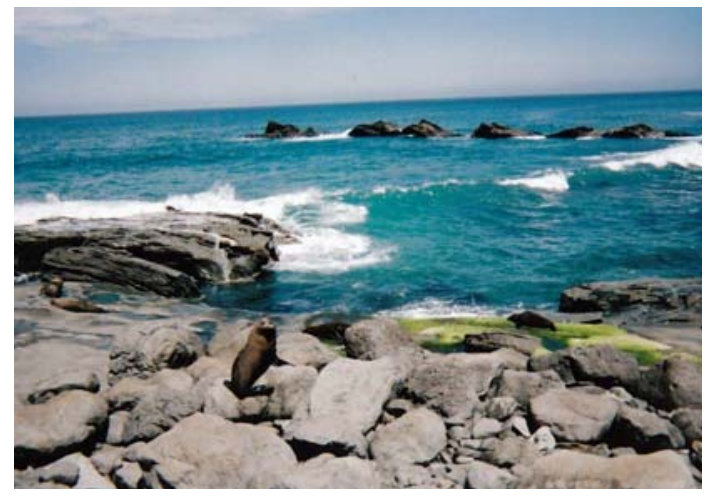

Time with peers was particularly valued by the children (see section 6.4):

"We [herself and friend] went on rides together it was really fun and cool. We met up at Splash Planet." (Takahe girl, 10, post-individual interview)

Holidays, then, also became about other people, such as extended family and established and new friends. Thus, on holiday conditions were constructed that allowed for own time through the use of social relations. This is also a reflection on the realities of family living. Family holidays, thus, represented a continuation 
of habits and group dynamics from home and from other holidays, so that life with children in general was about compromises:

"The whole thing is compromised, the whole thing is compromise. We haven't stopped for 10 years, turn your life upside down.” (Kakariki father, final individual interview)

Photos that captured the actual holiday experiences were mainly about children having fun and happy family images rather than negative or adults' only portrayals (see section 5.5.1). They, therefore, shaped the recollection of holiday experiences by emphasising positivity in the form of sociality and family time on holiday. While weather was important in anticipation and on holiday, it mainly faded with the passing of time, as discussed next.

\subsubsection{POST-HOLIDAY: RECOLLECTIONS AND ANTICIPATIONS OF IDEALS}

Remembered experiences were generally more positive about the time spent together, thus, perpetuating the idealisation of family time on holiday. Contextual factors such as weather and destination attributes became less important over time, i.e., bad weather became good over time, and holidays blended into each other unless there were outstanding (peak positive and negative) experiences (see section 5.3.1). Children, especially, seemed to forget about negative experiences with the passing of time, as this example in the Takahe family demonstrated:

Father: "We were having that cold snap and that was one of the overriding memories on how cold it was." (Post-individual interview)

Boy, 12: "I remember we drove up there and stayed at this motor camp and it was hot, which is good. I like hot weather and we went to the aquarium and that is all that I can remember." (Final individual interview)

This is supported by Mitchell et al. (1997) in that subsequent recollections can become more positive than the actual experiences, which was called the 'rosy view'. Another example was the incident of kayaking in a thunderstorm at a past holiday which retrospectively became a highlight for Hoiho boy1, 11, but was differently remembered by the mother:

"You tend to remember the good things about holidays like the thunderstorm when kayaking. You [son] remembered it as a fun thing even though at the time it was horrible...I seem to remember both of you crying on the way back because you were so miserable.” (Pre-family interview) 
This also illustrated how parents, and particularly mothers, had a more persistent memory about stressful events. It was not necessarily the event itself that was remembered negatively but the emotional upset it created (see section 6.6.2).

Another example was a strenuous walk that was remembered for its achievement rather the effort:

"I enjoyed the walk once we got there ...probably I remember it more fondly than I did at the time because you do not remember how tired you were. I think you don't remember the bad things." (Kakariki mother, final family interview)

Stressful leisure experiences, thus, faded away retrospectively, as identified by Lee et al. (1994), which resulted in more favourable memories. The rosy view persisted even for negative incidents that became humorous over time (see section 4.4.6). Positive memories were also deliberately constructed by the parents out of photos and storytelling (see section 5.5.1). The purposive nature of family holidays together with a human tendency for positive memories, therefore, obscured the existence of negative experiences over time.

Remembered experiences could also become more negative (see Wirtz et al., 2003), especially when concerning a perceived lack of own time on holiday. Below is the example of Goldfinch mother which exemplifies how not going shopping was perceived as a sacrifice over time:

"I remember before we went I actually said that I would like to have some time to go shopping on my own, just browse through the shops. At one stage I felt like I wish I could do that but then I felt, oh, we are having such a good time it is not really that important." (Post-individual interview)

"We went out like every day and there were days that I wished just to stay at home all day but we didn't. I felt that was a sacrifice and not to go for a stroll through the shops because I know they don't like it, not one of them. Yes, I gave that up for them. Big sacrifice!” (Final individual interview)

Mothers, in particular, unfavourably remembered emotional incidents and not being able to pursue own interests (see section 6.6.1), whereas a generous amount of own time and pursuit of own interests appeared more taken for granted and less valued. The following responses exemplify how little was remembered about some personal highlights and how unimportant they became compared with earlier accounts (see section 6.7.2): 
"I actually forgot about the seals on this photo...not memorable but I got a kick out of it." (Tui mother, final family interview)

"It was nice seeing them [friends] but it doesn't really matter to me if we don't see friends on holiday because sometimes you just want to spend time with your family.” (Takahe girl, 10, final family interview)

The longer-term memories were generally not only more positive but also more concerned about realising the ideal of family togetherness. Family time, then, dominated the discussions before and long after the holiday whereas closer to the holiday own time and family realities became more central. The temporal dimension highlights the continuous tension between ideals and reality and mirrored findings in the literature for family life at home (see section 2.3.1) and family leisure (see section 2.4.1). Consequently, temporality for the main themes was not as strong. This meant that experiences of family life were carried through time (bringing past holiday experiences forward) and over space (moving from one location to another), which made temporality and spatiality confounded dimensions (see Allen \& Daly, 2005). It also meant that while there was continuity from home and continuity between the holidays there was also a break or discontinuity sought from home realities in the form of family holiday ideals.

\subsection{CONCLUSION}

Own time was largely about pursuing own interests, either alone or in the company of peers, which included non-family holidays. The meanings of own time varied across the genders and generations and there were perceived variations in personal needs. For fathers it was more about physical and mental activities or challenges combined with hedonistic pursuits. For mothers it centred more on restful activities such as reading. Children sought more physical activities than their parents. For the boys this involved more adventurous activities than for the girls. The interests in own time generally were familiar whereas in family time novelty or difference was sought. Children desired more time with peers than the parents. The entitlement and need for own time was also correlated to the age of the children with older children allowing and desiring more than younger children. Own time for the parents meant freedom from parental obligations 
whereas for the children it meant freedom from parental restrictions. Parental facilitation of family time or spouse's own time might come at the expense of personal own time, especially for the fathers. Overall, generation was more important in own time than gender.

While having time away from the family on holiday could be perceived as counterintuitive to the ideology of family togetherness, it provided a balance to the hegemony of family time. Own time, thus, became an essential part of a more balanced and realistic reflection of holiday life, but any recognition of this is largely missing in the Western discourse. Instead, lack of own time or an imbalance of individual needs to pursue own interests could lead to conflicts. The idealisation of family time directed attention towards the positive aspects of family holidays before and after the holiday but obscured other internal dynamics of the actual holiday experiences that can range from positive to negative. The temporal dimension, thus, provides an understanding of the correlation between holiday ideals and family realities over time. As a result, a balanced focus on family time alongside own time might allow for a more realistic view of holidays which ultimately could mean more conflict-free holidays. This, therefore, would compensate the Western emphasis on togetherness over the individual needs and interests of its family members. 


\section{CHAPTER 7: THEORETICAL INTERPRETATION OF FAMILY HOLIDAY EXPERIENCES}

\subsection{INTRODUCTION}

This chapter discusses the theoretical implications of the findings into family holiday experiences from three dimensions: themes, perspectives, and temporality (Figure 3.3). It first expands on the key definitional characteristics, as established in chapter 4 , by conceptualising more the thematic dimension of family time and own time and the negotiation between the two. It then discusses the familial dimension from the perspectives of generation, gender, and group dynamics before examining the temporal and spatial dimension of family life on holiday compared with at home. The significance of domestic holidaying and the New Zealand context follow with the situatedness of this study. This chapter, thus, links the findings chapters to the broader literature, highlighting similarities and differences, and emphasizing continuities and discontinuities between family life in general and its intricacies on holiday.

Many of the themes that emerged in chapter 5 on family time (such as change of routine, the pursuit of fun/hedonism, social connection, and creating positive memories) have already been discussed in the broader tourism literature (although not related to family holidays). The novel contribution of this thesis is the exploration of the familial dimension of these themes which revealed the interactionist perspective of escaping to and from social relations and the implicit purposiveness of family group travel. Compared with other types of group travel, for example, family holidays deliberately include external social relations to alleviate internal strains. Compared with a focus on the individual self in most of the tourism literature, the three-dimensional perspective provided insights into familial desires, needs, and dynamics. This included parental intentions to establish social (including national) identities, the meaningfulness of social fun and sociality for the children, the use of social support to facilitate cooperation among social relations, and the need for a balance between family time and own time to pursue interests alone or with peers. It is the findings in chapter 6 on own 
time that provide a major contribution to the literature. The familial dimension, thus, resulted in highlighting the internal dynamics of cooperation, compromise, and conflict that signify the relationship between family and own time on holiday.

\subsection{THEMATIC DIMENSION: NEGOTIATION OF TIME ON FAMILY HOLIDAYS}

A symbolic interactionist approach to the study of family holiday experiences is concerned with the way social and familial forces operate in creating an understanding of time that is shared among individuals. On family holidays, meanings to time are created that shape the identities of the individuals involved and give direction to the course of interaction. Parents and children bring different meanings to time based on their different understandings of the situation. As a result, identities are created within a thematic dimension about time that is continually constructed and negotiated (see Thorpe \& Daly, 1999). Figure 7.1 is a thematic or applied model of the holiday experiences for the whole family group that centre on the ideal of family togetherness and the reality of needing own time, and the negotiation of the internal dynamics between the two. The circles and the overlap are not representative in size but must be seen as dynamic and dependent on other factors like type of family or holiday. Family time and own time provides a summary of the main holiday experiences which are not ranked by importance nor seen as present for all family holidays. The dynamic and outline of this model is indicative for the other models presented in this chapter (see Figures 7.3-7.5). Family time is defined here as purposive time with the immediate and extended family; own time as freedom from family commitments or time to pursue interests alone or with peers. The internal dynamics are ordered from positive to negative, from cooperation to compromise to constraints and conflict. The main definitional characteristics of family holidays have already been established (see section 4.3.2) but are discussed here within the experiential dimension: first, family time with togetherness, purpose, change of routine, and fun; second, own time with balance and individual pursuits; third, internal dynamics with compromise and conflict.

While the focus on family interactions is from a micro level there are other societal forces operating at the macro level that need to be acknowledged with 
regards to family holidays. This, however, is not exhaustive because of the research paradigm taken for this study. The main societal influences that apply here are the temporal and spatial dimensions of family experiences that are laden with social and ideological meanings (see Allen \& Daly, 2005). One of the most central dialectical tensions embedded in family life is the pull between the real and the ideal: the symbolic ideology of family time is carried through time and space in a continual struggle with the mundane, temporal reality of day-to-day family living. Holidays then become an extension of family home life (see section 7.4) in that family time is sought and own time is needed. This reflects the basic condition of families (see Hess \& Handel, 1959) and family systems theory (see Olsen \& Gorall, 2003), and addresses the inherent schism in family holidays (see Gram, 2005) in that a dynamic state of homeostasis or balance between togetherness (family time) and separateness (own time) must be worked out amongst the family members. This means that the navigation of time on holiday is subject to the dynamics of ideals, needs, exchanges, and tensions within the family group. These conceptualisations shift the understanding of time from something that is private and personal to an experience that is imbued with societal values and is subject to interpretation and negotiation.

\subsubsection{FAMILY TIME}

The concept of family time emerged from the analysis of the survey and the interviews as the overarching theme of how families experience time on holiday when travelling with the whole family (see chapters 4 and 5). Family time is used here to represent the all-encompassing experience of family holidays in relation to more individual experiences of time (Figure 7.1). From a generational perspective it includes providing quality time that is different from normal (see section 5.3) which symbolises 'parented time' that is tethered to the needs, identities, and activities of children. This is primarily seen as an investment into the future which is connected to beliefs about being a good parent (see Thorpe \& Daly, 1999). This can be linked to the increased pressure in Western societies that parents feel to provide large amounts of time to their children at home (e.g., Snyder, 2007), at leisure (e.g., Shaw, 2008), and on holiday (e.g., Blichfeldt, 2006). It reflects Giddens' (1984) macro-level structuration theory in that social systems are 
Figure 7.1 Dynamic state of balance or homeostasis of family holiday experiences

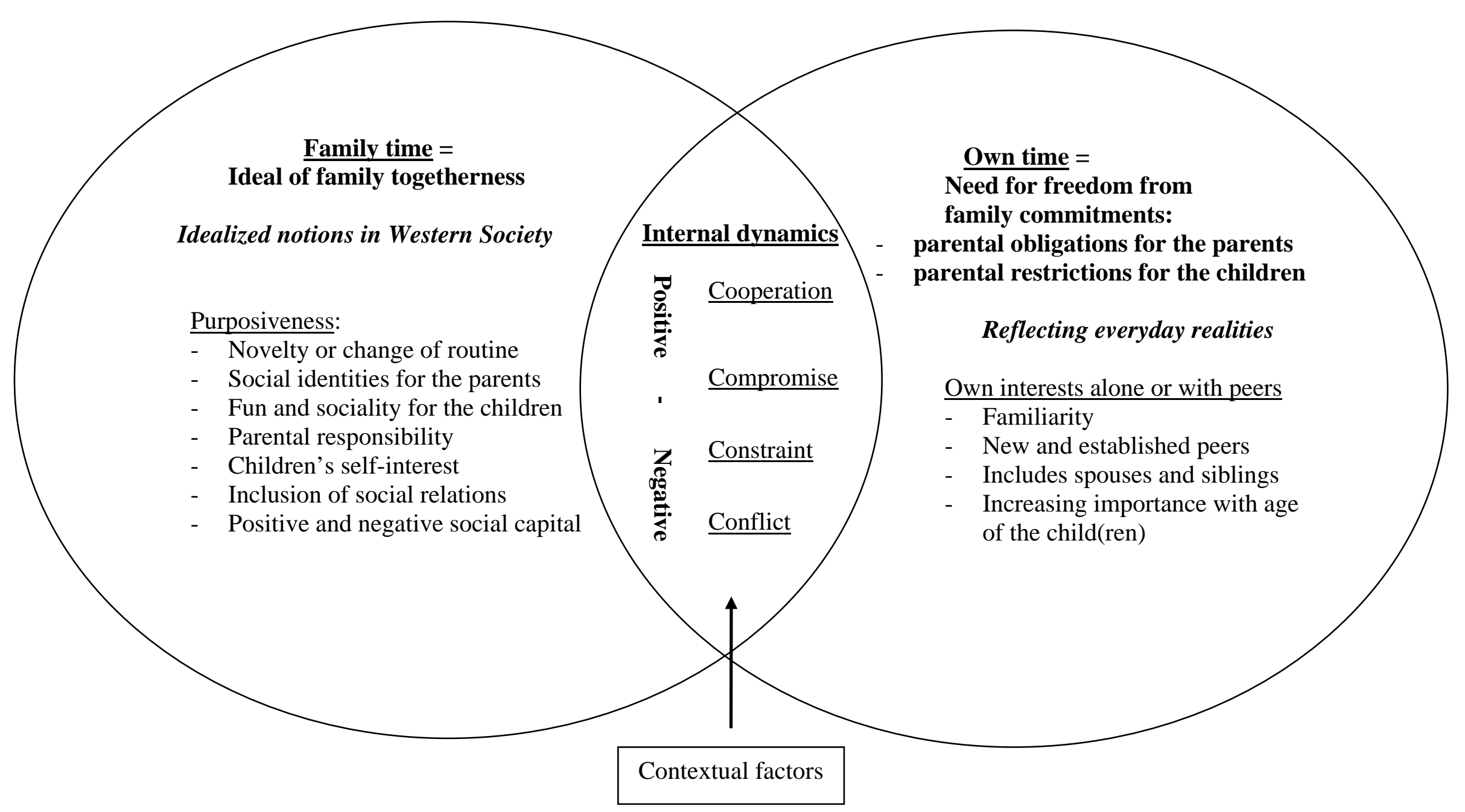


(re)produced in social interactions. Time, then, has lived, inter-subjective aspects that reflect reality and structured, normative dimensions that reflect ideals. It is the ideology of the family that is (re)constructed on holiday which is represented by the purposiveness of family time.

For the parents the purposiveness centred on a change of routine (see section 5.3) which are positive and novel experiences (see Hilbrecht et al., 2008) that result in establishing social identities and traditions (see section 5.5). This is based on the importance placed on social connectedness and social capital in the holiday experience which is part of the 'social turn' of tourism studies. It places family and friendship relations at the centre and claims that tourism is about (re)producing social relations (Larsen, 2008). Photographic images capturing these intimate family relations help in the creation of this 'family gaze' (see section 5.4) which can produce rather than reflect family life (Larsen, 2005). Social capital is a key concept in the social sciences which is obtained through securing benefits by virtue of membership in social networks such as family, friendship, and other social structures (Portes, 1998). The theoretical approach to social capital takes two directions: an individual interest or a collective good (Heimtun, 2007a); people use the social connections for personal gain (Bourdieu, 1984), and social relations integrate people (Putnam, 2000). According to Portes (1998) the latter perspective is based on social integration theory as applied here and, thus, goes to the core of sociology. Yet, this concept focuses attention on the positive consequences of sociability while neglecting its less attractive features.

The positive function of social capital includes social support which is about reciprocity and generalised trust (Johnston \& Percy-Smith, 2003). Family support is reported by Portes (1998) as a source of parental and kin support which primarily benefits children. This differs from the findings (see section 5.4.3.) because social support provided by the extended family is primarily used by the parents for domestic and child-care help rather than commented on by the children themselves. The cooperation provided by social relations, instead, aided in relieving tensions within the family group, which benefited all family members. It is noteworthy that neither social support nor cooperation have been mentioned within the tourism literature even though this highlights the fact that family 
tourism uses connections with social relations to escape from the multiple obligations of everyday family life. While seeking and escaping along with personal and interpersonal motivations for travel have been identified previously (e.g., Iso-Ahola, 1982; Larsen et al., 2007), it adds a third dimension in that interpersonal seeking is used for personal escape. It emphasizes the growing importance of VFR tourism because social networks are becoming increasingly geographically dispersed (Larsen, 2008) and all the interviewed families used their holidays to stay with, visit or travel with friends and relatives (see section 5.4.1). This can mean that holidays offer the only opportunities for (re)connection with extended families and friends. Family holidays then become a necessity that is integral to social life.

According to Putnam (2000) there are two interconnected forms of social capital: 'bonding social capital' and 'bridging social capital'. Bonding social capital in tourism refers to exclusive identities and strong ties to family and friends (e.g., Heimtun, 2007a), as exemplified in the findings (see section 5.4). Bridging social capital refers to weak ties to distant acquaintances based on inclusive identities such as religious organisations (Johnston \& Percy-Smith, 2003). It could be argued that fostering a sense of national awareness or identity, as identified in section 5.5.2, implies inclusion in a common national society which is bridging rather than bonding social capital. While much of tourism is on bonding social capital (Heimtun, 2007a), it must be acknowledged that within a domestic tourism context family holidays can also entail bridging social capital based on inclusive national identities or citizenship. Few studies deal with tourism experiences that promote a sense of collective belonging (e.g., Palmer, 2005), although this appears especially relevant for a geographically isolated country like New Zealand (see section 7.5). The family holiday experience, then, becomes an opportunity for identity formation: familial, national, and, ultimately, social.

The negative function of social capital included the meeting of social obligations and reciprocity as a form of restriction on individual freedom, since some families felt obligated to catch up with friends and family (see section 5.4.2). This is a representation of the dilemma between high levels of familistic solidarity and individual freedom (Portes, 1998). It could be argued that adherence to the 
ideology of family life results in excessive claims on group members. The high valuations that parents attach to the purposiveness of family time can mask the fact that parents do this at the expense of their own time. Thus, the level of societal control in family settings can be strong and also quite restrictive of personal freedoms, which could be the reason why there is such a perceived need for own time on holiday. It must be remembered that ideals about family time are seen as a personal trouble that require a private solution rather than a systemic or public dilemma applying to all families (see Daly, 2002). This might explain why the achievement of family time is portrayed more realistically closer to the holiday (see section 7.4) and why parents were generally resigned about their responsibilities rather than entering a debate about broader societal pressures.

For children, the primary purpose of family holidays was having fun (see Hilbrecht et al., 2008) but included connecting with friends and relatives. For example, the shared fun experienced on the kayak trolley or when playing cricket with the extended family (see section 5.3.2). The parental purposive component to the holiday remained largely unrecognised by the children, highlighting generational differences in intentions (see section 7.4), and was only appreciated later in life (see section 5.5). Fun for the children reflects their self-interest and is fundamentally perceived as interactive, as illustrated by the absence of social opportunities being perceived as boring (see section 5.6). This supports Podilchak (1991) in that fun emphasizes a social emotional interaction process, implying that it is difficult to have fun by oneself. While the enjoyment mentioned by the parents in a collective context articulates similar experiences to fun, for them fun was also talked about individually (see section 6.3.1). It explains the emphasis children put on having other people to interact with outside the immediate family, and especially, peers. This stresses the fact that holiday experiences for children have a stronger social dimension and are different from the individual focus of most tourism research (see section 2.6.1).

It further suggests that children's perceptions of holidaying not only differ from parents but also differ from adults in general, and emphasizes a need for a conceptual 'repertoire of experiencescapes' as suggested by Blichfeldt (2007). Figure 7.2 develops a new framework based on the different family holiday 
experiences at all ages (not just focus on the existing literature on youths and adults), from pre-schooler to grandparent. Based on this study, the experiences of the school-aged children and the parents can be expanded. The gaps highlight the need for more whole-family research on the experiential dimension of family travelling with pre-schoolers, teenagers, and grandchildren. It acknowledges that experiences change with age and travel party composition.

Figure 7.2 Conceptual family holiday life cycle: 'Repertoire of experiencescapes' as based on holidays with school-aged children

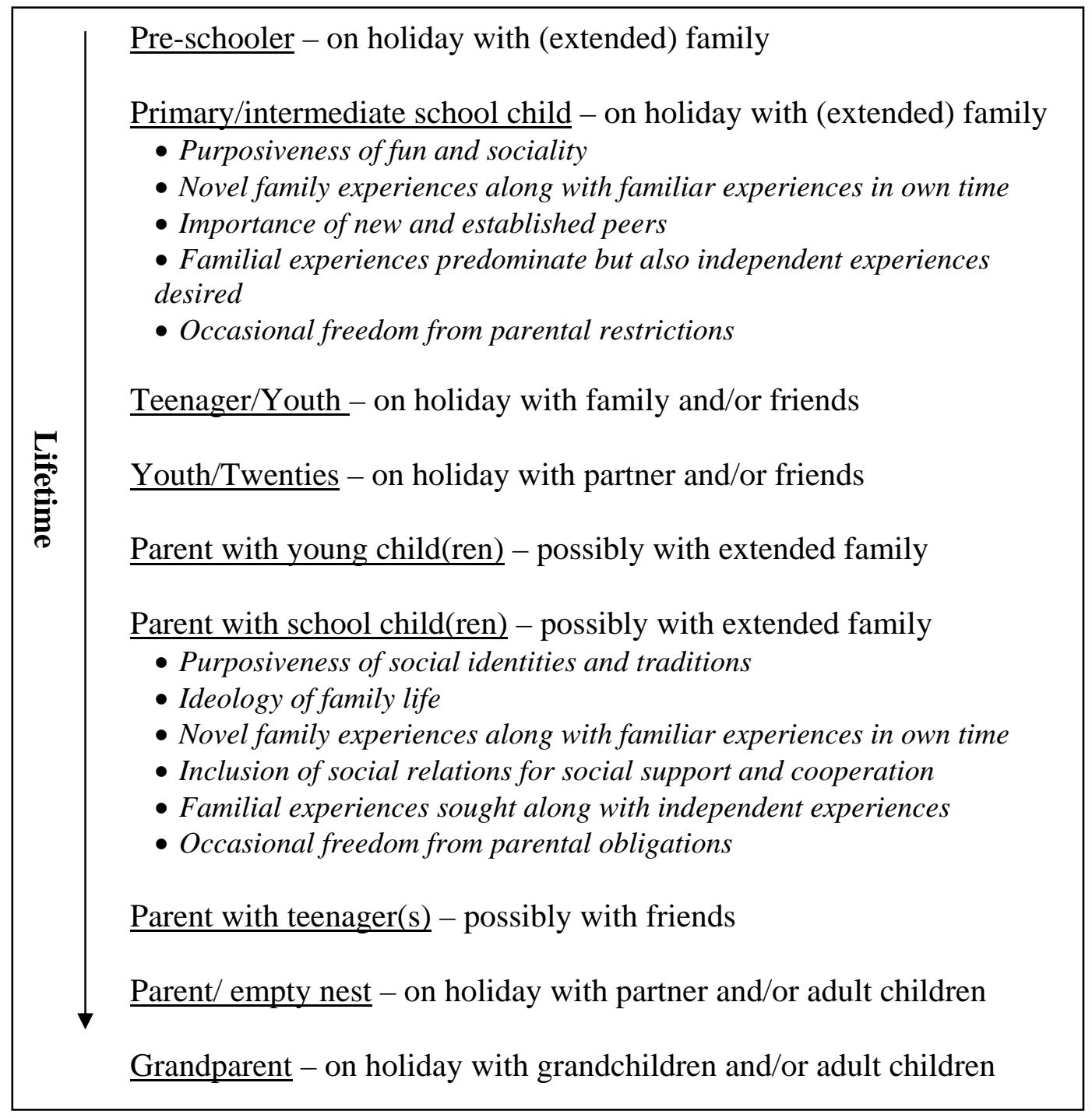




\subsubsection{OWN TIME}

The quest for time out from the whole family or own time represents an important desire for family members to assert their right to a space of their own within the holiday environment, and in the midst of the realities of family life (see chapter 6). In the literature it is also referred to as 'me-time' (e.g., Department of Labour, 2003; Stevens et al., 2007) or 'time for self' (Harrington, 2001) but, significantly, within the holiday environment it includes time with peers such as spouses and friends rather than just time alone. It spans across the generation rather than between the generations. Thus, own time on holiday is defined as freedom from family commitments or time to pursue interests alone or with peers (Figure 7.1). It symbolises a more private component of holiday life that has remained largely hidden in the family tourism literature (e.g., Gram, 2005; Shaw et al., 2008), unrecorded by the families themselves (few photos were chosen with parents engaging in own interests which confirms the focus on the family gaze), and predominantly surfacing in individual interviews closer to the actual holiday. In individual interviews, it was mentioned by parents and children alike.

The activities and interests pursued in own time were generally signified more by familiarity, from home or from other holidays (see Hilbrecht et al., 2008), such as reading, swimming, and shopping. Own time is, thus, more about familiar experiences compared with the more novel experiences sought in family time. It emerged that own time increases with the age of the children: the older the children the greater their need for own time, which also increases the own time available to the parents. Also, the older the children the higher the likelihood that peer time revolved around established peers, compared with making new friends for younger children (see section 6.4.2). So far the importance of the peer group has only been considered during adolescence (see Hilbrecht et al., 2008) and not for younger children on holiday. Peer time for the parents also included couple time, but, overall, less emphasis was given to it than peer time for the children. While the results of the survey showed a high proportion of non-family holidays undertaken by parents and children (see section 4.2.1), little is known in the literature about this aspect of tourism behaviour. This confirms findings by Harrington (2001) in family leisure that couple time was perceived as enhancing 
marital bonds but that parents felt socially pressured to put their children first, which is linked to the ideology of family time. The dominance given to family togetherness in the Western discourse on family life not only neglects the individual needs of family members but can also be unrealistic and lead to negative internal dynamics. Own time offers a component of holiday life that is more realistic and provides balance to the varied needs of family members with their inherent generational and gender differences.

\subsubsection{INTERNAL DYNAMICS}

The internal dynamics within the family group ranged from positive to negative: from cooperation to compromise to constraints and conflict (Figure 7.1). Essentially the internal dynamics are about facilitating own time: from positive facilitation through cooperation by social relations (as discussed earlier with regards to social capital), to compromises regarding the facilitation, to constraints affecting the facilitation, to conflicts resulting from the lack of facilitation. Compromises centred on the responsibilities expected within family life: parents to ensure that children had fun experiences (see Gram, 2007) and children to be considerate about familial needs. This is part of the ideology of family in that parents primarily put the needs of their children first whereas less was expected of the children. Compromises were largely accepted as a societal status quo for families rather than questioned within the holiday environment. Conflicts mainly emerged through probing and within family group interviews but were not represented in the photos selected, confirming that family frictions are not captured on camera (see Larsen, 2005). The social constraint on expressing dissatisfaction with the ideology of family holidays (Deem, 1996b) might explain why conflicts were more covert in the responses. It also revealed that conflicts could arise during holidays because family members were less insulated from internal dynamics on holiday than at home (see Rosenblatt \& Russell, 1975). For example, more time is spent in shared spaces, as on car journeys (see section 5.6) and in not having enough own time (see section 6.6.3). It highlights the fact that family holidays offer the only opportunity for the whole family to be closely together for an extended time without the distractions of outside commitments, which can reveal differences in interests and needs. 
Constraints can be both positive and negative (such as good and bad weather). Constraints only became apparent when the contextual factors negatively affected the family group dynamics (see section 4.4). The constraints mentioned by the participants were more personal and at the micro level but included ideologies at the macro or public level. They could, thus, exacerbate the internal dynamics but were not the cause of any problems in the negotiation between family time and own time. Overall, the balance between family time and own time was dynamic in that it depended on the family system (Olsen \& Gorall, 2003) as well as the divergent needs of individual family members. A balanced level of cohesion must be worked out on holiday which provides a healthy sense of both connectedness (family time) and separateness (own time) in family relationships. Extremely high levels can lead to enmeshment (too much closeness) (Perosa \& Perosa, 2001), which explains why an overemphasis on family time (cohesion) can be problematic for the family group dynamic. Adding generational and gender differences to this precarious juggle explains why family holidaying differs from other holiday experiences.

\subsection{FAMILIAL DIMENSION: PERSPECTIVES WITHIN THE FAMILY}

Most studies of family holidays have been approached from a marketing or business perspective and few have explored the experiences and meanings of holidays to family members (Hilbrecht et al., 2008); even less common are the children's (e.g., Small, 2008) and the fathers' perspectives. This is the first comprehensive whole-family study to employ a symbolic interactionist paradigm for understanding the meanings of these experiences for all family members taking into account generation, gender, and group dynamic perspectives. The model developed in Figure 7.1 was applied to the generational and gendered perspectives to illustrate the different key thematic findings for the three family groupings (children \& parents, mothers \& fathers, girls \& boys) which stress the experiential dimensions but not the extent (Figures 7.3-7.5). In consideration of these perspectives it became apparent that generational differences were more dominant than gender differences, which highlights the complexities of family 
holidaying compared with travels without children. It emerged that children's holiday experiences and meanings ascribed to them reflect shared societal notions of family togetherness including having fun; but they also differed at times from their parents', such as the importance placed on other people including peers. From a gendered perspective, it emerged that gender differences for the parents were more significant than for the children. Mothers sought a break from their domestic responsibilities whereas fathers felt more bound to their entertainment imperative. Gendered differences for the children centred on more adventurous activities for the boys and more social connection for the girls. The group dynamics highlighted the inclusion of other people and the need for own time, which provided insights into the social construction of family life on holiday.

\subsubsection{GENERATIONAL PERSPECTIVE}

At the micro level, symbolic interactionism provides an understanding for the two-way process during parent-child interaction. Theories of bidirectionality in parent-child relations have shifted attention from unidirectional models to frameworks that highlight the two-way, mutual, and reciprocal influence in parent-child interactions (Lollis \& Kuczynski, 1997). Of central importance here is the way that parents and children reconcile a set of competing desires and needs for time, and includes learning from and about each other. From this perspective children play an active role in negotiating social relationships and shaping the holiday experiences. Children mainly desire active fun and sociality whereas the parents' purposiveness centres more on establishing social identities and traditions (see section 7.2.1). Figures 7.3a and 7.3b provide a thematic summary of children's and parents' experiences of family holidays which emphasize generational differences. Children and parents also influenced each other in that the whole family sought fun activities such as going to animal parks (see section 5.3.2), and parents learned about their children through having more of an opportunity to observe (see section 5.5.2). There are generational differences in holiday priorities but these are mutually influential, highlighting dual purposes within the family. This replicates the duality of structure between societal ideals at the macro level that have an influence on the parents and daily realities at the micro family level. 


\section{Figure 7.3a Family holiday experiences for the children}

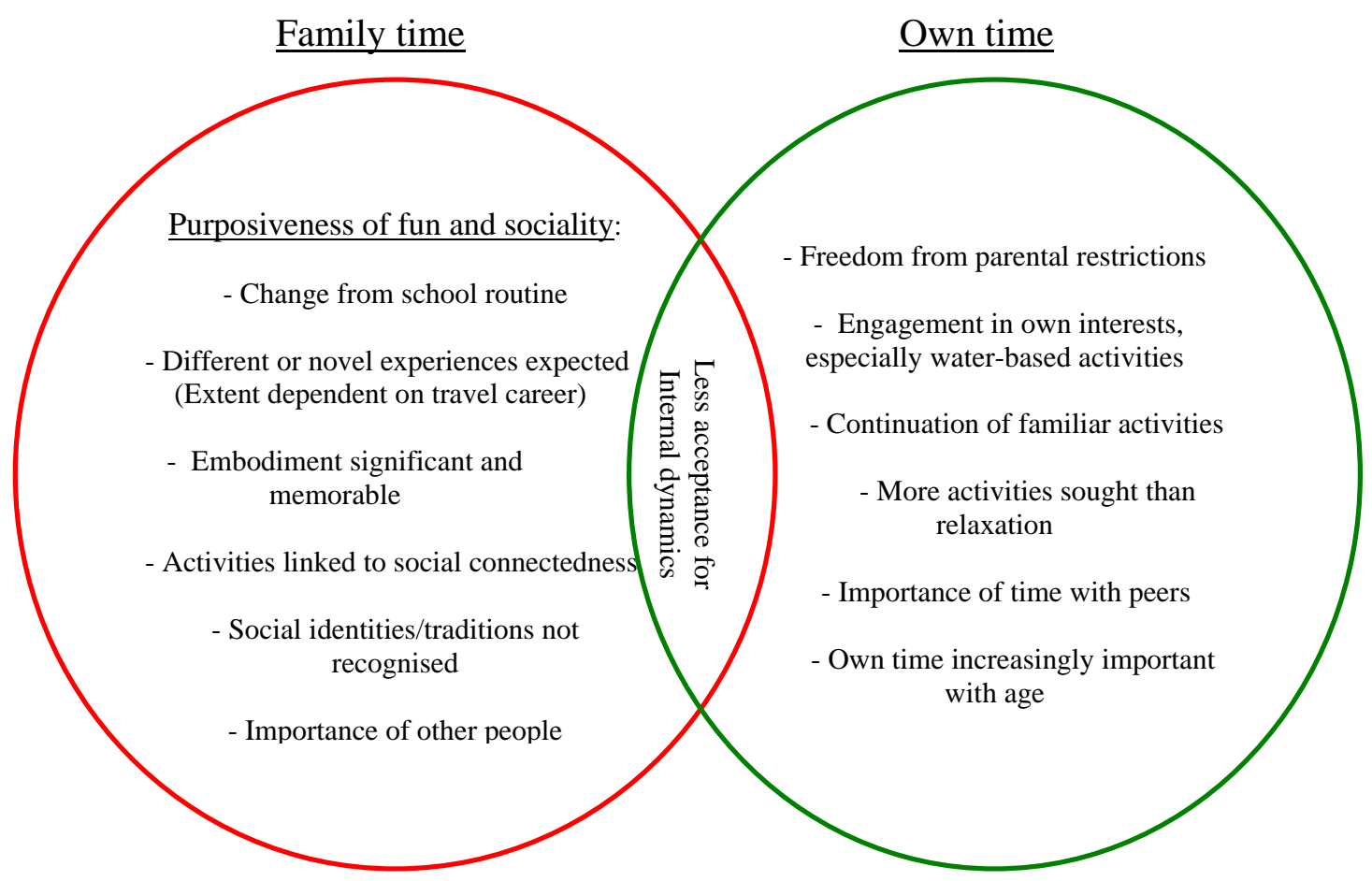

Figure 7.3b Family holiday experiences for the parents

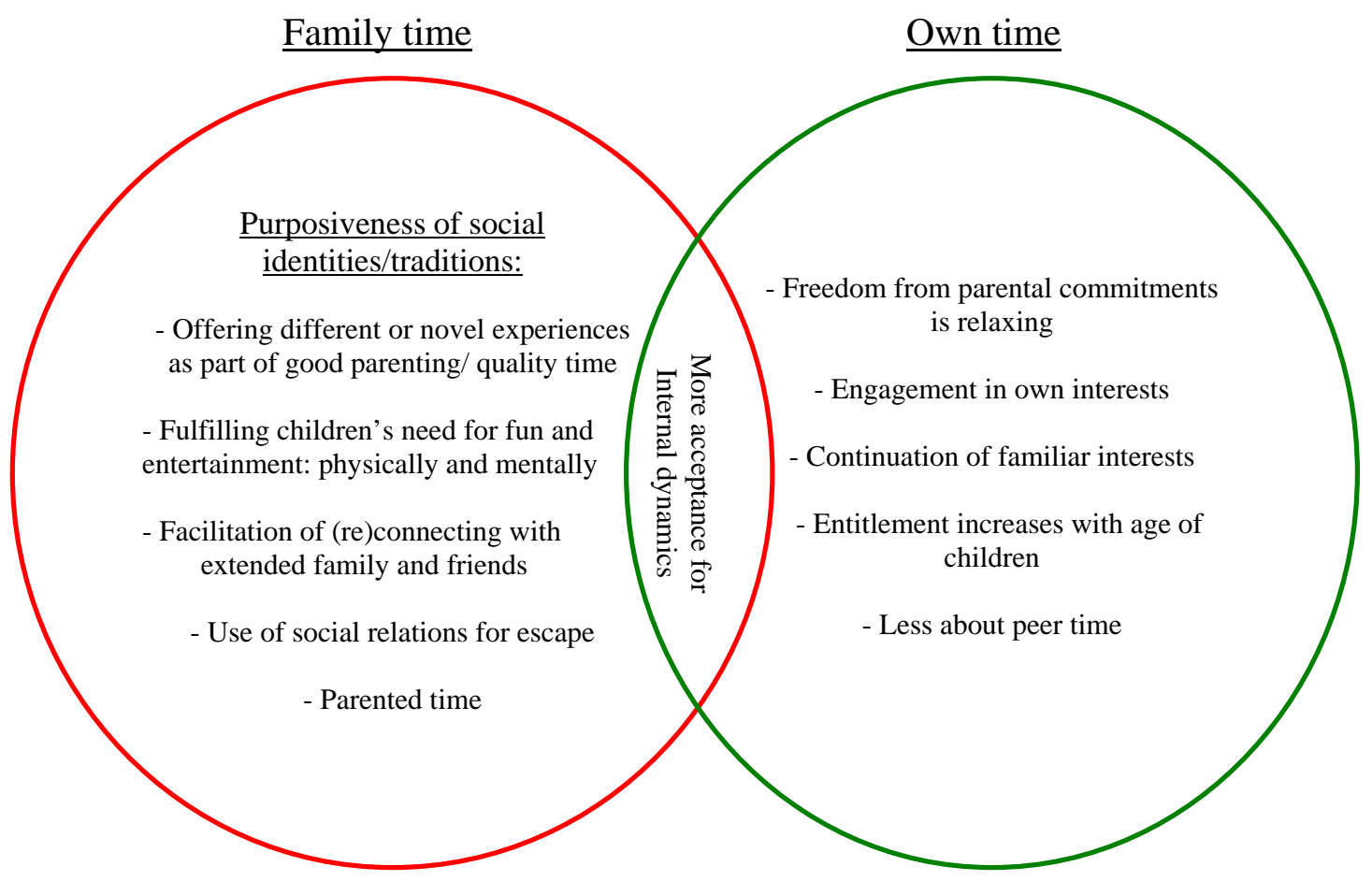


The duality of purpose, however, is also the underlying cause for possible tensions in that children seek more active fun and more connections to peers than their parents. This only partly confirms Gram's (2005) assertion that parents primarily seek time to rest and relax whereas children seek activities. In effect, for this study both parents and children sought activities as well as pursuits of relaxing interests, but the children sought more active fun than their parents. It appears that within a New Zealand context family holidays are generally more activity based. With regards to theme parks there is confirmation of the findings of Johns \& Gyimothy (2002, 2003) that there is a dichotomy between the 'fun' experienced by the children and the perceived self-sacrifice of the parent, as in this study mainly the mothers. Fathers were more embracing of their entertainment role in being actively involved with their children, reflecting New Zealand and Australian expectations of fathers' responsibilities (Harrington, 2006; Thompson, 1999), as discussed more in section 7.3.2.

The emphasis put by the children on the inclusion of friends and relatives on holiday highlights the notion that fun can also be experienced with people outside the immediate family, such as cousins (see section 5.4.1). While this might be contrary to shared societal notions of family time, it allowed parents to relax while the children were busy with activities, which was found conducive to family togetherness (Jepsen \& Blichfeldt, 2005). Other people, then, became an essential component of holidays to bridge the duality between parents' and children's purposiveness: parents could fulfil the children's need for fun and social connectedness while offering novel experiences as part of good parenting. At the same time, it allowed parents time out from their parental responsibilities and gave children freedom from parental restrictions or a balance of time: compliance and resistance to the ideology of family time. Overall, parental entitlement to own time was perceived to increase with the children's age as their time alone or with peers became increasingly important. Also, parents were more accepting of compromises on holiday and reported no parental conflicts compared with the conflicts between children (see section 6.6.3) highlighting generational differences in the perception of internal dynamics, as reflected in Figures 7.3a and 7.3b. 
Other generational differences were that embodied and sensory experiences such as having novel taste sensations and touching animals (see section 5.3.1) were particularly sought and remembered by the children, which might confirm that children are 'wired differently' from adults (Christensen et al., 2007). Additionally, peer time for the children was more important than for the parents, so that playing with other children was imperative while couple time was subsidiary to family time (see section 6.4). Also, social fun, sensory experiences, and excitement through shared activities were preferred by the children rather than educational attainment (see Small, 2008), as a break from school was desired (see section 3.5.2.2 with regards to scrapbooks). Any learning that occurred was incidental, with children not appearing to notice a purposive component to the holiday other than having fun (Hilbrecht et al., 2008) and sociality. Parents, thus, became facilitators of their children's holiday experiences, reflecting their children's interest and enjoyment, which were constructed as places of social identities and maintaining traditions from previous generations, such as the tradition of annual summer holidays (see section 5.6). From this perspective, parents allowed children some control of the present in the service of the future, a future which will confirm their success in having invested time with their children and as demanded by the ideology of family holidays. The meaning of family holidays is, therefore, not just concerned with the present time but appears in a circular relationship with future time in that children who then become parents gain a sense of themselves as part of a family that spans generations.

\subsubsection{GENDER PERSPECTIVE}

The discussion here of gender is divided by generation, first, mothers/fathers and second, girls/boys, as the generational perspective of parental roles was more dominant than the overall gender perspective. Also, differences for internal dynamics were less noticeable from a gender perspective and might be an avenue for future research. The main gender differences on holiday were regarding the parental responsibilities: mothers yearned for a break from their domestic responsibilities or motherhood discourse (Small, 2005b) and sought a time of their own. Fathers were more circumspect about a relief from their entertainment responsibilities and variously embraced their role to enable the facilitation of own 
time for their wives. Figures $7.4 \mathrm{a}$ and $7.4 \mathrm{~b}$ provide a thematic summary of mothers' and fathers' experiences of family holidays emphasizing gender differences. The theme of own time for the fathers compared with the mothers seemed muted in the responses, appearing less as a conscious, deliberate act of claiming 'time-out' from others and confirming other findings in family leisure research (see Harrington, 2001). It became evident that mothers exerted a greater control over the orchestration of time on holiday, just as at home (Allen \& Daly, 2005), and voiced greater claims on personal time. This confirms that more mothers today believe that they have a right to time and space for themselves (Wearing \& Fullagar, 1996).

One reason given in the literature for the parental differences is that mothers consider the facilitation of family time on holiday more as work than pleasure and sought freedom from their unpaid positions as carers (e.g., Anderson, 2001; Small, 2005b) rather than freedom from their paid jobs as fathers did (Hilbrecht et al., 2008) (Figures 7.4a and 7.4b). While there were some role reversals with regards to cooking responsibilities, the main domestic and emotional commitment remained with the mothers. The mothers committed emotional experiences more to memory (see Pinker, 2008), such as vividly recalling past upsets of their children (see section 6.7.3), and were generally more emotionally involved with their children than the fathers. The women in the study also yearned for a time and space of their own on holiday, which disrupts the myth of the forever-caring, uncomplaining mother (Small, 2005b) and mirrors other findings in family leisure research (Harrington, 2001). This highlights the never-ending physical and emotional work of motherhood at home, at leisure, and when travelling, and mothers desired a time to read or go shopping by themselves (see section 6.3.2). It extended the notion that women's magazines facilitate and legitimise 'me-time' for women at home (Stevens et al., 2007) to women’s general reading away from home. Reading at home and on holiday enables women to focus on their own needs and wants and to temporarily ignore the needs and wants of others, but could come at the expense of their husbands. 


\section{Figure 7.4a Family holiday experiences for the mothers}

\section{Family time $\quad$ Own time}

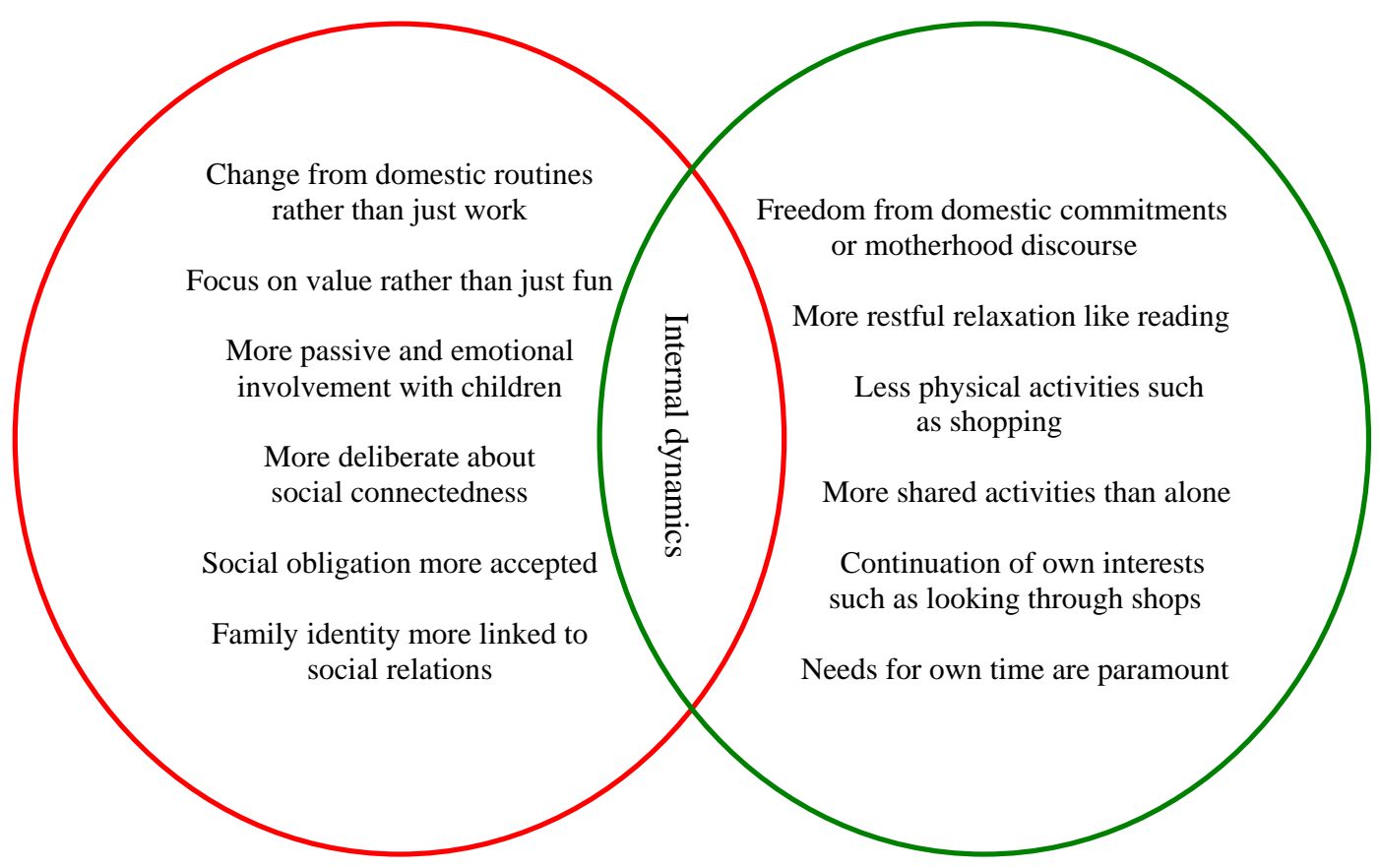

Figure 7.4b Family holiday experiences for the fathers

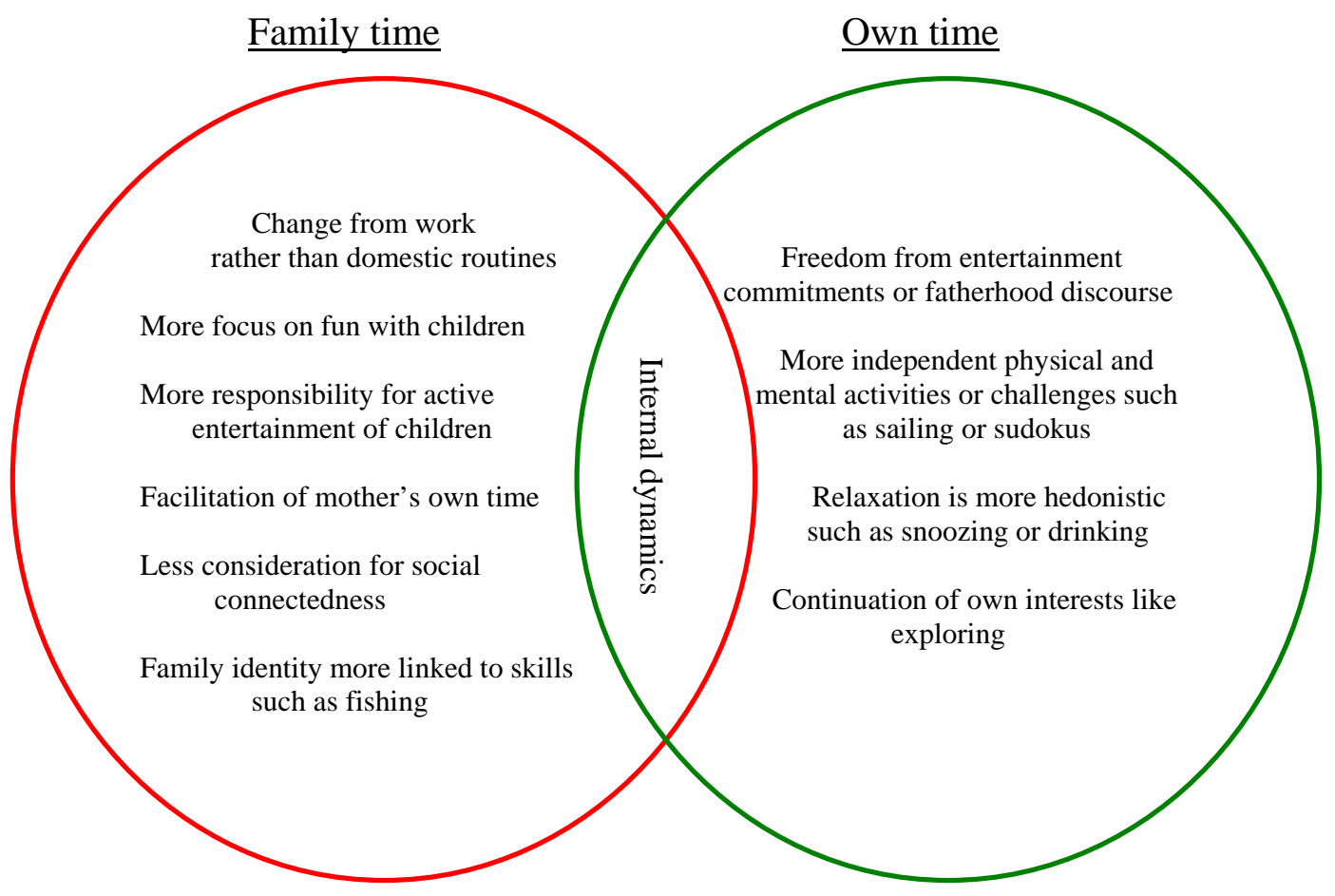


Fathers' role on holiday centred more on entertainment of the children based on fun and physical activities (Figure 7.4b), such as the fathers who primarily entertained their children at the theme park (see section 5.3.2). This meant a continuation of the fatherhood discourse based on activities and confirmed other findings in the leisure literature (see Harrington, 2006; Such, 2006). The activities-based parenting for the fathers was also linked to personal interests in that fathers were generally more physically active with their children than the mothers, as reflected in the children's responses (see section 5.4.1). This reflected New Zealand men's involvement with their children through physical activity and differed from Gram (2005) with regards to German fathers. According to Gram (2005) differences in gender roles on holiday are linked to German mothers being more full-time homemakers. It emerged that for New Zealand families the gender differences were more linked to personal interests than to employment status. There is, however, an entertainment imperative for the fathers that has largely been unreported due to lack of research into fatherhood on holiday. Getting a break from the fatherhood discourse was secondary to the needs of the mothers for own time. Thus, within the holiday environment some mothers' individual time entitlements are privileged over fathers', which is a reversal from general leisure behaviour (see Harrington, 2001).

When pursuing their own interests in own time, men sought more physically challenging activities than women, engaging in activities such as surf kayaking. This confirmed findings in the literature that men put more emphasis on action, self, and disengagement whereas women are more connected through relationships and seek more restful activities (e.g., Chaplin, 1999; Selänniemi, 2002). For example, men pursued more solitary activities such as sailing whereas women shared more activities with their children (see section 6.3.1). Less prominent gender differences emerged for the children in that boys sought more adventurous activities and exploration than girls, while girls sought more social connection. For example, some boys engaged in motor biking (see section 6.3.1) and some girls preferred to see their cousins to travelling overseas (see section 5.3.1). 
Figure 7.5a Family holiday experiences for the girls

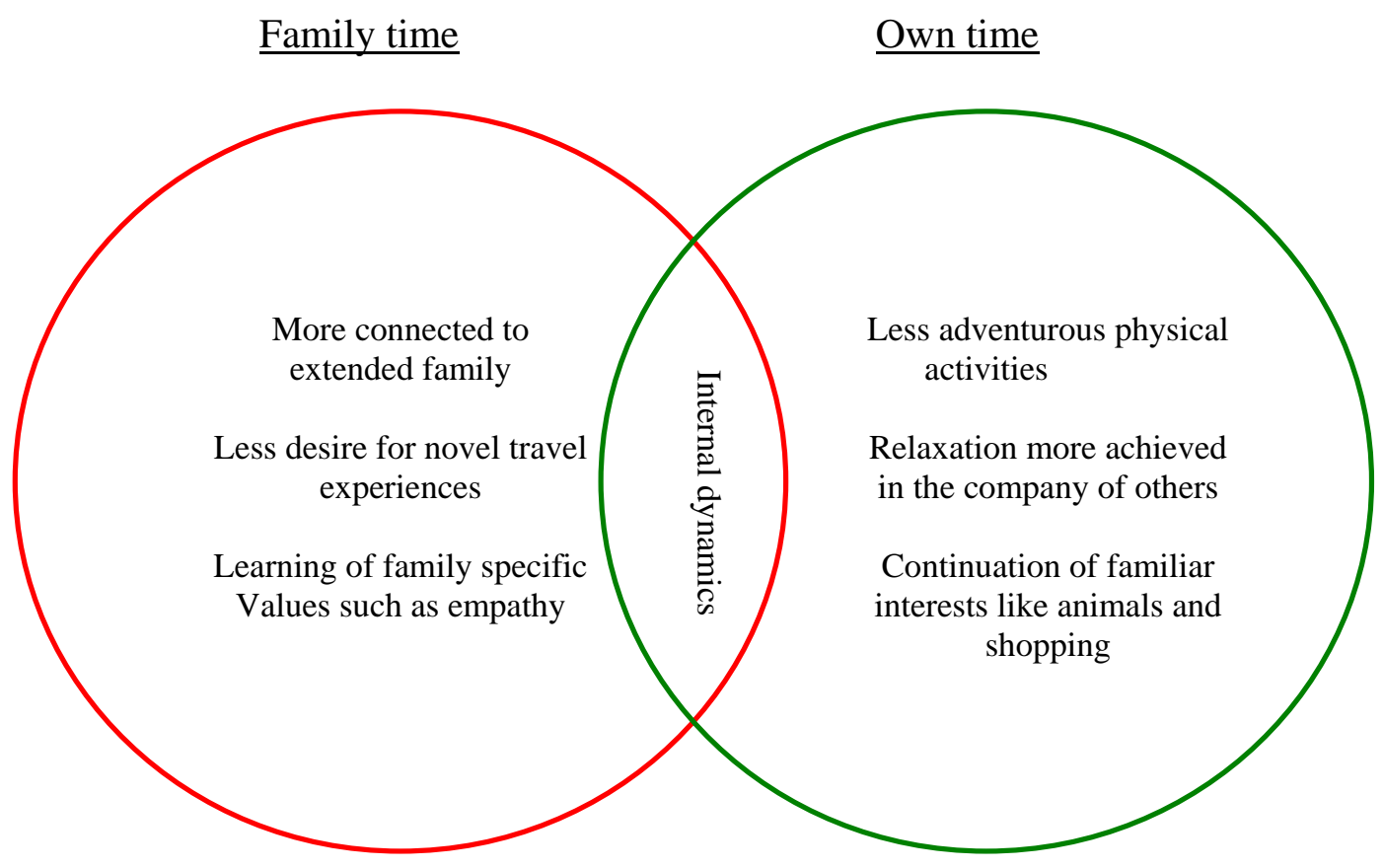

Figure 7.5b Family holiday experiences for the boys

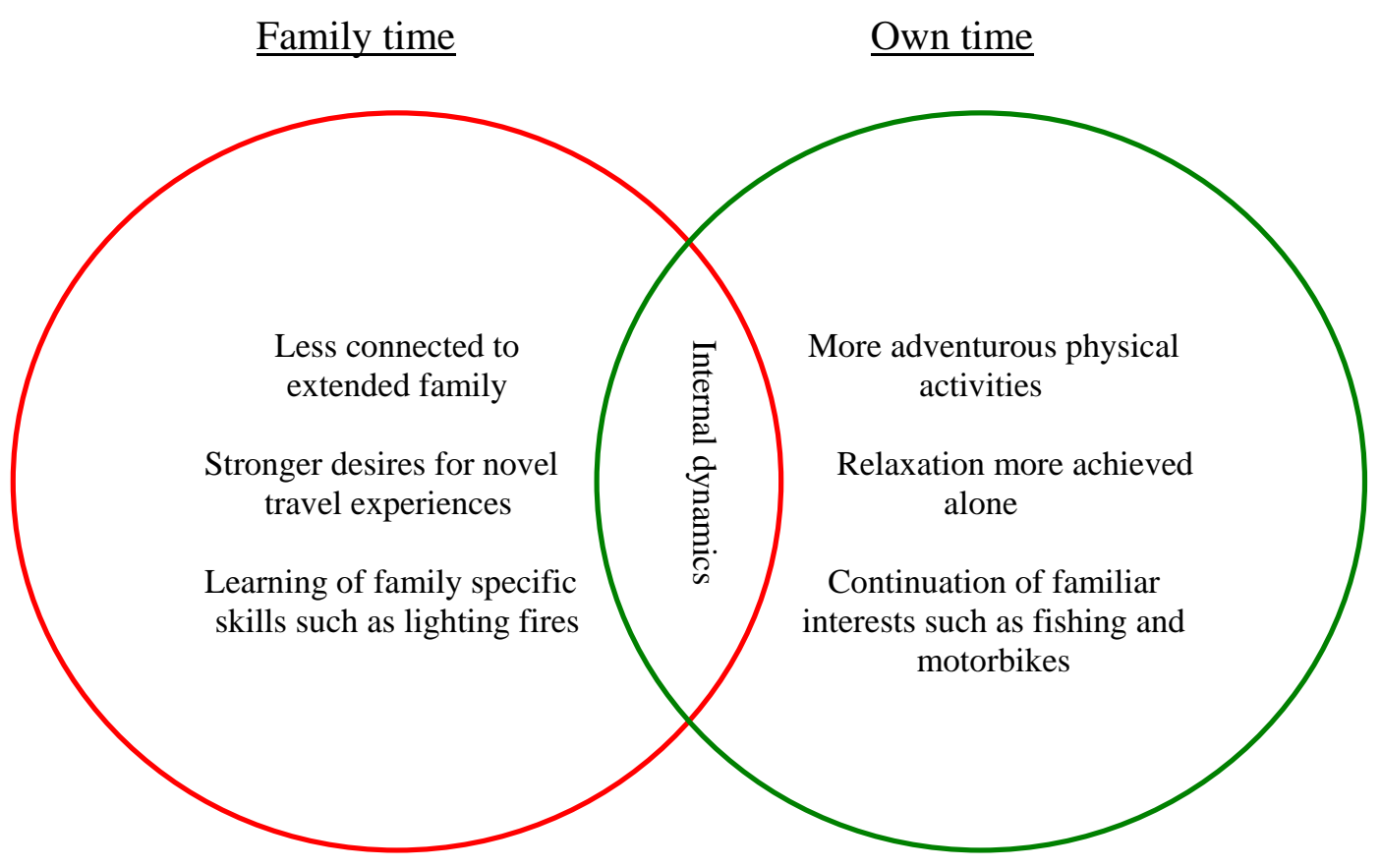


Figures 7.5a and 7.5b provide a thematic summary of girls' and boys' family holiday experiences, emphasizing gender differences which are less pronounced than for the parents. To some extent boys mirrored their fathers (seeking challenging activities) and girls mirrored their mothers (seeking social connection). However, children generally sought physical activities, and girls more so than their mothers. This confirms the more peripheral position of physical activities in women's holidays compared with children (Small, 2007) and men, which signifies a continuation from general leisure behaviour (e.g., Miller \& Brown, 2005; Roberts, 1996). Thus, holiday environments provide both a continuance and resistance to gender differences in parents' individual time: mothers assert more their right to time out while indulging in more restful relaxation; and men relish the physical challenges presented while embracing more their fatherhood role. However, both mothers and fathers want to temporarily escape from their respective roles or discourses in own time.

\subsubsection{GROUP DYNAMIC PERSPECTIVE}

An analysis of the experience of family time and own time on holiday reveals that parents, children, mothers, fathers, girls, and boys make different contributions and play different roles which result in creating different social identities. According to Daly (1996a), the construction of family time is based on the principles of togetherness, choice, and mutual engagement which might be more reflective of an ideal than a reality. As an ideological construct, family time may be a proxy for longings for a secure and loving environment where simplicity, calm, and intimacy prevail. Holidays are then no different from family time at home. However, in the absence of paid work, school, and leisure commitments, shared family activities and individual interests predominate depending on personal needs of family members. A distinction can then be made between freedom from and freedom to, and social identities can be differentiated on the basis of time for the whole family and time from various obligations and responsibilities. Social identities are, thus, formed on more individual and collective constructs but both are bound by the inescapability of the group dynamic or the notion of sociality. 
A new understanding of family holidays is needed that encapsulates the lived complexities of family life. Rather than giving in to the public demands for family togetherness, a more holistic approach allows acknowledgement of the private needs for time away from the whole family. At a micro-level life on holiday must be attentive to both generational and gender differences. At the macro level the hegemony of family ideology must be weakened to incorporate these individual needs, thus, reflecting a more realistic representation of holiday life than that presented in the media and literature. Family holiday environments offer places for compliance and resistance to the general ideology of family in that some role reversals are demanded. Holidays, then, offer a new insight into the negotiations of time within families without the distractions of paid work and school. Foremost among these is the experience of autonomy and connectedness in families in an environment different from home. Personal interests are expanded, social (re)connections are made, and novel experiences are embodied, all while bridging this duality within the confines of the family group dynamic.

\subsection{TEMPORAL AND SPATIAL DIMENSION: CONTINUITY AND DISCONTINUITY FROM HOME}

Social actions and interactions can be (re)produced over time and space. Giddens (1984) emphasizes space as proximity or distance and how these are mediated by social structures, and time as continuity and discontinuity and the organisation of experiences across time. In this respect, family holidays offer a spatial element of being away from home (distance) which allows for some continuity (family realities) and discontinuity (family ideals) from the home realities. Figure 7.6 illustrates how the family realities at home (proximity) continue on holiday (at a distance) as everyday experiences while holiday ideals differ from those realities. On holiday and shorter-term recollections (closer in time and space to holiday) captured more the everyday family realities, whereas longer-term recollections and anticipations (removed in time and space from holiday) were more about the family holiday ideals (see section 6.7). This means that over time family holidays are more about discontinuity (family ideals) than continuity (family realities). Space and time, thus, provide interconnected perspectives to the study of family holiday experiences: the closer in time and space to the actual holiday the more 
continuity; the more removed in time and space from the actual holiday the more discontinuity. This might explain why holidays at home, with no spatial distance available, were considered in practice as not providing sufficient discontinuity.

Figure 7.6 Continuity and discontinuity on holiday compared with family realities at home

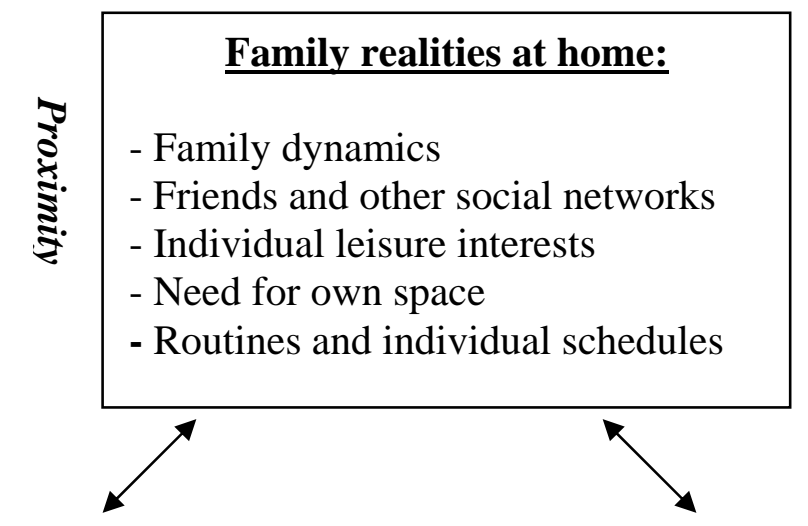

\begin{tabular}{|c|c|c|}
\hline $\begin{array}{l}\text { Continuity on holiday of } \\
\text { everyday realities: } \\
\text { - Gender and generational } \\
\text { differences in intentions and } \\
\text { interests } \\
\text { - Tensions and compromises } \\
\text { - Use of social relations for } \\
\text { cooperation } \\
\text { - Need for individual pursuits } \\
\text { - Time with peers } \\
\text { - Familiarity } \\
\text { - More temporary meanings }\end{array}$ & 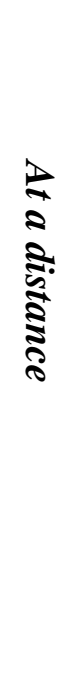 & $\begin{array}{l}\text { Discontinuity from home realities } \\
\text { as family holiday ideals: } \\
\text { - Purposiveness of togetherness \& } \\
\text { social fun } \\
\text { - Social identities \& traditions } \\
\text { - Gender role reversals } \\
\text { - Reconnecting with extended } \\
\text { family } \\
\text { - Positive memory creation } \\
\text { (photographic reconstruction) } \\
\text { - Novelty } \\
\text { - More symbolic and permanent } \\
\text { meanings }\end{array}$ \\
\hline
\end{tabular}

The continuity from home provided on holiday supports McCabe (2002) in that tourists do not escape everyday life but bring it with them. Also, insights into holiday experiences and dynamics shed light on everyday life. Researchers have begun to view tourism as increasingly constitutive of everyday life which is captured by the mobilities paradigm (Sheller \& Urry, 2006). Family holidays are also concerned with the mobilisation of special memories, traditions, and social identities which are signified more by a discontinuation from home, also termed 'peak experiences' (Quan \& Wang, 2004). This means that family holidays contain elements of both home and away and must be seen as a discontinuation and resistance to home and leisure behaviours along with a continuation and 
affirmation of them. From a mobilities perspective, family, leisure, and tourism studies merge and make disciplinary boundaries obsolete. While family tourism parallels other forms of tourism in this respect, the content of the underlying family dynamics differs with regards to generation and related gender roles.

Figure 7.6 extends the notion of Fiese et al. (2002) that family holidays are symbolic because they aim to create enduring memories across generations and provide a sense of belonging that is different from the daily routines at home (Table 2.2). This discontinuity on holiday centred mainly on fun family times, aided by photo-reconstructed memories (see Sutton, 1992), which were conducive to social identity formation and perpetuated the ideology of family holidays long before and after the holidays. This perpetuation of holiday ideals (or discontinuity from home) had more influence on future holidays than the realities of the actual holiday experiences (see Wirtz et al., 2003) and reflects the regular holiday behaviour of the participating families (or continuity of family travel). In this respect, before and after the holiday can be collapsed together as a time and space removed from the holiday, and then compared with experiences on holiday. The longitudinal approach taken for this study, thus, revealed the differences in anticipations/recollections removed from the actual holidays compared with those nearer the time of the holidays. It highlighted elements of continuity and discontinuity on family holidays: while ideals are desired as fundamentally different on holiday, the realities on holiday also reflect a continuation from family life at home. It is the acknowledgment of the continuity from home that allows for a more realistic and holistic understanding of holiday experiences for all its family members.

\subsection{NEW ZEALAND CONTEXT: DOMESTIC HOLIDAYS}

Consistent with the symbolic interactionist notion that identity is situated insofar as self-definition is contingent on social location, the meaning and definition of time on holiday is situated in a context and a set of interactive dynamics (see Thorpe \& Daly, 1999). The context here is New Zealand which is marked by geographical isolation as a nation of islands. The fact that it has no land borders 
shapes the holiday experience and gives New Zealanders an immediate sense of identity which is different from that of joined nation-states as in Europe. The importance of national identity formation as part of the parental rationale of establishing social identities/traditions emphasizes the social aspect of domestic tourism (see section 5.5.2). It means that the development of a national sense of belonging is not just relevant for developing countries (Jafari, 1986) but also for relatively isolated countries. It highlights the under representation of national identity creation as part of domestic tourism behaviour in the literature. In fact, this study offers a broader perspective on tourism and national identity that is different from a preoccupation on specific sites or events in the literature (e.g., Palmer, 2005). This further underlines the fact that family holidays are perceived differently from other travel behaviour in that more general meanings are generated between the generations that differ from more attraction-specific understandings for the non-family tourist.

The New Zealand context also has other influences on the holiday experience such as the tradition of active and adventure-based domestic tourism (see Perkins \& Thorns, 2001). New Zealand not only offers a diversity of outdoor recreational opportunities, but participation in this is considered a cultural imperative (see Devlin \& Booth, 1998) and forms part of the Kiwi holiday tradition. In contrast, experiences based on Maori culture were not mentioned by the participants, which confirms the work of Ryan \& Pike (2003). The family holiday experiences in the findings revolved more around physical activities than sedentary relaxation or cultural activities and reflect those New Zealand ideals about outdoor behaviours. However, the main responsibility for the facilitation of physical activity is carried by the men. This might be a legacy of the collective identity of men in New Zealand based on sport (see Thomson, 2000) that now forms part of a fatherhood role which is questioned at times (see section 5.3.2). It highlights the notion that gendered cultures are enduring within a domestic holiday context and that more debate is needed about the distribution of roles within the family for both women and men.

While the overall importance of New Zealand holidays was rated very high for the families in this study, especially for the annual summer holiday, it also 
emphasized differences from international holidays. Climatic considerations formed a main reason for overseas holidays, but also a desire for more novel or exotic experiences than offered by domestic holidays. In this way, international holidays offered more different or grander experiences than those at home. Figure 7.7 illustrates the continuum of experiences formed from normal/small to exotic/grand depending on the holiday destination, so that travelling in Asia, for example, is perceived as more adventurous than domestic holidays (see section 5.3.1). Holidaying at home was considered as not different enough or too normal, especially in light of more novel experiences desired on holiday. The propensity for overseas holidays generally increases with the age of the children, as families with older children seek more exotic or grander experiences (see Blichfeldt, 2007). Domestic holidays must be understood within this continuum of experiences as offering some novelty and medium experiences but not being able to compete with overseas on exoticism and grandness.

\section{Figure 7.7 Continuum of experiences compared with destinations}

\begin{tabular}{llr}
$\begin{array}{l}\text { Destinations: } \\
\text { At home }\end{array}$ & Domestic & \\
\hline \hline Experiences: & & \\
Normal & Novel & Exotic \\
Small & Medium & Grand
\end{tabular}

There were some remarkable consistencies across the meanings of the main themes for the parents and the children regardless of type of holiday, domestic or overseas (see section 5.3.1), confirming the work of Shaw et al. (2008) and Hilbrecht et al. (2008) in Canada. This indicates that there are thematic dimensions that can be independent of destination, but more research is needed with regards to international holidays. However, this study extends the Canadian research in regards to the importance placed on own time by all family members, the gendered and generational nature of own time, and the dynamic tensions between own time and family time. The findings further indicate that there are different roles and perspectives of fathers in New Zealand compared to Canada and there is less of an emphasis on escaping family stress possibly reflecting 
broader cultural differences. The importance placed by parents on the role of domestic holidays in forming the national identities of their children is a new finding that warrants further research. This differs from the Canadian studies but confirms the place domestic family holidays occupy in the New Zealand psyche (see section 2.2.3).

\subsection{CONCLUSION}

The structural imposition of the ideal of family life at the macro level is replicated by the adherence to a family holiday ideal compared with everyday family life realities at the micro-level. Applying a symbolic interactionist paradigm to this study provided insights into the internal family group dynamics while on holiday. This led to a new interactionist perspective of emphasising the holiday experience as a negotiated social space: family holidays offer an interpersonal escape with the family to a social space which allows for social identity formation and interaction with social relations who then allow a personal escape from the social realities of the everyday world. This is different from most research on the individual tourist that considers tourism as an escape from the everyday world, and again different from the literature on social experiences that sees tourism primarily as an escape to a social space. Family holidays, then, must be seen as three dimensional and containing elements of escaping with the whole family to seek social relations in order to individually escape from the family commitments. The collective escape, thus, signifies discontinuity from home while the collective seeking and individual escape suggests continuity with home. Discontinuity is achieved by following a holiday ideal while continuity is present through the realities of family living. It highlights the fact that family holidays do not occur in a social vacuum but that other people such as extended family and friends are needed for its functioning. Also, acknowledgement of the day-to-day realities of family living is needed to counteract the ideological hegemony of family life.

The lack of research on the children's and father's perspectives of holiday experiences has concealed significant differences in meanings. Parents and children bring different purposes on holiday in that parents are more deliberate 
about the formation of social identities and traditions whereas children seek mainly fun and sociality. These disparities can be cause for internal tensions, especially since family members sometimes also desire a break from the whole family group to pursue their own interests. An overemphasis in the literature on mothers' continuing domestic role on holiday led to the undervaluation of the continuation of the fathers' role as main entertainer of the children. Thus, more debate is needed about the different generational, gendered, and group roles and understandings on holiday. Special recognition is needed that family holidays also contain more individualistic elements of own time and that an overemphasis on family time can lead to tensions resulting in unrealistic and unsustainable portrayals of family life on holiday. Therefore, a homeostasis is needed between family time and own time and its representation in society. 


\section{CHAPTER 8: CONCLUSIONS}

\subsection{INTRODUCTION}

This study has developed a conceptual understanding of family holidays along with establishing its key definitional characteristics. Family holidays, then, can be times for affirmations of gendered, generational, and group roles entrenched in an ideology of family life as well as offering freedoms to its members through more individual pursuits. However, recognition of a balance or homeostasis between collective and individual perspectives amongst the family group is largely missing in tourism research, policy, and practice. The application of a new conceptual framework led to the methodological and analytical frameworks used and resulted in the theoretical framework of family time and own time. This enabled the emancipation of the individual concealed amongst a societal hegemony on togetherness and offered an alternative group perspective to the domination of the individual tourist and host-guest relationships in most tourism studies.

A tenet of critical tourism research is giving voice to under-acknowledged people such as children, fathers, and family groups. Giving voice to all family members is the first step in their empowerment and recognises the complexities involved when two generations (or more) and genders travel together. It is vital that others hear these voices and respond to the needs of the family group and their individual members and compare them with the needs of other travellers. The situatedness of the data collection in a climate of relative economic prosperity needs to be recognised, which differs from the current downturn. A repetition of the study now may emphasize issues of affordability and further strengthen the role of domestic holidays. This final chapter revisits the research questions before considering the methodological and theoretical contributions surrounding this study. It then looks ahead to recommendations for the tourism industry and policy legislators of ways to enable families and their members to benefit from their holiday experiences and suggests future directions for tourism research. 


\subsection{RESEARCH QUESTIONS REVISITED}

\section{Overall question: What are the social experiences and meanings of family}

holidays over time for the family and its members using gender, generation, and group dynamic perspectives?

It emerged that the experiences and meanings gained from family holidaying are multifarious and multidimensional, reflecting the complexities inherent in mixed gender and intergenerational holidaying as covered over the course of one year. The social experiences and meanings centre on family time and own time as identified in the theoretical framework (Figure 4.7) and are reflective of the fundamental family life conditions of connectedness/sociality and separateness/individuality along with the methodological perspectives of group and individual interviews. It emerged that the ideal of togetherness in family time concealed the realities of more individual interests in own time, when a balance is needed between the two (Figure 7.1). Family holidays, thus, must be understood as being affected by the ideological hegemonies in Western society and the philosophical schisms dominating within Western thinking. The families in this study were influenced by an emphasis on togetherness on holiday at the expense of more individual pursuits. A unified and more realistic understanding is required: own time is as much a reflection of family time as individual interests are part of the family group make-up, and one should not be understood without the other. The generational and gender differences further add to this complex mix of multiple people holidaying together and then reflecting over time, which resulted in the following conclusions:

- Family holidays are mainly based on generational differences that bring a variance in purposiveness: the parental meanings are more about social identity formation whereas the children's are primarily about social fun;

- National identity and social capital construction make a valuable part of the social identities formation although this remains unrecognised by the children at the time since they are more concerned about hedonistic pursuits and sociality, especially in the form of peers; 
- A generational distinction can be made between freedom to spend time together in family time and freedom from obligations (for the parents) and from restrictions (for the children) in own time;

- Inclusion of other people on holiday can alleviate tensions in the family group dynamics along with offering social support;

- The internal group dynamics are mainly concerned with a balance between family time and own time and can range from positive to negative: from cooperation to compromise to constraints to conflicts;

- Family holidays centre on the creation of positive memories but can contain negative elements such as conflict;

- Family holidays must be understood as three-dimensional in that they involve escape with the whole family to social relations which allow for a personal escape from family commitments;

- The gender differences for the parents are that mothers seek a break from the domestic discourse or motherhood role at times whereas fathers are more accepting of their entertainment imperative or fatherhood role;

- There are gender differences with regards to physical activity and social connection in that the males in this study are seeking more physical challenges and the females more emotional connection to social relations;

- Anticipations and longer-term recollections are generally more positive than the actual holiday experiences, reflecting a more realistic portrayal of holiday events closer to the holiday and a more idealised depiction further removed from the holiday;

- Family holidays are signified by a continuation of family life realities on holiday and a discontinuation in the form of holiday ideals away from it;

- Overall, the temporal dimension of pre-, on-, and post-holiday was less dominant than the thematic dimension of family time and own time and the generation, gender, and group dynamic perspectives;

In sum, family holidays have multiple meanings and purposes reflecting the multivocality of its members. A more holistic and critical approach to thinking is needed to allow for a homeostasis between social identities based on collective pursuits and based on more individual interests. 


\section{Other research questions:}

These are contained in the overall question and reflect the iterative research:

\section{What are the individual and collective anticipations for their family holiday experiences?}

The anticipations pre-holiday are signified by an adherence to a vague holiday ideal that is comprised by a collective purpose for family time. This is more about generation than the individual family member:

- For parents this is constituted as having notions of quality time whereas for the children it is more about social fun;

- For parents the destination becomes secondary to the paramount notion of family time whereas children have even less expectations because of their general lack of choice in the destination;

- This is a reflection of their regular holiday behaviours where holidays become intrinsically bound to everyday family life worlds.

\section{How do individual family members, and the entire family, experience and remember their time on holiday?}

Compared with the actual holiday experiences the recollections are constituted of a more positive collective portrayal reflected in the photographic images, and a more negative individual portrayal when revealing a lack of own time:

- The on-holiday experiences are more inclusive of the individual perspectives, which contain more realistic and negative elements such as individual differences in interests and intentions that can lead to compromise and conflicts;

- Photos capture the actual holiday experiences but perpetuate the positive notion of family time rather than depicting negative portrayals;

- Remembered experiences become generally more positive or 'rosy' over time for the whole family, which is constitutive of the holiday ideal;

- A lack of individual pursuits can be remembered more negatively over time, reflecting a personal sacrifice within a dominance of collective pursuits. 
How are anticipations connected to the actual meanings derived from the holiday experience for the family and its members?

The anticipations and more long-term recollections can be collapsed together into a spatial and temporal dimension that is physically distanced and removed in time from the actual holiday experiences. This is constituted by a discontinuity from home in that it adheres to a collective holiday ideal that differs from family realities, whereas on and closer to the holiday the actual meanings also revolve around a continuation of family realities (Figure 7.6). Anticipations, then, become an intrinsic part of the collective meanings and recollections surrounding holidays for all the family members, whereas the meanings on and closer to the holiday are more reflective of the individual differences in interests and needs.

\section{$\underline{\text { Secondary research questions: }}$}

These provide a New Zealand context to the primary research questions.

\section{How do families in New Zealand describe or define a family holiday?}

A definition based on the familial perspective was established that encapsulates the whole research and mirrors the main themes:

A purposive time, at least a weekend, spent together with the whole and extended family having experiences different from normal routines that are fun. This centres on a balance of time that includes individual pursuits and which may involve compromise and conflict.

However, no clear consensus about holidays at home existed. This requires further research which might be linked to income and other constraining factors.

\section{How important is the New Zealand holiday setting or space for the family and its members?}

Domestic holidays reflect a tendency to either travel to the same regional destination annually or to seek out different regional destinations which results in a wide coverage of the country. This is mainly done for establishing a social and national identity along with a continuation of family holiday traditions:

- National identity formation and bridging social capital is part of the parental rationale of establishing social identities/traditions; 
- Domestic holidays can constitute the only opportunity to (re)connect with extended family as well as providing social support and cooperation;

- Domestic holidays offer novel or different experiences compared with home which is constitutive of good parenting and reflects the ideology of family life. International holidays can offer grander and more exotic experiences compared with those available in New Zealand;

- Domestic holidays signify an investment into the next generation of travellers as continuing connections to familiar people, national places, and Kiwi culture can be maintained.

\subsection{METHODOLOGICAL CONTRIBUTIONS}

This study reflects a move beyond a narrow focus on positivistic research and embraced a more reflexive, interpretive, and critical path of inquiry as advocated by Tribe (2005), which made it part of the 'critical turn' in tourism (Ateljevic et al., 2005). It followed the lead of family and leisure research by encompassing different perspectives, time frames, and methodologies. This led to a linking of the survey with data triangulation of whole-family interviews that encapsulated three time phases (once before and twice after the holiday) and three perspectives (gender, generation, and group dynamics) (Figure 3.1). It also included the novel use of photos for APE for all family members and other projective techniques. Criticality is a contested idea and how the term critical is used inevitably reflects the ideology and worldview of the researcher (Wilson et al., 2008).

This study is based on symbolic interactionism to understand the meanings derived from social interactions within a family group on holiday. It used constructivist GTM to develop the themes through interaction with the literature and directly with the data throughout the research phases (Table 3.11) resulting in a theoretical framework (Figure 4.7) and seven applied models according to the different perspectives (Figures 7.1 and 7.3-7.5), thus, revealing the complexities of these social processes. The theoretical sensitivity attained from the literature led to a conceptual framework (Figure 2.4) that informed the methodological framework (Figure 3.1) and the analytical framework (Figure 3.2 and 3.3). These frameworks provided a structure for the GTM process of generating theory from 
the data throughout the iterative research and allowed a conceptualisation of the findings that led to the main themes (theoretical framework) and the thematic application of the perspectives (applied models). A parental survey was used for general family holiday behaviour and to highlight generational differences in definitional themes when combined with the whole family experiential dimension. Linking the survey with family interviews achieved a continuation of parental themes along with a broadening of the thematic development to encompass the familial perspectives and temporality (Figures 3.2 and 3.3).

By applying critical theories and methods to understand the social world of family tourism this study reveals experiences and interactions intrinsic to everyday worlds as well as those that are different from daily life. It provided thematic continuity and discontinuity from home thereby linking the disciplines of family, leisure, and tourism studies. It embraced true gender scholarship and the other five moments of qualitative research to provide insights into the social dynamics amongst the different family members, generating a small scale theory based on specific personal situations (see Lynch, 2005). This study moved away from a preoccupation with investigating tourists as consumers and provides a more comprehensive understanding of family life on holiday that is inclusive of multiple voices, embodiments, mobilities, and temporalities. It resulted in exploring the social theme of family time versus the more individual theme of own time, which is encapsulated by the connectedness and separateness of life in a family group.

Considering the methodological implications of linking a parental survey with data triangulation of whole-family interviews there are several points to be made. This entailed distributing the survey through schools before conducting interviews with whole family groups and individual interviews with all family members over three time periods (once before and twice after their holiday):

- Wider distribution of the parental survey through a range of decileranked schools was not possible due to lack of access. This resulted in mainly higher socio-economic and European families volunteering for the ensuing interview stage; 
- The whole-family interviews succeeded in bringing out more of the family group dynamics and collective perspective whereas the individual interviews provided a more personal perspective on own interests. The use of this novel method helped in the identification of key themes;

- Whole-family interviewing replicated the underlying holiday life condition of family time and own time to some extent;

- The problems experienced with implementing the methodology (see section 3.5.2) mirrors findings on family group dynamics: the difficulty of scheduling time with the whole family and engaging children during that period; novelty was sought (with regards to questions) but some repetition was necessary for the research process; different levels of contributions reflected the differences in age, personality, and vocality inherent in a family group;

- My situatedness as a mother might have influenced the finding that men were generally very supportive of their wives and wanted to appear positive to me. However, the statements made by the men usually corresponded with the women's contributions and also occurred in group interviews with their wives present;

- While the methodology succeeded in providing a more individualised perspective on fathers and children on family holidays which is largely absent in tourism research, it came at the exclusion of single parent or gay/lesbian families. No blended families, non-European, or economically disadvantaged families volunteered for this study, and the extended family was not included.

Future research into family holidays needs to be mindful of the broadened definition of families and trends such as multigenerational travel and grandtravel (see Yeoman, 2008). Inclusion of more financially disadvantaged and nonEuropean families as well as families with mainly pre-schoolers or teenagers would further add to the experiential understanding of family holidays. Using male interviewers for the men and female interviewers for the women could overcome any gendered biases (e.g., Thorpe \& Daly, 1999), whereas using younger interviewers for the teenagers could overcome any generational biases. This, however, would lack the holistic perspective brought by a single researcher. 


\subsection{THEORETICAL CONTRIBUTIONS}

This study developed a conceptual understanding of family holidays, first, with the definitional characteristics (see section 4.3.2) and second, with the thematic model of family holiday experiences (Figure 7.1). From this, family holidays emerge as complex, multi-dimensional, and reflecting the multiple voices inherent in generational and gender differences within families. These sentiments are echoed in that family holidays are never one sided. They have multiple meanings and purposes which are characterised by dynamic negotiations:

- There is the ideal of family time versus the reality of own time reflecting affirmation and resistance to the ideological hegemony of family life;

- There are experiences and interactions intrinsic to and different from every day life reflecting a continuity as well as discontinuity from home;

- There is purposiveness in social identities/capital and fun/sociality reflecting generativity by the parents and hedonism by the children;

- There is escape to as well as escape from social connections, highlighting the necessity of other people for family functioning;

- Different or novel experiences from normal are sought in family time alongside familiar interests in own time;

- There are planned activities but the most memorable experiences are often found in serendipity;

- There are positive as well as negative internal dynamics;

- There is facilitation of national identity formation as well as more exotic experiences reflecting ideologies about good parenting.

The symbolic interactionist approach focusing on family group dynamics revealed that the main paradoxes on family holidays centre on generational differences at the micro level that were influenced by societal impositions at the macro level. Parents take on the role of establishing bonding and bridging social capital or identities while this effort is not recognised by the children at the time. Instead, children are more concerned about hedonistic fun and sociality. However, all family members engage on holiday in a multitude of different ways, and the negotiations undertaken by them are used in social identity formations. Family holidays, then, are primarily about interweaving sociality with identity, which 
includes nationality within a domestic context. The fact that tourism is wrapped up with identity formation is not new (see McCabe \& Marson, 2006) and is related to parents seeking more lasting holiday experiences for their children. Social identity here means belonging to a family group from which to draw a sense of 'who one is' and can include extended family and friends. It is conceptualised at the level of both the individual and wider society.

This study made a distinction between thinking and acting as an individual family member, the 'I or individual perspective', versus as a family group member, the 'we or collective perspective' as reflected in the methodology. In this way it confirmed the central theory of Tuomela (2007) that the we-mode is seen as primary compared with the I-mode, which made family holidays about collective experiences centred on sociality rather than individual pursuits. This reflects an underlying assumption supported by society that family time experiences are qualitatively different from more individual time experiences and that family holidays are about social rather than individual identities. Taking this distinction for granted is inherently problematic and theorisation between the two should not be treated as axiomatic. In many ways, this distinction reflects the dualism prevalent in Western society such as the opposition of body and mind as argued for a male individual tourist perspective (see section 2.6.1). It merely replaces an individual dominance in tourism research with a collective dominance.

Rather than treating family experiences as superior to more individual experiences, they should be treated as unified, one should not be understood without the other, and family members should be encompassed in the wider family network. This would imply less conflict between the collective and individual experiences of family members. In this conception of experiences, more individual experiences have no meaning if the other family members are not considered. Thus, without the recognition of the other family members one cannot arrive at a definition of one's own experiences. This holds true for non-family holidays in the way they were contrasted with the usual family experiences (see section 6.5.2). Sociality and individuality in this conceptualization are supportive rather than antagonistic. Social identities, thus, are about the individual, the family, and society rather than being antagonistic to individual experiences. What 
is needed then is recognition of social experiences that encompass collective and more individual experiences (family time and own time), and social identities that encompass a collective identity based on family along with a more individual identity based on interests and personality. While much tourism research is dominated by individual pursuits, most family research is dominated by collective pursuits, when both need to be treated as complementary to each other. The realities of family life on holiday need to be reflected by encompassing the needs of the individual within the social identities of the family, therefore, bridging dichotomies of generational intentions and societal ideologies.

\subsection{IMPLICATIONS FOR TOURISM INDUSTRY AND POLICY}

This study is based on two-parent, European, relatively affluent families with school-aged children, and the practical implications reflect their particular needs. These needs might differ from families with mainly pre-schoolers or families with teenagers/young adults (Figure 7.2), single parent or blended families, Maori, or economically disadvantaged families. It centres on summer family holidays in New Zealand along with reflections on other domestic and international holidays. The findings highlight the need for the tourism industry to cater for the divergent needs of individual family members and the family unit. The tourism industry is generally aware that children have different needs, and inclusive packages such as resort holidays in the South Pacific already offer children's programmes. However, this study provides a broader perspective, within a domestic rather than overseas context. The practical implications of this study for the tourism industry are more general, manifold and include:

- Family holidays are about achieving a dynamic state of balance or homeostasis between family time and own time that is dependent on the individual family members;

- Domestic family holidays are about national identity formation which entail repeat visits and experiencing new regional destinations;

- Family holidays are primarily about social experiences, keeping children happy, and parents pursuing their own interests some of the time, which means that any management objectives need to be directed towards 
- Family holidays are about novel or different from normal shared experiences. This includes food, activities, animals, and sleeping arrangements, and can consist of more traditional experiences such as going fishing and playing card games;

- Family holidays are also about familiar experiences that reflect individual pursuits like swimming for the children;

- Children desire the social connection with other children their age. Facilitation of that interaction in children-specific facilities is desirable;

- With regards to external factors, provisions need to be made for allweather and affordable activities as well as enforcement of camp rules;

- Mothers desire a break from their domestic commitments while fathers can also desire a break from their entertainment imperative;

- The industry needs to be mindful that mothers have a need for more restful rather than high adrenalin activities while fathers prefer more physical challenges and explorations along with more hedonistic pursuits;

- Family holidays include travelling with extended family and friends. The tourism industry needs to be mindful of the divergent needs of multiple generations travelling together;

- Generally, there needs to be recognition of a diversity of needs that takes account of generational, gender, and group differences.

The implications of this study for the real world centre on catering to the multifarious needs of the family market with school-aged children. While the focus of the tourism industry should be on facilitating social experiences that are fun and conducive to generativity there needs to be a balance with individual pursuits. Family holidays are about keeping the children happy, but entertaining the children cannot be at the expense of the parents. Instead, entertaining the children also means looking after the parents and indulging their passions. Also, families can benefit from the support they receive from other families, which intertwines family holidays with VFR travel. Families, therefore, require a specific approach that differs from other non-family travellers such as backpackers, independent travellers, or even other group travel. 
The family market is also missing in the overseas marketing campaign by Tourism New Zealand, with its focus on the Interactive Traveller ${ }^{\circledR}$ (see chapter 1). According to Tourism New Zealand (2009):

"These people travel regularly; participate in a wide range of tourism experiences; actively participate in the natural environment, are environmentally and culturally aware; and seek authentic and new experiences - and then want to share them with others."

Apart from having collective experiences at the forefront, family travellers do not appear to significantly differ from the Interactive Traveller ${ }^{\circledR}$. More consideration needs to be given for the international family market to be included in the marketing campaign as families are increasingly seeking grander experiences for their children, which is considered to be part of good parenting. This would provide better diversification of target markets as well as offering more families the unique experiences available in New Zealand. Reflection of a more diversified international marketing strategy needs to be given in tourism policy.

Within the domestic market family holidays must be considered more as essential to social life conducted away from home as they can offer the only opportunity to (re)connect with extended family and friends and establish social identities. This is particularly significant for children, as they value the social connections with grandparents and cousins. Not facilitating such holiday reunions would entail a social deprivation or exclusion on their behalf. Extended family living geographically apart also needs to be recognised as providing social support for the parents. Holidaying, thus, should not be deemed a privilege open only to financially secure families but a social right available to all parents with children, which is part of the argument for social inclusion (see Hazel, 2005). However, visitor-related social tourism (see Minnaert et al., 2006) has not yet featured on any New Zealand government's social care agenda. Attention needs to be paid to the provision of holidays for families in need, both in more research and in New Zealand policy and practice.

The domestic family tourism market is also signified by a continuation of holiday traditions and establishing social identities based on building a national 
awareness. This form of bridging social capital is perceived as integral to the Kiwi way of life and reflects the symbolism of traditional Kiwi summer holidays (see DoC, 2006; Pryor, 2006). Domestic tourism remains the largest contributor of income to the tourism industry, but there is no coordinated industry or government body charged with marketing or managing domestic tourism even though making domestic travel affordable was included in the Tourism Strategy 2015 (Ministry of Tourism, 2007c). More research is needed to identify the size and travel patterns of the domestic family holiday market, including VFR travel, as currently this is not captured by the DTS. Better targeting of the family market could then be achieved compared with other markets, such as offering a family discount card to all New Zealand families similar to the senior card, which could work above any existing family concessions. This is based on the familial definition (see section 4.3.2) which encompasses family holidaying at home and away from home. Reflection needs to be given in policy and practice that family holidays can entail daytrips, spending time with extended family and friends, establishing social identities based on national and family characteristics, or social capital investments, and, thus, signify an investment into future generations (the children of today being the parents of tomorrow).

\subsection{FUTURE DIRECTIONS}

This research provides a comprehensive understanding of the individual and collective meanings and interactions gained from family holiday experiences. The findings of this study indicate that family holidays can fill a social need for all family members which entails social identities formation and social fun along with more individual pursuits. The substantive theory created is based on data from a selection of New Zealand families on holiday at a specific time. Discovering similar concepts and themes across a wider area of study, setting, time, and informants can then lead to formal theory (see section 3.3.1). It must be acknowledged that the experiential dimension of family holidaying is not static and can change over time as well as according to family composition, life cycle stage, holiday destination, and financial accessibility. Factors such as affordability of holidays, ethnicity, ages of children, and the meanings of holidays today 
compared with in the future could have an influence on the experience acquisition. Therefore, more research could address the future directions of family holiday experiences and formalise the theory:

- Accessing families through other means than schools needs to be considered to ensure a better participation of economically disadvantaged and non-European families;

- Allowances need to be made for changing family structures, and future family research should include single parents, gay/lesbian parents, blended families, and multigenerational as well as grandtravel, which requires a more complex conceptual framework, such as a crystal suggested in section 2.7;

- Accepting that there are different experiencescapes according to the family life cycle, future research is necessary to see how families develop and cover expectant couples, families with more pre-school or teenaged children, and transitions to holidays without children;

- Future research into non-family holidays taken by family members is necessary to further highlight aspects of own time within family holidays;

- Future research into the affordability of holidays for all families or social tourism is required when considering the social role of holidays in bringing extended family together, providing social support, and aiding in social identity formation and social capital investments;

- Future research into domestic tourism is necessary to understand more about the role of family holidays in national identity formation, bridging social capital, continuation of Kiwi culture, and as an investment for future generations;

- Future research is required into the international family market in relation to considering holidays as a parental opportunity for providing children with novel or grander experiences;

- In general, more research is needed, also outside the Western discourse, into the social rather than economic role of family holidays as very little research has been conducted about the meanings derived from those encounters from the perspective of all family travellers. 
As a result, the theoretical framework based on the findings and incorporating the three experiential dimensions could be expanded across other geographical contexts, family forms, family life cycle stages, and holiday destinations to then qualify for formal theory.

\subsection{CONCLUSION}

This study is based on an application of symbolic interactionism to inquire into the social interactions and experiences of family groups holidaying with their family members. These interactions at a micro level are also affected by a societal belief system that is shaped by a Western discourse on family life. The interactions of family members, then, are structurally embedded in a broader system. By empirically researching family holidays I must reacknowledge my position as a mother and European to this subject matter and its discursive phenomena. The inherent dualisms of the individual amongst the family holiday group and the family as part of Western society are reflected by the social connectedness in family time compared with more individual pursuits in own time and adherences to Western ideologies about family life that can conflict with daily realities of family holiday living. Recognition of the dominance of togetherness within this discourse at the expense of individuality can result in a more realistic and sustainable portrayal of family holidaying for all its members.

The use of critical approaches to philosophy and methodology can, thus, lead to the liberation of marginalised subjects in tourism research and the development of new substantive theory. Setting out with a new conceptual framework based on holistic principles to further true gender scholarship, this study linked methodologies from opposing paradigms as part of progressive qualitative tourism research to produce analytical frameworks that combine multiple dimensions through the GTM. It also acknowledged the situatedness of the researcher and its participants amongst the Western discourse in New Zealand at a time of economic affluence to advance up to five moments of research. The resulting theoretical framework is a reflection of the inclusive approach taken in that it combines divergent perspectives and recognises the individual family member amongst the 
dynamics of the family group. It theorises a more unified and realistic understanding of family holidaying that encompasses individual pursuits alongside preponderances for family togetherness. More appreciation is needed for critical and deviant approaches to tourism research that challenge dominant paradigms and discourses and reveal the complexities of gendered and generational identities holidaying within the social identities of the family group. 


\section{REFERENCES}

Aitchison, C. (2001a). Gender and leisure research: The 'codification of knowledge'. Leisure Sciences, 23, 1-19.

Aitchison, C. (2001b). Theorizing other discourses of tourism, gender and culture: Can the subaltern speak (in tourism)? Tourist Studies, 1(2), 133-147.

Aitchison, C. (2005). Feminist and gender research in sport and leisure management: Understanding the social-cultural nexus of gender-power relations. Journal of Sport Management, 19(4), 422-441.

Allen, K. R., Blieszner, R., \& Roberto, K. A. (2000). Families in the middle and later years: A review and critique of research in the 1990s. Journal of Marriage and the Family, 62(4), 911-926.

Allen, S. (2005, 16 June). Gap seen in tourist market. The Dominion Post, p. C3,

Allen, S. M., \& Daly, K. (2005). Fathers and the navigation of family space and time. In W. Marsiglio, K. Roy \& G. L. Fox (Eds.), Situated Fathering: A Focus on Physical and Social Spaces (pp. 49-70). Oxford, UK: Rowman \& Littlefield Publishers.

Ambert, A.-M., Adler, P. A., Adler, P., \& Detzner, D. F. (1995). Understanding and evaluating qualitative research. Journal of Marriage and the Family, 57(4), 879-893.

Andereck, K. L., \& Caldwell, L. L. (1994). Variable selection in tourism market segmentation models. Journal of Travel Research, 33(2), 40-46.

Anderson, J. (2001). Mothers on family activity holidays overseas. In S. Clough \& J. White (Eds.), Women's Leisure Experiences: Ages, Stages and Roles (pp. 99-112). Eastbourne: Leisure Studies Association.

Anderson, L. F., \& Littrell, M. A. (1995). Souvenir-purchase behavior of women tourists. Annals of Tourism Research, 22(2), 328-348.

Andersson-Cederholm, E. (2004). The use of photo-elicitation in tourism research - framing the backpacker experience. Scandinavian Journal of Hospitality \& Tourism, 4(3), 225-241.

Apostolopoulos, Y., \& Sönmez, S. (2001). Working producers, leisured consumers: Women's experiences in developing regions. In Y. Apostolopoulos, S. Sönmez \& D. J. Timothy (Eds.), Women as Producers and Consumers of Tourism in Developing Regions (pp. 3-17). Westport, CT: Praeger.

Arai, S., \& Pedlar, A. (2003). Moving beyond individualism in leisure theory: A critical analysis of concepts of community and social engagement. Leisure Studies, 22(3), 185-202. 
Aramberri, J. (2001). The host should get lost: Paradigms in the tourism theory. Annals of Tourism Research, 28(3), 738-761.

Archer, B., \& Cooper, C. (1998). The positive and negative impacts of tourism. In W. Theobald (Ed.), Global Tourism (2nd ed., pp. 63-81). Oxford, UK: Butterworth-Heinemann.

Astedt-Kurki, P., \& Hopia, H. (1996). The family interview: Exploring experiences of family health and well-being. Journal of Advanced Nursing, 24(3), 506-511.

Astedt-Kurki, P., Paavilainen, E., \& Lehti, K. (2001). Methodological issues in interviewing families in family nursing research. Journal of Advanced Nursing, 35(2), 288-293.

Ateljevic, I., Harris, C., Wilson, E., \& Collins, F. L. (2005). Getting 'entangled’: Reflexivity and the 'critical turn' in tourism studies. Tourism Recreation Research, 30(2), 9-21.

Automobile Association (AA) (2006). 101 Must-do's for Kiwis. Retrieved 3 December 2007 from: http://www.aatravel.co.nz/101-must-dos-for-kiwis/

Backer, E. (2007). VFR travel: An examination of the expenditures of VFR travellers and their hosts. Current Issues in Tourism, 10(4), 366-377.

Bærenholdt, J. O., Haldrup, M., Larsen, J., \& Urry, J. (2004). Performing Tourist Places. Aldershot, UK: Ashgate.

Balkhy, H. H. (2003). Travelling with children. International Journal of Antimicrobial Agents, 21(2), 193-199.

Barker, J., \& Weller, S. (2003). 'Is it fun?' Developing children centered research methods. The International Journal of Sociology and Social Policy, 23(1/2), 33-58.

Barnett, S., \& Wolfe, R. (1993). At the Beach: The great New Zealand Holiday. Auckland, NZ: Hodder \& Stoughton.

Baron-Cohen, S. (2004). The Essential Difference. London: Penguin Books.

Bassett, R., Beagan, B. L., Ristovski-Slijepcevic, S., \& Chapman, G. E. (2008). Tough teens: The methodological challenges of interviewing teenagers as research participants. Journal of Adolescent Research, 23(2), 119.

Beck, M. E., \& Arnold, J. E. (2009). Gendered time use at home: An ethnographic examination of leisure time in middle-class families. Leisure Studies, 28(2), 121-142.

Belch, G. E., Belch, M. A., \& Ceresino, G. (1985). Parental and teenage child influences in family decision making. Journal of Business Research, 13(2), 163-176. 
Belch, M. A., \& Willis, L. A. (2002). Family decision at the turn of the century: Has the changing structure of households impacted the family decisionmaking process? Journal of Consumer Behaviour, 2(2), 111-124.

Belhassen, Y., \& Santos, C. A. (2006). An American evangelical pilgrimage to Israel: A case study on politics and triangulation. Journal of Travel Research, 44(4), 431-441.

Bella, L. (1992). The Christmas Imperative: Leisure, Family, and Women's Work. Halifax, Nova Scotia: Fernwood Publishing.

Benchley, N. (2001). The Benchley Roundup: A Selection by Nathaniel Benchley of his Favorites. Chicago: University of Chicago Press.

Bengtson, V., Acock, A., Allen, K., Dilworth-Anderson, P., \& Klein, D. (2005). Sourcebook of Family Theory and Research. Thousand Oaks, CA: Sage.

Bialeschki, M. D. (1994). Re-entering leisure: Transition within the role of motherhood. Journal of Leisure Research, 26(1), 57-74.

Bialeschki, M. D., \& Kimberly, D. P. (1997). 'I don't want a lifestyle-I want a life': The effect of role negotiations on the leisure of lesbian mothers. Journal of Leisure Research, 29(1), 113-132.

Bittman, M. (1999). Parenthood without penalty: Time use and public policy in Australia and Finland. Feminist Economics, 5(3), 27-42.

Bittman, M., \& Wajcman, J. (2004). The rush hour: The quality of leisure time and gender equity. In N. Folbre \& M. Bittman (Eds.), Family Time: The Social Organization of Care (pp. 171-193). London and New York: Routledge.

Blackwell, P. (2009). Domestic market at last seen as critical. Inside Tourism, (729), 5.

Blaikie, N. W. H. (1991). A critique of the use of triangulation in social research. Quality \& Quantity, 25, 115-136.

Blair, S. L., \& Johnson, M. P. (1992). Wives' perceptions of the fairness of the division of household labor: The intersection of housework and ideology. Journal of Marriage and the Family, 54(3), 570-581.

Blichfeldt, B. S. (2006). A nice Vacation (IME Report No. 8/06). Esbjerg, DK: University of Southern Denmark.

Blichfeldt, B. S. (2007). A nice vacation: Variations in experience aspirations and travel careers. Journal of Vacation Marketing, 13(2), 149-164.

Blichfeldt, B. S. (2008). Vacationing at home. Tourism Recreation Research, 33(1), 93-97. 
Blud, L. M. (1990). Observations on the way families interact during a museum visit. Museum Management and Curatorship, 9(3), 257-264.

Blumer, H. (1969). Symbolic Interactionism: Perspective and Method. Eaglewood Cliffs, NJ: Prentice-Hall.

Bojanic, D. C. (1992). A look at a modernized family life cycle and overseas travel. Journal of Travel \& Tourism Marketing, 1(1), 61-79.

Botterill, D. (2001). The epistemology of a set of tourism studies. Leisure Studies, 20(3), 199-214.

Botterill, D., \& Crompton, J. L. (1996). Two case studies exploring the nature of the tourist's experience. Journal of Leisure Research, 28(1), 57.

Botterill, D. T., \& Crompton, J. L. (1987). Personal constructions of holiday snapshots. Annals of Tourism Research, 14(1), 152-156.

Bourdieu, P. (1984). Distinction: A Social Critique of the Judgement of Taste. Cambridge, MA: Harvard University Press.

Bowen, H. E. (2005). Introduction: Special issue on female travelers - part I. Tourism Review International, 9, 119-121.

Brannen, J. (1992). Combining qualitative and quantitative approaches: An overview. In J. Brannen (Ed.), Mixing Methods: Qualitative and Quantitative Research (2000 ed., pp. 3-37). Aldershot, UK: Ashgate.

Braun, B. M., \& Soskin, M. D. (1999). Theme park competitive strategies. Annals of Tourism Research, 26(2), 438-442.

Brey, E. T., \& Lehto, X. (2008). Changing family dynamics: A force of change for the family-resort industry? International Journal of Hospitality Management, 27(2), 241-248.

Brizendine, L. (2006). The Female Brain. London: Bantam Press.

Brocx, B. M. (2003). Visits by friends and relatives revisited: A study of host behaviour in Auckland, New Zealand. Unpublished Masters Thesis, Victoria University, Wellington, NZ.

Bronner, F., \& de Hoog, R. (2008). Agreement and disagreement in family vacation decision-making. Tourism Management, 29(5), 967-979.

Brotherson, S. E., Dollahite, D. C., \& Hawkins, A. J. (2005). Generative fathering and the dynamics of connection between fathers and their children. Fathering, 3(1), 1-28.

Brown, C. (1995). Making the most of family visits: Some observations of parents with children in a museum science centre. Museum Management and Curatorship, 14(1), 65-71. 
Bryant, A., \& Charmaz, K. (2007). Introduction: Grounded Theory Research: Methods and Practices. In A. Bryant \& K. Charmaz (Eds.), The SAGE handbook of Grounded Theory (pp. 1-28). London: Sage.

Bryman, A. (2006). Integrating quantitative and qualitative research: How is it done? Qualitative Research, 6(1), 97-113.

Burbank, P. M., \& Martins, D. C. (2009). Symbolic interactionism and critical perspective: divergent or synergistic? Nursing Philosophy, 11(1), 25-41.

Burgess, E. W. (1926). The family as a unity of interacting personalities. The Family, 7, 3-9.

Butler, K. L. (1995). Independence for western women through tourism. Annals of Tourism Research, 22(2), 487-489.

Buttle, F. A. (1994). The co-ordinated management of meaning: A case exemplar of a new consumer research technology. European Journal of Marketing, 28(8/9), 76-99.

Carr, N. (1999). A study of gender differences: Young tourist behaviour in a UK coastal resort. Tourism Management, 20(2), 223-228.

Carr, N. (2000). An exploratory study of young women's use of leisure spaces and times: Constrained, negotiated, or unconstrained behaviour? World Leisure, 42(3), 25-32.

Carr, N. (2001). An exploratory study of gendered differences in young tourists perception of danger within London. Tourism Management, 22(5), 565570.

Carr, N. (2002a). Going with the flow: An assessment of the relationship between young people's leisure and holiday behaviour. Tourism Geographies, 4(2), 115-134.

Carr, N. (2002b). The tourism-leisure behavioural continuum. Annals of Tourism Research, 29(4), 972-986.

Carr, N. (2006). A comparison of adolescents' and parents' holiday motivations and desires. Tourism and Hospitality Research, 6(2), 129-142.

Carr, N. (2007). Partying, getting drunk, laid, and high: Gender and university students' holiday behaviour (Web case study). In C. M. Hall (Ed.), Introduction to Tourism in Australia: Development, Issues and Change (5th ed.). Frenchs Forest, Australia: Pearson Education.

Cater, C., \& Cloke, P. (2007). Bodies in action. Anthropology Today, 23(6), 1316.

Cerullo, M., \& Ewen, P. (1984). The American family goes camping: Gender, family, and the politics of space. Antipode, 16(3), 35-46. 
Chaplin, D. (1999). Back to the cave or playing away? Gender roles in homefrom-home environments. Journal of Consumer Studies \& Home Economics, 23(3), 181-189.

Charmaz, K. (2000). Grounded theory: Objectivist and constructivist methods. In N. K. Denzin \& Y. S. Lincoln (Eds.), Handbook of Qualitative Research (2nd ed., pp. 509-535). Thousand Oaks, CA: Sage.

Charmaz, K. (2002). Qualitative interviewing and grounded theory analysis. In J. F. Gubrium \& J. A. Holstein (Eds.), Handbook of Interview Research: Context \& Method (pp. 675-694). Thousand Oaks, CA: Sage.

Chesworth, N. (2003). The family vacation: A double-edged sword. International Journal of Consumer Studies, 27(4), 346-348.

Chodorow, N. (1978). The Reproduction of Mothering. Berkeley, CA: University of California Press.

Chodorow, N. (1989). Feminism and Psychoanalytic Theory. New Haven, CT: Yale University Press.

Christensen, L. H., Gram, M., \& Jensen, T. (2007). Family attractions - attracting families staging experiences. In M. Kylänen \& A. Häkkinen (Eds.), Articles on Experiences 5: Arts \& Experiences (pp. 136-163). Rovaniemi, Finland: LCEEI.

Christensen, P. H. (2002). Why more 'quality time' is not on the top of children's lists: The ‘qualities of time’ for children. Children \& Society, 16(2), 77-88.

Churchill, S. L., Clark, V. L. P., Prochaska-Cue, K., Creswell, J. W., \& OntaiGrzebik, L. (2007). How rural low-income families have fun: A grounded theory study. Journal of Leisure Research, 39(2), 271-294.

Clancy, S. M., \& Dollinger, S. J. (1993). Photographic depictions of the self: Gender and age differences in social connectedness. Sex Roles, 29(7/8), 477-495.

Clark-Ibáñez, M. (2004). Framing the social world with photo-elicitation interviews. American Behavioral Scientist, 47(12), 1507-1527.

Clark, C. D. (1999). The autodriven interview: A photographic viewfinder into children's experience. Visual Sociology, 14, 39-50.

Clawson, M., \& Knetsch, J. L. (1966). Economics of Outdoor Recreation. Baltimore, MD: John Hopkins Press.

Cloke, P., \& Perkins, H. C. (1998). 'Cracking the canyon with the awesome foursome': Representations of adventure tourism in New Zealand. Environment and Planning D: Society and Space, 16(2), 185-218. 
Clough, S. (2001). A juggling act: Women balancing work, family and leisure. In S. Clough \& J. White (Eds.), Women's Leisure Experiences: Ages, Stages and Roles (pp. 129-138). Eastbourne, UK: Leisure Studies Association.

Coakley, J. (2006). The good father: Parental expectations and youth sports. Leisure Studies, 25(2), 153-163.

Cohen, E. (1988). Authenticity and commoditization in tourism. Annals of Tourism Research, 15(3), 371-386.

Cohen, S., \& Taylor, L. (1976). Escape Attempts. Harmondsworth, UK: Penguin.

Coles, T., Hall, C. M., \& Duval, D. T. (2005). Mobilizing tourism: A postdisciplinary critique. Tourism Recreation Research, 30(2), 31-41.

Collins, D., \& Tisdell, C. (2002). Gender and differences in travel life cycles. Journal of Travel Research, 41(2), 133-143.

Colton, C. W. (1987). Leisure, recreation, tourism: A symbolic interactionism view. Annals of Tourism Research, 14(3), 345-360.

Commuri, S., \& Gentry, J. W. (2000). Opportunities for family research in marketing. Academy of Marketing Science Review, 8, 1-34.

Connell, J. (2005). Toddlers, tourism and Tobermory: Destination marketing issues and television-induced tourism. Tourism Management, 26(5), 763776.

Connell, J., \& Lowe, A. (1997). Generating grounded theory from qualitative data: The application of inductive methods in tourism and hospitality management research. Progress in Tourism and Hospitality Research, 3(2), 165-173.

Cook, R. (2007). New Zealand families. Marriage \& Family Review, 41(3/4), 241-259.

Cooper, C., \& Latham, J. (1988). English educational tourism. Tourism Management, 9(4), 331-334.

Cosenza, R. M., \& Davis, D. L. (1981). Family vacation decision making over the family life cycle: A decision and influence structure analysis. Journal of Travel Research, 20(2), 17-23.

Coventry, N. (2006). What parents want during school holidays. Inside Tourism, 592, 12.

Coventry, N. (2007a). Focus on: Holiday parks. Inside Tourism, 635, 7.

Coventry, N. (2007b). Holiday parks' summer sizzle. Inside Tourism, 634, 12.

Coventry, N. (2008). Pages past. Inside Tourism, 679, 2. 
Cowdery, R. S., \& Knudson-Martin, C. (2005). The construction of motherhood: Tasks, relational connection, and gender equality. Family Relations, 54(3), 335-345.

Craig, L. (2006). Does father care mean father share? A comparison of how mothers and fathers in intact families spend time with children. Gender \& Society, 20(2), 259-281.

Crawford, J., Kippax, S., Onyx, J., Gault, U., \& Benton, P. (1992). Emotion and Gender: Constructing Meaning from Memory. London: Sage.

Cromie, K., Henderson, K., Sexton, H., \& Weissinger, E., (Eds.) (1997). Special issue on family leisure. Journal of Leisure Research, 29(1), 1-145.

Crompton, J. L. (1979). Motivations for pleasure vacation. Annals of Tourism Research, 6(4), 408-424.

Crompton, J. L. (1981). Dimensions of the social group role in pleasure vacations. Annals of Tourism Research, 8(4), 550-568.

Cropp, A. (2006a, May). Meet the people. North \& South, 56-67.

Cropp, A. (2006b, June 24). Not so close to home. Listener, 30-31.

Crouch, D. (2000). Places around us: Embodied lay geographies in leisure and tourism. Leisure Studies, 19(2), 63-76.

Crouch, D., \& Desforges, L. (2003). The sensuous in the tourist encounter. Tourist Studies, 3(1), 5-22.

Crouter, A. C., \& Booth, A. (Eds.). (2003). Children's Influence on Family Dynamics: The Neglected Side of Family Relationships. Mahwah, NJ: Erlbaum.

Cullingford, C. (1995). Children's attitudes to holidays overseas. Tourism Management, 16(2), 121-127.

Cunningham, C., Jones, M., \& Barlow, M. (1996). Town Planning and Children. Armidale, Australia: University of New England.

Cushman, G. (1995). The development of leisure studies in Aotearoa-New Zealand. In G. Cushman, C. Simpson \& L. Trenberth (Eds.), ANZALS Leisure Research Series (Vol. 2, pp. 44-60). Lincoln, NZ: Lincoln University.

Cyba, E. (1992). Women's attitudes towards leisure and family. Society and Leisure, 15(1), 79-94.

Daengbuppha, J., Hemmington, N., \& Wilkes, K. (2006). Using grounded theory to model visitor experiences at heritage sites. Qualitative Market Research, 9(4), 367-388. 
Daly, K. (1992). The fit between qualitative research and characteristics of families. In J. F. Gilgun, D. Kerry \& G. Handel (Eds.), Qualitative Methods in Family Research (pp. 3-11). Newbury Park, CA: Sage.

Daly, K. (1994). Using qualitative methods to study families. In G. Handel \& G. G. Whitchurch (Eds.), The Psychosocial Interior of the Family (4 ed., pp. 53-68). New York: Aldine de Gruyter.

Daly, K. (1996a). Families \& Time: Keeping Pace in a Hurried Culture. Thousand Oaks, CA: Sage.

Daly, K. (1996b). Spending time with the kids: Meanings of family time for fathers. Family Relations, 45(4), 466-476.

Daly, K. (2001). Deconstructing family time: From ideology to lived experience. Journal of Marriage and Family, 63(2), 283-294.

Daly, K. (2002). Time, gender, and the negotiation of family schedules. Symbolic Interaction, 25(3), 323-342.

Daly, K. (2003). Family theory versus the theories families live by. Journal of Marriage and Family, 65(4), 771-784.

Daly, K. (2004). The Changing Culture of Parenting. Ottawa, Canada: The Vanier Institute of the Family.

Daly, K., \& Palkovitz, R. (2004). Guest editorial: Reworking work and family issues for fathers. Fathering, 2(3), 211-213.

Dann, G. M. S. (1996). Tourists' images of a destination - an alternative analysis. Journal of Travel \& Tourism Marketing, 5(1/2), 41-55.

Dann, G. M. S., \& Jacobsen, J. K. S. (2002). Leading the tourist by the nose. In G. M. S. Dann (Ed.), The Tourist as a Metaphor of the Social World (pp. 209235). Wallingford: CABI.

Darley, W. K., \& Smith, R. E. (1995). Gender differences in information processing strategies. Journal of Advertising, 24(1), 41-56.

Davidson, P. (1996). The holiday and work experiences of women with young children. Leisure Studies, 15(2), 89-103.

Dean, C. (2007). Young travellers and the children's fund: Some practical notes on an experimental image-based research project. Journal of Research in Special Education Needs, 7(1), 16-22.

Decrop, A. (1999). Triangulation in qualitative tourism research. Tourism Management, 20, 157-161.

Decrop, A. (2005). Group processes in vacation decision-making. Journal of Travel \& Tourism Marketing, 18(3), 23-36. 
Decrop, A. (2006). Vacation Decision Making. Wallingford: CABI.

Decrop, A., \& Snelders, D. (2004). Planning the summer vacation: An adaptable process. Annals of Tourism Research, 31(4), 1008-1030.

Decrop, A., \& Snelders, D. (2005). A grounded typology of vacation decisionmaking. Tourism Management, 26(2), 121-132.

Deem, R. (1996a). No time for a rest? Time \& Society, 5(1), 5-25.

Deem, R. (1996b). Women, the city and holidays. Leisure Studies, 15(2), 105119.

Denzin, N. (1978). The Research Act. Chicago: Aldine de Gruyter.

Denzin, N. (2001). Symbolic Interactionism, Poststructuralism, and the Racial Subject. Symbolic Interaction, 24(2), 243-249.

Denzin, N. K. (2002). Interpretive Interactionism. Newbury Park, CA: Sage.

Denzin, N. K., \& Lincoln, Y. S. (1994). Handbook of Qualitative Research. Thousand Oaks, CA: Sage.

Denzin, N. K., \& Lincoln, Y. S. (Eds.). (2000). Handbook of Qualitative Research (2nd ed.). Thousand Oaks, CA: Sage.

Denzin, N. K., \& Lincoln, Y. S. (Eds.). (2008). The Landscape of Qualitative Research (3rd ed.). Thousand Oaks, CA: Sage.

Department of Conservation (2006). Review of Camping Opportunities in New Zealand: Report to the Minister of Conservation. Wellington, NZ.

Department of Labour (2003). Perceptions and Attitudes towards Work-Life Balance in New Zealand: A Qualitative Study. Wellington, NZ: UMR Research.

Department of Labour (2006). Work-Life Balance in New Zealand: A Snapshot of Employee and Employer Attitudes and Experiences. Retrieved 8 August 2006 from: www.dol.govt.nz/worklife

DeVault, M. L. (2000). Producing family time: Practices of leisure activity beyond the home. Qualitative Sociology, 23, 485-503.

Devlin, P. J., \& Booth, K. L. (1998). Outdoor recreation and the environment: Towards an understanding of the recreational use of the outdoors in New Zealand. In H. C. Perkins \& G. Cushman (Eds.), Time out? Leisure, Recreation and Tourism in New Zealand and Australia (pp. 109-126). Auckland, NZ: Addison Wesley Longman.

Dey, I. (2004). Grounded theory. In C. Seale, G. Gobo, J. F. Gubrium \& D. Silverman (Eds.), Qualitative Research Practice. London: Sage. 
Di Leonardo, M. (1992). The female world of cards and holidays: Women, families, and the work of kinship. In B. Thorne \& M. Yalom (Eds.), Rethinking the Family: Some Feminist Questions (pp. 246-261). Boston: Northeastern University Press.

Digance, J., \& Marles, K. (2004). Repeat visitation to theme parks: The Dreamworld experience. In K. A. Smith \& C. Schott (Eds.), New Zealand Tourism and Hospitality Research Conference Proceedings (pp. 79-85). Wellington, NZ: Victoria University

Dollahite, D. C., Hawkins, A. J., \& Brotherson, S. E. (1997). Fatherwork: A conceptual ethic of fathering as generative work. In A. J. Hawkins \& D. C. Dollahite (Eds.), Generative Fathering: Beyond Deficit Perspectives (pp. 17-35). Thousand Oaks, CA: Sage.

Douglas, S. J., \& Michaels, M. W. (2004). The Mommy Myth: The Idealization of Motherhood and how it has undermined Women. New York: The Free Press.

Draucker, C. B., Martsolf, D. S., Ross, R., \& Rusk, T. B. (2007). Theoretical sampling and category development in grounded theory. Qualitative Health Research, 17(8), 1137-1148.

Driscoll, A. M. (1990). New Zealand's position as a destination for New Zealanders: A mulitdimensional scaling approach. Unpublished Masters Thesis, University of Otago, Dunedin, NZ.

Dumon, W. (1997). The situation of families in Western Europe: A sociological perspective. In S. Dreman (Ed.), The Family on the Threshold of the 21st Century (pp. 181-200). New Jersey: Lawrence Erlbaum Associates.

Dyck, V., \& Daly, K. (2006). Rising to the challenge: Fathers' role in the negotiation of couple time. Leisure Studies, 25(2), 201-217.

Edensor, T. (2006). Sensing tourist spaces. In C. Minca \& T. Oakes (Eds.), Travels in Paradox: Remapping Tourism (pp. 23-45). Lanham, ML: Rowman \& Littlefield.

Eggebeen, D. J., \& Knoester, C. (2001). Does fatherhood matter for men? Journal of Marriage and Family, 63(2), 381-393.

Ek, R., Larsen, J., Hornskov, S. B., \& Mansfeldt, O. K. (2008). A dynamic framework of tourist experiences: Space-time and performances in the experience economy. Scandinavian Journal of Hospitality and Tourism, 8(2), 122-140.

Elsrud, T. (2006). Gender creation in travelling, or the art of transforming an adventuress. In K. Meethan, A. Aderson \& S. Miles (Eds.), Tourism Consumption and Representation: Narratives of Place and Self (pp. 178195). Wallingford: CABI. 
Enloe, C. (1989). Bananas, Beaches, and Bases: Making Feminist Sense of International Politics. Berkeley: University of California Press.

Erikson, E. H. (1950). Childhood and Society. New York: Norton.

Everett, S. (2008). Beyond the visual gaze?: The pursuit of an embodied experience through food tourism. Tourist Studies, 8(3), 337-358.

Fairweather, J. R., \& Swaffield, S. R. (2001). Visitor experiences of Kaikoura, New Zealand: An interpretative study using photographs of landscapes and Q method. Tourism Management, 22(3), 219-228.

Families Commission (2006). What makes your Family tick? Families with dependent Children - Successful Outcomes Project (Research Report No. 1/06). Wellington, NZ.

Families Commission (2008). About us. Retrieved 2 April 2008 from http://www.nzfamilies.org.nz/

Farrell, A. (2005). Ethics and research with children. In A. Farrell (Ed.), Ethical Research with Children (pp. 1-14). New York: Open University Press.

Feighery, W. (2006). Reflexivity and tourism research: Telling an (other) story. Current Issues in Tourism, 9(3), 269-282.

Ferree, M. M. (1990). Beyond separate spheres: Feminism and family research. Journal of Marriage and the Family, 52(4), 866-884.

Fielding, N. G., \& Fielding, J. L. (1986). Linking Data. Beverly Hills, CA: Sage.

Fiese, B. H., Tomcho, T. J., Douglas, M., Josephs, K., Poltrock, S., \& Baker, T. (2002). A review of 50 years of research on naturally occurring family routines and rituals: Cause for celebration? Journal of Family Psychology, 16(4), 381-390.

Filiatrault, P., \& Ritchie, J. R. B. (1980). Joint purchasing decisions: A comparison of influence structure in family and couple decision-making units. The Journal of Consumer Research, 7(2), 131-140.

Finlay, L. (2002). 'Outing' the researcher: The provenance, process, and practice of reflexivity. Qualitative Health Research, 12(4), 531-545.

Fitzgerald, C. H. (1993). Getting away from it all? An exploration into New Zealand women's experience of Christmas holidays. Unpublished Masters Thesis, Victoria University, Wellington, NZ.

Fodness, D. (1992). The impact of family life cycle on the vacation decisionmaking process. Journal of Travel Research, 31(2), 8-13.

Fodness, D. (1994). Measuring tourist motivation. Annals of Tourism Research, 21(3), 555-581. 
Foley, C. (2007). Tourism and community: Reflections on caravan holiday experiences. Paper presented at the CAUTHE 2007. Sydney, Australia.

Fontana, A., \& Frey, J. H. (2005). The interview: From neutral stance to political involvement. In N. K. Denzin \& Y. S. Lincoln (Eds.), The Sage Handbook of Qualitative Research (3rd ed., pp. 695-727). Thousand Oaks, CA: Sage.

Francis, N., \& Kentel, J. A. (2008). The fun factor: Adolescents' self-regulated leisure activity and the implications for practitioners and researchers. Leisure/Loisir, 32(1), 65-90.

Franklin, A., \& Crang, M. A. (2001). The trouble with tourism and travel theory? Tourist Studies, 1(1), 5-22.

Fredrickson, B. L. (2000). Extracting meaning from past affective experiences: The importance of peaks, ends, and specific emotions. Cognition and Emotion, 14, 577-606.

Frew, E. A., \& Shaw, R. N. (1999). The relationship between personality, gender, and tourism behavior. Tourism Management, 20(2), 193-202.

Freysinger, V. J. (1994). Leisure with children and parental satisfaction: Further evidence of a sex difference in the experience of adult roles and leisure. Journal of Leisure Research, 26(3), 212-226.

Freysinger, V. J., \& Flannery, D. (1992). Women's leisure: Affiliation, selfdetermination, empowerment and resistance? Society and Leisure, 15(1), 303-322.

Freysinger, V. J., \& Ray, R. O. (1994). The activity involvement of women and men in young and middle adulthood: A panel study. Leisure Sciences, 16(3), 193-217.

Fullagar, S. (2002). Narratives of travel: Desire and the movement of feminine subjectivity. Leisure Studies, 21, 57-74.

Gage, J. (forthcoming). An Exploration of the Contribution of Fathering to Family Health (Blue Skies). Wellington, NZ: Families Commission.

Gaines, B. L., Hubbard, S. S., Witte, J. E., \& O’Neill, M. A. (2004). An analysis of children's programs in the hotel and resort industry market segment. International Journal of Hospitality \& Tourism Administration, 5(4), 8599.

Galani-Moutafi, V. (2000). The self and the other: Traveler, ethnographer, tourist. Annals of Tourism Research, 27(1), 203-224.

Galinsky, E. (1999). Ask the children. New York: Harper Collins.

Gamradt, J. (1995). Jamaican children's representations of tourism. Annals of Tourism Research, 22(4), 735-762. 
Gardyn, R. (2001). The new family vacation. American Demographics, 23(8), 4247.

Garrod, B. (2007). A snapshot into the past: The utility of volunteer-employed photography in planning and managing heritage tourism. Journal of Heritage Tourism, 2(1), 14-35.

Gauthier, A. H., Smeeding, T. M., \& Furstenberg, F. F. (2004). Are parents investing less time in children? Trends in selected industrialized countries. Population and Development Review, 30(4), 647-672.

Gautier, A. (2003, 31 January). Room for excitement. National Business Review, 21.

Geertz, C. (1973). The Interpretation of Culture. New York: Basic Books.

Gendall, P. (2003). The Roles of Men and Women in Society: International Social Survey Programme. Palmerston North, NZ: Massey University.

Gentry, J. W., Commuri, S., \& Jun, S. (2003). Review of literature on gender in the family. Academy of Marketing Science Review, 2003, 1-18.

Gerring, J. (2007). Case Study Research: Principles and Practices. New York: Cambridge University Press.

Getz, D., \& Carlsen, J. (2005). Family business in tourism: State of the art. Annals of Tourism Research, 32(1), 237-258.

Gibson, H. (2001). Gender in tourism: Theoretical perspectives. In Y. Apostolopoulos, S. Sönmez \& D. J. Timothy (Eds.), Women as Producers and Consumers of Tourism in developing Regions (pp. 19-43). Westport, CT: Praeger.

Gibson, H., \& Yiannakis, A. (2002). Tourist roles: Needs and the lifecourse. Annals of Tourism Research, 29(2), 358-383.

Giddens, A. (1984). The Constitution of Society: Outline of the Theory of Structuration. Berkeley, CA: University of California Press.

Gilbert, D. (1990). Conceptual issues in the meaning of tourism. In C. Cooper (Ed.), Progress in Tourism, Recreation and Hospitality Management (Vol. 2, pp. 4-27). London: Belhaven Press.

Gilbert, D., \& Abdullah, J. (2004). Holidaytaking and the sense of well-being. Annals of Tourism Research, 31(1), 103-121.

Gilgun, J. F. (1992). Definitions, methodologies, and methods in qualitative family research. In J. F. Gilgun, K. Daly \& G. Handel (Eds.), Qualitative Methods in Family Research (pp. 22-39). Newbury Park, CA: Sage. 
Gilgun, J. F. (1999). Methodological pluralism and qualitative family research. In M. B. Sussman, S. K. Steinmetz \& G. W. Peterson (Eds.), Handbook of Marriage and the Family (2 ed., pp. 219-261). New York: Plenum Press.

Gilligan, C. (1982). In a different Voice: Psychological Theory and Women's Development. Cambridge, MA: Harvard University Press.

Gillis, J. (1996). A World of their own Making: Myth, Ritual and the Quest for Family Values. New York: Basic Books.

Gillis, J. R. (2000). Our Virtual Families: Toward a Cultural Understanding of Modern Family Life. Atlanta: The Emory Center for Myth and Ritual in American Life.

Gillis, J. R. (2001). Never enough time: Some paradoxes of modern family time(s). In K. J. Daly (Ed.), Minding the time in Family Experience: Emerging Perspectives and Issues (pp. 19-36). New York: JAI Press.

Gios, G., Goio, I., Notaro, S., \& Raffaelli, R. (2006). The value of natural resources for tourism: A case study of the Italian Alps. The International Journal of Tourism Research, 8(2), 77-85.

Gladwell, N. J., \& Bedini, L. A. (2004). In search of lost leisure: The impact of caregiving on leisure travel. Tourism Management, 25(6), 685-693.

Glaser, B. (1987). Theoretical Sensitivity: Advances in Grounded Theory. Mill Valley, CA: The Sociology Press.

Glaser, B. G. (1992). Basics of Grounded Theory Analysis. Mill Valley, CA: Sociology Press.

Glaser, B. G., \& Strauss, A. L. (1967). The Discovery of Grounded Theory. Chicago: Aldine de Gruyter.

Gnoth, J. (1997). Tourism motivation and expectation formation. Annals of Tourism Research, 24(2), 283-304.

Goodson, L., \& Phillimore, J. (2004). The inquiry paradigm in qualitative tourism research. In J. Phillimore \& L. Goodson (Eds.), Qualitative Research in Tourism: Ontologies, Epistemologies and Methodologies (pp. 30-45). London: Routledge.

Goossens, C. (2000). Tourism information and pleasure motivation. Annals of Tourism Research, 27(2), 301-321.

Graburn, N. H. H. (1983). Editor's page. Annals of Tourism Research, 10(1), 1-3.

Gram, M. (2005). Family holidays. A qualitative analysis of family holiday experiences. Scandinavian Journal of Hospitality \& Tourism, 5(1), 2-22.

Gram, M. (2007). Children as co-decision makers in the family? The case of family holidays. Young Consumers, 8(1), 19-28. 
Grant, B., \& Thompson, S. (2000). Leisure in midlife. In P. Koopman-Boyden, A. Dharmalingam, B. Grant, V. Hendy, S. Hillcoat-Nalletamby, D. Mitchell, M. O'Driscoll \& S. Thompson (Eds.), Transactions in the Mid-life Family (pp. 113-130). Hamilton, NZ: Population Association of New Zealand.

Grant, I. (2006). Creative approaches to new media research. Young Consumers, 7(3), 51-56.

Green Party (2005). Tourism Policy. Retrieved 3 December 2007 from http://www.greens.org.nz/searchdocs/policy4762.html

Grosz, E. (1994). Volatile Bodies: Towards a Corporeal Feminism. Sydney, Australia: Allen \& Unwin.

Grosz, E. (1995). Women, chora, dwelling. In S. Watson \& K. Gibson (Eds.), Postmodern Cities and Spaces (pp. 47-58). Oxford, UK: Blackwell.

Gubrium, J. F., \& Holstein, J. A. (Eds.). (2002). Handbook of Interview Research: Context \& Method. Thousand Oaks, CA: Sage.

Gyimothy, S. (1999). Visitors' perceptions of holiday experiences and service providers: An exploratory study. Journal of Travel \& Tourism Marketing, 8(2), 57-74.

Haldrup, M. (2004). Laid-back mobilities: Second-home holidays in time and space. Tourism Geographies, 6(4), 434-454.

Haldrup, M., \& Larsen, J. (2003). The family gaze. Tourist Studies, 3(1), 23-46.

Hall, C. M., \& Müller, D. K. (Eds.). (2004). Tourism, Mobility and Second Homes: Between Elite Landscape and Common Ground. Clevdon, UK: Channel View.

Hall, C. M., Williams, A. M., \& Lew, A. A. (2004). Tourism: Conceptualisations, Institutions, and Issues. In A. A. Lew, C. M. Hall \& A. M. Williams (Eds.), A Companion to Tourism (pp. 3-22). Oxford, UK: Blackwell Publishing.

Hall, D., Swain, M. B., \& Kinnard, V. (2003). Tourism and gender: An evolving agenda. Tourism Recreation Research, 28(2), 7-11.

Hallman, B. C., Mary, S., \& Benbow, P. (2007). Family leisure, family photography and zoos: Exploring the emotional geographies of families. Social \& Cultural Geography, 8(6), 871-888.

Handel, G. (1965). Psychosocial study of whole families. Psychological Bulletin, 63(1), 19-41.

Handel, G. (1985). The Psychosocial Interior of the Family (3rd ed.). New York: Aldine de Gruyter. 
Handel, G. (1991). Case study in family research. In J. R. Feagin, A. M. Orum \& G. Sjoberg (Eds.), A Case for the Case Study (pp. 244-268). Chapel Hill: The University of North Carolina Press.

Handel, G. (1992). The qualitative tradition in family research. In J. F. Gilgun, K. Daly \& G. Handel (Eds.), Qualitative Methods in Family Research (pp. 12-21). Newbury Park, CA: Sage.

Handel, G. (1996). Family worlds and qualitative family research: Emergence and prospects of whole-family methodology. Marriage \& Family Review, 24(3/4), 335-348.

Handel, G. (2001). Toward understanding families as groups. Marriage \& Family Review, 31(3/4), 9-20.

Handel, G., Cahill, S. E., \& Elkin, F. (2007). Children and Society: The Sociology of Children and Childhood Socialization. Los Angeles, CA: Roxbury.

Hannam, K. (2008). Tourism geographies, tourist studies and the turn towards mobilities. Geography Compass, 2(1), 127-139.

Hardy, A. (2005). Using grounded theory to explore stakeholder perceptions of tourism. Journal of Tourism \& Cultural Change, 3(2), 108-133.

Harper, D. (2002). Talking about pictures: A case for photo elicitation. Visual Studies, 17(1), 13-26.

Harrington, M. (2001). Gendered time: Leisure in family life. In K. J. Daly (Ed.), Minding the Time in Family Experience: Emerging Perspectives and Issues (Vol. 3, pp. 343-382). Oxford, UK: Elsevier Science.

Harrington, M. (2006). Sport and leisure as contexts for fathering in Australian families. Leisure Studies, 25(2), 165-183.

Harrington, M., \& Bell, B. (1999). The Australian family at leisure: Values and conflicts in participation. In B. C. Grant \& R. Pringle (Eds.), ANZALS Conference (pp. 77-81). Hamilton, NZ: University of Waikato.

Harris, C., \& Ateljevic, I. (2003). Perpetuating the male gaze as the norm: Challenges for 'her' participation in business travel. Tourism Recreation Research, 28(2), 21-30.

Harris, C., \& Wilson, E. (2007). Travelling beyond the boundaries of constraint: Women, travel and empowerment. In A. Pritchard, N. Morgan, I. Ateljevic \& C. Harris (Eds.), Tourism and Gender: Embodiment, Sensuality and Experience (pp. 235-250). Wallingford: CABI.

Havitz, M. E. (2007). A host, a guest, and our lifetime relationship: Another hour with grandma Havitz. Leisure Sciences, 29(2), 131-141.

Hay, R. (1998). Sense of place in developmental context. Journal of Environmental Psychology, 18(1), 5-29. 
Hazel, N. (2005). Holidays for children and families in need: An exploration of the research and policy context for social tourism in the UK. Children \& Society, 19(3), 225-236.

Heimtun, B. (2007a). Depathologizing the tourist syndrome: Tourism as social capital production. Tourist Studies, 7(3), 271-293.

Heimtun, B. (2007b). From principles to practices in feminist tourism research: A call for greater use of the survey method and the solicited diary. In I. Ateljevic, A. Pritchard \& N. Morgan (Eds.), The Critical Turn in Tourism Studies: Innovative Research Methodologies (pp. 245-259). Oxford, UK: Elsevier.

Heimtun, B. (2007c). Mobile identities of gender and tourism: The value of social capital. Unpublished $\mathrm{PhD}$ Thesis, University of West of England, UK.

Heisley, D. D., \& Levy, S. J. (1991). Autodriving: A photoelicitation technique. Journal of Consumer Research, 18(3), 257-272.

Henderson, K. A. (1994). Perspectives on analyzing gender, women, and leisure. Journal of Leisure Research, 26(2), 119-137.

Henderson, K. A. (2006). Dimensions of Choice: Qualitative Approaches to Parks, Recreation, Tourism, Sport, and Leisure Research (2nd ed.). State College, PA: Venture.

Henderson, K. A., \& Allen, K. R. (1991). The ethic of care: Leisure possibilities and constraints for women. Society and Leisure, 14(1), 97-113.

Henderson, K. A., \& Bedini, L. A. (1995). Notes on linking qualitative and quantitative data. Therapeutic Recreational Journal, 29(2), 124-130.

Henderson, K. A., Hodges, S., \& Kivel, B. D. (2002). Context and dialogue in research on women and leisure. Journal of Leisure Research, 34(3), 253271.

Hess, R. D., \& Handel, G. (1959). Family Worlds: A Psychosocial Approach to Family Life. Chicago: The University of Chicago Press.

Hilbrecht, M., Shaw, S. M., Delamere, F. M., \& Havitz, M. E. (2008). Experiences, perspectives, and meanings of family vacations for children. Leisure/Loisir, 32(2), 541-571.

Hobson, J. S. P. (2003). The case for more exploratory and grounded tourism research: Martin Oppermann memorial lecture 2001. Pacific Tourism Review, 6, 73-81.

Hochschild, A. R., \& Machung, A. (1989). The second Shift: Working Parents and the Revolution at Home. New York: Viking. 
Holbrook, M. B., \& Hirschman, E. C. (1982). The experiential aspects of consumption: Consumer fantasies, feelings, and fun. The Journal of Consumer Research, 9(2), 132-140.

Hollinshead, K. (1996). The tourism researcher as bricoleur: The new wealth and diversity in qualitative inquiry. Tourism Analysis, 1(1), 67-74.

Hollinshead, K. (2004). A primer in ontological craft: The creative capture of people and places through qualitative research. In J. Phillimore \& L. Goodson (Eds.), Qualitative Research in Tourism: Ontologies, Epistemologies and Methodologies (pp. 63-82). London: Routledge.

Hollinshead, K. (2006). The shift to constructivism in social inquiry: Some pointers for tourism studies. Tourism Recreation Research, 31(2), 43-58.

Hollinshead, K., \& Jamal, T. B. (2007). Tourism and 'the third ear': Further prospects for qualitative inquiry. Tourism Analysis, 12(1/2), 85-129.

Hong, G.-S., Fan, J. X., Palmer, L., \& Bhargava, V. (2005). Leisure travel expenditure patterns by family life cycle stages. Journal of Travel \& Tourism Marketing, 18(2), 15-30.

Howard, D. R., \& Madrigal, R. (1990). Who makes the decision: The parent or the child?: The perceived influence of parents and children on the purchase of recreation services. Journal of Leisure Research, 22(3), 244-258.

Hsu, C. H. C., Cai, L. A., \& Wong, K. K. F. (2007). A model of senior tourism motivations - anecdotes from Beijing and Shanghai. Tourism Management, 28(5), 1262-1273.

Hudson, S. (2000). The segmentation of potential tourists: Constraint differences between men and women. Journal of Travel Research, 38(4), 363-368.

Hughes, H. L. (1991). Holidays and the economically disadvantaged. Tourism Management, 12(3), 193-196.

Irigaray, L. (1993). An Ethics of Sexual Difference. New York: Cornell University Press.

Iso-Ahola, S. E. (1982). Toward a social psychological theory of tourism motivation: A rejoinder. Annals of Tourism Research, 9(2), 256-262.

Jaakson, R. (1986). Second-home domestic tourism. Annals of Tourism Research, 13(3), 367-391.

Jackson, N., \& Pool, I. (1994). Fertility and Family Formation in the 'Second Demographic Transition': New Zealand Patterns and Trends (Research Report No. 2). Christchurch, NZ: Institute of Social Research and Development.

Jackson, R. T. (1990). VFR tourism: Is it underestimated? The Journal of Tourism Studies, 1(2), 10-17. 
Jafari, J. (1986). On domestic tourism. Annals of Tourism Research, 13(3), 491496.

Jaffé, D. (2007). Eve-olution: Women's rising power in travel decisions. In R. Conrady \& M. Buck (Eds.), Trends and Issues in Global Tourism 2007 (pp. 19-31). Berlin: Springer.

Jamal, T., \& Hollinshead, K. (2001). Tourism and the forbidden zone: The underserved power of qualitative inquiry. Tourism Management, 22(1), 63-82.

Jenkins, R. L. (1978). Family vacation decision-making. Journal of Travel Research, 16(4), 2-7.

Jennings, G., \& Junek, O. (2007). Grounded theory: Innovative methodology or a critical turning point from hegemonic methodological praxis in tourism studies. In I. Ateljevic, A. Pritchard \& N. Morgan (Eds.), The Critical Turn in Tourism Studies: Innovative Research Methods (pp. 197-210). Oxford, UK: Elsevier.

Jennings, G. R. (2005). Caught in the irons: One of the lived experiences of longterm ocean cruising women. Tourism Review International, 9, 177-193.

Jepsen, A. L., \& Blichfeldt, B. S. (2005, August). Freed from experience: Why people spend their vacations at a nearby caravan site. Paper presented at the 18th Scandinavian Academy of Management (NFF) Conference, Århus, Denmark.

Johns, N., \& Gyimothy, S. (2002). Mythologies of a theme park: An icon of modern family life. Journal of Vacation Marketing, 8(4), 320-331.

Johns, N., \& Gyimothy, S. (2003). Postmodern family tourism at Legoland. Scandinavian Journal of Hospitality \& Tourism, 3(1), 3-23.

Johnston, G., \& Percy-Smith, J. (2003). In search of social capital. Policy \& Politics, 31, 321-334.

Johnston, L. (2001). (Other) bodies and tourism studies. Annals of Tourism Research, 28(1), 180-201.

Jordan, F., \& Aitchison, C. (2008). Tourism and the sexualisation of the gaze: Solo female tourists' experiences of gendered power, surveillance and embodiment. Leisure Studies, 27(3), 329-349.

Joux, M. d. (1985). The Family, Leisure and Recreation (Monograph Series No. 6). Wellington, NZ: Department of Internal Affairs.

Kang, S.-K. (2002). Vacation destination selection: Spousal conflict arousal and conflict resolution in the family decision-making process. Unpublished Ph.D. Thesis, Kansas State University, Manhattan, US. 
Kang, S. K., \& Hsu, C. H. C. (2005). Dyadic consensus on family vacation destination selection. Tourism Management, 26(4), 571-582.

Kaufman, E. (2006). The Travel Mom's Ultimate Book of Family Travel: Planning, Surviving, and Enjoying your Vacation Together. New York: Broadway Books.

Kay, T. (2001). New women, same old leisure: The upholding of gender stereotypes and leisure disadvantage in contemporary dual-earner households. In S. Clough \& J. White (Eds.), Women's Leisure Experiences: Ages, Stages and Roles (pp. 113-128). Eastbourne, UK: Leisure Studies Association.

Kay, T. (2003). Leisure, gender and self in the analysis of family. World Leisure, 45(4), 4-14.

Kay, T. (2006a). Editorial: Fathering through leisure. Leisure Studies, 25(2), 125131.

Kay, T. (2006b). Where's dad? Fatherhood in leisure studies. Leisure Studies, 25(2), 133-152.

Kay, T., (Ed.) (2006c). Special Issue: Fathering through Leisure. Leisure Studies, 25(2), 125-256.

Kearsley, G. W., Coughlan, D. P., \& Ritchie, B. W. (1998). Images of New Zealand Holiday Destinations: An International and Domestic Perspective (Research Paper No. 2). Dunedin, NZ: Centre for Tourism, University of Otago.

Keen, D., \& Hall, C. M. (2004). Second homes in New Zealand. In C. M. Hall \& D. K. Müller (Eds.), Tourism, Mobility and Second Homes: Between Elite Landscape and Common Ground (pp. 174-195). Clevdon, UK: Channel View.

Kelly, J. R. (1994). The symbolic interaction metaphor and leisure: Critical challenges. Leisure Studies, 13(2), 81-96.

Kelly, J. R. (1997). Changing issues in leisure-family research - again. Journal of Leisure Research, 29(1), 132-134.

Kimmel, M. (2004). The Gendered Society (2nd ed.). New York: Oxford University Press.

Kinnaird, V., \& Hall, D. (1996). Understanding tourism processes: A genderaware framework. Tourism Management, 17(2), 95-102.

Kinnaird, V., \& Hall, D. (Eds.). (1994). Tourism: A Gendered Analysis. Chichester, UK: John Wiley \& Sons. 
Kitzinger, J. (1994). The methodology of focus groups: The importance of interaction between research participants. Sociology of Health and Illness, 16(1), 103-121.

Koc, E. (2002). The impact of gender in marketing communications: The role of cognitive and affective cues. Journal of Marketing Communications, 8(4), 257-275.

Kousis, M. (1989). Tourism and the family in a rural Cretan community. Annals of Tourism Research, 16(3), 318-332.

Krähenbühl, S., \& Blades, M. (2006). The effect of interviewing techniques on young children's responses to questions. Child: Care, Health \& Development, 32(3), 321-331.

Kyle, G., \& Chick, G. (2004). Enduring leisure involvement: The importance of personal relationship. Leisure Studies, 23(3), 243-266.

Kyle, G., \& Chick, G. (2007). The social construction of a sense of place. Leisure Sciences, 29, 209-225.

Labone, M., \& Wearing, S. (1994). Family leisure decisions and national parks: A sociological perspective. In D. Mercer (Ed.), New Viewpoints in Australian Outdoor Recreation Research and Planning (pp. 69-78). Williamstown, Australia: Hepper Marriott \& Associates.

Labour Party (2005). Tourism Policy. Retrieved 1 August 2006 from www.labour.org.nz

Lackman, C., \& Lanasa, J. M. (1993). Family decision-making theory: An overview and assessment. Psychology \& Marketing, 10(2), 81-93.

Landon, E. L., \& Locander, W. B. (1979). Family life cycle and leisure behaviour research. Advances in Consumer Research, 6(1), 133-138.

Lareau, A. (2000). My wife can tell me who I know: Methodological and conceptual problems in studying fathers. Qualitative Sociology, 23(4), 407-433.

Lareau, A. (2003). Unequal Childhoods: Class, Race, and Family Life. Berkeley, CA: University of California Press.

LaRossa, R. (2005). Grounded theory methods and qualitative family research. Journal of Marriage and Family, 67(4), 837-857.

LaRossa, R., Bennett, L. A., \& Gelles, R. J. (1994). Ethical dilemmas in qualitative family research. In G. Handel \& G. G. Whitchurch (Eds.), The Psychosocial Interior of the Family (4 ed., pp. 109-126). New York: Aldine de Gruyter.

LaRossa, R., \& Reitzes, D. C. (1993). Symbolic interactionism and family studies. In P. G. Boss, W. J. Doherty, R. LaRossa, W. R. Schumm \& S. K. 
Steinmetz (Eds.), Sourcebook of Family Theories and Methods: A Contextual Approach (pp. 135-163). New York: Plenum Press.

LaRossa, R., \& Wolf, J. H. (1985). On qualitative family research. Journal of Marriage and the Family, 47(3), 531-541.

Larsen, J. (2001). Tourism mobilities and the travel glance: Experiences of being on the move. Scandinavian Journal of Hospitality \& Tourism, 1(2), 80-98.

Larsen, J. (2005). Families seen sightseeing: Performativity of tourist photography. Space and Culture, 8(4), 416-434.

Larsen, J. (2008). De-exoticizing tourist travel: Everyday life and sociality on the move. Leisure Studies, 27(1), 21-34.

Larsen, J., Urry, J., \& Axhausen, K. W. (2007). Networks and tourism: Mobile social life. Annals of Tourism Research, 34(1), 244-262.

Larsen, S. (2007). Aspects of a psychology of the tourist experience. Scandinavian Journal of Hospitality \& Tourism, 7(1), 7-18.

Larsen, S., \& Jenssen, D. (2004). The school trip: Travelling with, not to or from. Scandinavian Journal of Hospitality \& Tourism, 4(1), 43-57.

Larson, R. W., Gillman, S. A., \& Richards, M. H. (1997). Divergent experiences of family leisure: Fathers, mothers, and young adolescents. Journal of Leisure Research, 29(1), 78-97.

Larson, V. (2005, April). The end of the family life - as we knew it. North \& South, 36-48.

Lawson, R. (1991). Patterns of tourist expenditure and types of vacation across the family life cycle. Journal of Travel Research, 29(4), 12-18.

Lawson, R., Thyne, M., \& Young, T. (1997). New Zealand Holidays: A Travel Lifestyles Study. Dunedin, NZ: University of Otago, Marketing Department.

Lawson, R., Todd, S., \& Evans, S. (2006). New Zealand in the 21st Century: A Consumer Lifestyles Study. Dunedin, NZ: University of Otago, Consumer Research Group.

Lee, C. K. C., \& Beatty, S. E. (2002). Family structure and influence in family decision making. The Journal of Consumer Marketing, 19(1), 24-41.

Lee, Y., Dattilo, J., \& Howard, D. (1994). The complex and dynamic nature of leisure experience. Journal of Leisure Research, 26(3), 195-211.

Leiper, N. (1979). The framework of tourism: Towards a definition of tourism, tourist, and the tourist industry. Annals of Tourism Research, 6(4), 390407. 
Leontidou, L. (1994). Gender dimensions of tourism sub-cultures and restructuring. In V. Kinnaird \& D. Hall (Eds.), Tourism: A Gender Analysis (pp. 74-105). Chichester, UK: Wiley.

Leung, P. (2003). Child sex tourism. Tourism Recreation Research, 28(2), 83-87.

Lewis, C. (2000). A Man's Place in the Home: Fathers and Families in the UK (No. 440). York, UK: Joseph Rowntree Foundation.

Lin, Y.-C., \& Lehto, X. Y. (2006). A study of female travelers' needs trajectory and family life cycle. Journal of Hospitality and Leisure Marketing, 15(1), 65-88.

Litvin, S. W., Xu, G., \& Kang, S. K. (2004). Spousal vacation-buying decision making revisited across time and place. Journal of Travel Research, 43(2), 193-198.

Lockyer, T., \& Ryan, C. (2007). Visiting friends and relatives - distinguishing between the two groups: The case of Hamilton, New Zealand. Tourism Recreation Research, 32(1), 59-68.

Loeffler, T. A. (2004). A photo elicitation study of the meanings of outdoor adventure experiences. Journal of Leisure Research, 36(4), 536-556.

Lofman, B. (1991). Elements of experiential consumption: An exploratory study. Advances in Consumer Research, 18(1), 729-735.

Lollis, S., \& Kuczynski, L. (1997). Beyond one hand clapping: Seeing bidirectionality in parent-child relations. Journal of Social and Personal Relationships, 14(4), 441-461.

Lynch, P. A. (2005). Sociological impressionism in a hospitality context. Annals of Tourism Research, 32(3), 527-548.

MacCannell, D. (1976). The Tourist: A new Theory of the Leisure Class. London: Macmillan.

Mactavish, J. B., \& Schleien, S. J. (2004). Re-injecting spontaneity and balance in family life: Parents' perspectives on recreation in families that include children with developmental disability. Journal of Intellectual Disability Research, 48(2), 123-141.

Madrigal, R., Havitz, M. E., \& Howard, D. R. (1992). Married couples' involvement with family vacations. Leisure Sciences, 14(4), 287-301.

Magee, A. (2001). Women. Asia Pacific Viewpoint, 42(1), 35-45.

Maher, J. (2005). A mother by trade: Australian women reflecting mothering as activity, not identity. Australian Feminist Studies, 20, 17-29.

Mahon, A., Glendinning, C., Clark, K., \& Craig, G. (1996). Researching children: Methods and ethics. Children \& Society, 10(2), 145-154. 
Makens, J. C. (1992). Children at resorts: Customer service at its best. Cornell Hotel and Restaurant Administration Quarterly, 33(4), 25-35.

Mannell, R. C., \& Iso-Ahola, S. E. (1987). Psychological nature of leisure and tourism experience. Annals of Tourism Research, 14(3), 314-331.

Mannell, R. C., \& Kleiber, D. A. (1997). A Social Psychology of Leisure. State College, PA: Venture.

Manning, J. (1980). Family holidays in New Zealand. In J. Shallcrass, B. Larkin \& B. Stothart (Eds.), Recreation reconsidered into the Eighties. Auckland and Wellington, NZ: Auckland Regional Authority and NZ Council for Recreation and Sport.

Mansfeld, Y. (1992). From motivation to actual travel. Annals of Tourism Research, 19(3), 399-419.

Markwell, K., \& Basche, C. (1998). Using personal diaries to collect data. Annals of Tourism Research, 25(1), 228-231.

Marles, K. (2002). Regular revisitation in caravan parks. In D. Carson, I. Waller \& N. Scott (Eds.), Drive Tourism: Up the Wall and around the Bend (pp. 41-52). Melbourne, Australia: Common Ground Publishing.

Marshall, J. (2001). Women and strangers: Issues of marginalization in seasonal tourism. Tourism Geographies, 3, 165-186.

Marsiglio, W., Amato, P., Day, R. D., \& Lamb, M. E. (2000). Scholarship on fatherhood in the 1990s and beyond. Journal of Marriage and the Family, 62(4), 1173-1191.

Mason, J. (2006). Mixing methods in a qualitatively driven way. Qualitative Research, 6(1), 9-25.

Massey, D. (1994). Space, Place and Gender. Oxford, UK: Polity Press.

Matta, D. S., \& Knudson-Martin, C. (2006). Father responsivity: Couple processes and the coconstruction of fatherhood. Family Process, 45(1), 1937.

Matthews, H., Limb, M., \& Taylor, M. (1998). The geography of children: Some ethical and methodological considerations for project and dissertation work. Journal of Geography in Higher Education, 22(3), 311-324.

Maume, D. J. (2006). Gender differences in taking vacation time. Work and Occupations, 33(2), 161-190.

McCabe, A. S. (2000). Tourism motivation process. Annals of Tourism Research, 27(4), 1049-1052.

McCabe, S. (1999). The problem of motivation in understanding the demand for leisure day visits. In A. G. Woodside, G. I. Crouch, J. A. Mazanec \& M. 
Y. Sakai (Eds.), Consumer Psychology of Tourism, Hospitality and Leisure (pp. 211-225). Wallingford: CABI.

McCabe, S. (2002). The tourist experience and everyday life. In G. M. S. Dann (Ed.), The Tourist as a Metaphor of the Social World (pp. 61-75). Wallingford: CABI.

McCabe, S., \& Marson, D. (2006). Tourist constructions and consumptions of space: Place, modernity and meaning. In P. M. Burns \& M. Novelli (Eds.), Tourism and Social Identities: Global Frameworks and Local Realities. Oxford: Elsevier.

McCormack, C. (1998). Memories bridge the gap between theory and practice in women's leisure research. Annals of Leisure Research, 1(1), 37-49.

McDonald, D. A., \& Almeida, D. M. (2004). The interweave of fathers' daily work experiences and fathering behaviors. Fathering, 2(3), 235-251.

McGehee, N. G., Loker-Murphy, L., \& Uysal, M. (1996). The Australian international pleasure travel market: Motivations from a gendered perspective. The Journal of Tourism Studies, 7(1), 45-57.

McIntosh, A. (1998). Mixing methods: Putting the tourist at the forefront of tourism research. Tourism Analysis, 3(2), 121-127.

McIntosh, A. J. (1999). Into the tourist's mind: Understanding the value of the heritage experience. Journal of Travel \& Tourism Marketing, 8(1), 41-64.

McIntosh, A. J., \& Zahra, A. (2007). A cultural encounter through volunteer tourism: Towards the ideals of sustainable tourism? Journal of Sustainable Tourism, 15(5), 541-556.

McMahon, M. (1995). Engendering Motherhood: Identity and Self-transformation in Women's Lives. New York: Guilford Press.

McPherson, M. (2006). New Zealand Cultural Norms of Parenting and Childcare and how these relate to Labour Force Participation Decisions and Requirements (Blue Skies Report No. 14/06). Wellington, NZ: Families Commission.

McWhirter, A., \& Brookes, J. (2001, July/August). Family fortunes: Taking your family on holiday should be a pleasure - not an expensive ordeal. Business Traveller UK/Europe, 36-37.

Mead, G. H. (1934). Mind, Self, and Society. Chicago: University of Chicago Press.

Mestdag, I., \& Vandeweyer, J. (2005). Where has family time gone? In search of joint family activities and the role of the family meal in 1966 and 1999. Journal of Family History, 30(3), 304-323. 
Miers, A., \& Murphy, J. (2004). Giving kids a voice: Methodological and practical considerations in conducting research with children and young people. Survey Methods Newsletter, 22(Spring), 6-18.

Milkie, M. A., Mattingly, M. J., Nomaguchi, K. M., Bianchi, S. M., \& Robinson, J. P. (2004). The time squeeze: Parental statuses and feelings about time with children. Journal of Marriage and Family, 66(3), 739-761.

Miller, Y., \& Brown, W. (2005). Determinants of active leisure for women with young children-an 'ethic of care' prevails. Leisure Sciences, 27, 405-420.

Ministry of Social Development (2004). New Zealand Families Today: A Briefing for the Families Commission. Retrieved 26 March 2008 from: http://www.msd.govt.nz/documents/publications/msd/nz-familiestoday.pdf

Ministry of Social Development (2007). The Social Report. Wellington, NZ.

Ministry of Tourism (2006). New Zealand Tourism Forecasts 2006-2012: Summary Document. Wellington, NZ.

Ministry of Tourism (2007a). Domestic Travel Survey YE June. Retrieved 13 September 2007 from: http://www.tourismresearch.govt.nz

Ministry of Tourism (2007b). Key Tourism Statistics December. Retrieved 13 December 2007 from: http://www.tourismresearch.govt.nz

Ministry of Tourism (2007c). New Zealand Tourism Strategy 2015. Wellington, NZ.

Ministry of Tourism (2008a). Domestic Travel Survey YE September 2007. Retrieved 9 April 2008 from http://www.tourismresearch.govt.nz

Ministry of Tourism (2008b). International Visitor Survey YE March 2007. Retrieved 10 April 2008 from http://www.tourismresearch.govt.nz

Ministry of Tourism (2009). Tourism Industry Monitor, April. Retrieved 6 May 2009 from http://www.trcnz.govt.nz

Ministry of Women's Affairs (2008). Mothers. Retrieved 27 March 2008 from http://www.mwa.govt.nz/women-in-nz/mothers

Minnaert, L., Maitland, R., \& Miller, G. (2006). Social tourism and its ethical foundations. Tourism Culture \& Communication, 7(1), 7-17.

Mintz, S. (2004). Huck's Raft: A History of American Childhood. Cambridge, MA: Harvard University Press.

Mitchell, T. R., Thompson, L., Peterson, E., \& Cronk, R. (1997). Temporal adjustments in the evaluation of events: The 'rosy view'. Journal of Experimental Social Psychology, 33(4), 421-448. 
Morgan, D. L. (1997). Focus Groups as Qualitative Research (2nd ed.). Thousand Oaks, CA: Sage.

Morin, M. (1984). A sociopsychological approach to vacation and mobility in touristic sites. Annals of Tourism Research, 11(1), 113-127.

Morrison, A., Woods, B., Pearce, P., Moscardo, G., \& Sung, H. H. (2000). Marketing to the visiting friends and relatives segment: An international analysis. Journal of Vacation Marketing, 6(2), 102-118.

Morrow, V., \& Richards, M. (1996). The ethics of social research with children: An overview. Children \& Society, 10(2), 90-105.

Morse, J. M. (1995). The significance of saturation. Qualitative Health Research, 5(2), 147-149.

Morse, J. M. (2007). Sampling in grounded theory. In A. Bryant \& K. Charmaz (Eds.), The SAGE Handbook of Grounded Theory (pp. 229-244). London: Sage.

Moscardo, G. (2008). Gender, travel party and Great Barrier Reef travel experiences. In CAUTHE Conference Proceedings. Gold Coast, Australia: Griffith University.

Moscardo, G., Pearce, P., Morrison, A., Green, D., \& O'Leary, J. T. (2000). Developing a typology for understanding visiting friends and relatives markets. Journal of Travel Research, 38(3), 251-259.

Mottiar, Z., \& Quinn, D. (2004). Couple dynamics in household tourism decision making: Women as the gatekeepers? Journal of Vacation Marketing, 10(2), 149-160.

Mowen, A. J., \& Graefe, A. R. (2006). An examination of family/group roles in the decision to visit a public zoological park. Journal of Park \& Recreation Administration, 24(1), 104-123.

Mulvaney, R. H., O’Neill, J. W., Cleveland, J. N., \& Crouter, A. C. (2007). A model of work-family dynamics of hotel managers. Annals of Tourism Research, 34(1), 66-87.

Murphy, S. O. (1992). Using multiple forms of family data. In J. F. Gilgun, K. Daly \& G. Handel (Eds.), Qualitative Methods in Family Research (pp. 146-171). Newbury Park, CA: Sage.

Nanda, D., Hu, C., \& Bai, B. (2006). Exploring family roles in purchasing decisions during vacation planning: review and discussions for future research. Journal of Travel \& Tourism Marketing, 20(3/4), 107-125.

Ndubisi, N. O. (2007). Impact of joint product usage and family structure on joint decision to purchase a vacation by Malaysian spouses. Journal of Vacation Marketing, 13(2), 135-147. 
Neal, J. D., \& Gursoy, D. (2008). A multifaceted analysis of tourism satisfaction. Journal of Travel Research, 47(1), 53-62.

Neal, J. D., Sirgy, M. J., \& Uysal, M. (2004). Measuring the effect of tourism services on travellers' quality of life: Further validation. Social Indicators Research, 69, 243-277.

New Zealand Tourist and Publicity Department (NZTP) (1989). Domestic Travel Segmentation Study: Domestic Research Series 1989/24. Wellington, NZ: Colmar Brunton Research.

Nichols, C. M., \& Snepenger, D. J. (1988). Family decision making and tourism behavior and attitudes. Journal of Travel Research, 26(4), 2-6.

Nickerson, N. P., \& Jurowski, C. (2001). The influence of children on vacation travel patterns. Journal of Vacation Marketing, 7(1), 19-30.

Norris, J., \& Wall, G. (1994). Gender and tourism. Progress in Tourism, Recreation, and Hospitality Management, 6, 57-78.

Noy, C. (2007). The poetics of tourist experience: An autoethnography of a family trip to Eilat. Journal of Tourism and Cultural Change, 5(3), 141-157.

O'Dell, T. (2007). Tourist Experiences and Academic Junctures. Scandinavian Journal of Hospitality \& Tourism, 7(1), 34-45.

Oh, H., Parks, S. C., \& DeMicco, F. J. (2002). Age- and gender-based market segmentation: A structural understanding. International Journal of Hospitality \& Tourism Administration, 3(1), 1-20.

Øksnes, M. (2008). The carnival goes on and on! Children's perceptions of their leisure time and play in SFO. Leisure Studies, 27(2), 149-164.

Olsen, D. H., \& Gorall, D. M. (2003). Circumplex model of marital and family systems. In F. Walsh (Ed.), Normal Family Processes: Growing Diversity and Complexity (Third ed., pp. 514-548). New York/London: The Guilford Press.

Ooi, C.-S. (2006). Tourism experiences as attention products. In M. Kylänen (Ed.), Articles on Experiences (2nd ed.). Rovaniemi, Finland: LCEEI.

Oppermann, M. (1995a). Mutitemporal perspective of changing travel patterns. Journal of Travel \& Tourism Marketing, 4(3), 101-109.

Oppermann, M. (1995b). Travel life cycle. Annals of Tourism Research, 22(3), 535-552.

Oppermann, M. (1998). Sex Tourism and Prostitution: Aspects of Leisure, Recreation and Work. Elmsford, NY: Cognizant Communication Corporation. 
Oppermann, M. (2000). Triangulation - a methodological discussion. The International Journal of Tourism Research, 2(2), 141-146.

Orthner, D. K., \& Mancini, J. A. (1990). Leisure impacts on family interaction and cohesion. Journal of Leisure Research, 22(2), 125-137.

Orum, A. M., Feagin, J. R., \& Sjoberg, G. (1991). Introduction: The nature of the case study. In J. R. Feagin, A. M. Orum \& G. Sjoberg (Eds.), A Case for the Case Study (pp. 1-26). Chapel Hill: The University of North Carolina Press.

Osmond, M. W., \& Thorne, B. (1993). Feminist theories: The social construction of gender in families and society. In P. G. Boss, W. J. Doherty, R. LaRossa, W. R. Schumm \& S. K. Steinmetz (Eds.), Sourcebook of Family Theories and Methods (pp. 591-623). New York: Plenum Press.

Otto, J. E., \& Ritchie, J. R. B. (1996). The service experience in tourism. Tourism Management, 17(3), 165-174.

Palmer, C. (2005). An ethnography of Englishness: Experiencing identity through tourism. Annals of Tourism Research, 32(1), 7-27.

Park, J., \& Tansuhaj, P. (1995). An emotion-based perspective of family purchase decisions. Advances in Consumer Research, 22(1), 723-728.

Park, O.-J., Lehto, X., \& Park, J.-K. (2008). Service failures and complaints in the family travel market: A justice dimension approach. The Journal of Services Marketing, 22(7), 520-532.

Pearce, D. (1993a). Domestic tourist travel patterns in New Zealand. GeoJournal, 29(3), 225-232.

Pearce, D. (1999). Towards a geography of the geography of tourism: Issues and examples from New Zealand. Tourism Geographies, 1(4), 406-424.

Pearce, D. (2001). Tourism. Asia Pacific Viewpoint, 42(1), 75.

Pearce, D., \& Simmons, D. G. (1997). New Zealand: Tourism - the challenges of growth. In F. M. Go \& C. L. Jenkins (Eds.), Tourism and Economic Development in Asia and Australasia (pp. 197-220). London: Pinter.

Pearce, P. L. (1993b). Fundamentals of tourist motivation. In D. G. Pearce \& R. W. Butler (Eds.), Tourism Research: Critiques and Challenges (pp. 113134). New York: Routledge.

Pearce, P. L. (2005). Tourist Behaviour: Themes and Conceptual Schemes. Clevedon, UK: Channel View.

Pennington-Gray, L. (2003). Understanding the domestic VFR drive market in Florida. Journal of Vacation Marketing, 9(4), 354-366. 
Pennington-Gray, L., \& Kerstetter, D. L. (2001). What do university-educated women want from their pleasure travel experiences? Journal of Travel Research, 40(1), 49-56.

Perkins, H. C., \& Gidlow, B. (1991). Leisure research in New Zealand: Patterns, problems and prospects. Leisure Studies, 10(2), 93-104.

Perkins, H. C., \& Thorns, D. C. (2001). Gazing or performing? International Sociology, 16(2), 185-204.

Perkins, H. C., \& Thorns, D. C. (2006). Home away from home: The primary/second-home relationship. In N. MacIntyre, D. R. Williams \& K. McHugh (Eds.), Multiple Dwelling and Tourism: Negotiating Place, Home and Identity (pp. 67-81). Wallingford: CABI.

Perlesz, A., \& Lindsay, J. (2003). Methodological triangulation in researching families: Making sense of dissonant data. International Journal of Social Research Methodology, 6(1), 25-40.

Perosa, L. M., \& Perosa, S. L. (2001). Adolescent perceptions of cohesion, adaptability, and communication: Revisiting the circumplex model. The Family Journal, 9(4), 407-419.

Phillimore, J., \& Goodson, L. (Eds.). (2004). Qualitative Research in Tourism: Ontologies, epistemologies and methodologies. London: Routledge.

Phillips, J. (1996). A Man's Country: The Image of the Pakeha Male - a History (revised ed.). Auckland, NZ: Penguin.

Phillips, J. (1999). Men, women and leisure since the second World War. In C. Daley \& D. Montgomerie (Eds.), The Gendered Kiwi (pp. 213-233). Auckland, NZ: Auckland University Press.

Phillips, J. (2007). Beach Culture. Retrieved 3 April 2008, from Te Ara - the Encyclopedia of New Zealand: http://www.teara.govt.nz

Pine, B. J., II, \& Gilmore, J. H. (1998). Welcome to the experience economy. Harvard Business Review, 76(4), 97-105.

Pinker, S. (2008). The Sexual Paradox: Troubled Boys, gifted Girls and the real Difference between the Sexes. London: Atlantic Books.

Piotrkowski, C. (1979). Work and the Family System. New York: The Free Press.

Podilchak, W. (1988). The neglect of fun in leisure: Denying social interaction. Leisure Information Quarterly, 14(3), 3-5.

Podilchak, W. (1991). Distinctions of fun, enjoyment and leisure. Leisure Studies, 10(2), 133-148.

Pool, I., Dharmalingam, A., \& Sceats, J. (2007). The New Zealand Family from 1840: A Demographic History. Auckland, NZ: Auckland University Press. 
Poria, Y., Atzaba-Poria, N., \& Barrett, M. (2005). The relationship between children's geographical knowledge and travel experience: An exploratory study. Tourism Geographies, 7(4), 389-397.

Portes, A. (1998). Social capital: Its origins and applications in modern sociology. Annual Review of Sociology, 24(1), 1-24.

Prentice, R. (2004). Tourist motivation and typologies. In A. A. Lew, C. M. Hall \& A. M. Williams (Eds.), A Companion to Tourism (pp. 261-279). Malden, MA: Blackwell.

Prentice, R., Witt, S. F., \& Hamer, C. (1998). Tourism as experience: The case of heritage parks. Annals of Tourism Research, 25(1), 1-24.

Pritchard, A., Morgan, N., Ateljevic, I., \& Harris, C. (2007). Editor's introduction: Tourism, gender, embodiment and experience. In A. Pritchard, N. Morgan, I. Ateljevic \& C. Harris (Eds.), Tourism and Gender: Embodiment, Sensuality and Experience (pp. 1-12). Wallingford: CABI.

Pritchard, A., \& Morgan, N. J. (2000). Privileging the male gaze: Gendered tourism landscapes. Annals of Tourism Research, 27(4), 884-905.

Pritchard, M. P., \& Havitz, M. E. (2006). Ratios of tourist experience: It was the best of times, it was the worst of times. Tourism Analysis, 10, 291-297.

Pryor, J. (2006). Beyond Demography: History, Ritual and Families in the Twenty-first Century (Blue Skies Report No. 7/06). Wellington, NZ: Families Commission.

Pryor, J. (2007). Family wellbeing - Confusions and Challenges. Retrieved 15 February, 2010, from http://www.victoria.ac.nz/mckenziecentre/research/complete/index.aspx

Punch, S. (2002). Research with children: The same or different from research with adults? Childhood, 9(3), 321-341.

Putnam, R. D. (2000). Bowling Alone. New York: Simon \& Schuster.

Puwar, N. (1997). 'Reflections on interviewing women MPs'. Sociological Research Online, 2(1), 1-13

Quan, S., \& Wang, N. (2004). Towards a structural model of the tourist experience: An illustration from food experiences in tourism. Tourism Management, 25(3), 297-305.

Rehman, L. A. (2001). Using Eichler to inform family leisure research. In S. Clough \& J. White (Eds.), Women's Leisure Experiences: Ages, Stages and Roles (pp. 87-97). Eastbourne: Leisure Studies Association.

Reilly, K. S., Eroglu, S. A., Macheit, K. A., \& Omura, G. S. (1984). Consumer decision making across family life cycle stages. Advances in Consumer Research, 11(1), 400-404. 
Reilly, R. C. (2002/2003). Family volunteering: Making a difference together. Leisure/Loisir, 27(3/4), 305-332.

Richards, G. (1999). Vacations and the quality of life: Patterns and structures. Journal of Business Research, 44(3), 189-198.

Richards, G. (2002). Gastronomy: An essential ingredient in tourism production and consumption? In A.-M. Hjalager \& G. Richards (Eds.), Tourism and Gastronomy (pp. 3-20). London and New York: Routledge.

Richardson, L., \& St. Pierre, E. A. (2005). Writing a method of inquiry. In N. K. Denzin \& Y. S. Lincoln (Eds.), The SAGE Handbook of Qualitative Research (pp. 959-978). Thousand Oaks, CA: Sage.

Richmond, E. H., \& Tolich, M. (2000). The third shift: Task allocation and ultimate responsibility on family camping holidays. New Zealand Sociology, 15(2), 284-303.

Richter, L. K. (2005). Not a minor problem: Developing international travel policy for the welfare of children. Tourism Analysis, 10(1), 27-36.

Riley, R. W. (1995). Prestige-worthy tourism behavior. Annals of Tourism Research, 22(3), 630-649.

Riley, R. W., \& Love, L. L. (2000). The state of qualitative tourism research. Annals of Tourism Research, 27(1), 164-187.

Ritchie, J. R. B., \& Filiatrault, P. (1980). Family vacation decision-making - a replication and extension. Journal of Travel Research, 18(4), 3-14.

Roberts, K. (1996). Young people, schools, sport and government policies. Sport, Education and Society, 1(1), 47-57.

Robertson, J. (2006). New Zealanders' Satisfaction with Family Relationships and Parenting (Blues Skies Report No. 10/06). Wellington, NZ: Families Commission.

Robinson, J. R., \& Godbey, G. (1997). Time for Life: The Surprising Ways Americans use their Time. University Park: Pennsylvania State University Press.

Rojek, C. (1993). Ways of Escape: Modern Transformations in Leisure and Travel. London: Macmillan.

Rojek, C. (1995). Decentering Leisure: Rethinking Leisure Theory. London: Sage.

Rosaldo, M. Z. (1980). The use and abuse of anthropology: Reflections on feminism and cross-cultural understanding. Signs, 5(3), 389-417.

Rosenblatt, P. C., \& Russell, M. G. (1975). The social psychology of potential problems in family vacation travel. The Family Coordinator, 24(2), 209215. 
Roxburgh, S. (2006). 'I wish we had more time to spend together...': The distribution and predictors of perceived family time pressures among married men and women in the paid labor force. Journal of Family Issues, 27(4), 529-553.

Rubin, H. J., \& Rubin, I. S. (2005). Qualitative Interviewing: The Art of Hearing Data (2nd ed.). Thousand Oaks, CA: Sage.

Ryan, C. (1992). The child as a visitor. World Travel and Tourism Review, 14, 135-139.

Ryan, C. (2002a). Motives, behaviours, body and mind. In C. Ryan (Ed.), The Tourist Experience (2nd ed., pp. 27-57). London: Continuum.

Ryan, C. (2002b). Tourism and cultural proximity: Examples from New Zealand. Annals of Tourism Research, 29(4), 952-971.

Ryan, C. (2003). A new wave - or beached fathers! Gender issues in academic tourism literature - where is the dad? CAUTHE Conference Proceedings. Coffs Harbour, Australia: Southern Cross University.

Ryan, C., \& Hall, C. M. (2001). Sex Tourism: Marginal People and Liminalities. London: Routledge.

Ryan, C., \& Pike, S. (2003). Maori-based tourism in Rotorua: Perceptions of place by domestic visitors. Journal of Sustainable Tourism, 11(4), 307-321.

Samuel, N. (1993). Vacation time and the French family. World Leisure \& Recreation, 35(3), 15-16.

Sandberg, J. F., \& Hofferth, S. L. (2001). Changes in children's time with parents: United States, 1981-1997. Demography, 38(3), 423-436.

Sapsford, R., \& Jupp, V. (2006). Data Collection and Analysis (2nd ed.). London: Sage.

Sayer, L. C., Bianchi, S. M., \& Robinson, J. P. (2004). Are parents investing less in children? Trends in mothers' and fathers' time with children. The American Journal of Sociology, 110(1), 1-43.

Sceats, J. (2002). Report on a Qualitative Interview Study of Children, Childrearing and the Family in New Zealand. Tokyo, Japan: National Institute of Population and Social Security.

Schänzel, H. A., \& McIntosh, A. J. (2000). An insight into the personal and emotive context of wildlife viewing at the Penguin Place, Otago Peninsula, New Zealand. Journal of Sustainable Tourism, 8(1), 36-52.

Schänzel, H. A., Smith, K. A., \& Weaver, A. (2005). Family holidays: A research review and application to New Zealand. Annals of Leisure Research, 8(23), 105-123. 
Schwandt, T. A. (1994). Constructivist, interpretivist approaches to human inquiry. In N. K. Denzin \& Y. S. Lincoln (Eds.), Handbook of Qualitative Research (1st ed., pp. 118-137). Thousand Oaks, CA: Sage.

Schwandt, T. A. (2000). Three epistemological stances for qualitative inquiry: Interpretivism, hermeneutics, and social constructivism. In N. K. Denzin \& Y. S. Lincoln (Eds.), Handbook of Qualitative Research (2nd ed., pp. 189-213). Thousand Oaks, CA: Sage.

Seaton, A. V., \& Palmer, C. (1997). Understanding VFR tourism behaviour: The first five years of the United Kingdom tourism survey. Tourism Management, 18(6), 345-355.

Seaton, A. V., \& Tagg, S. (1995). The family vacation in Europe: Paedonomic aspects of choices and satisfactions. Journal of Travel \& Tourism Marketing, 4(1), 1-21.

Selänniemi, T. (2002). Couples on holiday: (En)gendered or endangered experiences? In M. B. Swain \& J. H. Momsen (Eds.), Gender/Tourism/Fun(?) (pp. 15-23). New York: Cognizant Communication Corporation.

Serrell, B. (1980, Nov/Dec). Looking at zoo and aquarium visitors. Museum News, 37-41.

Sharp, H., \& Mott, P. (1956). Consumer decisions in the metropolitan family. Journal of Marketing, 21(2), 149-156.

Shaw, G., Agarwal, S., \& Bull, P. (2000). Tourism consumption and tourist behaviour: A British perspective. Tourism Geographies, 2(3), 264-289.

Shaw, S. M. (1985). Gender and leisure: Inequality in the distribution of leisure time. Journal of Leisure Research, 17(4), 266-282.

Shaw, S. M. (1992). Dereifying family leisure: An examination of women's and men's everyday experiences and perceptions of family time. Leisure Sciences, 14(4), 271-286.

Shaw, S. M. (1997). Controversies and contradictions in family leisure: An analysis of conflicting paradigms. Journal of Leisure Research, 29(1), 98112.

Shaw, S. M. (2001). The family leisure dilemma: Insights from research with Canadian families. World Leisure, 43(4), 53-62.

Shaw, S. M. (2008). Family leisure and changing ideologies of parenthood. Sociology Compass, 2(2), 688-703.

Shaw, S. M., \& Dawson, D. (2001). Purposive leisure: Examining parental discourses on family activities. Leisure Sciences, 23, 217-231. 
Shaw, S. M., \& Dawson, D. (2003/2004). Contradictory aspects of family leisure: Idealization versus experience. Leisure/Loisir, 28(3/4), 179-201.

Shaw, S. M., Havitz, M. E., \& Delemere, F. M. (2008). I decided to invest in my kids' memories: Family vacations, memories, and the social construction of the family. Tourism Culture \& Communication, 8(1), 13-26.

Sheller, M., \& Urry, J. (2006). The new mobilities paradigm. Environment and Planning A, 38(2), 207-226.

Shoham, A., \& Dalakas, V. (2005). He said, she said ... they said: Parents' and children's assessment of children's influence on family consumption decisions. The Journal of Consumer Marketing, 22(2/3), 152-160.

Siegenthaler, K. L., \& O'Dell, I. (2000). Leisure attitude, leisure satisfaction, and perceived freedom in leisure within family dyads. Leisure Sciences, 22(4), 281-296.

Siese, S. (2007). Heaven on Earth - Kids: The World's best Family Holidays. UK: St. Christoper's.

Silverman, D. (2000). Doing Qualitative Research: A practical Handbook. London: Sage.

Sinclair, M. T. (Ed.). (1997). Gender, Work and Tourism. London: Routledge.

Small, J. (1999). Memory-work: A method for researching women's tourist experiences. Tourism Management, 20(1), 25-35.

Small, J. (2002). Good and bad holiday experiences: Women's and girls' perspectives. In M. B. Swain \& J. H. Momsen (Eds.), Gender/Tourism/Fun? (pp. 24-37). Elmsford, New York: Cognizant Communication Corporation.

Small, J. (2003). The voices of older women tourists. Tourism Recreation Research, 28(2), 31-39.

Small, J. (2005a). Holiday Experiences of Women and Girls over the Life-Course. Unpublished $\mathrm{PhD}$ Thesis, University of Technology, Sydney, Australia.

Small, J. (2005b). Women's holidays: Disruption of the motherhood myth. Tourism Review International, 9, 139-154.

Small, J. (2007). The emergence of the body in the holiday accounts of women and girls. In A. Pritchard, N. Morgan, I. Ateljevic \& C. Harris (Eds.), Tourism and Gender: Embodiment, Sensuality and Experience (pp. 7391). Wallingford: CABI.

Small, J. (2008). The absence of childhood in tourism studies. Annals of Tourism Research, 35(3), 772-789. 
Smith, V., \& Hughes, H. (1999). Disadvantaged families and the meaning of the holiday. The International Journal of Tourism Research, 1(2), 123-133.

Smith, V. L. (1979). Women the taste-makers in tourism. Annals of Tourism Research, 6(1), 49-60.

Snyder, K. A. (2007). A vocabulary of motives: Understanding how parents define quality time. Journal of Marriage and Family, 69(2), 320-340.

So, S.-I., \& Lehto, X. Y. (2006). The situational influence of travel group composition: Contrasting Japanese family travelers with other travel parties. Journal of Travel \& Tourism Marketing, 20(3/4), 79-91.

Sontag, S. (1977). On Photography. London: Penguin Books.

Speedling, E. J. (1982). Heart Attack: The Family Response at Home and in the Hospital. New York: Tavistock.

Sport \& Recreation New Zealand (2006). SPARC Facts '97-'01. Retrieved 2 April 2008 from: http://www.sparc.org.nz/about-sparc

Sport \& Recreation New Zealand (2007). Overview. Retrieved 2 April 2008 from: http://www.sparc.org.nz/about-sparc/minister-ministry/overview

Stacey, J. (1990). Brave New Families. New York: Basic.

Stafford, A., Laybourn, A., Hill, M., \& Walker, M. (2003). 'Having a say': Children and young people talk about consultation. Children \& Society, 17(5), 361-373.

Statistics New Zealand (1999). New Zealand Now: Women. Wellington, NZ.

Statistics New Zealand (2001). Around the Clock: Findings from the New Zealand Time Use Survey 1998-99. Wellington, NZ.

Statistics New Zealand (2004). New Zealand official Yearbook 2004 (104th ed.). Wellington, NZ: David Bateman.

Statistics New Zealand (2005). Families and households. Focusing on Women 2005 (pp. 27-41). Wellington, NZ.

Statistics New Zealand (2006a). New Zealand Census of Population and Dwellings, Individual Form. Retrieved 2 September 2006 from: www.stats.govt.nz

Statistics New Zealand (2006b). New Zealand Income Survey: June 2006 Quarter. Retrieved 12 September 2007 from: http://www.stats.govt.nz/

Statistics New Zealand (2007). About 2006 Census Retrieved 2 April 2008 from: http://www.stats.govt.nz/census/about-2006-census/default.htm 
Statistics New Zealand (2008). Food Price Index: February 2008. Retrieved 1 April 2008 from: http://www.stats.govt.nz/products-and-services/hot-offthe-press/food-price-index/food-price-index-feb08-hotp.htm

Steel, B. F., \& Riddell, P. M. (1981). Holiday Destination New Zealand: New Zealanders' perception of Holidays in New Zealand. Wellington, NZ: NZTP.

Sterry, P., \& Beaumont, E. (2006). Methods for studying family visitors in art museums: A cross-disciplinary review of current research. Museum Management and Curatorship, 21(3), 222-239.

Stevens, L., Maclaran, P., \& Catterall, M. (2007). A space of one's own: Women's magazine consumption within family life. Journal of Consumer Behaviour, 6(4), 236-252.

Stewart, A. J., \& McDermott, C. (2004). Gender in psychology. Annual Review of Psychology, 55, 519-544.

Strauss, A. L., \& Corbin, J. M. (1990). Basics of Qualitative Research: Grounded Theory Procedures and Techniques. Newbury Park, CA: Sage.

Such, E. (2006). Leisure and fatherhood in dual-earner families. Leisure Studies, 25(2), 185-199.

Sue, W., Jenny, R., \& Alistair, G. (1999). Participation in sport and active leisure by New Zealand children and adolescents. Journal of Physical Education New Zealand, 32(1), 4-8.

Sutton, R. I. (1992). Feelings about a Disneyland visit: Photography and the reconstruction of bygone emotions. Journal of Management Inquiry, 1(4), 278-287.

Suvantola, J. (2002). Tourist's Experience of Place. Hampshire, UK: Ashgate.

Swain, M. B. (1995). Gender in tourism. Annals of Tourism Research, 22(2), 247266.

Swarbrooke, J., \& Horner, S. (1999). Consumer Behaviour in Tourism. Oxford, UK: Butterworth-Heinemann.

Tagg, S., \& Seaton, A. V. (1994). How different are Scottish family holidays from English? In A. V. Seaton (Ed.), Tourism: The State of the Art (pp. 540549). Chichester, UK: Wiley.

Taylor, K., \& Beston, A. (2005, March 29). Brash says carry on camping. The New Zealand Herald, p. A3,

Thomas Cook (1983). Children's Attitudes to Holidays. London: Market \& Opinion Research International. 
Thomas, W. I., \& Znaniecki, F. (1927). The Polish Peasant in Europe and America. New York: Knopf.

Thompson, J. A., \& Bunderson, J. S. (2001). Work-nonwork conflict and the phenomenology of time: Beyond the balance metaphor. Work and Occupations, 28(1), 17-39.

Thompson, S. M. (1999). Mother's Taxi: Sport and Women's Labor. Albany: State University of New York Press.

Thompson, S. M., Grant, B. C., \& Dharmalingam, A. (2002). Leisure time in midlife: What are the odds? Leisure Studies, 21(2), 125-143.

Thompson, W. N., Pinney, J. K., \& Schibrowsky, J. A. (1996). The family that gambles together: Business and social concerns. Journal of Travel Research, 34(3), 70-74.

Thomson, R. (2000). Physical activity through sport and leisure: Traditional versus non-competitive activities. Journal of Physical Education New Zealand, 33(1), 34-39.

Thornton, P. R., Shaw, G., \& Williams, A. M. (1997). Tourist group holiday decision-making and behaviour: The influence of children. Tourism Management, 18(5), 287-297.

Thorpe, K., \& Daly, K. (1999). Children, parents, and time: The dialectics of control. In C. L. Shehan (Ed.), Contemporary Perspectives on Family Research (Vol. 1, pp. 199-223). Stamford, CT: JAI Press.

Timothy, D. J. (2005). Shopping Tourism, Retailing and Leisure. Clevdon, UK: Channel View.

Todd, S. (1999). Examining tourism motivation methodologies. Annals of Tourism Research, 26(4), 1022-1024.

Todd, S., Lawson, R., \& Jamieson, T. (2001). New Zealand beyond 2000: A consumer lifestyle study. Dunedin, NZ: University of Otago, Consumer Research Group.

Tourism Australia (2005). Summary of the Caravan and Camping Report: A Profile of Travellers who used Caravan and Camping Accommodation in Australia in 2003/04 (Report No. 6). Canberra, Australia: Tourism Research Australia.

Tourism Industry Association New Zealand (TIANZ) (2005). Domestic Tourism Promotion - a Discussion Paper. Retrieved 1 August 2006 from: www.tianz.org.nz

Tourism Industry Association New Zealand (TIANZ) (2006). Domestic Tourism Marketing - Recommendations for ongoing Work. Retrieved 1 August 2006 from: www.tianz.org.nz 
Tourism New Zealand (2008). 100\% Pure New Zealand. Retrieved 29 October 2008 from: http://www.newzealand.com/travel/destinations/regions/

Tourism New Zealand (2009). 100\% Pure New Zealand: Interactive Travellers ${ }^{\circledR}$ : Who are they? Retrieved 2 April 2009 from, from Accessed from www.tourismnewzealand.com: www.tourismnewzealand.com

Tourism Research Council (2000). New Zealand Domestic Travel Survey 2000. Wellington, NZ: Ministry of Tourism.

Tourism Research Council (2006). Domestic Travel Survey Questionnaire. Retrieved 2 September 2006 from: http://www.tourismresearch.govt.nz/

Tovar, C., \& Lockwood, M. (2008). Social impacts of tourism: An Australian regional case study. The International Journal of Tourism Research, 10(4), 365-378.

Tribe, J. (1999). Economics of Leisure and Tourism. Oxford, UK: ButterworthHeinemann.

Tribe, J. (2005). New tourism research. Tourism Recreation Research, 30(2), 5-8.

Tribe, J. (2006). The truth about tourism. Annals of Tourism Research, 33(2), 360381.

Tuomela, R. (2007). The Philosophy of Sociality. New York: Oxford University Press.

Turley, S. K. (2001). Children and the demand for recreational experiences: The case of zoos. Leisure Studies, 20(1), 1-18.

Uriely, N. (2005). The tourist experience: Conceptual developments. Annals of Tourism Research, 32(1), 199-216.

Urry, J. (1990). The Tourist Gaze. Leisure and Tourism in Contemporary Societies. London: Sage.

Urry, J. (2003). Social networks, travel and talk. British Journal of Sociology, 54(1), 155-175.

Uysal, M., \& Jurowski, C. (1994). Testing the push and pull factors. Annals of Tourism Research, 21(4), 844-846.

Van Middelkoop, M., Borgers, A., \& Timmermans, H. (2003). Inducing heuristic principles of tourist choice of travel mode: A rule-based approach. Journal of Travel Research, 42(1), 75-83.

Van Teijlingen, E. R., \& Hundley, V. (2001). The importance of pilot studies. Social Research Update, 35, 1-4.

Veijola, S., \& Jokinen, E. (1994). The body in tourism. Theory, Culture \& Society, 11, 125-151. 
Vittersø, G. (2007). Norwegian cabin life in transition. Scandinavian Journal of Hospitality \& Tourism, 7(3), 266-280.

Vitterso, J., Vorkinn, M., Vistad, O. I., \& Vaagland, J. (2000). Tourist experiences and attractions. Annals of Tourism Research, 27(2), 432-450.

Walker, A. J. (1999). Gender and family relationships. In M. B. Sussman, S. K. Steinmetz \& G. W. Peterson (Eds.), Handbook of Marriage and the Family (2nd ed., pp. 439-474). New York: Plenum Press.

Walle, A. H. (1997). Quantitative versus qualitative tourism research. Annals of Tourism Research, 24(3), 524-536.

Wang, K.-C., Hsieh, A.-T., Yeh, Y.-C., \& Tsai, C.-W. (2004). Who is the decision-maker: The parents or the child in group package tours? Tourism Management, 25(2), 183-194.

Wang, N. (2000). The Sociology of Tourism. New York: Sage.

Wang, N. (2002). The tourist as peak consumer. In G. M. S. Dann (Ed.), The Tourist as a Metaphor of the Social World (pp. 281-295). Wallingford: CABI.

Wearing, B. (1993). The family that plays together stays together: Or does it? Leisure and mothers. World Leisure \& Recreation, 35(3), 25-29.

Wearing, B., \& Fullagar, S. (1996). The Ambiguity of Australian Women's Family Leisure: some Figures and Refiguring. In N. Samuel (Ed.), Women, Leisure and the Family in Contemporary Society: A Multinational Perspective. Wallingford: CABI.

Wearing, B., \& Wearing, S. (1988). 'All in a day's leisure': Gender and the concept of leisure. Leisure Studies, 7(2), 111-123.

Wearing, B., \& Wearing, S. (1996). Refocussing the tourist experience: The flaneur and the choraster. Leisure Studies, 15(4), 229-243.

Wearing, S., \& Deane, B. (2003). Seeking self: Leisure and Tourism on common ground. World Leisure, 45(1), 4-12.

Wearing, S., \& Wearing, B. (2001). Conceptualising the selves of tourism. Leisure Studies, 20, 143-159.

Weber, M. (1947). The Theory of Social and Economic Organization (A. M. Henderson \& T. Parsons, Trans.). New York: The Free Press.

Westwood, S., Morgan, N., \& Pritchard, A. (2006). Situation, participation and reflexivity in tourism research: Furthering interpretive approaches to tourism enquiry. Tourism Recreation Research, 31(2), 33-41.

Wheeler, M., \& Lanigan, C. (2002). Travel with Children: Lonely Planet Travel Guides Series (4th ed.). Australia: Lonely Planet Publications. 
White, J. (1996). Making time for family: The invention of family time(s) and the reinvention of family history. Journal of Family History, 21(1), 4-21.

Wickens, E. (2002). The sacred and the profane: A tourist typology. Annals of Tourism Research, 29(3), 834-851.

Wilkes, R. E., \& Laverie, D. A. (2007). Purchasing decisions in non-traditional households: The case of lesbian couples. Journal of Consumer Behaviour, 6(1), 60-73.

Williams, D. R., \& Kaltenborn, B. P. (1999). Leisure places and modernity: The use and meaning of recreational cottages in Norway and the USA. In D. Crouch (Ed.), Leisure/Tourism Geographies: Practices and Geographical Knowledge (pp. 214-230). London Routledge.

Willson, G. B., \& McIntosh, A. J. (2007). Heritage buildings and tourism: An experiential view. Journal of Heritage Tourism, 2(2), 75-93.

Wilson, D. (1997). Paradoxes of tourism in Goa. Annals of Tourism Research, 24(1), 52-75.

Wilson, E. (1995). The invisible flaneur. In S. Watson \& K. Gibson (Eds.), Postmodern Cities and Spaces (pp. 59-79). Oxford, UK: Blackwell.

Wilson, E., \& Ateljevic, I. (2008). Challenging the 'tourist-other' dualism: Gender, backpackers and the embodiment of tourism research. In K. Hannam \& I. Ateljevic (Eds.), Backpacker Tourism: Concepts and Profiles (pp. 95-110). Clevedon, UK: Channel View.

Wilson, E., Harris, C., \& Small, J. (2008). Furthering critical approaches in tourism and hospitality studies: Perspectives from Australia and New Zealand. Journal of Hospitality \& Tourism Management, 15, 15-18.

Wilson, E., \& Little, D. E. (2008). The solo female travel experience: Exploring the 'geography of women's fear'. Current Issues in Tourism, 11(2), 167186.

Winter, C. (2005, February). True Camping: Is there a place for it? Paper presented at the CAUTHE Conference, Alice Springs, Australia.

Wirtz, D., Kruger, J., Napa Scollon, C., \& Diener, E. (2003). What to do on spring break? The role of predicted, on-line, and remembered experience in future choice. Psychological Science, 14(5), 520-524.

Wolgast, E. H. (1958). Do husbands or wives make the purchasing decisions? Journal of Marketing, 23(2), 151-158.

Wood, J. (1994). Gendered Lives: Communication, Gender, and Culture. Belmont, CA: Wadsworth.

Woodside, A. G., MacDonald, R., \& Burford, M. (2004). Grounded theory of leisure travel. Journal of Travel \& Tourism Marketing, 17(1), 7-39. 
Yarnal, C. (2004). Missing the boat? A playfully serious look at a group cruise tour experience. Leisure Sciences, 26, 349-372.

Yarnal, C., \& Kerstetter, D. (2005). Casting off: An exploration of cruise ship space, group tour behavior, and social interaction. Journal of Travel Research, 43(4), 368-379.

Yeoman, I. (2008). Tomorrow's Tourist: Scenarios \& Trends. Oxford, UK: Elsevier.

Yesawich, P., Pepperdine, \& Brown (2001). Portrait of Family Travel (Report). Orlando, FL: YP\&B.

Yeung, W. J., John, F. S., Pamela, E. D.-K., \& Sandra, L. H. (2001). Children's time with fathers in intact families. Journal of Marriage and Family, 63(1), 136-154.

Yin, R. K. (2003). Case Study Research: Design and Methods (3rd ed.). Thousand Oaks, CA: Sage.

Zabriskie, R. B., \& McCormick, B. P. (2001). The influences of family leisure patterns on perceptions of family functioning. Family Relations, 50(3), 281-289.

Zabriskie, R. B., \& McCormick, B. P. (2003). Parent and child perspectives of family leisure involvement and satisfaction with family life. Journal of Leisure Research, 35(2), 163-189.

Zalatan, A. (1998). Wives' involvement in tourism decision processes. Annals of Tourism Research, 25(4), 890-903.

Zelizer, V. (1985). Pricing the Priceless Child: The Changing Social Value of Children. New York: Basic Books.

Zuzanek, J. (2001). Parenting time: Enough or too little? Isuma - Canadian Journal of Policy Research, 2(2), 125-133. 


\section{APPENDICES}

Appendix A: Parental survey

Appendix B: Information letter and consent forms

Appendix C: Interview schedule (pre-holiday)

Appendix D: Interview schedule (post-holiday)

Appendix E: Interview schedule (final) 
Appendix A:

Parental survey 
Dear Parent(s) or Care-giver(s)

13 November 2006

My name is Heike Schänzel and I am currently undertaking $\mathrm{PhD}$ research at Victoria University on family holidays. I am a parent of three children raising my family in Eastbourne. Earlier this year, I decided to go back to university in order to obtain my Doctorate. My area of specialisation is tourism studies. I have discovered that very few tourism researchers have studied family holidays. Like me, you have probably found that travelling with your family has both great rewards and challenges. The joys and frustrations of travel with my own family got me interested in this topic.

I have been in contact with Andrew Bird and Steve Bielby at [name of school]. They have permitted me to distribute this letter and questionnaire at [name of school] School and for your child to bring it home. [Name of school] is not conducting this research and will not have access to data from this study. It is part of my $\mathrm{PhD}$ project on family holidays and is independent of the school.

This questionnaire offers you a chance to show what New Zealand families do on their holidays, as well as the opportunity to win a prize. With your help, I am seeking to understand the travel pattems of New Zealand families and to develop a definition of a family holiday. This questionnaire may take 15 minutes to complete, but your responses will be very useful to me. As a busy parent, I appreciate that finding time to participate may be difficult. But I would really value your help. The questionnaire needs to be completed by only one parent/caregiver per family. If you retum the questionnaire by November $28^{\text {th }}$ you can be entered into a draw for a $\$ 30$ book voucher.

A self-addressed freepost envelope is included for the return of the questionnaire. The answers will be kept in a secure location until one year after the completion of this project (approx. 2010) and then be destroyed. Any information you provide me will be handled with the strictest confidentiality and you will not be identifiable in any way. You may decline to answer a question. But you may choose to include your details for participation in the prize draw, to receive a copy of the survey results, and to take part in the interview phase of this project. I plan to report the results of my survey at a conference in $2007 \mathrm{and} /$ or in an academic journal.

It is now a requirement for all university research involving people to be approved by the University Ethics Committee. This study has been reviewed by this committee. If you require further information about the project, please contact myself or my supervisors. We will gladly answer your questions.

Your co-operation in this project would be greatly appreciated. I hope you find the questions interesting and engaging.

Yours sincerely

Heike Schänzel, Doctoral Candidate, Victoria Management School, Victoria University of Wellington; Email: heike.schaenzel@vuw.ac.nz

Supervisors: Dr Adam Weaver, Lecturer, and Dr Karen Smith, Senior Lecturer Email: Adam.weaver@vuw.ac.nz (Ph: 463 5375); Karen.smith@vuw.ac.nz 

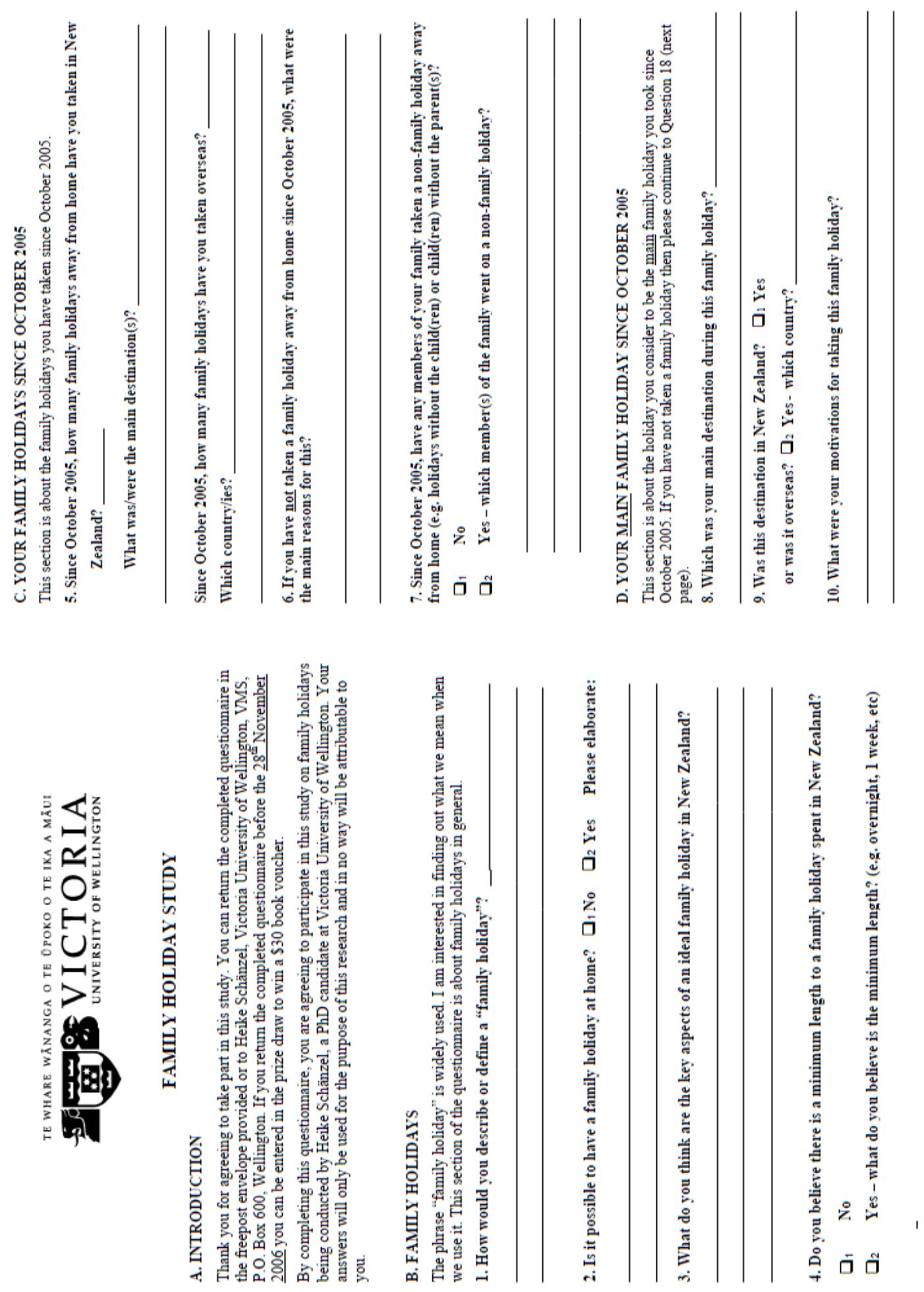

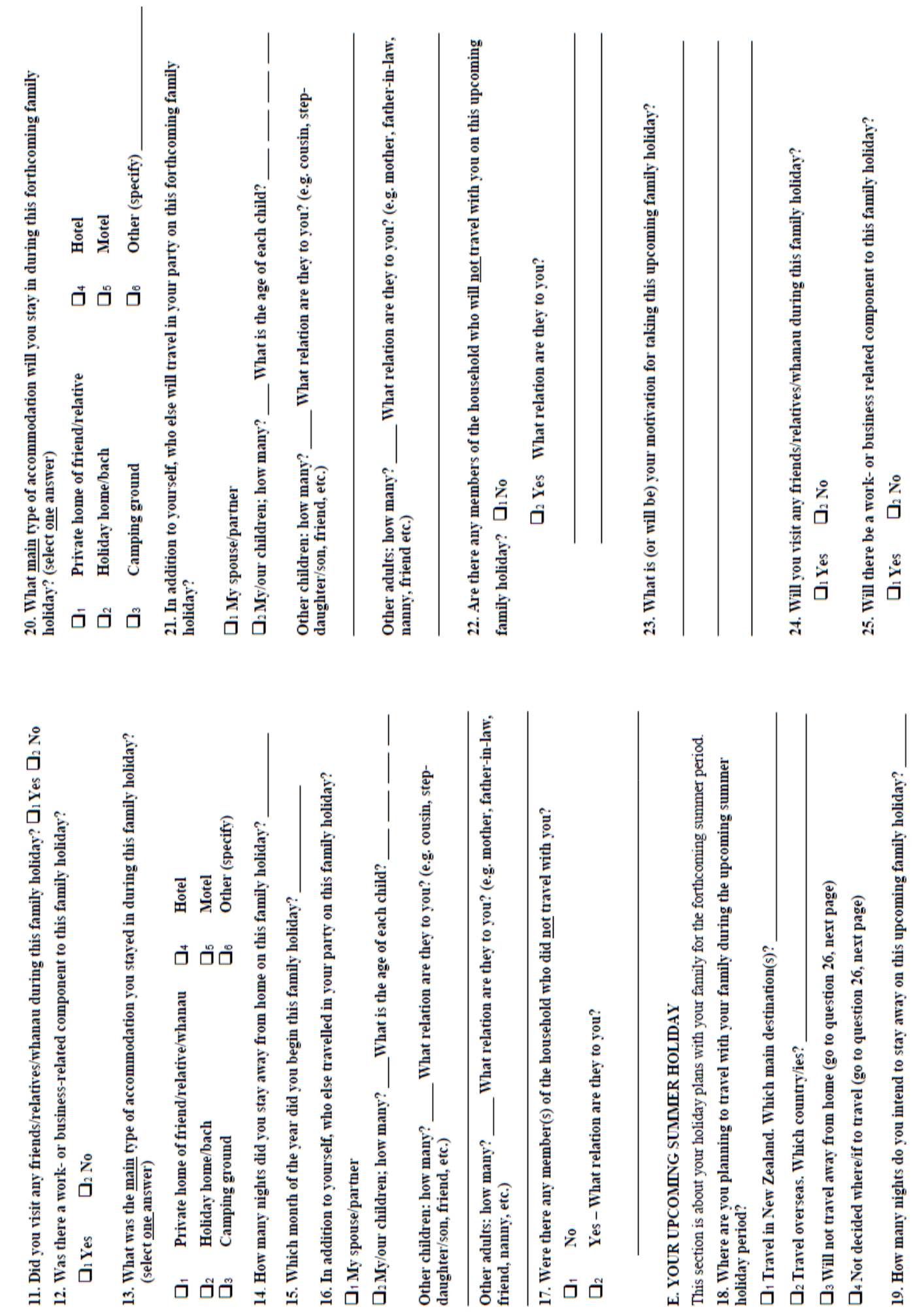

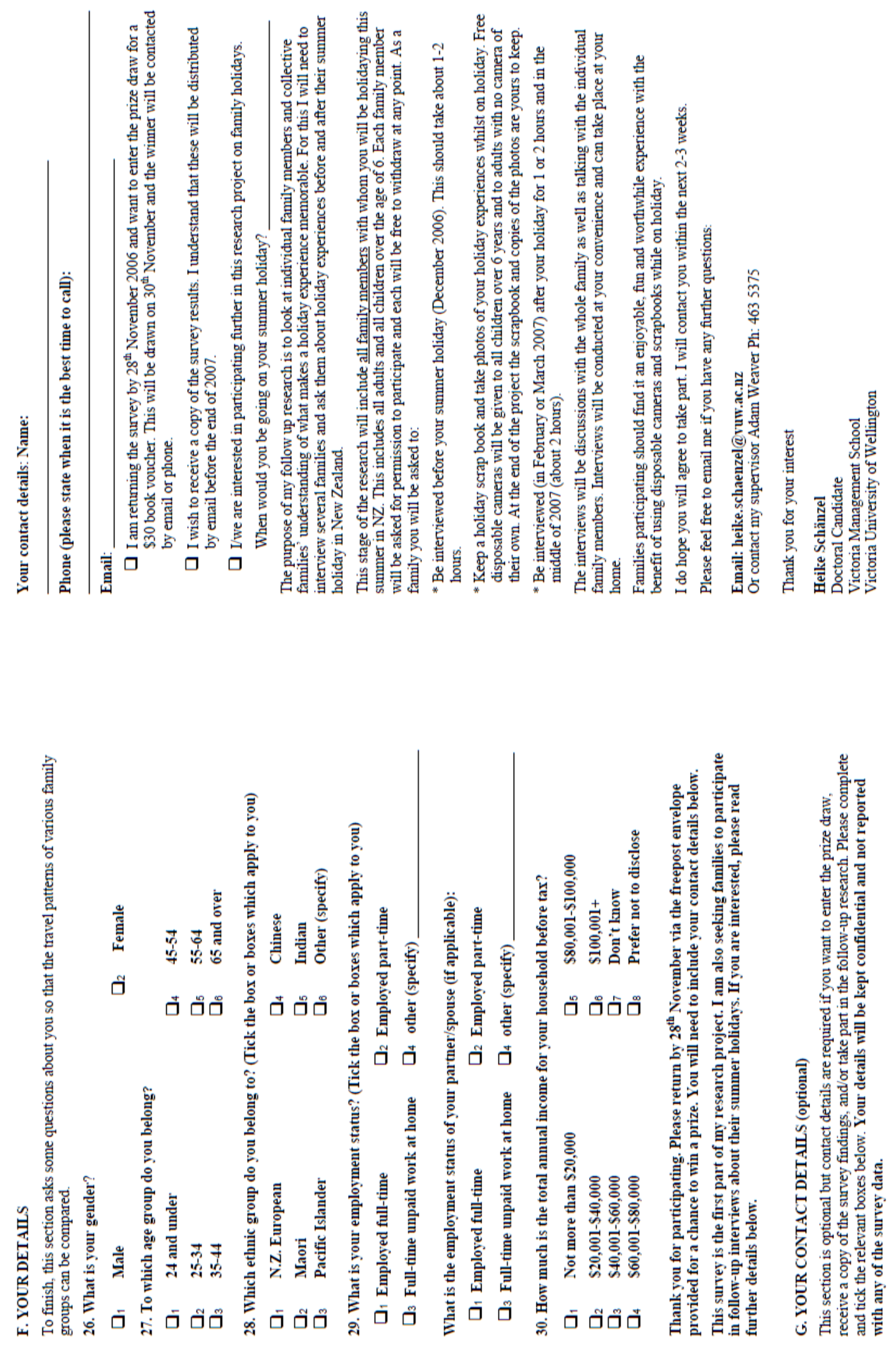
Appendix B:

Information letter and consent forms 


\section{TE WHARE WĀNANGA O TE ŪPOKO O TE IKA A MĀUI

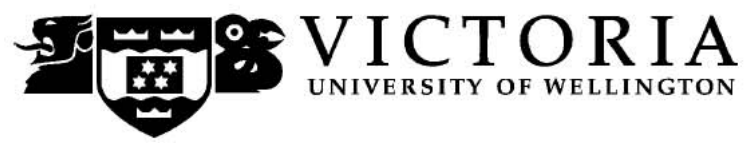

FAMILY HOLIDAY STUDY

Dear

December 2006

I would like to thank you for completing my questionnaire and agreeing to be interviewed for the next stage of my research. I appreciate the contribution you make to my project. As I mentioned in the information sheet that accompanied my questionnaire I am also a parent of three children. Earlier this year, I decided to go back to university in order to obtain my Doctorate. I have discovered that few researchers have studied family holidays. Like me, you have probably found that travelling with your family has both rewards and challenges. The joys and frustrations of travel with my own family got me interested in this topic.

The aim of this project is to find out more about why families go on holiday, what they do on holiday and how important the different aspects of a family holiday are for the whole family and individual family members. For this I will need to interview several families and ask them about holiday experiences before and after their summer holiday in New Zealand. The interviews will include all family members with whom you will be holidaying this summer in NZ. This includes all adults and all children over the age of 6 . The interviews will be discussions with the whole family as well as one-on-one interviews with the individual family members at various stages. Each family will be asked to:

* Be interviewed before their summer holiday (December 2006). This should take about 1-2 hours.

* Keep a holiday scrap book and take photos of their holiday experiences whilst on holiday. Free disposable cameras will be given to all children over 6 years and to adults with no camera of their own. At the end of the project the scrapbook and copies of the photos are yours to keep.

* Be interviewed (in February or March 2007) after their holiday for 1 or 2 hours and in the middle of 2007 (about 2 hours).

Each family member will be asked for permission to participate and each will be free to withdraw at any point before the final data analysis. Also, what one family member says will not be repeated to any other family member. Each family member can speak with me and be assured confidentiality. However, one-onone interviews with children will not be confidential if you like to be present. The interviewing will deal with the experiences of family holidaying and will not involve probing into the most intimate aspects of family life. Interviews will be conducted at your convenience and can take place at your home. With your permission the interviews will be tape recorded or otherwise only notes taken.

Family members who are interviewed will not be referred to by name in my study and will only be identified by their role in the family (such as mother, father, daughter, etc.). I will make every effort to protect the anonymity of participants. In the case of the photos, drawings and scrapbook you will have the right of exclude items you don't want to show me. A summary of the research findings will be available to you via mail by the end of this project in about March 2009. It is now a requirement for all university research involving people to be approved by the University Ethics Committee. This study has been approved by this committee.

Families participating should find it an enjoyable, fun and worthwhile experience. The other expected reward is that you will be contributing to an understanding about family holidays. If you require further information about the study please contact myself or my supervisors. We will gladly answer your questions.

Heike Schänzel, Doctoral Candidate, Victoria Management School, Email: Heike.schaenzel@vuw.ac.nz Phone (home): 5627299

Supervisors: Prof Doug Pearce, Dr Adam Weaver, Lecturer, and Dr Karen Smith, Senior Lecturer Email: Adam.weaver@vuw.ac.nz (Ph: 463 5375); Douglas.pearce@vuw.ac.nz; Karen.smith@vuw.ac.nz 


\section{TE WHARE WĀNANGA O TE ŨPOKO O TE IKA A MĀUI

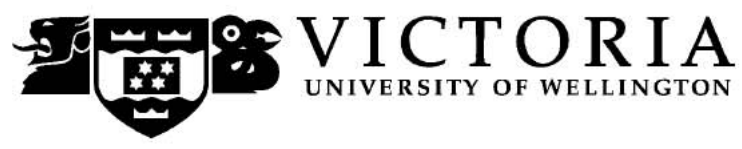

\section{Consent Form for Family Holiday Study}

I am asking for your consent to participate in my research project. I would appreciate it if you could provide me with the names of family members who are able to take part:

Parent name:

Parent name:

Children's names:

Please tick the boxes for which you give consent for yourself and your child(ren)

I freely give consent for my child(ren) and I to take part in this project.

$\square$ I have been provided with adequate information relating to the nature and objectives of this research project. I have understood that information and have been given the opportunity to seek further clarification or explanation.

$\square$ I consent for the interviews to be audio recorded. If not, would you consent for notes to be taken?

$\square$ I consent for notes to be taken.

$\square$ I understand that I or my child(ren) may withdraw from this study at any time before the final analysis of data (before September 2007) without providing reasons. I understand that if I or my child(ren) withdraw from the project, any data already provided will be destroyed if so requested.

I I understand that any information I and my child(ren) provide will be kept confidential and every effort will be made to report data only in a non-attributable form. Also, I understand that the interview notes and tapes will be destroyed two years after completion of this project (approx. 2011). The use of any holiday photos, drawings and the scrapbook will be at our discretion.

$\square$ I understand that I have the right to check interview notes regarding the interviews with all family members and my own private interviews. To ensure confidentiality between family members I am unable to check the interview notes of the other family members.

$\square$ I am happy for my child(ren) to be interviewed one-on-one with Heike.

I understand that the information I and my child(ren) have provided will be used only for this research project in the form of a $\mathrm{PhD}$ thesis and possible academic journal and conference papers. Any further use of the information will require my written consent.

$\square$ I wish to receive a summary of the research findings which will be available to me via mail by the end of this project in about March 2009.

Parent signature:

Date:

Parent signature:

Date:

Heike Schänzel, Doctoral Candidate, Victoria Management School, Email: heike.schaenzel@vuw.ac.nz Phone (home): 5627299

Supervisors: Prof Doug Pearce, Dr Adam Weaver, Lecturer, and Dr Karen Smith, Senior Lecturer Email: Adam.weaver@vuw.ac.nz (Ph: 463 5375); Douglas.pearce@vuw.ac.nz; Karen.smith@vuw.ac.nz 


\section{TE WHARE WĀNANGA O TE ŪPOKO O TE IKA A MĀUI

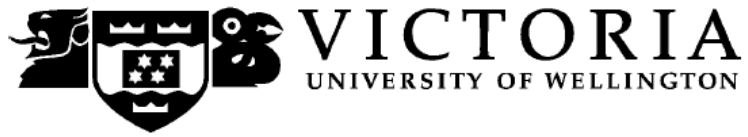

\section{Information notes and consent for children over 6 years for Family Holiday Study}

(This will be read out by myself to ensure that the children understand the text)

My name is Heike Schänzel and I am the mother of three children. Earlier this year, I decided to go back to university to continue studying. My area of study is tourism. I have discovered that very little is known about family holidays and that is why I set out to do this project.

The aim of my project is to find out more about why families go on holiday, what they do on holiday and what they remember about their holiday. For this I will need to interview several families and ask them about their holidays before and after their summer holiday. The interviews will include all family members with whom you will be holidaying this summer in New Zealand. This includes all grown-ups and all children over the age of 6 . The interviews will be discussions with your whole family as well as talking with the other family members individually including yourself. You and your family will be asked to:

* Be interviewed before your summer holiday (December 2006). This should take about 1-2 hours. I will also hand out a disposable camera and a family scrapbook for you to use on holiday.

* Keep a holiday scrap book whilst on holiday and take photos of what you do on holiday. At the end of the project the scrapbook and copies of the photos are yours to keep.

* Be interviewed after your holiday (in February or March 2007) for 1 or 2 hours and in the middle of 2007 (about 2 hours).

What you say to me will not be repeated to any other member of the family. This means that what you tell me about your holiday in private will be safe with me. But you do have the option of having another adult present. With your permission I will tape record the interviews and then make notes from them. If you only want me to take notes in a notebook that is fine.

You should find it an enjoyable and fun experience and you get to use a disposable camera and a scrapbook while on holiday. The other reward is by you participating you will be helping me understand more about family holidays. I would be very thankful for your help.

Please let me know if you have more questions.

Are you happy to take part in this project? $\quad \square$ Yes $\quad$ No

If no: Thanks for listening and being honest about not wanting to take part.

If yes: Would you prefer to have another grown-up present during my interview with you?

Yes Can you please identify the family member you would like present?

$\square$ No

Are you happy for the interviews to be tape recorded? Yes

$\square$ No If not, is it fine for me to take notes? $\square$ Yes

Thanks for listening and agreeing to take part.

Name/signature of the child: 
Appendix C:

Interview schedule (pre-holiday) 


\section{Interview schedule (pre-holiday)}

I will be asking probing questions throughout the interview in order to elicit more detailed responses from both parents and children like:?

What do you mean by that?

How do you feel about that?

Can you give me an example?

Why is that important to you?

\section{Interviews with the whole family/family focus groups:}

The first set of questions is intended to get everyone to define and describe a family holiday in general.

- As a family, how would you describe a family holiday? What do you all think is a family holiday? Can you give me examples of the things you like to do on holiday?

(everyone can give examples to compile a list)

- Does everyone like these activities or experiences?

- Can we discuss some activities or experiences that you have not enjoyed on a family holiday?

- Do you think it is possible to spend a family holiday at home? Why not/yes?

If yes: What would a holiday at home be like?

- What do you think is the ideal length of a family holiday in NZ? Can a holiday be too long or can it be too short? Or does it not matter?

- Do you think a family holiday is different from other types of holidays? How is it different?

- As a family, how important is it to you to visit friends or relatives on your family holiday? What part does extended family play on your holiday?

The next questions will be specifically about your upcoming summer holiday:

- As a family, what is your motivation or what are your reasons for going on a holiday? Why do you want to go on a family holiday?

- How did you decide on this holiday destination? Was that a family decision? Why did you choose that destination? Who made the decisions?

- Can you all tell me a bit about the destination (name of the place)?

- As a family, what do are your expectations for this holiday? What do you want from this holiday? Do you all share these expectations?

- As a family, what activities or experiences are you looking forward to?

- Is there anything that you as a family are not looking forward to?

- As a family, how would you describe an ideal day during your upcoming family holiday? What is your dream of an ideal holiday?

- What do you think makes for a successful family holiday for everyone? 


\section{Individual interviews:}

- What are your personal motivations or reasons for taking this holiday? How do you think this compares with the rest of the family?

- Why do you want to go (or not go) on a family holiday?

- What part did you play in deciding this holiday destination?

- Why did you choose that destination? How do you feel about the decision? Would you rather go somewhere else?

(Where would you prefer to go?)

- Technique of asking: (to close your eyes and) describe in your own words how you see one ideal day during the next summer holiday. What is your dream of an ideal family holiday?

- What are your expectations for this holiday? What do you want from this holiday?

- What activities or experiences are you particularly looking forward to? Any particular highlights you are looking forward to? Why are these important to you?

- Is there anything that you are not looking forward to? Why?

- What do you think makes for a successful family holiday for yourself?

- How do you think this compares with the rest of the family? 
Appendix D:

Interview schedule (post-holiday) 


\section{Interview schedule (post-holiday)}

I will be asking probing questions throughout the interview in order to elicit more detailed responses from both parents and children like:

What do you mean by that?

How do you feel about that?

Can you give me an example?

Why is that important to you?

Interviews with the whole family: find out first who was involved with the scrapbook and who took the photos.

- As a family, how would you describe your family holiday? What made it a family holiday for you? Can you give me examples of the things (activities and experiences) that were fun or that you enjoyed on holiday? (everyone can give examples to compile a list and make use of the photos and scrapbook)

Did you all join in those activities?

- Are you normally doing these activities at home as well? Or only on holiday?

- As a family, can you agree on your best time on this holiday? Why did you all enjoy it? Was that close to your ideal day?

- As a family, what things did you do for relaxation? Did you do that together as a family or separate?

- As a family, how important was it to you to visit friends or relatives on this family holiday (or to have friends or relatives come along on your family holiday)?

- Can we discuss some activities or experiences that you did not enjoy or were not fun on this family holiday?

- As a family, can you agree on a time that you did not enjoy that much? Why was it not so good?

- As a family, can you tell me of choices you made that were particularly successful on this holiday? Why was this successful?

- As a family, was there anything not particularly successful on this holiday? Why not?

- As a family can you think of examples on how to better arrange or organise the next holiday?

- As a family, what do you think makes for a successful holiday? What worked and what did not work so well?

This set of questions links the pre-holiday questions on motivations/expectations with their evaluations post-holiday.

- As a family, can you remember your reasons or motivations for going on this summer holiday?

- As a family, were your expectations met on this holiday? Was it better than you expected or not? Why? Do you all agree?

- As a family, how important was staying in New Zealand for your holiday? How did it compare with other holidays you had in the past (in NZ or overseas)? How would you rate it? As a family were you happy with your decision? Do you already have any plans for your next summer holiday?

- As a family is there anything else you like to tell me? 


\section{Individual interviews:}

- Can you tell me in your own words about the holiday you just had (by using the photos)?

- Do you want to tell me more about your chosen photos? Why are they important to you? Would you normally have taken these photos?

- Can you give me examples of the activities and experiences you personally enjoyed on this holiday? Do you usually do this at home as well? Did you do that by yourself or with the family?

- What do you think was your best time on this holiday? How close was that to your ideal day? How do you think this compares with the rest of the family?

- What things did you do for relaxation? Did you do that by yourself or with others? Did you find enough time for yourself on this holiday or is that not important? How important is having your own time on a family holiday to you?

- How important was it to you to visit friends or relatives on this family holiday (or to have friends or relatives come along on your family holiday)?

- Can you give me examples of activities and experiences you did not enjoy?

- Was there a time you did not enjoy? Why was it not so good?

- Can you tell me of choices you made that were particularly successful for yourself?

- In your opinion, was there anything that was not so successful for yourself?

- Is there anything you would like to do different on your next family holiday?

- How would you sum up the holiday you just had for yourself? Was it successful or not so successful for yourself? How do you think this compares with the rest of the family?

This set of questions links the pre-holiday questions on motivations/expectations with their individual evaluations post-holiday.

- Can you remember your personal motivations or reasons for taking this family holiday? How do you think this compares with the rest of the family?

- Did this holiday meet your expectations? Was it better than what you expected or not? Why? How do you think this compares with the rest of the family?

- For yourself, how important was staying in NZ for your holiday? How did it compare with other holidays you had in the past? How would you rate it? In retrospect how happy were you with the decision? Where would you like to go next year?

- Anything else you like to tell me about this holiday? 
Appendix E:

Interview schedule (final) 


\section{Interview schedule (final)}

\section{Interviews with the whole family/family focus groups:}

- Did you have another holiday since we last spoke? If yes: where did you go to?

Can we focus now on your last summer holiday which you spent in ...

Last summer holiday:

- As a family, can you tell me what you remember about your last summer holiday?

- As a family, can you give me examples of the activities, experiences or events you remember enjoying (or liked) on this holiday? (everyone can give examples to compile a list and make use of the photos) Why do you remember them? Did you all like them?

- As a family, can you remember activities, experiences or events that you did not like (or did not enjoy)?

- Can you remember your best time together as a family on this holiday? What made it so special? Do you all agree? Did it include other people?

- As a family, how important is it to you now that you met up with family or friends on this holiday? What did you learn from or about each other on this holiday (including family and friends)? Did you learn something about New Zealand?

- As a family, can you remember a time that you spent together that was not so good? Why was it not so good?

- As a family, what experiences do you think you will remember for a long time? What does this holiday mean to you now? What did you take away from this holiday? Is there anything you would do differently on your next family holiday?

- How does your holiday time compare with your everyday life now? What is different? What is the same? How much time do you find now for spending together as a family?

- Would you like to spend more time together?

- Only if they had a holiday in the meantime: In retrospect, how did this last summer holiday compare with the other holiday (in NZ or overseas)?

- Have you already made plans for your next family holiday? What are your plans? What are your motivations or reasons for taking your next family holiday? How do they compare with the motivations or reasons for your last summer holiday? (What is different? What is the same?)

- As a family, what are your expectations for your next family holiday? How do they compare with your expectations for your last summer holiday?

- As a family is there anything else you would like to tell me about family holidays? 


\section{Individual interviews:}

- Can you tell me in your own words what you personally remember about your last summer holiday?

- (Do you want to tell me about your chosen photos? Why are they important to you?)

- Can you give me examples of the activities, experiences and events you particularly enjoyed (or liked) on this holiday? What was your best or favourite activity on this holiday? Did you find that relaxing? Why yes/not?

- Can you give me examples of activities, experiences and events you personally did not like (or did not enjoy)?

- What do you think was your best time together as a family on this holiday? What made it so special for you?

- Was there a time you spent together as a family that you did not enjoy (or liked)? Why was it not so good?

\section{For parents:}

- Can you tell me about the most enjoyable experience you had with your children or individual child on holiday? More than 1 child: Is there a difference between spending time with your individual children? What meaning does that experience have for you now?

- Can you remember any compromises (or sacrifices) you made to ensure your child(ren) were entertained on this holiday? Can you think of other compromises you had to make during the holiday in order to keep other family members happy?

- How important are holidays for you to spend time with your husband/wife? Did you find enough time for each other on your last holiday? (if yes) How did you manage that? (if not) Why not?

\section{For child(ren):}

- Can you tell me about the most enjoyable experience you had with your mum? And your dad on holiday? Is there a difference between spending time with your mum and your dad? How important is that experience to you now?

- Can you remember your mum and dad spending any time away from you (and your brother and sister), either alone or together on holiday? If no: do you think they would have wanted to? If yes: how did you feel about that?

- More than 1 child: How important are holidays for you to spend time with your brother(s) or sister(s)? Every child: How important are holidays for you to spend time with friends or make new friends? Did you find enough time for that? 
- How important is it to you now that you met up with family or friends on holiday?

For parents: how important was it to you to instil certain values, traditions or skills to your child(ren) on holiday? Can you tell me more about these values, traditions or skills? Do you think you learned something from or about your child(ren) as well?

For children; can you remember learning something on holiday (like from your parents)? What was it? Do you think your parents learned something from you as well?

- Did you find out something new about New Zealand?

- What do you think you will remember about this holiday for a long time? What does this holiday mean to you now? What did you personally take away from this holiday?

- How does the time you spent on holiday with your family compare with everyday life? What is different for you? What is the same for you? Would you like to spend more time together?

This set of questions links the pre-holiday questions on motivations/expectations with their individual longer term evaluations post-holiday.

- In retrospect, how did the last summer holiday compare with other holidays you had in the meantime (in NZ and overseas)?

- Do you want to go on another family holiday? Why yes/not? What are your personal motivations or reasons for taking your next family holiday? How do they compare with the motivations or reasons for your last summer holiday?

- What are your personal expectations for your next family holiday? How do they compare with your expectations for your last summer holiday?

- Is there anything else you like to tell me about family holidays? 